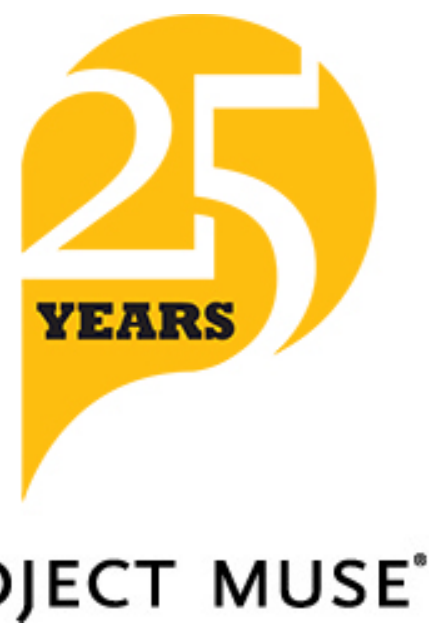

\title{
Figural Realism
}

White, Hayden

\section{PROJECT MUSE}

Published by Johns Hopkins University Press

White, Hayden.

Figural Realism: Studies in the Mimesis Effect.

Johns Hopkins University Press, 1998.

Project MUSE. doi:10.1353/book.72311.

$\Rightarrow$ For additional information about this book

https://muse.jhu.edu/book/72311 


\section{Figural Realism}

Studies in the Mimesis Effect 
Open access edition supported by the National Endowment for the Humanities / Andrew W. Mellon Foundation Humanities Open Book Program.

(c) 2019 Johns Hopkins University Press

Published 2019

Johns Hopkins University Press

2715 North Charles Street

Baltimore, Maryland 21218-4363

www.press.jhu.edu

The text of this book is licensed under a Creative Commons

Attribution-NonCommercial-NoDerivatives 4.0 International License:

https://creativecommons.org/licenses/by-nc-nd/4.0/.

CC BY-NC-ND

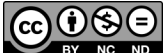

ISBN-13: 978-1-4214-3732-3 (open access)

ISBN-10: 1-4214-3732-5 (open access)

ISBN-13: 978-1-4214-3730-9 (pbk. : alk. paper)

ISBN-10: 1-4214-3730-9 (pbk. : alk. paper)

ISBN-13: 978-1-4214-3731-6 (electronic)

ISBN-10: 1-4214-3731-7 (electronic)

This page supersedes the copyright page included in the original publication of this work. 

Figural Realism 



\section{Hayden White}

\section{Figural Realism}

Studies in the Mimesis Effect

The Johns Hopkins University Press Baltimore \& London 
(C) 1999 The Johns Hopkins University Press

All rights reserved. Published 1999

Printed in the United States of America on acid-free paper

Johns Hopkins Paperbacks edition, 2000

$\begin{array}{llllllllll}9 & 8 & 7 & 6 & 5 & 4 & 3 & 2 & \text { I }\end{array}$

The Johns Hopkins University Press

27is North Charles Street

Baltimore, Maryland 21218-4363

www.press.jhu.edu

Library of Congress Cataloging-in-Publication Data will be found at the end of this book.

A catalog record for this book is available from the British Library.

ISBN 0-80I8-6524-7 (pbk.) 


\section{Contents}

Preface vii

Acknowledgments $\quad x i$

I Literary Theory AND Historical Writing I

2 Historical Emplotment and the Problem of Truth in Historical Representation 27

3 Formalist and Contextualist Strategies in Historical Explanation 43

4 The Modernist Event 66

5 Auerbach's Literary History Figural Causation and Modernist Historicism 87

6 Freud's Tropology of Dreaming ioi

7 Narrative, Description, and Tropology in Proust I26

8 Form, Reference, ANd IdeOlogy in Musical Discourse I 47

Notes $\quad 177$

Index 20I 



\section{Preface}

This book is a selection of essays I have written since the publication, in 1987, of The Content of the Form. I have gathered them under the title Figural Realism - a phrase I take from Erich Auerbach's great work, Mimesis because they all, in one way or another, try to show how figurative language can be said to refer to reality quite as faithfully and much more effectively than any putatively literalist idiom or mode of discourse might do. In fact, all of these essays are set forth in defense of the idea that the very distinction between literal and figurative speech is a purely conventional(ist) distinction and is to be understood by its relevance to the sociopolitical context in which it arises. The essays are, in a word, about discourse, discursivity, and modes of language use - the domains of cultural production in which the very distinctions between what can count as literal and figurative, denotation and connotation, proper and deviant, fact and fiction, and yes, even truth and lie, are set forth, debated, and authorized as proper or improper intellectual and artistic practice.

I had intended to write a long introduction relating the essays of this collection to one another and to the sets of essays I have published in the past. But after a few attempts at synthesis that bored even me - I had rather get on with other tasks - I decided to let the essays stand by themselves as contributions to the specific discussions that occasioned them. I am unsure how useful they will be to a generation of scholars who have grown wary of theory in general and positively allergic to what is condescendingly called grand theory (meaning Hegel, Marx, Weber, et al.). I understand, I think, the desire - after decades of "star wars" on a grand scale - to abandon theory and get back to the text, back to what Wittgenstein called "the rough 
ground," back to personal experience and attention to the phenomena of everyday life; these cries go up regularly after every era of efforts to envision the whole, whether of culture, society, civilization, history, or being in general. And in such postmodernist times, it is understandable why people of goodwill, wanting to do justice to particularities of existence, should turn against totalizing systems of thought which privilege the whole and ignore the parts of life which are to be sacrificed to it. The reaction is, in my view, healthy and morally justified.

But it is a mistake to think that theoretical thinking itself is the cause of the ills that an atheoretical or antitheoretical mode of reflection can set right. And this is because the very distinction between a theoretical mode of thought and whatever is conceived to be an alternative to it (empiricism, facts, particularity, the humble, the abject, or the practical) is itself founded on a theoretical or, more precisely, a metatheoretical point of view. To think that one can think outside or without theory is a delusion. Because, as the etymology of the term theory suggests, theoretical thinking is the mode of thought that seeks to problematize the very relation between what can be seen (Greek, theorein, "to view, to look, to regard, to survey") and what can be thought about what one has perceived from the vantage point of the perception. One can do very many important and valuable things without theory, such as talking and listening, loving and hating, fighting and making up, taking pleasure and causing pain, but thinking is not among them. Where there is no theory, there is no active thought; there is only impression.

On the other hand, there is good theory and bad theory - by which I would mean theory that conduces to morally responsible thought and that which leads us away from it. It is not a matter of theories being true or false, because theory, being inherently speculative and deliberative, cannot be submitted to criteria of falsification on the basis of an appeal to facts. Theory is produced on a site of reflection that puts in abeyance the very distinction between the true and the false, fact and fiction or delusion, lie, or mistake. Theory asks us to consider what, from a specific perspective, will be permitted to count as a fact, the truth, rationality, morality, and so forth.

This is why the only criterion that is appropriately invoked for the assessment of a theory is its utility in promoting aims, goals, or ends of a specifically ethical, moral, or political kind. Bad theory promotes bad ends, good theory, good ones. Good for whom? For the human species at large. This is why theoretical thought is always involved in ethical and aesthetic as well as cognitive concerns. And this is why a given theory is appropriately 
assessed as to its ethical and aesthetic implications and not, as in science and philosophy, as to its cognitive validity alone.

Thus, to ask, What is the good of science? is a theoretical question, not only or even primarily a factual one. It involves questions of fact, to be sure, but more importantly, it involves the questions of, first, what can, from a given theoretical perspective, count as a fact; second, what kind of facts conduces to the good of the community and not merely to the growth of its fund of information; and, third, what could the good of the community possibly consist of. These are all theoretical questions whose utility must be assessed on the basis of what the community to which they are addressed conceives to be its own good, its own proper ends, its own established practices and moral principles.

The issues I address in these essays - having to do, for the most part, with the relations between literary discourse and historical discourse - may seem far removed from these larger and much more important cognitive, ethical, and aesthetic issues. They may seem theoretical in a much more restricted, parochial, even pedantic, and ultimately less important sense. But I have long thought that the relation between literary discourse (where writing is supposed to be free and even abandoned) and historical discourse (where factuality, realism, and rational commonsense are supposed to prevail) provides a microcosm of modern Western thought's effort to relate imagination (the vision of what might be) and commonsense (the thought of what is the case, what goes without saying). In trying to show the literariness of historical writing and the realism of literary writing, I have sought to establish the "mutual implicativeness" (Windelband's term) of their respective techniques of composition, description, imitation, narration, and demonstration. Each in its way is an example of a distinctively Western practice, not so much of representation as of presentation, which is to say, of production rather than of reproduction or mimesis. That is why I have subtitled this collection of essays Studies of the Mimesis Effect.

I DEDiCATE THIS COLLECTION OF ESSAYs to four dear friends who taught me much while they were alive and whose memory continues to sustain me in my work - Louis O. Mink, Joel Fineman, Giorgio Tagliacozzo, and Kurt Weinberg - in the battle for the spirit over the letter. 



\section{ACKNOWLEDGMENTS}

Most of these essays and parts of them have appeared elsewhere, and therefore I wish to thank their original editors for their kind treatment of my work and indicate where they first appeared.

I. "Literary Theory and Historical Writing": as "Figuring the Nature of the Times Deceased: Literary Theory and Historical Writing," in The Future of Literary Theory, ed. Ralph Cohen (London: Methuen, I988).

2. "Historical Emplotment and the Problem of Truth in Historical Representation": as "Historical Emplotment and the Problem of Truth," in Probing the Limits of Representation: Nazism and the "Final Solution," ed. Saul Friedlander (Cambridge: Harvard University Press, I992).

3. "Formalist and Contextualist Strategies in Historical Explanation": as "Geschichte erklären. Formalistiche und kontextualistische Strategien," Neue Rundschau N. 105, Heft I ( 1994): 4I-56; and as "New Historicism: A Comment," in The New Historicism: Political Commitment and the Postmodern Critic, ed. H. Aram Veeser (New York: Routledge, 1989).

4. "The Modernist Event": as "The Modernist Event," in The Persistence of History: Cinema, Television, and the Modern Event, ed. Vivian Sobchack (New York: Routledge, 1996).

5. "Auerbach's Literary History: Figural Causation and Modernist Historicism" as "Auerbach's Literary History: Figural Causation and Mod- 
ernist Historicism," in Literary History and the Challenge of Philology: The Legacy of Erich Auerbach, ed. Seth Lerer (Stanford: Stanford University Press, 1996).

7. "Narrative, Description, and Tropology in Proust": as "The Rhetoric of Interpretation," Poetics Today 9, no. 2 ( I988): 253-74.

8. "Form, Reference, and Ideology in Musical Discourse": as "Form, Reference, and Ideology in Musical Discourse," in Music and Text: Critical Inquiries, ed. Steven Paul Scher (Cambridge: Cambridge University Press, I992). 
Figural Realism 



\section{LITERARY THEORY AND HistoricAL WRITING}

In a late essay, Jacques Barzun characterized himself as "a student of history ... formerly engaged in the strange ritual of teaching it."' By history, of course, Barzun did not mean the actual events of the past but, rather, the accumulated learning of his profession. In this brief aside, however, he reminds us of some truths that modern historical theory has tended regularly to forget: namely, that the history that is the subject of all this learning is accessible only by way of language; our experience of history is indissociable from our discourse about it; this discourse must be written before it can be digested as history; and this experience, therefore, can be as various as the different kinds of discourse met with in the history of writing itself.

In this view, history is not only an object we can study and our study of it; it is also and even primarily a certain kind of relationship to the past mediated by a distinctive kind of written discourse. It is because historical discourse is actualized in its culturally significant form as a specific kind of writing that we may consider the relevance of literary theory to both the theory and the practice of historiography.

Before proceeding to a discussion of the relevance of literary theory to historical writing, however, a few remarks about historical discourse and the kind of knowledge it deals in must be made. First, historical discourse is possible only on the presumption of the existence of the past as something about which it is possible to speak meaningfully. This is why historians do not normally concern themselves with the metaphysical question of whether the past really exists or the epistemological question of whether, if 
it does exist, we can really know it. The existence of the past is a necessary presupposition of historical discourse, and the fact that we can actually write histories is a sufficient proof that we can know it.

Second, historical discourse, unlike scientific discourse, does not presuppose that our knowledge of history derives from a distinctive method for studying the kinds of things that happen to be past rather than present. The events, persons, structures, and processes of the past can be taken as objects of study by any and all of the disciplines of the human and social sciences, and indeed, even by many of the physical sciences. To be sure, it is only insofar as they are past or are effectively so treated that such entities can be studied historically; but it is not their pastness that makes them historical. They become historical only in the extent to which they are represented as subjects of a specifically historical kind of writing. Barzun is right in saying that history "can only be read," but it can only be read if it is first written. And it is because history must be written before it can be read (or, for that matter, before it can be spoken, sung, danced, acted, or even filmed) that literary theory has a relevance not only to historiography but also and especially to philosophy of history.

This characterization of historical discourse does not imply that past events, persons, institutions, and processes never really existed. It does not imply that we cannot have more or less precise information about these past entities. And it does not imply that we cannot transform this information into knowledge by application of the various methods developed by the different disciplines comprising the "science" of an age or culture. It is intended, rather, to stress that information about the past is not in itself a specifically historical kind of information and that any knowledge based on this kind of information is not in itself a specifically historical kind of knowledge. Such information might better be called archival, inasmuch as it can serve as the object of any discipline simply by being taken as a subject of that discipline's distinctive discursive practices. So, too, it is only by being made into the subject of historical discourse that our information about and knowledge of the past can be said to be historical.

Historical discourse does not, then, produce new information about the past, since the possession of both old and new information about the past is a precondition of the composition of such a discourse. Nor can it be said to provide new knowledge about the past insofar as knowledge is conceived to be a product of a distinctive method of inquiry. ${ }^{2}$ What historical discourse produces are interpretations of whatever information about and knowledge of the past the historian commands. These interpretations can take a number 
of forms, ranging from simple chronicles or lists of facts all the way over to highly abstract philosophies of history, but what they all have in common is their treatment of a narrative mode of representation as fundamental to the grasping of their referents as distinctively historical phenomena. Adapting a famous phrase of Croce's to our purposes, we may say that, where there is no narrative, there is no distinctively historical discourse. ${ }^{3}$

I realize that in characterizing historical discourse as interpretation and historical interpretation as narrativization, I am taking a position in a debate over the nature of historical knowledge that sets narrative in opposition to theory in the manner of an opposition between a thought that remains for the most part literary and even mythical and one that is or aspires to be scientific. ${ }^{4}$ But it must be stressed that we are here considering not the question of the methods of research that should be used to investigate the past but, rather, that of historical writing, the kind of discourses actually produced by historians over the course of history's long career as a discipline. And narrative has always been and continues to be the predominant mode of historical writing. The principal problem for any theory of historical writing, then, is not that of the possibility or impossibility of a scientific approach to the study of the past but, rather, that of explaining the persistence of narrative in historiography. A theory of historical discourse must address the question of the function of narrativity in the production of the historical text.

We must begin, then, with the undeniable historical fact that distinctively historical discourses typically produce narrative interpretations of their subject matter. The translation of these discourses into a written form produces a distinctive object, the historiographical text, which in turn can serve as the subject of a philosophical or critical reflection. Whence the distinctions, conventional in modern historical theory, between past reality, which is the historian's object of study; historiography, which is the historian's written discourse about this object; and philosophy of history, which is the study of the possible relations obtaining between this object and this discourse. These distinctions must be borne in mind if we are to comprehend the different kinds of relevance that modern literary theory bears to both the practice and the theory of historical writing.

Current literary theory has both a direct and an indirect relevance to the understanding of historical writing. It is direct insofar as literary theory 
has elaborated, on the basis of modern language theory, some general theories of discourse that can be used to analyze historical writing and to identify its specifically literary (i.e., poetic and rhetorical) aspects. In the substitution of the notion of discursive structure for the older, nineteenthcentury notion of style, considered to be the secret of fine writing, modern literary theory provides new conceptions of literariness itself. These new conceptions of literariness permit a finer discrimination of the relation between the form and the content of the historical discourse than was formerly possible on the basis of the idea that facts constituted the body of the historical discourse and style its more or less attractive, but by no means essential, clothing. ${ }^{5}$ It is now possible to recognize that in realistic, no less than in imaginary, discourse, language is both a form and a content and that this linguistic content must be counted among the other kinds of content (factual, conceptual, and generic) that make up the total content of the discourse as a whole. This recognition liberates historiographical criticism from fidelity to an impossible literalism and permits the analyst of historical discourse to perceive the extent to which it constructs its subject matter in the very process of speaking about it. The notion of the content of linguistic form scumbles the distinction between literal and figurative discourses and authorizes a search for and analysis of the function of the figurative elements in historiographical, no less than in fictional, prose.

The relevance of modern literary theory to historical writing is indirect insofar as the conceptions of language, speech, writing, discourse, and textuality that inform it provide insights into some problems traditionally posed by philosophy of history, such as the classification of the genres of historical discourse, the relation of a historical representation to its referents, the epistemological status of historical explanations, and the relation of the interpretative to the descriptive and explanatory aspects of the historian's discourse. Modern literary theory illuminates all of these problems by directing attention to what is most obvious about historical discourse but has not been systematically taken account of until recently, namely, that every history is first and foremost a verbal artifact, a product of a special kind of language use. And this suggests that, if historical discourse is to be comprehended as productive of a distinctive kind of knowledge, it must first be analyzed as a structure of language.

It is remarkable that philosophers of history should have taken so long to recognize the importance of language for the understanding of historical discourse, especially since modern philosophy in general has made language a central object of interest in its examination of other de- 
partments of science. This lapse occurred in part because modern historians themselves have tended to treat their own language as an unproblematical, transparent medium for both the representation of past events and the expression of their thought about these events. But it occurred also because the philosophers who took historical discourse as a specific object of analysis tended to believe in the possibility of dissociating the factual and conceptual content of a discourse from its literary and linguistic form for purposes of assessing its truth-value and the nature of its relationship to reality. Thus, for example, recent philosophers of history have typically treated narrative less as a verbal structure than as a kind of explanation by storytelling and have regarded the story told in a given history as a structure of argumentative concepts, the relations among whose parts were logical (specifically syllogistic) rather than linguistic in nature. All this implied that the content of a historical discourse could be extracted from its linguistic form, served up in a condensed paraphrase purged of all figurative and tropological elements, and subjected to tests of logical consistency as an argument and of predicative adequacy as a body of fact. This, however, was to ignore the one "content" without which a historical discourse could never come into existence at all: language.

During the very period in which this argument model predominated among analysts of historical discourse, philosophers such as Quine, Searle, Goodman, and Rorty were showing the difficulty of distinguishing what was said from how it was said even in the discourses of the physical sciences, let alone in such a nonformalized discourse as history. ${ }^{6}$ Their work confirmed what had been a founding presupposition of modern linguistics, namely, that language is never a set of empty forms waiting to be filled with a factual and conceptual content or attached to preexistent referents in the world but is itself in the world as one "thing" among others and is already freighted with figurative, tropological, and generic contents before it is actualized in any given utterance. All this implied that the very distinctions between imaginative and realistic writing and between fictional and factual discourse, on the basis of which historiographical writing had been analyzed since its disengagement from rhetoric in the early nineteenth century, ${ }^{7}$ had to be reassessed and reconceptualized.

Indeed, the most cursory examination of the language of actual historical writings would have revealed that the content of the historiographical discourse is indistinguishable from its discursive form. That this is so is confirmed by the fact that classic historiographical works have continued to be valued for their literary qualities long after their information has become 
outdated and their explanations have been consigned to the status of commonplaces of the cultural moment in which they were written. It is true that, in speaking of the literary nature of such historiographical classics as those written by Herodotus, Tacitus, Guicciardini, Gibbon, Michelet, Tocqueville, Burckhardt, Mommsen, Huizinga, Febvre, or Tawney, we may often have in mind their status as models of interpretative thought as well as their status as exemplars of a felicitous writing style. But by designating their work as literary we do not so much remove it from the domain of knowledge production as simply indicate the extent to which literature itself must be considered to inhabit that domain insofar as it, too, provides us with similar models of interpretative thought. Literary discourse may differ from historical discourse by virtue of its primary referents, conceived as imaginary rather than real events, but the two kinds of discourse are more similar than different since both operate language in such a way that any clear distinction between their discursive form and their interpretative content remains impossible.

It is for reasons such as these that we must reject, revise, or augment the older mimetic and model theories of historical discourse. A history is, as Ankersmit puts it, less like a picture intended to resemble the objects of which it speaks or a model "tied to the past by certain translation rules" than "a complex linguistic structure specifically built for the purpose of showing a part of the past." 8 In this view, historical discourse is not to be likened to a picture that permits us to see more clearly an object that would otherwise remain vague and imprecisely apprehended. Nor is it a representation of an explanatory procedure intended finally to provide a definitive answer to the problem of "what really happened" in some given domain of the past. On the contrary, to use a formulation popularized by E. H. Gombrich in his studies of Western pictorial realism, historical discourse is less a matching of an image or a model with some extrinsic reality than a making of a verbal image, a discursive "thing" that interferes with our perception of its putative referent even while fixing our attention on and illuminating it.9

Paul Ricoeur has argued that a historiographical text is related to its referent in the way that the vehicle of a metaphor is related to its tenor. In his view, a historical discourse is a kind of extended metaphor - the traditional definition of allegory - and must be seen, therefore, as belonging to the order of figurative, as well as to those of literal and technical, speech. ${ }^{10}$ This is why historical discourse, like literary discourse or figurative language in general, typically appears to be, as Ankersmit puts it, "dense and opaque" rather than thin and transparent and resists both paraphrase and 
analysis by logical concepts alone. ${ }^{11}$ Like poetic discourse as characterized by Jakobson, historical discourse is intensional, that is, is systemically intra- as well as extrareferential. This intensionality endows the historical discourse with a quality of "thinginess" similar to that of the poetic utterance, and this is why any attempt to comprehend how historical discourse works to produce a knowledge-effect must be based not on an epistemological analysis of the relation of the mind of the historian to a past world but, rather, on a scientific study of the relation of the things produced by and in language to the other kinds of thing that comprise the common reality. In short, historical discourse should be considered not primarily as a special case of the "workings of our minds" in its efforts to know reality or to describe it but, rather, as a special kind of language use which, like metaphoric speech, symbolic language, and allegorical representation, always means more than it literally says, says something other than what it seems to mean, and reveals something about the world only at the cost of concealing something else.

It is the metaphoric nature of the great classics of historiography that explains why none of them has ever wrapped up a historical problem definitively; rather, they have always opened up a prospect on the past that inspires more study. It is this fact that authorizes us to classify historical discourse primarily as interpretation, rather than as explanation or description, and above all as a kind of writing that, instead of pacifying our will to know, stimulates us to ever more research, ever more discourse, ever more writing. As Ankersmit puts it:

The great books in the field of the history of historiography, the works of Ranke, de Tocqueville, Burckhardt, Huizinga, Meinecke or Braudel, do not put an end to a historical debate, do not give us the feeling that we now finally know how things actually were in the past and that clarity has ultimately been achieved. On the contrary: these books have proved to be the most powerful stimulators of the production of more writing - their effect is thus to estrange us from the past, instead of placing it upon a kind of pedestal in a historiographical museum so that we can inspect it from all possible perspectives. ${ }^{12}$

None of this implies that we should not discriminate between the activity of historical research (historians' study of an archive containing information about the past) and that of historical writing (historians' composition of a discourse and the translation of it into a written form). In the research phase of their work, historians are concerned to discover the truth 
about the past and to recover information either forgotten, suppressed, or obscured, and, of course, to make of it whatever sense they can. But between this research phase, which is really quite indistinguishable from that of a journalist or a detective, and the completion of a written history, a number of important transformative operations must be performed in which the figurative aspect of the historian's thought is intensified rather than diminished.

In the passage from a study of an archive to the composition of a discourse to its translation into a written form, historians must employ the same strategies of linguistic figuration used by imaginative writers to endow their discourses with the kind of latent, secondary, or connotative meanings that will require that their works be not only received as messages but read as symbolic structures. ${ }^{13}$ The latent, secondary, or connotative meaning contained in the historical discourses is its interpretation of the events that make up its manifest content. The kind of interpretation typically produced by the historical discourse is that which endows what would otherwise remain only a chronologically ordered series of events with the formal coherency of the kind of plot structures met with in narrative fiction. This endowment of a chronicle of events with a plot structure, which I call the operation of emplotment, is carried out by discursive techniques that are more tropological than logical in nature.

If this is so, then logical analysis must be augmented by tropological analysis if we are to have the analytical categories necessary for an understanding of how historical discourse produces its characteristic knowledgeeffects. If, when viewed from the perspective of the logician, the typical historical discourse must be seen as having the structure of an enthymeme rather than that of a true syllogism, it is because "turns" more tropical than logical preside over both its endowment of a series of events with the structural coherency of a plot form and its endowment of a set of facts with whatever meaning it is supposed to possess. Indeed, it is only by troping, rather than by logical deduction, that any given set of the kinds of past event we would wish to call historical can be (first) represented as having the order of a chronicle; (second) transformed by emplotment into a story with identifiable beginning, middle, and end phases; and (third) constituted as the subject of whatever formal arguments may be adduced to establish their "meaning" - cognitive, ethical, or aesthetic, as the case may be. These three tropological abductions occur in the composition of every historical discourse, even those which, as in modern structuralist historiography, eschew storytelling and try to limit themselves to statistical analyses of institu- 
tions and long-term, effectively synchronic, ecological and ethnological processes.

Why characterize these abductions as tropological?

First of all, while events may occur in time, the chronological codes used to order them into specific temporal units are culture specific, not natural; and, moreover, must be filled with their specific contents by the historian if he is to constitute them as phases of a continuous process of historical development. The constitution of a chronicle as a set of events that can provide the elements of a story is an operation more poetic than scientific in nature. The events may be given, but their functions as elements of a story are imposed upon them - by discursive techniques more tropological than logical in nature.

Second, the transformation of a chronicle of events into a story (or congeries of stories) requires a choice among the many kinds of plot structure provided by the cultural tradition of the historian. And while convention may limit this choice to the range of types of plot structure deemed suitable for the representation of the types of event being dealt with, this choice is at least relatively free. There is no necessity, logical or natural, governing the decision to emplot a given sequence of events as a tragedy rather than as a comedy or romance. Are there intrinsically tragic events, or does it depend upon the perspective from which they are viewed? To emplot real events as a story of a specific kind (or as a mixture of stories of specific kinds) is to trope those events. This is because stories are not lived; there is no such thing as a real story. Stories are told or written, not found. And as for the notion of a true story, this is virtually a contradiction in terms. All stories are fictions. Which means, of course, that they can be true only in a metaphorical sense and in the sense in which a figure of speech can be true. Is this true enough?

And, third, whatever argument a historian may explicitly advance to explain the meaning of the events contained in the chronicle will be as much about the plot used to fashion the chronicle into a particular kind of story as it will be about the events themselves. This means that the argument of a historical discourse is ultimately a second-order fiction, a fiction of a fiction or a fiction of fiction making, which bears the same relationship to the plot that the plot bears to the chronicle. Typically, the explanation will be the story with the events left out and only its conceptual content (facts on the one side and plot connectives on the other) offered up as the material for logical (or, more technically, nomological-deductive) handling.

Structuralist historical discourse achieves the effect of producing a 
"scientific" account more by the tropological move of disemplotting previously emplotted sets of historical events than by the provision of anything like the kind of understanding of history that the physical sciences provide for the understanding of nature. Paul Ricoeur has shown, in his recent Time and Narrative, how the Annales school of historians were required first to build narrative discursive structures into their accounts of the past, in order to permit them to pass for specifically historical accounts, prior to depriving them of this narrativity in order to pass them off as scientific analyses. ${ }^{14}$ In historiographical reflection, it would appear, a scientific handling of historical materials is rendered possible only on the basis of a tropological swerve neither more nor, it should be added, less justifiable on cognitive grounds than that which renders possible a literary handling of these same materials.

Historical studies have never had a Copernican revolution similar to that which founded the physical sciences. It is only the prestige of the physical sciences themselves, based on their success in providing modern mankind with a control over nature only previously dreamed of, that inspires the effort to apply their principles of description, analysis, and explanation to history. But until such a Copernican revolution occurs, historical studies will remain a field of inquiry in which the choice of a method for investigating the past and of a mode of discourse for writing about it will remain free, rather than constrained. In historiography, discourse has always been, and is likely to remain, rule inventive as well as rule governed. In any scientific discipline, you can make new rules only by troping, swerving from, old ones, but in historiography you can apply the old rules only by tropological tactics. This does not imply that traditional historiography is inherently untruthful, but only that its truths are of two kinds: factual and figurative.

Tropology is not, of course, $a$ theory of language but, rather, a more or less systematized cluster of notions about figurative language deriving from neoclassical rhetorics. ${ }^{15}$ It thus provides a perspective on language from which to analyze the elements, levels, and combinatorial procedures of nonformalized, and especially pragmatic, discourses. ${ }^{16}$ Tropology centers attention on the turns in a discourse: turns from one level of generalization to another, from one phase of a sequence to another, from a description to an analysis or the reverse, from a figure to a ground or from an event to its context, from the conventions of one genre to those of another within a 
single discourse, and so on. Such turns may be governed by formal rules of logical exposition, mathematical projection, statistical inference, generic or oratorical conventions (of storytelling, legal disputation, political debate, and so on), but most often they consist of violations of such rules. ${ }^{17}$ In complex discourses such as those met with in historiography or indeed any of the human sciences, the rules of discourse formation are not fixed. Unlike the transitions of a formalized discourse, which are governed by explicit rules of selection and combination, the turns of any given nonformalized discourse and the order of their occurrence are not predictable in advance of their actualization in a specific utterance. This is why efforts to construct a logic or even a grammar of narrative have failed. But the turns can be identified, classified as types, and generic patterns of their typical orders of occurrence in specific discourses established.

The classification of the tropes of language, speech, and discourse remains an uncompleted (and, in principle, uncompletable) project of figurative linguistics, semiotics, neorhetoric, and deconstructive criticism. However, the four general types of trope identified by neoclassical rhetorical theory appear to be basic: metaphor (based on the principle of similitude), metonymy (based on that of contiguity), synecdoche (based on the identification of parts of a thing as belonging to a whole), and irony (based on opposition)..$^{18}$ Considered as the basic structures of figuration, these four tropes provide us with categories for identifying the modes of linking an order of words to an order of thoughts (e.g., apple with temptation) on the paradigmatic axis of an utterance and of one phase of a discourse with preceding and succeeding phases (e.g., transitional paragraphs or chapters) on the syntagmatic axis. The dominance of one mode of associating words and thoughts with one another across an entire discourse allows us to characterize the structure of the discourse as a whole in tropological terms. The tropological structures of metaphor, metonymy, synecdoche, and irony (and what I take - following Northrop Frye - to be their corresponding plot types: romance, tragedy, comedy, and satire) provide us with a much more refined classification of the kinds of historical discourse than that based on the conventional distinction between linear and cyclical representations of historical processes. ${ }^{19}$ They also allow us to see more clearly the ways in which historical discourse resembles and indeed converges with fictional narrative, both in the strategies it uses to endow events with meanings and in the kinds of truth in which it deals.

But, it might very well be asked, so what? As Arnaldo Momigliano puts it: "Why should it concern me if a historian prefers to present the part 
for the whole rather than the whole for the part? After all, I do not care if a historian has chosen to write in an epic style or to introduce speeches (discorsi) into his narration. I have no reason to prefer synecdochic historians to ironic ones or vice versa." ${ }^{20}$ In Momigliano's view, the only requirements of historians are that they discover the truth, present new facts, and offer new interpretations of the facts. "To be sure," he concedes, "in order to be called historians, they have to turn their research into some form of story. But their stories have to be true stories."21 Only the truth of the facts and, presumably, the plausibility of interpretations count; the linguistic form and generic mode in which these are presented, the diction and the rhetoric of the discourse, are of no import.

But it does matter whether events are presented as parts of a whole (with a meaning not apprehendible in any of the parts taken individually), after the manner of a Platonic realist, or a whole is presented as nothing but the sum of its several constituent parts, after the manner of a nominalist. It matters to the kind of truth that one can expect to derive from a study of any given set of events. And I am confident that even Momigliano would admit that the choice of a farcical style for the representation of some kinds of historical events would constitute not only a lapse in taste but also a distortion of the truth about them. So, too, for an ironic mode of representation. A mode of representation such as irony is a content of the discourse in which it is used, not merely a form - as anyone who has had ironic remarks directed at them will know all too well. When I speak to or about someone or something in an ironic mode, I am doing more than clothing my observations in a witty style. I am saying about them something more and other than I seem to be asserting on the literal level of my speech. So it is with historical discourse cast in a predominantly ironic mode, and so it is with the other modes of utterance I may employ to speak about anything whatsoever.

The same kind of response can be made to historians and philosophers of history who reject rhetorical analysis of historical texts on the grounds that they divert us from the more serious issues with which a politically committed or socially engaged criticism should be concerned. In a recent essay, Gene Bell-Villada, a historically self-conscious critic of Latin American literature, writes:

Meanwhile, in the face of a domestic sociopolitical panorama that begins to look vaguely "Latin American," plus certain South American "friendly regimes" that behave more and more Nazi-like, the only response that the U.S. "critical establishment" can come up with is its elaborate paraliterary schemes, 
its wars on referentiality and its preachments that "History is Fiction, Trope and Discourse." The families of several thousand Salvadoran death-squad victims may entertain other thoughts about history. ${ }^{22}$

I have no doubt that the families alluded to in this passage do indeed have "other thoughts about history" than that it consists of "Fiction, Trope and Discourse" - if they bother to think about history at all. They would be as foolish as Bell-Villada apparently thinks I am if they even entertained such thoughts. But that is really not the point at issue. The history we are discussing is that which takes shape in language, emotion, thought, and discourse in the attempt to make sense of the kind of experiences those families have endured. In the case he cites, these are first and foremost political experiences, and one of the ways of making sense of such experiences is to think about them historically. But such thought is all the more likely to be tropical, discursive, and fictional (in the sense of "imaginary") in the extent to which it is politically engaged or ideologically motivated. There is no position above the battle - not even the Marxist one - which is not similarly tropical, discursive, and fictional. A failure of historical consciousness occurs when one forgets that history, in the sense of both events and accounts of events, does not just happen but is made. Moreover, it is made on both sides of the barricades, and just as effectively by one side as by the other.

Bell-Villada knows this perfectly well, as his own remarks on the sense of history that pervades the work of the modern Latin American writers makes clear. Would he wish to say that their works do not teach us about real history because they are fictions? Or that, being fictions about history, they are devoid of tropisms and discursivity? Are their novels less true for being fictional? Are they less fictional for being historical? Could any history be as true as these novels without availing itself of the kind of poetic tropes found in the work of Vargas Llosa, Carpentier, Donoso, and Cortazar?

I have offered elsewhere some arguments in support of the positions outlined above and demonstrations, in the form of extensive explications of specific historiographical texts, of their possible utility for understanding what is involved in the composition of a historical discourse. ${ }^{23}$ I will not try here, for want of space, to recapitulate the details of these arguments, but it may be helpful to have summarized some of the kinds of objection raised by critics of the positions advanced here. The general objections are four. 
The first objection to the theory is that it seems to commit us to linguistic determinism or, what amounts to the same thing in the minds of some critics, linguistic relativism. According to this theory, it is argued, the historian appears to be a prisoner of the linguistic mode in which he initially describes or characterizes his object of study: he can see only what his language permits him to conceptualize. This circumstance appears to set limits on what can be learned in the process of investigating the evidence, and it does not take account of the fact that historians undeniably do change their perceptions of things in the course of their research and revise their conceptions of the meanings of these things on reflection on the evidence.

A similar argument, advanced on the same general grounds, is raised with respect to the historian's finished written account of her findings. The tropological theory of historical discourse appears to obscure the nature of a historical work; it is a report of facts discovered in research, of the historian's beliefs about the truth of these facts, and of the best argument he can envisage regarding the causes, meaning, significance, or import of these truths for the comprehension of the domain of occurrences that he has studied. The suggestion that the connections among the various elements, levels, and dimensions of the discourse in which the argument is set forth are tropological rather than logical or rationally deliberative deprives historical discourse of its claims to truthfulness and relegates it to the fanciful domain of fiction. These two arguments are often united and expressed more concisely in the declaration that the theory makes of historiography little more than a rhetorical exercise and thereby undermines history's claim to provide truths about and knowledge of its objects of study.

The second general objection is directed against the theory of the tropological nature of language and its implications for the theory of historical discourse. The tropological theory of language appears to dissolve the distinction between figurative and literal speech, making the latter into a special case of the former. The theory views literal language as a set of figurative usages that happen to have been regularized and established as literal speech by convention alone. What is literal in one moment of a language community's development can therefore become figurative at another moment and vice versa, so that the meaning of a given discourse can change with any change in the rules for determining what counts as literal speech and what counts only as metaphor. This seems to vest the authority to determine the meanings of discourses not in the intentions of their authors or in what the texts written by them manifestly say but in readers or 
reading communities, who are permitted to make of them whatever they wish or whatever the current conventions governing the distinction between literal and figurative speech permit.

Thus, it seems that, on the tropological theory of language, we could no longer appeal to the facts in order to justify or to criticize any given interpretation of reality. What could count as a fact would be infinitely revisable, as the notion of what counted as a literal statement and what counted as a metaphorical one changed. In sum, the tropological theory of language and of discourse strikes at the very conception of factuality, and especially at historians' claims regarding the factual truthfulness not only of their statements about particular events but of their discourse as a whole. If a factual statement is not only a singular existential proposition cast in literal language but such a proposition plus the implied conventions for determining what shall count as literal and what as figurative in that proposition, then such statements can no longer be taken at their face value. Like printed money, they can only be cashed in at the going rate of their value in literalist specie. Since this rate of exchange is always in flux, one can never know where one stands in relation to the facts of reality. The tropological theory of language, then, threatens history's centuries-long claim to deal in facts and therewith its status as an empirical discipline.

The third general objection to the tropological theory of language and discourse in its relation to historical discourse turns upon its implications regarding the nature of the objects studied by historians. The theory seems to imply that these objects are not found in the real world (even if this real world is a past one) but are, rather, constructions of language, spectral and unreal objects, poetically or rhetorically invented and having their existence only in books. The theory, in a word, stresses the poetic (self-referring), conative (affective), and above all metalinguistic (codifying) functions of historical discourse at the expense of its referential (predicative), phatic (communicative), and expressive (authorial) functions. ${ }^{24}$ Since a historical discourse is intended to be primarily referential, expressive (of its author's rational thought about its referents), and communicative, the tropological theory of discourse improperly treats the history as if it were only a fiction. Thereby the reality of its referents is denied, being replaced by what Barthes disparagingly called "the reality-effect," 25 a purely rhetorical construction. But since the objects of historical study are (or were) real objects and historians intend to make precise references to them and truthful statements about them, the elision of the distinction between 
the referential function and the other functions of discourse brings under question the existence of reality itself and the very possibility of a specifically realistic representation of it.

If the tropological theory of language and discourse seems to undermine the historian's claim to deal in facts about particular real objects, it is even more threatening to the claim to deal in facts of a more general, collective, or processual nature. This is especially the case with respect to the notion that the tale told by the narrative historian is a true rather than an invented story. True is here understood as conforming to "what really happened" wherein "what really happened" is considered to have been a form of human life, individual or collective, having the outline and structure of a story. Tropological theory, in suggesting that a story can only be a construction of language and a fact of discourse, appears to undermine the legitimacy of the claims to truthfulness of the traditional mode of historical discourse, the narrative. Thus, while seeming to dissolve the scientific historian's claims to scientificity, the tropological theory of the historical discourse also dissolves the traditional narrative historian's claim to have provided a story that is true rather than imaginary.

Finally, a fourth objection to the use of a tropological theory of language for the analysis of historical discourse turns upon the question of its implications for the epistemic status of the historiographical critic's own discourse. If all discourse is fictive, figurative, imaginative, poeticorhetorical, if it invents its subjects rather than finds them in the real world, if it is only to be taken figuratively, and so on, as the tropological theory seems to suggest, then is this not true also of the discourse of the tropologist? How can the tropological critic take his own discourse seriously or expect others to do so? Is not tropology itself a fiction, and whatever statements made on its basis nothing but fictions of the fictions it purports to find everywhere? In short, the tropological theory of language appears to make a cognitively responsible criticism impossible and as such undermines the activity of criticism itself.

These objections will appear more or less compelling in the degree to which one has confidence in the conventional distinctions between literal and figurative speech, referential and nonreferential discourse, factual and fictional prose, the content and the form of a given type of discourse, and so on. Where that confidence is strong, the alternative formulations of the 
distinctions offered by modern language and literary theory will appear unnecessary and their utility for the understanding of historical discourse inconsequential. It should be stressed, however, that tropological theories of discourse do not so much dissolve these distinctions as reconceptualize them. Whereas traditional critical theory views the literal and figurative, fictional and factual, referential and intensional dimensions of language as opposed, and even mutually exclusive alternatives for all serious discourse, modern language and literary theory tends to view them as the poles of a linguistic continuum between which speech must move in the articulation of any discourse whatsoever, serious or frivolous. Insofar as this movement within discourse is itself tropological in nature, we need a tropological theory to guide analysis of it.

As for the objections themselves, several replies can be made. First, there is nothing in tropological theory implying linguistic determinism or relativism. Tropology is a theory of discourse, not of mind or consciousness. Although it assumes that figuration cannot be avoided in discourse, the theory, far from implying linguistic determinism, seeks to provide the knowledge necessary for a free choice among different strategies of figuration. Nor does it suggest, after the manner of Whorf, that perception is determined by language and that the truthfulness of a discourse is relative to the language in which it is written. As a theory of discourse, tropology has much to say about representation but nothing to say about perception.

Second, tropology does not deny the existence of extradiscursive entities or our capacity to refer to and represent them in speech. It does not suggest that everything is language, speech, discourse, or text, only that linguistic referentiality and representation are much more complicated matters than the older, literalist notions of language and discourse made out. Tropology stresses the metalinguistic over the referential function of discourse because it is concerned more with codes than with whatever contingent messages can be transmitted by specific uses of them. Insofar as codes are themselves message-contents in their own right, tropology expands the notion of message itself and alerts us to the performance, as well as the communicative, aspect of discourse.

Third, the thesis that all discourse is tropological in structure does indeed suggest that this is true also of the tropologist's own discourse. But this implies only that tropological analysis must be elaborated in full consciousness of its own figurative aspect. Far from implying that tropological analysis is a frivolous game, tropological theory implies, rather, that we should rethink the distinction between serious and playful discourse itself. 
When tropological critics analyze the tropological structure of a text, they are speaking about facts - facts of language, discourse, and textuality even if they are speaking in a language that they know to be as much figurative as literal. They are referring to things they perceive or believe that they perceive in the text, even if they are referring as much in the indirect way of figurative speech as in the direct way of literalist speech. Is their discourse to be taken seriously, then, as really meaning what it says? Of course it is, but only insofar as seriousness is not equated with a narrow literal-mindedness, meaning is not equated with only literal meaning, and really is not understood as foreclosing the possibility that figurative speech can be as truthful in its own way as literal speech.

Fourth, then, tropological theory does not collapse the difference between fact and fiction but redefines the relations between them within any given discourse. If there is no such thing as raw facts but only events under different descriptions, then factuality becomes a matter of the descriptive protocols used to transform events into facts. Figurative descriptions of real events are not less factual than literalist descriptions; they are factual - or, as I would put it, "factological" - only in a different way. Tropological theory implies that we must not confuse facts with events.

Events happen, whereas facts are constituted by linguistic description. The mode of language used to constitute facts may be formalized and rule governed, as in scientific and traditional discourses; it may be relatively free, as in every modernist literary discourse; or it may be a combination of formalized and free discursive practices. In the second and third cases, tropology offers a better prospect for a theory of discursive invention than either logical or grammatical models of discursivity. And since historiography has for the most part been and is likely to remain a combination of rulegoverned and free discursive practice, tropology has an especial relevance to the effort to understand it.

Tropology is especially useful for the analysis of narrative historiography because narrative history is a mode of discourse in which the relations between what a given culture regards as literal truths and the figurative truths expressed in its characteristic fictions, the kinds of stories it tells about itself and about others, can be tested. In historical narratives, the dominant plot forms utilized by a culture to imagine the different kinds of meaning (tragic, comic, epic, farcical, etc.) which a distinctively human form of life might have are tested against the information and knowledge that specific forms of human life have had in the past. In the process, not only are past forms of human life endowed with the kinds of meaning met 
with in the forms of fiction produced by a given culture, but the degrees of truthfulness and realism of these forms of fiction to the facts of historical reality and our knowledge of it can be measured. This relationship between historical interpretation and literary representation applies not only to their mutual interest in generic plot structures but also to the narrative mode of discourse that they mutually share.

It is because historical discourse utilizes structures of meaning-production found in their purest forms in literary fictions that modern literary theory, and especially those versions of it oriented toward tropological conceptions of language, discourse, and textuality, is immediately relevant to contemporary theory of historical writing. It bears directly on one of the most important debates in contemporary historical theory: that of the epistemic status of narrativity.

This debate arises against the background of a forty-year discussion, begun in the I940s, among philosophers and historians over the issue of history's possible status as a science. ${ }^{26}$ The question of narrative was addressed in this discussion, but primarily in terms of its suitability to the aim and purposes of scientific discourse. One side in this debate held that if historical studies were to be transformed into a science, the narrative mode of discourse, being manifestly literary in nature, was inessential to the study and writing of history. The other side considered narrative to be not only a mode of discourse but also, and most importantly, a specific mode of explanation. Although narrative explanation differed from the mode of (nomological-deductive) explanation prevailing in the physical sciences, it was not to be considered inferior to it, was especially suited to the representation of historical as against natural events, and could therefore be used with perfect propriety for the explication of specifically historical events. This particular debate came to an end sometime during the 1970s, in the way one would expect a philosophical debate to end, in a compromise. It was decided by general consensus that narrative was properly used in historiography for some purposes but not for others.

No sooner had the matter seemingly been resolved, however, than it was reopened by the explosion on the critical scene of another argument that had been building in another quarter and which had to do with the implicit content of narrative discourse in general. Whereas the older dispute had focused on the relation of narrative discourse to scientific knowledge, 
the newer one stressed the relationship of narrative to myth and ideology. Thus, for example, Barthes argued that narrativity itself was the effective content of "modern myth" (by which he meant ideology). Kristeva (following Althusser) indicted narrativity as the instrument by which society produced the self-oppressing, compliant subject out of the originally autonomous individual. Derrida cited narrative as the privileged "genre of the law." Lyotard attributed the "postmodernist condition" to the breakdown of a "narrative knowledge" purely customary in nature. And, most recently, Sande Cohen represented narrative consciousness as the incarnation of a purely reactive and "disintellective" mode of thinking and the principal impediment to critical and theoretical thought in the human sciences. ${ }^{27}$

At the same time, however, defenders of narrativity were not wanting. Certain leading historians, such as Laurence Stone, Dominick LaCapra, James Henretta, and Bernard Bailyn, have recently stressed the desirability, if not the necessity, of narrative as an antidote to the disaffection of lay readers put off by the abstractness and lack of intimacy of technical historiography. Some redoubtable Annalistes, most prominently Leroy Ladurie and Le Goff, have not only come around to admitting the desirability of narrative for the representation of certain kinds of historical phenomena but have actually committed overt acts of historiographical narrativity. Among literary theorists, Fredric Jameson has attempted to reenergize Marxism by stressing its status less as a science than as a "master narrative" of history which could provide both an understanding of the past and the grounds necessary for the hope of transcending the "alienating necessities" of a history lived as a story of class oppression. And finally, from the quarter of philosophical hermeneutics, Paul Ricoeur, in what amounts to the most comprehensive attempt to synthesize modern Western thought about history, Time and Narrative, has set forth a veritable metaphysics of narrativity and defense of its adequacy, not only to historical representation, but also to the representation of the fundamental "structures of temporality."28

Obviously, something other than a question of literary form was involved in this debate. Except for those professional historians who regarded it as a cosmetic for a knowledge too dreary to be taken straight by a lay audience, narrative was being treated as much more than a medium for transmitting messages that might just as well be conveyed by other discursive techniques. On the contrary, narrative was being treated as if it were a message in its own right, a message with its own referent and a meaning quite other than that which it appears only to contain. For example, Jameson speaks of narrative as "a central instance of the human mind and a mode 
of thinking fully as legitimate as that of abstract thought." ${ }^{29}$ Lyotard and McIntyre, though from diametrically opposed ideological perspectives, cite the social function of narrative as a mainstay of any effective legitimation of knowledge and ethicopolitical authority. ${ }^{30}$ And Ricoeur maintains that narrative, far from being only a form, is the manifestation in language of a distinctively human experience of temporality. ${ }^{31}$ All this in opposition to the idea, advanced by the hostile deconstructors of narrativity, such as Barthes, Kristeva, Derrida, and Cohen, that narrative is the still undissolved residue of mythic consciousness in modern thought. In a word, far from being considered only a form, narrative is increasingly being recognized as a discursive mode whose content is its form.

Now, from the standpoint of traditional literary theory, the notion that the form of a discourse might be one of its contents would have to be treated as either a paradox or a mystery. From the perspective provided by tropological theory, however, there would be nothing paradoxical or mysterious at all about such a notion. This content of a form of discourse would be linguistic in nature and would consist of the structure of its dominant trope, the trope that serves as the paradigm in language for the representation of things as parts of identifiable wholes. In this view of the matter, narrative can be characterized as a kind of discourse in which synecdoche functions as the dominant trope for "grasping together" (Greek, synecdoche; Latin, subintellectio) the parts of a totality apprehended as being dispersed across a temporal series into a whole in the mode of identification. ${ }^{32}$ This mode of discourse can be differentiated from those in which the parts of an apparent whole are related to one another by resemblance (metaphor), contiguity (metonymy), or opposition (irony or catachresis). There is nothing particularly metaphysical about the representation of discrete things, whether these be individual persons, social institutions, or sets of events, as unities whose aspects are identifiable as attributes of the wholes of which they are part. We do this in ordinary speech (whatever that may be) all the time. We do it in philosophical language when, after the manner of Aristotle, Leibniz, Hegel, James, Whitehead, and Dewey, we wish to indicate and reflect upon those aspects of reality that appear to be organic rather than mechanistic in their structure and mode of development and articulation. We do it in historical language when we wish to speak about continuities, transitions, and integrations. And we do it in literary language when we wish to write narrative novels, poems, or plays.

Viewed from this perspective, narrative is not so much either a distortion of that reality given to us in perception (Barthes's "myth") or an 
epiphanic manifestation of a metaphysical ground of being (Ricoeur's "structures of temporality") as the appearance in discursive form of one of the tropological possibilities of language use. Viewing the matter this way, we can begin to appreciate the extent to which programs undertaken either to expunge narrativity from serious discourse or to elevate it to the status of an expression of Being, or Time, or Historicity are equally misguided. Narrative is a cultural universal because language is a human universal. We can no more expunge it from discourse than we can legislate discourse itself out of existence. Narrative may be the very soul of myth, but this is because myth is a form of linguistic discourse, not because narrative is inherently mythical. And the same can be said of the relation of narrative to literary fiction. Some literary fictions are cast in a narrative mode, but this does not mean that all narratives are literary fictions. What it means is that both mythic and literary narratives are linguistic figurations.

So, too, for the relation of narrative to historical (and, by extension, all "realistic") discourses. A historical representation can be cast in the mode of a narrative because the tropological nature of language provides that possibility. Therefore, it is absurd to suppose that, because a historical discourse is cast in the mode of a narrative, it must be mythical, fictional, substantially imaginary, or otherwise "unrealistic" in what it tells us about the world. To suppose this is to indulge in the kind of thinking that results in belief in contagious magic or guilt by association. If myth, literary fiction, and traditional historiography utilize the narrative mode of discourse, this is because they are all forms of language use. This in itself tells us nothing about their truthfulness - and even less about their "realism" inasmuch as this notion is always culturally determinate and varies from culture to culture. Anyway, does anyone seriously believe that myth and literary fiction do not refer to the real world, tell truths about it, and provide useful knowledge of it?

The question of the relation between narrative and history has received especial attention in recent literary theory because it is central to a crucial problem of literary history, that of the relation of literary modernism to literary realism. The transition from realism to modernism appears to many interpreters to have entailed the repudiation of both the form of the narrative and any interest in the representation of historical reality. ${ }^{33} \mathrm{To}$ Marxist interpreters especially, the one repudiation appears to have been a function of the other. Thus, the argument runs, the realism of the classical nineteenth-century novel was a result of the discovery that social reality was historical in nature. The discovery of the historical nature of social reality 
was the discovery that society was not only, or even primarily, tradition, consensus, and continuity but also conflict, revolution, and change. The realistic novel was the necessary expression in literature of this discovery, not only because it took historical reality as its content but also because it developed the inherently dialectical capability of narrative form for the representation of any reality specifically historical in nature. The abandonment of normal narrativity by modernist writers, therefore, was the expression on the level of form of the rejection of historical reality on the level of content. And since fascism was based on a similar rejection of historical reality and a flight into purely formalist political solutions for real social contradictions, modernism could be seen as the expression in literature of fascism in politics. ${ }^{34}$

Now, this debate within modern literary theory over the nature of literary modernism - a debate that has been extended to comprise postmodernism as well-recapitulates many of the arguments of an earlier debate in the human sciences precipitated by the so-called crisis of historicism. ${ }^{35}$ This crisis was manifested in a general despair of ever attaining to that "objective science of history" sought in the nineteenth century as an antidote to ideology in social and political thought. It was marked by the onset in the human sciences of moral and epistemological relativism, critical pluralism, and methodological eclecticism. In many respects, the crisis was caused by the very success of traditional, Rankean historical studies in mapping the political, social, and cultural diversity not only of human history in general but, in particular, of those ethical values, aesthetic ideals, and cognitive structures that supposedly made human nature qualitatively different from its animal counterparts. Historical knowledge appeared to confirm the idea that, if culture distinguished human beings from animals, the forms of culture were infinitely variable and both knowledge and values were culture specific rather than universal. Moreover, it appeared that historical knowledge itself, far from being the key to the comprehension of human nature, might be only a particular prejudice of modern Western civilization. Whence the need felt for new sciences of society and culture that would be genuinely universalistic in scope and orientation, utterly free of any link to the values of any specific culture, and programmatically ahistorical in their approach to the study of social and cultural phenomena.

Neopositivism and structuralism were the forms assumed by the envisioned new sciences. These were offered as alternatives to a superannuated historicism in the human sciences in general and to traditional historical studies in particular. At issue in historical studies specifically was the pos- 
sibility of an approach to the study of history shorn of the illusions of nineteenth-century realism in all its forms, literary, philosophical, social scientific, and historiographical alike.

In many respects, then, contemporary debates within the human sciences over the relation of traditional historiography to its scientific alternatives resemble current debates within the field of literary studies over the relation of literary realism to literary modernism - and not accidentally, since what is at issue in both is the question of the adequacy of a given form of discourse, the narrative, to the representation of a given content, historical reality. If the two debates seem seldom to converge or fuse, it is because each of them tends to take for granted as an explanans what the other treats as an explanandum.

Thus, for example, the debate within literary studies over modernism unfolds under the aegis of a notion, shared by modernists and antimodernists alike, that history provides a neutral ground of facts that can be appealed to for the characterization of what modernism is really all about, what its true social or cultural significance consists of, and what its ideological function really is. This is especially the case when Marxist critics, secure in the conviction that Marxism is the science of history promised by the nineteenth century, purport to disclose the true ideological content and historical significance of modernism considered as a period style. Similarly, the debate within historical theory over the status of traditional narrative history proceeds on the assumption, shared by anti- and pronarrativists alike, that narrative is a form of literary discourse, that literature deals in imaginary rather than real events, and that, therefore, historical studies must either purge themselves of narrative or use it only to make the details of historical reality interesting to an otherwise distracted readership. The literary critics appeal to history as an unproblematical body of facts for the solution of problems in literary theory, while the historical theorists appeal to what they conceive to be an unproblematical notion of the relation of literature to reality to site the question of narrative's function in historical discourse. So it goes in most theoretical discussions: any given field of knowledge must presuppose the adequacy of the practices of at least one other field in order to get on with its business.

But modern literary theory provides a perspective on historical writing more comprehensive than those envisioned by participants in the debate over the nature of narrative discourse, on the one side, and those engaged in the debate over the nature of historical knowledge, on the other. Historical discourse (as against historical inquiry) is a special case of dis- 
course in general. Consequently, theorists of historical discourse cannot afford to ignore the general theories of discourse that have been developed within modern literary theory, on the basis of new conceptions of language, speech, and textuality which permit reformulations of the traditional notions of literality, reference, authorship, audience, and codes. Not because modern literary theory provides definitive answers to the questions raised by these new conceptions of language, speech, and textuality, but because, on the contrary, it has reproblematized an area of inquiry which, in historical theory at least, had for too long been treated as having nothing problematical about it.

In an essay published in Communications in 1972, Barthes suggested that the kind of interdisciplinary work demanded by the modern human sciences required not so much the use of a number of established disciplines for the analysis of a traditionally defined object of study as the invention of a new object that would not belong to any particular established discipline. ${ }^{36}$ Barthes proffered "the text" in its modern, linguistic-semiotic conceptualization as such an object. If we follow out the implications of this suggestion, we can begin to grasp the significance of modern literary theory for the understanding of what is involved in our own efforts to theorize historical writing. One of the most important implications is that we will no longer be able to regard the historiographical text as an unproblematical, neutral container of a content supposedly given in its entirety by a reality that lies beyond its confines. We do not have to go as far as Barthes was willing to go at that time in dividing text into the two possibilities of the "readerly" and the "writerly" and then holding that the former was only a special, disguised case of the latter-especially inasmuch as the heuristic utility of the notion of text derives from its function as designating a new problem for research rather than serving as a solution to an old one. We might wish, however, to explore the extent to which historical writing serves as the privileged site of the readerly text and provides a paradigm of all putatively realistic discourses.

Barthes himself suggested as much in an essay entitled "The Discourse of History" ( I 970). Here he points out how contemporary scientific historiography has given up the quest for the real in favor of the more modest, and ultimately more realistic, task of simply rendering history intelligible. At that point in the development of his own theories of discursivity, Barthes thought that this entailed the abandonment of narrative structure. He thought that because narrative had been "developed within the cauldron of fiction (in myths and the first epics)," it was therefore 
inherently unsuited to serve as "the sign and the proof of reality" in any discourse whatsoever. ${ }^{37}$

In Barthes's view, modern scientific history, by which he meant the structuralist historiography of the Annales type, resembled literary modernism by virtue of its interest in the intelligible rather than the real. But if this is the case, it follows that structuralist history is no more realistic than traditional history. Moreover, if it is a question of the intelligible rather than the real, narrative is just as effective a discursive instrumentality for producing it as the dissertative mode favored by every scientistic historiography.

However, Barthes's suggestion of the resemblances between structuralist history and literary modernism does have implications for our understanding of what is involved in their apparent, shared hostility to narrative discourse. I say apparent because it is now possible to recognize that literary modernism did not so much reject narrativity, historicity, or even realism as explore the limits of their peculiarly nineteenth-century forms and expose the mutual complicity of these forms in the dominant discursive practices of high bourgeois culture. In the process, literary modernism revealed new or forgotten potentialities of narrative discourse itself, potentialities for rendering intelligible the specifically modern experiences of time, historical consciousness, and social reality. Literary modernism did not repudiate narrative discourse but discovered in it a content, linguistic and tropological, adequate to the representation of dimensions of historical life only implicitly perceived in nineteenth-century realism, both literary and historical. The adequacy of the "content of the form" of literary modernism to the representation of both the form and the content of the kind of historical life we wish to call modern argues for the relevance of literary modernism to a modern historical discourse.

It also argues, I would suggest, for the relevance of modern literary theory to our understanding of the issues being debated among theorists of historical thought, research, and writing. Not only because modern literary theory is in many respects fashioned out of the necessity of making sense of literary modernism, determining its historical specificity and significance as a cultural movement, and devising a critical practice adequate to its object of study. But also, and primarily, because modern literary theory must of necessity be a theory of history, historical consciousness, historical discourse, and historical writing. 


\section{HisTORICAL EMPLOTMENT AND THe Problem of Truth in Historical Representation}

I have been asked to speak about "historical emplotments and the problem of 'truth.' " I presume I was asked to address this issue because I am thought to hold a relativist view of historical knowledge. Actually, I do hold that there is an inexpungeable relativity in every representation of historical phenomena. The relativity of the representation is a function of the language used to describe and thereby constitute past events as possible objects of explanation and understanding. This is obvious when, as in the social sciences, a technical language is so used. Scientific explanations openly purport to bear upon only those aspects of events - for example, quantitative and therefore measurable aspects - which can be denoted by the linguistic protocols used to describe them. It is less obvious in traditional narrative accounts of historical phenomena because: first, narrative is regarded as a neutral "container" of historical fact, a mode of discourse naturally suited to representing historical events directly; second, narrative histories usually employ so-called natural or ordinary, rather than technical, languages both to describe their subjects and to tell the story thereof; and third, historical events are supposed to consist of or manifest a congeries of real or lived stories that have only to be uncovered or extracted from the evidence and displayed before the reader to have their truth recognized immediately and intuitively.

Obviously, I regard this view of the relation between historical story- 
telling and historical reality as naïve or, at least, misconceived. Stories, like factual statements, are linguistic entities and belong to the order of discourse.

The question that arises with respect to the problem of historical emplotments and the topic of our conference, "Nazism and the 'Final Solution': Probing the Limits of Representation," is this: are there any limits on the kind of story that can responsibly be told about these phenomena? Can these events be responsibly emplotted in any of the modes, symbols, plot types, and genres with which our culture provides us for making sense of such extreme events in our past? Or do Nazism and the Final Solution belong to a special class of events such that, unlike even the French Revolution, the American Civil War, the Russian Revolution, or the Chinese Great Leap Forward, they must be viewed as manifesting only one story, as being emplottable in one way only, and as signifying only one kind of meaning? In a word, does the nature of Nazism and the Final Solution set absolute limits on what can be truthfully said about them? Does it set limits on the uses that can be made of them by writers of fiction or poetry? Do they lend themselves to emplotment in any number of ways, or are they, like other historical events, infinitely interpretable and ultimately undecidable as to their specific meaning?

In his memorandum on the rationale for this conference, Friedlander distinguishes between two kinds of question that might arise in the consideration of the question of historical emplotments and the problem of "truth": epistemological questions raised by the fact of "competing narratives about the Nazi epoch and the Final Solution" and ethical questions raised by the rise of "representations of Nazism . . . based on what used to be [regarded as] unacceptable modes of emplotment" (my emphases). Obviously, considered as accounts of events already established as facts, competing narratives can be assessed, criticized, and ranked on the basis of their fidelity to the factual record, their comprehensiveness, and the coherence of whatever arguments they may contain. But narrative accounts do not consist only of factual statements (singular existential propositions) and arguments; they consist as well of poetic and rhetorical elements by which what would otherwise be a list of facts is transformed into a story. ${ }^{1}$ Among these elements are those generic story patterns we recognize as providing the plots. Thus, one narrative account may represent a set of events as having the form and meaning of an epic or tragic story, while another may represent the same set of events - with equal plausibility and without doing any violence to the factual record - as describing a farce. ${ }^{2}$ 
Here the conflict between competing narratives has less to do with the facts of the matter in question than with the different story-meanings with which the facts can be endowed by emplotment. This raises the question of the relation of the various generic plot types that can be used to endow events with different kinds of meaning - tragic, epic, comic, romantic, pastoral, farcical, and the like - to the events themselves. Is this relationship between a given story told about a given set of events the same as that obtaining between a factual statement and its referent? Can it be said that sets of real events are intrinsically tragic, comic, or epic, such that the representation of those events as a tragic, comic, or epic story could be assessed as to its factual accuracy? Or does it all have to do with the perspective from which the events are viewed?

Of course, most theorists of narrative history take the view that emplotment produces not so much another, more comprehensive and synthetic, factual statement as an interpretation of the facts. But the distinction between factual statements (considered as a product of object-language) and interpretations of them (considered as a product of one or more metalanguages) does not help us when it is a matter of interpretations produced by the modes of emplotment used to represent the facts as displaying the form and meaning of different kinds of story. We are not helped by the suggestion that competing narratives are a result of the facts having been interpreted by one historian as a tragedy and interpreted by another as a farce. ${ }^{3}$ This is especially the case in traditional historical discourse in which the facts are always given precedence over any interpretation of them.

Thus, for traditional historical discourse, there is presumed to be a crucial difference between an interpretation of the facts and a story told about them. This difference is indicated by the currency of the notions of a real story (as against an imaginary story) and a true story (as against a false story). Whereas interpretations are typically thought of as commentaries on the facts, the stories told in narrative histories are presumed to inhere either in the events themselves (whence the notion of a real story) or in the facts derived from the critical study of evidence bearing upon those events (which yields the notion of the true story).

Considerations such as these provide some insight into the problems both of competing narratives and of unacceptable modes of emplotment of a period such as the Nazi epoch and of events such as the Final Solution. We can confidently presume that the facts of the matter set limits on the kinds of story that can be properly (in the sense both of veraciously and appropriately) told about them only if we believe that the events themselves possess 
a "story" kind of form and a "plot" kind of meaning. We might then dismiss a comic or pastoral story, with an upbeat tone and a humorous point of view, from the ranks of competing narratives as manifestly false to the facts - or at least to the facts that matter - of the Nazi era. But we could dismiss such a story from the ranks of competing narratives only if (I) it had been presented as a literal (rather than figurative) representation of the events, and (2) the plot type used to transform the facts into a specific kind of story had been presented as having been inherent in (rather than imposed upon) the facts. For unless a historical story is presented as a literal representation of real events, we cannot criticize it as being either true or untrue to the facts of the matter. If it were presented as a figurative representation of real events, then the question of its truthfulness would fall under the principles governing our assessment of the truth of fictions. And if it did not suggest that the plot type chosen to render the facts into a story of a specific kind had been found to inhere in the facts themselves, then we would have no basis for comparing this particular account to other kinds of narrative account, informed by other kinds of plot type, and for assessing their relative adequacy to the representation, not so much of the facts as of what the facts mean.

For the differences among competing narratives are differences among the modes of emplotments which predominate in them. It is because narratives are always emplotted that they are meaningfully comparable; it is because narratives are differently emplotted that discriminations among the kinds of plot type can be made. In the case of an emplotment of the events of the Third Reich in a comic or pastoral mode, we would be eminently justified in appealing to the facts in order to dismiss it from the lists of competing narratives of the Third Reich. But what if a story of this kind had been set forth in a pointedly ironic way and in the interest of making a metacritical comment not so much on the facts as on versions of the facts emplotted in a comic or pastoral way? Surely it would be beside the point to dismiss this kind of narrative from the competition on the basis of its infidelity to the facts. For even if it were not positively faithful to the facts, it would at least be negatively so - in the fun it poked at narratives of the Third Reich emplotted in the mode of comedy or pastoral.

On the other hand, we might wish to regard such an ironic emplotment as unacceptable in the manner suggested by Friedlander in his indictment of histories, novels, and films that, under the guise of seeming to portray faithfully the most horrible facts of life in Hitler's Germany, actually aestheticize the whole scene and translate its contents into fetish objects and 
the stuff of sadomasochistic fantasies. ${ }^{4}$ As Friedlander pointed out, such glamorizing representations of the phenomena of the Third Reich used to be unacceptable, whatever the accuracy or veracity of their factual contents, because they offended against morality or taste. That such representations have become increasingly common and therefore obviously more acceptable over the last twenty years or so indicates profound changes in socially sanctioned standards of morality and taste. But what does this circumstance suggest about the grounds on which we might wish to judge a narrative account of the Third Reich and the Final Solution to be unacceptable even though its factual content were both accurate and ample?

Here it seems to be a matter of distinguishing between a specific body of factual contents and a specific form of narrative and of applying the kind of rule that stipulates that a serious theme-such as mass murder or genocide-demands a noble genre, such as epic or tragedy, for its proper representation. This is the kind of issue posed by Art Spiegelman's Maus: $A$ Survivor's Tale, ${ }^{5}$ which presents the events of the Holocaust in the medium of the (black and white) comic book and in a mode of bitter satire, with Germans portrayed as cats, Jews as mice, and Poles as pigs. The manifest content of Spiegelman's comic book is the story of the artist's effort to extract from his father the story of his parents' experience of the events of the Holocaust. Thus the story of the Holocaust which is told in the book is framed by a story of how this story came to be told. But the manifest contents of both the frame story and the framed story are, as it were, compromised as fact by their allegorization as a game of cat-and-mouseand-pig in which everyone-perpetrators, victims, and bystanders in the story of the Holocaust and both Spiegelman and his father in the story of their relationship-comes out looking more like a beast than a human being. Maus presents a particularly ironic and bewildered view of the Holocaust, but it is at the same time one of the most moving narrative accounts of it that I know of, not least because it makes the difficulty of discovering and telling the whole truth about even a small part of it as much a part of the story as the events whose meaning it is seeking to discover.

To be sure, Maus is not a conventional history, but it is a representation of past real events or at least of events that are represented as having actually occurred. There is nothing of that aestheticization of which Friedlander complains in his assessments of many recent filmic and novelistic treatments of the Nazi epoch and the Final Solution. At the same time, this comic book is a masterpiece of stylization, figuration, and allegorization. It assimilates the events of the Holocaust to the conventions of comic book 
representation, and, in this absurd mixture of a "low" genre with events of the most momentous significance, Maus manages to raise all of the crucial issues regarding the limits of representation in general.

Indeed, Maus is much more critically self-conscious than Andreas Hillgruber's Zweierlei Untergang: Die Zerschlagung des Deutschen Reiches und das Ende des europäischen Judentums. ${ }^{6}$ In this extended essay, Hillgruber suggests that, even though the Third Reich lacked the nobility of purpose to permit its shattering to be called a tragedy, the defense of the eastern front by the Wehrmacht in I944/45 could appropriately be emplotted and without any violence to the facts - as a "tragic" story. Hillgruber's manifest purpose was to salvage the moral dignity of a part of the Nazi epoch in German history by splitting the whole of it into two discrete stories - the "shattering [Zerschlagung] of the German Empire" and the "end of European Jewry" - and emplotting them differently, the one as a tragedy, the other as an incomprehensible enigma. ${ }^{7}$

Critics of Hillgruber immediately pointed out that (I) even to cast the account in the mode of a narrative was to subordinate any analysis of the events to their aestheticization; (2) one could confer the morally ennobling epithet tragic on these events only at the cost of ignoring the extent to which the "heroic" actions of the Wehrmacht had made possible the destruction of many Jews who might have been saved had the army surrendered earlier; and (3) the attempt to ennoble one part of the history of the "German Empire" by dissociating it from the Final Solution was as morally offensive as it was scientifically untenable. ${ }^{8}$ And yet Hillgruber's suggestion for emplotting the story of the defense of the eastern front did not violate any of the conventions governing the writing of professionally respectable narrative history. He had simply suggested narrowing the focus to a particular domain of the historical continuum, casting the agents and agencies occupying that scene as characters in a dramatic conflict and emplotting this drama in terms of the familiar conventions of the genre of tragedy.

Hillgruber's suggestion for the emplotment of the history of the eastern front during the winter of I $944 / 45$ indicates the ways in which a specific plot type (tragedy) can simultaneously determine the kinds of event to be featured in any story that can be told about them and provide a pattern for the assignment of the roles that can possibly be played by the agents and agencies inhabiting the scene thus constituted. ${ }^{9}$ At the same time, however, Hillgruber's suggestion also indicates how the choice of a mode of emplotment can justify ignoring certain kinds of event, agent, action, agency, and patient which may inhabit a given historical scene or its context. There is no 
place for any form of low or ignoble life in a tragedy; in tragedies even villains are noble, or rather, villainy can be shown to have its noble incarnations. Asked why he had not included a treatment of Joan of Arc in his Waning of the Middle Ages, Huizinga is said to have replied, "Because I did not want my story to have a heroine." Hillgruber's recommendation to emplot the story of the Wehrmacht's defense of the eastern front as a tragedy indicates that he wants the story to be told about it to have a hero, be heroic, and redeem at least a remnant of the Nazi epoch in the history of Germany thereby.

Hillgruber may not have considered that his division of one epoch of German history into two stories - one the story of a shattering (Zerschlagung) of an empire, the other a story of the "end" (Ende) of a people - sets up an oppositional structure constitutive of a semantic field in which the naming of the plot type of one story determines the semantic domain within which the name of the plot type of the other is to be found. Hillgruber does not name the plot type that might provide the meaning of the story of "the end of European Jewry." But if the plot type of the tragedy is reserved for the telling of the story of the Wehrmacht on the eastern front in I $944 / 45$, it follows that some other plot type must be used to tell the story of this "end of European Jewry."

In forgoing the impulse to name the kind of story that should be told about the Jews in Hitler's Reich, Hillgruber approaches the position of a number of scholars and writers who view the Holocaust as virtually unrepresentable in language. The most extreme version of this idea takes the form of the commonplace that this event (or Auschwitz or the Final Solution, etc.) is of such a nature as to escape the grasp of any language to describe it or any medium to represent it. Thus, for example, George Steiner's famous remark, "The world of Auschwitz lies outside speech as it lies outside reason." ${ }^{\prime \prime}$ Or Alice and A. R. Eckhardt's question: "How is the unspeakable to be spoken about? Certainly, we ought to speak about it, but how can we ever do so?"11 Berel Lang suggests that expressions such as these must be understood figuratively, as indicating the difficulty of writing about the Holocaust and the extent to which any representation of it must be judged against the criterion of respectful silence that should be our first response to it ( 160$)$.

Nonetheless, Lang himself argues against any use of the genocide as a subject of fictional or poetic writing. According to him, only the most literal chronicle of the facts of the genocide comes close to passing the test of "authenticity and truthfulness" by which both literary and scientific ac- 
counts of this event must be judged. Only the facts must be recounted because otherwise one lapses into figurative speech and stylization (aestheticism). And only a chronicle of the facts is warranted because otherwise one opens up oneself to the dangers of narrativization and the relativization of emplotment.

Lang's analysis of the limitations of any "literary" representation of the genocide and its moral inferiority to a sparse or denarrativized historical account is worth considering in detail because it raises the question of the limits of representation in the matter of the Holocaust in the most extreme terms. The analysis hinges on a radical opposition between literal and figurative speech, the identification of literary language with figurative language, a particular view of the peculiar effects produced by any figurative characterization of real events, and a notion of morally extreme events of which the Holocaust is considered to be a rare, if not historically unique, instantiation. Lang argues that the genocide, quite apart from being a real event, an event that really happened, is also a "literal event," that is, an event whose nature permits it to serve as a paradigm of the kind of event about which we can be permitted to speak only in a literal manner.

Lang holds that figurative language not only turns or swerves away from literalness of expression but also deflects attention from the states of affairs about which it pretends to speak. Any figurative expression, he argues, adds something to the representation of the object to which it refers. First of all, it adds itself (i.e., the specific figure used) and the decision it presupposes (i.e., the choice to use one figure rather than another). Figuration produces stylization, which directs attention to the author and his or her creative talent. Second, figuration produces a perspective on the referent of the utterance, but featuring one particular perspective, it necessarily closes off others. Thus, it reduces or obscures certain aspects of events ( I43). Third, the kind of figuration needed to transform what would otherwise be only a chronicle of real events into a story at once personalizes (humanizes) the agents and agencies involved in those events - by transforming them into the kind of intending, feeling, and thinking subjects with whom the reader can identify and empathize, in the way one does with characters in fictional stories - and generalizes them, by representing them as instantiations of the types of agent, agency, event, and so on met with in the genres of literature and myth.

According to this view, the impropriety of any literary representation of the genocide derives from the distortions of the facts of the matter effected by the use of figurative language. Over against any merely literary 
representation of the events comprising the genocide, Lang sets the ideal of what a literalist representation of the facts of the matter reveals to be their true nature. And it is worth quoting a longish passage from Lang's book in which he sets up this opposition between figurative and literalist speech as being homologous with the opposition between false and truthful discourse.

If ... the act of genocide is directed against individuals who do not motivate that act as individuals; and if the evil represented by genocide also reflects a deliberate intent for evil in principle, in conceptualizing [a] group and in the decision to annihilate it, then the intrinsic limitations of figurative discourse for the representation of genocide come into view. On the account given, imaginative representation would personalize even events that are impersonal and corporate; it would dehistoricize and generalize events that occur specifically and contingently.

And the unavoidable dissonance here is evident. For a subject which historically combines the feature of impersonality with a challenge to the conception of moral boundaries, the attempt to personalize it - or, for that matter, only to add to it - appears at once gratuitous and inconsistent: gratuitous because it individualizes where the subject by its nature is corporate; inconsistent because it sets limits when the subject itself has denied them. The effect of the additions is then to misrepresent the subject and thus - where the aspects misrepresented are essential - to diminish it. In asserting the possibility of alternate figurative perspectives, furthermore, the writer asserts the process of representation and his own persona as parts of the representation - a further diminution of what (for a subject like the Nazi genocide) is its essential core; beside this, an "individual" perspective is at most irrelevant. For certain subjects, it seems, their significance may be too broad or deep to be chanced by an individual point of view, [the significance may be] morally more compelling - and actual - than the concept of possibility can sustain. Under this pressure, the presumption of illumination, usually conceded prima facie to the act of writing (any writing), begins to lose its force. ( $\mathrm{I} 44-45$ )

But literary writing and the kind of historical writing that aspires to the status of literary writing are especially objectionable to Lang because in them the figure of the author obtrudes itself between the thing to be represented and the representation of it. The figure of the author must obtrude itself into the discourse as the agent of that act of figuration without which the subject of the discourse would remain unpersonalized. Since literary 
writing unfolds under the delusion that it is only by figuration that individuals can be personalized, "the implication is unavoidable," Lang says, that "a subject ... could be represented in many different ways and as having no necessary and perhaps not even an actual basis. The assertion of alternate possibilities [of figuration] . . . suggests a denial of limitation: no possibilities are excluded," neither the possibility of figuring a real person as an imaginary or nonperson nor that of figuring a real event as a nonevent (I46).

It is considerations such as these that lead Lang to advance the notion that "the events of the Nazi genocide" are intrinsically "anti-representational," by which he apparently means not that they cannot be represented but that they are paradigmatic of the kind of event that can be spoken about only in a factual and literalist manner. Indeed, the genocide consists of occurrences in which the very distinction between event and fact is dissolved ( I 46-47). Thus, Lang writes, "If there ever was a 'literal' fact, beyond the possibility of alternate formulations among which reversal or denial must always be one, it is here in the act of the Nazi genocide; and if the moral implication of the role of facts needed proof, it is also to be found here, again in the phenomena of the Nazi genocide" (157-58). It is the overriding actuality and literalness of this event which, in Lang's view, warrant the effort on the part of historians to represent real events "direct $[\mathrm{ly}]$... immediately and unaltered" in a language purged of all metaphor, trope, and figuration. Indeed, it is the literalness of this event which indexes the difference between "historical discourse" on the one hand and "imaginative representation and its figurative space" on the other. "However it may be conceived beyond [the distinction between history and fiction] the fact of the Nazi genocide is a crux that separates historical discourse from the process of imaginative representation, perhaps not uniquely, but as certainly as any fact might be required or is able to do" ( $158-59)$.

I have lingered on Lang's argument because I think that it carries us to the crux of many current discussions regarding both the possibility of representing the Holocaust and the relative value of different ways of representing it. His objection to the use of this event as an occasion for a merely literary performance is directed at novels and poetry, but it can easily be extended to cover the kind of belletristic historiography which features literary flourish and what the book clubs identify as "fine writing." But it must, by implication, be extended also to include any kind of narrative history, which is to say, any attempt to represent the Holocaust as a story. 
And this is because, if every story must be said to have a plot, and if every emplotment is a kind of figuration, then it follows that every narrative account of the Holocaust, whatever its mode of emplotment, stands condemned on the same grounds that any merely literary representation of it must be condemned.

To be sure, Lang argues that, although historical representation may "make use of narrative and figurative means," it is not "essentially dependent on those means." Indeed, in his view, historical discourse is posited on "the possibility of representation that stands in direct relation to its object - in effect, if not in principle, immediate and unaltered" (I56). This is not to suggest that historians can or should try to occupy the position of the naïve realist or mere seeker after information. The matter is more complex than that. For Lang indicates that what is needed for anyone writing about the Holocaust is an attitude, position, or posture that is neither subjective nor objective, neither that of the social scientist with a methodology and a theory nor that of the poet intent upon expressing a personal reaction. ${ }^{12}$ Indeed, in the introduction to Act and Idea, Lang invokes Roland Barthes's notion of "intransitive writing" as a model of the kind of discourse appropriate to discussion of the philosophical and theoretical issues raised by reflection on the Holocaust. Unlike the kind of writing which is intended to be "read through, ... designed to enable readers to see what they would otherwise see differently or perhaps not at all," intransitive writing "denies the distances among the writer, text, what is written about, and, finally, the reader." In intransitive writing,

an author does not write to provide access to something independent of both author and reader, but "writes himself." .. . In the traditional account [of writing], the writer is conceived as first looking at an object with eyes already expectant, patterned, and then, having seen, as representing it in his own writing. For the writer who writes himself, writing becomes itself the means of vision or comprehension, not a mirror of something independent, but an act and commitment - a doing or making rather than a reflection or description. (xii)

Lang explicitly commends intransitive writing (and speech) as appropriate to individual Jews who, as in the recounting of the story of the Exodus at Passover, "should tell the story of the genocide as though he or she had passed through it" and in an exercise of self-identification specifically Jewish in nature (xiii). But the further suggestion is that the product of intransi- 
tive writing, which is to say, a discourse "that denies the distances among the writer, text, what is written about, and, finally, the reader," might serve as a model for any representation of the Holocaust, historical or fictional. And it is with a consideration of the ways in which the notion of intransitive writing might serve as a way of resolving many of the issues raised by the representation of the Holocaust that I would like to conclude this essay.

I would note that Berel Lang invokes the idea of intransitive writing without remarking that Barthes himself had used it to characterize the differences between the dominant style of modernist writing and that of classical realism. In the essay entitled "To Write: An Intransitive Verb?" Barthes purports to ask if the verb to write has become an intransitive verb, and if so, when. The question is asked within the context of a discussion of diathesis (voice) in order to focus attention on the different kinds of relationship that an agent can be represented as bearing to an action. He points out that although modern Indo-European languages offer two possibilities for expressing this relationship, the active and the passive voices, other languages offer a third possibility, that expressed, for example, in the ancient Greek middle voice. Whereas, in the active and passive voices, the subject of the verb is presumed to be external to the action, as either agent or patient, in the middle voice the subject is presumed to be interior to the action. ${ }^{13}$ He then goes on to conclude that, in literary modernism, the verb to write connotes neither an active nor a passive relationship but, rather, a middle one.

Thus in the middle voice of to write, the distance between scriptor and language diminishes asymptotically. We could even say that it is the writings of subjectivity, such as romantic writing, which are active, for in them the agent is not interior but anterior to the process of writing: here the one who writes does not write for himself, but as if by proxy, for an exterior and antecedent person (even if both bear the same name), while, in the modern verb of middle voice to write, the subject is constituted as immediately contemporary with the writing, being effected and affected by it: this is the exemplary case of the Proustean narrator, who exists only by writing, despite the references to a pseudo-memory. ${ }^{14}$

This is, of course, only one of the many differences that distinguish modernist writing from its nineteenth-century realist counterpart. But this difference indicates a new and distinctive way of imagining, describing, and conceptualizing the relationships obtaining between agents and acts, sub- 
jects and objects, a statement and its referent, between the literal and figurative levels of speech, and indeed, therefore, between factual and fictional discourse. What modernism envisions, according to Barthes's account, is nothing less than an order of experience beyond (or prior to) that expressable in the kinds of opposition we are forced to draw (between agency and patiency, subjectivity and objectivity, literalness and figurativeness, fact and fiction, history and myth, and so forth) in any version of realism. This does not imply that such oppositions cannot be used to represent some real relationships, only that the relationships between the entities designated by the polar terms may not be oppositional ones in some experiences of the world. What I am getting at is expressed very well in Jacques Derrida's explication of his notion of differrance, which also uses the idea of the middle voice to express what it is meant to convey.

Differance is not simply active (any more than it is a subjective accomplishment); it rather indicates the middle voice, it precedes and sets up the opposition between passivity and activity. . . . And we shall see why what is designated by "differance" is neither simply active nor simply passive, that it announces or rather recalls something like the middle voice, that it speaks of an operation that is not an operation, which cannot be thought of either as a passion or as an action of a subject on an object, as starting from an agent or a patient, or on the basis of, or in view of, any of these terms. And philosophy has perhaps commenced by distributing the middle voice, expressing a certain intransitiveness, into the active and the passive voice, and has itself been constituted by this repression. ${ }^{15}$

I cite Derrida as representing a modernist conception of the project of philosophy, founded on the recognition of the differences between a distinctively modernist experience of the world (or is it the experience of a distinctively modernist world?) and the notions of representation, knowledge, and meaning prevailing in the inherited realist cultural endowment. And I do so in order to suggest that the kind of anomalies, enigmas, and dead ends met with in discussions of the representation of the Holocaust are the result of a conception of discourse that owes too much to a realism that is inadequate to the representation of events, such as the Holocaust, which are themselves modernist in nature. ${ }^{16}$ The concept of cultural modernism is relevant to the discussion inasmuch as it reflects a reaction to (if not a rejection of) the great efforts of nineteenth-century writers - both historians and fictioneers - to represent reality realistically - where veality is 
understood to mean "history" and realistically means the treatment not only of the past but also of the present as "history." Thus, for example, in Mimesis, a study of the history of the idea of realistic representation in Western culture, Erich Auerbach characterized "the foundations of modern realism" in the following terms: "The serious treatment of everyday reality, the rise of more extensive and socially inferior human groups to the position of subject matter for problematic-existential representation, on the one hand; on the other, the embedding of random persons and events in the general course of contemporary history, the fluid background - these, we believe, are the foundations of modern realism."'17

In this view, the modernist version of the realist project could be seen as consisting of a radical rejection of history, of reality as history, and of historical consciousness itself. But Auerbach was concerned to show the continuities as well as the differences between realism and modernism. Thus, in a famous exegesis of a passage from Virginia Woolf's To the Lighthouse, Auerbach identifies among the "distinguishing stylistic characteristics" of that modernism which the passage has been chosen to exemplify:

I. the disappearance of the "writer as narrator of objective facts; almost everything stated appears by way of reflection in the consciousness of the dramatis personae";

2. the dissolution of any "viewpoint ... outside the novel from which the people and events within it are observed, ...”;

3. the predominance of a "tone of doubt and questioning" in the narrator's interpretation of those events seemingly described in an objective manner;

4. the employment of such devices as "erlebte Rede, stream of consciousness, monologue interieur" for "aesthetic purposes" that "obscure and obliterate the impression of an objective reality completely known to the author. ...";

5. the use of new techniques for the representation of the experience of time and temporality, for example, use of the "chance occasion" to release "processes of consciousness" that remain unconnected to a "specific subject of thought"; obliteration of the distinction between exterior and interior time; and representation of events not as "successive episodes of [a] story" but as random occurrences. ${ }^{18}$

This is as good a characterization of what Barthes and Derrida might have called the style of "middle voicedness" as any we might find. Auerbach's characterization of literary modernism indicates not that history is no longer 
represented realistically but, rather, that the conceptions of both history and realism have changed. Modernism is still concerned to represent reality realistically, and it still identifies reality with history. But the history that modernism confronts is not the history envisaged by nineteenth-century realism. And this is because the social order that is the subject of this history has undergone a radical transformation - a change that permitted the crystallization of the totalitarian form that Western society would assume in the twentieth century.

As thus envisaged, cultural modernism has to be seen as both a reflection of and a response to this new actuality. Accordingly, the affinities of form and content between literary modernism and social totalitarianism can be granted - but without necessarily implying that modernism is a cultural expression of the fascist form of social totalitarianism. ${ }^{19}$ Indeed, another view of the relation between modernism and fascism is possible: literary modernism was a product of an effort to represent a historical reality for which the older, classical realist modes of representation were inadequate, based as they were on different experiences of history or, rather, on experiences of a different history.

Modernism was no doubt immanent in classical realism - in the way in which Nazism and the Final Solution were immanent in the structures and practices of the nineteenth-century nation-state and the social relations of production of which it was a political expression. Looked at in this way, however, modernism appears less as a rejection of the realist project and a denial of history than as an anticipation of a new form of historical reality, a reality that included among its supposedly unimaginable, unthinkable, and unspeakable aspects: the phenomena of Hitlerism, the Final Solution, total war, nuclear contamination, mass starvation, and ecological suicide; a profound sense of the incapacity of our sciences to explain, let alone control or contain these; and a growing awareness of the incapacity of our traditional modes of representation even to describe them adequately.

What all this suggests is that modernist modes of representation may offer possibilities of representing the reality of both the Holocaust and the experience of it that no other version of realism could do. Indeed, we can follow out Lang's suggestion that the best way to represent the Holocaust and the experience of it may well be by a kind of intransitive writing which lays no claim to the kind of realism aspired to by nineteenth-century historians and writers. But we might want to consider that by intransitive writing we must intend something like the relationship to that event expressed in the middle voice. This is not to suggest that we will give up the effort to represent the Holocaust realistically but, rather, that our notion of what 
constitutes realistic representation must be revised to take account of experiences that are unique to our century and for which the older modes of representation have proven to be inadequate.

In fact, I do not think that the Holocaust, Final Solution, Shoah, Churban, or German genocide of the Jews is any more unrepresentable than any other event in human history. It is only that its representation, whether in history or in fiction, requires the kind of style, the modernist style, that was developed in order to represent the kind of experiences which social modernism made possible, the kind of style met with in any number of modernist writers but of which Primo Levi must be invoked as an example.

In Il Sistema periodico (The Periodic Table), Levi begins the chapter entitled "Carbon" thus:

The reader, at this point, will have realized for some time now that this is not a chemical treatise: my presumption does not reach so far - "ma voix est foible, et même un peu profane.” Nor is it an autobiography, save in the partial and symbolic limits in which every piece of writing is autobiographical, indeed every human work; but it is in some fashion a history.

It is - or would have liked to be - a microhistory, the history of a trade and its defects, victories, and miseries, such as everyone wants to tell when he feels close to concluding the arc of his career and art ceases to be long.

Levi goes on to tell the story of a particular atom of carbon which becomes an allegory (what he calls "this completely arbitrary story" that is "nonetheless true"). "I will tell just one more story", he says, "the most secret, and I will tell it with the humility and restraint of him who knows from the start that this theme is desperate, the means feeble, and the trade of clothing facts in words is bound by its very nature to fail." The story he tells is of how an atom of carbon which turns up in a glass of milk which he, Levi, drinks, migrates into a cell in his own brain - "the brain of me who is writing, and [how] the cell in question, and within it the atom in question, is in charge of my writing, in a gigantic minuscule game which nobody has yet described." This game he then proceeds to describe in the following terms: "It is that which at this instant, issuing out of a labyrinthine tangle of yeses and nos, makes my hand run along a certain path on a paper, mark it with these volutes that are signs: a double snap, up and down, between two levels of energy, guides this hand of mine to impress on this paper this dot, here, this one." 20 


\section{FORMALIST AND CONTEXTUALIST STRATEgies IN HistoricAL EXPLANATION}

The conflict between the notions of formalist and contextualist strategies of explanation is as old as historiography itself (it informs Thucydides' criticism of Herodotus and the logographers) and may be inherent in any effort to produce systematic knowledge of (rather than simply information about) sets of particular events. The conflict assumes major epistemological proportions only in those disciplines in which the ideal of truth is identified (or confused) with empiricism. Thus, for example, this conflict ceases to be a problem for philosophy and becomes a problem of philosophy only in its empiricist incarnation. It would be instructive to reflect on the ways in which the conflict between formalism and contextualism ceases to be a problem in the disciplines of the modern physical sciences precisely at the point at which they detach themselves from what used to be called natural history, effectively abandon the effort to account for events in their particularity, and give themselves over to the effort to conceptualize the kinds of structure of relationships governing possible worlds rather than the causes of time- and place-specific sets of events. Indeed, the most recent full-scale effort to transform historical studies into a science, that of the Annales group in France, took as the theoretical centerpiece of its program the expulsion of the very notion of event from historical reflection. We might gain some insight into the relation between the notion of the event, on the one side, and the conflict between formalism and contextualism in histor- 
ical studies, on the other, by reflecting on the history of this effort, which turned out to be a failure insofar as many of the Annalistes discovered that a microscopic representation of historical phenomena could only be a contextualist, never a consistently formalist, one. Is the same thing happening in the social sciences?

The question is suggested by the way in which the topics of this symposium have been framed. We have been asked to address what is characterized as "a prime epistemological question in social science" in terms of a comparison of the "use, value, and limits of two modes of social science inquiry," formalist, on the one hand, contextualist, on the other. The further specification of the problem suggests that our approach to it might be cast in either or both of the two modes of inquiry we are asked to compare. In other words, we might address our problem in a formalist or a contextualist manner, here understood respectively as "the effort to construct formal, general representations of social forms and processes" and "the effort to comprehend social phenomena interpretively in the context of particular times and places."

This formulation of the issues refers us, albeit indirectly, to the vexed relationship that the modern Western social sciences have borne, since their inception in the later nineteenth century, to modern Western historical studies. For one-perhaps the most pertinent-connotation of the term contextualist (understood as "the effort to comprehend social phenomena interpretively in the context of particular times and places") is "historical." The effort to represent the relation of social phenomena to the "context of particular times and places" is a precise characterization of what a specifically historical kind of inquiry is all about.

I do not mean to suggest that context cannot be construed to mean something other than "particular times and places." But where time and place are conceptualized as, say, general rather than as particular or where they are represented as generalized rather than as particularized, it is difficult to imagine how such conceptualizations could be thought of as being specifically historical in nature.

To be sure, context, like times and places, admits of differentiations of scale in both duration and extent. But it is this circumstance that throws open what is conventionally thought of as a specifically historical account of social phenomena to the threat of the hated philosophy of history à la Hegel, Marx in his more Hegelian moments, Spengler, and Toynbee - not to mention Polybius, St. Augustine, and Voltaire. It is the tendency toward excessive generalization, that is, abstraction, formalization, and theoriza- 
tion, which the modern social sciences share with philosophy of history, that constitutes the grounds for the traditional antipathy between history and the social sciences.

This antipathy, it seems to me, is quite different from the tension informing the relationship between formalizers and contextualizers within the social sciences. For insofar as the ultimate aim of inquiry is to contribute to a body of knowledge more scientific (which is to say, explanatory) than appreciative (which is to say, comprehending) or simply critical (in the sense of "deliberative"), then formalism and contextualism can be regarded as existing in a means-ends relationship to each other-depending on whether explanation is conceived to be a theoretical or a practical activity.

But historical studies have never unambiguously or unambivalently embraced the ideal of explanation conceived on the model of that prevailing in the natural sciences, whereas the embracing of that ideal was the necessary precondition of the social sciences' differentiation from disciplines merely historical in their orientation. This is why practitioners of the social sciences can believe in the possibility of contextualizing social phenomena without necessarily particularizing them. Particularistic representations of social phenomena are in any science always only a preliminary stage on the way to general knowledges. By contrast, in historical studies, even among the most scientifically inclined, general knowledge derives its utility from the illumination it provides of events, actions, structures, and processes assignable to discrete domains, that is, "particular times and places", in the finite-what Paul Veyne calls the "sublunary" - world of human species-existence. ${ }^{2}$

The historical relationship between historical studies and the social sciences is complex and variously mediated. On one hand (and here I am beginning to historicize, but in a formalist manner), it was only on the basis of the historical mode of human being in the world, presupposed as a condition of possibility for a specifically historical kind of knowledge, that the modern Western social sciences were able to conceptualize the field of "empiricities" (Foucault's term) which would provide them with their objects of study, their data. ${ }^{3}$ At the same time, however, it was only by the adoption of the formalist techniques of analysis favored by the modern natural sciences that such disciplines as political economy, sociology, anthropology, and psychology could lay claim to the status of sciences at all. Thus, while the social sciences shared with historical studies a common kind of object of analysis - those time- and space-specific entities that can be treated empirically - they differed in the predominantly formalist methods they sought to develop for the study thereof. Post-Enlightenment his- 
torical studies remained for the most part committed to techniques of contextualization for the historical, or more precisely the historicist, analysis of those empiricities which the social sciences handled in a more formalist manner. ${ }^{4}$

Whence the anxiety aroused within the modern social sciences by any contextualizing impulse among their practitioners. To be sure, such an impulse can be consciously entertained as a salutary reminder that, after all, both the data and the findings of social science inquiry are time and place specific - and both reflect as well as reflect on the contexts of the particular times and places in which they are produced. However, at the level of what we may call the unconscious of the social science disciplines, every contextualizing impulse threatens to end not only in the historicization of their findings and practices but also in the reabsorption of the social sciences by that historism in opposition to which they have, by their commitment to a formalist mode of analysis, differentiated themselves and signaled their aspiration to the status of sciences. While historical studies remained so suspicious of formalist techniques of representation and analysis as to regard formalism as an antonym of historical, the social sciences have tended to identify contextualism with both those parascientific (because merely empirical and narrative) accounts of discrete domains of past social reality produced by traditional historical research, on the one side, and those antiscientific (because relativizing) attacks on the authority of scientific knowledge produced by a certain ideology of historicism, on the other. It is for reasons such as these that, in the metatheoretical discourses of the social sciences, the term contextualism carries with it connotations both positive and negative.

Considered as a product of metatheoretical reflection, contextualism connotes theoretical and methodological self-consciousness, a recognition that the objects of study of the social sciences exist in history (rather than in nature only), which is to say that they are individualizable in a way that the objects of study of the natural sciences are not generally conceived to be. Moreover, when turned upon the study of the social sciences themselves, contextualist modes of social science inquiry remind their practitioners that, in contrast to the mainstream of modern historical studies, they have an active, problem-solving, applied, and therapeutic rather than a merely contemplative dimension. Contextualist analysis reminds the social sciences - in a way that no formalist analysis could ever do - that their social justification stems from the practical knowledge they seek to provide for the solution of social problems endemic to the social formations within which 
they themselves have arisen. All of this is deemed positive in the extent to which it conduces to an awareness that one aim of the social sciences is to contribute to the production of concrete rather than merely abstract knowledge about the conditions and possibilities of a life lived under the conditions of "sociality."

On the other hand, contextualism carries negative connotations in the metatheoretical discourses of the social sciences in the extent to which it is thought to conduce to the historicization and thereby the relativization of findings produced by the application of both formalist and contextualist techniques to the analysis of social phenomena. It is this identification of contextualism with historicization $\mathrm{cum}$ relativization that informs the antipathy traditionally manifested by social scientists for a merely historical approach to the study of social phenomena. Contextualism, insofar as it authorizes the conceptualization of all sciences, including the natural sciences, as a function of the sociocultural conditions prevailing both at the time of their origination and across the trajectory of their evolution, appears as a version of what has come to be called, even within the mainstream of contemporary historical studies itself, the ideology of historicism.

Here historicism is understood as equivalent to what epistemologists call the genetic fallacy, which reduces the truth-value of all putatively general knowledges to the status of abstractions from the limited range of perceptions determined by the modes of knowledge production prevailing at a given time and place in history. Thus, what appears to be the very essence of a distinctively historical method for studying the modes, means, and social relations of knowledge production is apprehendible, from the standpoint of the social sciences' aspiration to a knowledge of society that is context transcendent, as a principal threat to this aspiration precisely insofar as it features contextualization as its principal technique of analysis. This is why the historicizing impulse that periodically erupts within the social sciences in the guise of contextualism tends to take a structuralist rather than a geneticist form.

In contrast to a geneticist conceptualization of the relation between the modes of knowledge production, on the one side, and the sociocultural contexts in which they arise and are practiced, on the other, a structuralist conceptualization of this relation authorizes the mooting of the question of the causal relationships obtaining between them. A geneticist approach presupposes a causal relationship (either mechanistic or organicist) between a given sociocultural context and the entities arising within it. A structuralist approach, by contrast, presupposes merely formal relation- 
ships among all of the elements of a sociocultural totality: a relationship of analogy when the elements of a sociocultural totality are classified in terms of the similarities of their manifest attributes; and of homology when the specific differences between them are identified as functions of the latent structure of relationships informing and determining the manifest aspects of the system as a whole.

As thus envisaged, structuralism can be seen to address the problems raised by a traditional, geneticist, or historicist version of contextualism; it is capable of providing a kind of contextualist analysis even of the relation between given modes of knowledge production (such as those informing the practices of the social sciences) and given sociocultural contexts. But a structuralist solution of these problems results in the creation of a formalist version of contextualism, a formalist contextualism, which purports to resolve the conflict between the formalist and contextualist modes of social science inquiry by radically decontextualizing, that is, dehistoricizing, the conflict itself. This is why the most recent manifestation of the structuralist moment in social science theory was able to lay claim to being a synthesis of the most diverse systems of thought: of Rousseau, Hegel, Marx, Freud, Nietzsche, Weber, Durkheim, Parsons, Saussure, Mauss, Bergson, Bachelard, Duhem, and so on ad infinitum and, at the same time, celebrate bricolage as its own unique method of both discovery and invention.

Having so radically decontextualized the problem of the relationship between formalist and contextualist modes of social science inquiry, structuralism of the kind associated with the names of Lévi-Strauss, Jakobson, Piaget, Saussure, Geertz, and so on was incapable of imagining its own sociocultural significance as a manifestation of a theoretical crisis in modern Western social science. The crisis was manifested in the fetishistic nature of the structuralist social sciences' relationship to the formalist method itself. Like Jakobson's famous formalist analysis of Edgar Allan Poe's poem "The Bells," which, as one commentator (I believe it was Leo Bersani) put it, explained everything about the poem except why it was so bad, structuralist social science proved able to tell us everything about human psychology, society, and culture except why they were so violent, painful, and selfdestructive and why the knowledge provided by structuralist analyses provided no enlightenment on how we might ameliorate the condition of them all.

Viewed from one perspective, structuralism was a fail-safe form of formalist analysis. It always worked because it took the model of its own decoding procedures as the implicit principle of the encoding procedures 
by which every culture, society, and psyche endowed nature with the meaning of formal structure. Wherever it looked, it found a simulacrum of itself. And why should it not? It had no real theoretical basis for discriminating between contexts and the entities arising within their confines. How could it discriminate between its own and others' analytical practices or, for that matter, between others and itself? Nonetheless, the current revival of interest among social scientists in a contextualism more historical than structuralist in nature indicates a desire - or so it seems to me - less to abandon formalist techniques of analysis, or even their structuralist versions, than to determine their relevance to the analysis of late-twentieth-century (as against nineteenth-century) psychological, social, and cultural contexts.

One version of the turn away from the dead end at which structuralist hyperformalism appears to have arrived consists of a turn toward the possibility of wedding a formalist mode of analysis with a historically informed sensitivity to the relations obtaining between the modes of social science knowledge production and their sociocultural contexts. But what can historically informed mean in this metatheoretical context? What would a distinctively historical apprehension of the relations obtaining among (I) social events, structures, and processes, (2) the modes of production of the different kinds of knowledge we can realistically expect to have of them, and (3) their many different historical contexts, consist of ? It is not as if historical studies have ever presented a unified front in the conceptualization of what constitutes a uniquely historical entity, a specifically historical method of studying such entities, or a theory of the relationship between a specifically historical and other kinds of knowledge. Indeed, historical studies have been able to pass for a science only in the extent to which they have borrowed formalist-structuralist analytical techniques from the various disciplines of the "bourgeois" social sciences or embraced (and succeeded in forcing upon their audiences a belief in) the Marxist illusion that dialectical materialism is a science of history.

Accordingly, social scientists turning to historical studies are unlikely to find very much there, in the way of suggestions for a new approach to social science inquiry, with which they are not already familiar. What they are likely to find is some historians utilizing what are for the most part formalist and/or structuralist analytical techniques borrowed from the various disciplines of the social sciences themselves; others practicing a Marxian version of these techniques; and yet others, by far the vast majority, engaged in small-scale, empirical, and archival or information-gathering work intended for presentation in the putatively commonsensical, infor- 
mal, and allegedly nontheoretical mode of narrative or storytelling. About the only thing these different groups of researchers have in common is a shared interest in the past, the processes by which any given present is transmogrified into a past, and a commitment, more or less vague, to one or another version of contextualism as a necessary moment in any account of anything whatsoever that can pass for a generically historical explanation.

It is this circumstance that suggests that the term contextualism, far from referring to a theoretically elaborated method for studying historical phenomena in a specifically historical way, functions, rather, in the metatheoretical discourse of historical studies - much as it does in aesthetic theory - to signify little more than a dissatisfaction with, resistance to, and desire for an alternative to formalism. Where formalism is thought of as a method of abstraction, contextualism can serve to indicate the concretizing function of a putative historical method that remains otherwise indistinguishable from the discursive practices of nineteenth-century historicism (or historism, if one prefers the locution used by theorists of historical studies in order to distinguish the work of so-called straight historians from that of such "speculative philosophers of history" as Hegel, Comte, Marx, Spengler, and Toynbee).

I have not been able to locate the point at which the term contextualism began to be used to indicate a method or mode of analysis peculiar to a distinctively historical approach to the study of specifically historical phenomena. In modern philosophical discourse, the notion of a contextualist epistemology is of course intimately associated with the pragmatism of James and Dewey, while that of a contextualist aesthetics appears to have been first set forth by the utopian socialist philosophers Saint-Simon and Fourier and later elaborated by the positivists Comte and Taine. In the history of literature, the notion that one value of the literary work of art consisted of the extent to which it mirrored the historical context of its composition informed the theory of what Erich Auerbach taught us to call historistic realism (represented by Stendhal, Balzac, and Flaubert) in contrast to the aesthetic historism of Goethe, the writers of the Sturm und Drang, and the Romantics in general. ${ }^{5}$

Auerbach's treatment of the relation between the (anti-Enlightenment) theory of historism and the (anti-Romanticist) theory of literary realism is suggestive. He held that historism and literary realism shared a (Viconian) conviction that representations of social reality required the depiction of the relations that events, actions, structures, and processes bore to their historical contexts as a necessary condition of their claim to veracity 
and as a sufficient condition for their claim to realism. As thus envisaged, both nineteenth-century historism and literary realism featured contextualist or, more accurately, contextualizing strategies for the kinds of representation of social reality they provided in discourses more or less narrativistic in kind - historism in factual narratives, realism in fictional ones.

But in Auerbach's account, historism and literary realism can be said to have had a history, which they more or less mutually share, because the relationships obtaining between historical contexts and the entities inhabiting them can be construed in many different ways - as many different ways as there are of construing the relation between history and the natural world, against which history takes its rise. Indeed, it is no easier to determine where to draw the line between a historical event, structure, or process and its context than it is to determine where nature leaves off and history begins. ${ }^{6}$ This is why every contextualism requires, as a condition of its enablement as a representational or an explanatory strategy, a formalist component, which is to say, a theoretical model on the basis of which, first, to distinguish contexts from the entities inhabiting them; second, to generate hypotheses about the nature of the relations between the entities and contexts thus distinguished; and third, to discriminate between radical, primary, and determining transformations of these relationships and what are only secondary, superficial, or local changes in them. This formal theoretical model may remain only implicit or latent within any given contextualization. Indeed, the sense of a difference between a contextualist and a formalist mode of inquiry, on the basis of which the former can be entertained as an alternative, complement, or corrective to the latter, requires that the theoretical model remain only implicit or latent.

But the fact that the relations between a historical event, structure, or process can be construed in a number of different but equally plausible ways suggests not only the figurative nature of every distinction drawn between them but also the tropological basis of every effort to characterize the relations between the elements thus distinguished.

I am going to resist the impulse to hop on my own hobby-horse and beat it to death by trying to defend this notion of the necessarily tropological relation between historical objects and their contexts. Suffice it to say that, in my view, the necessarily figurative nature of all descriptions of historical objects and their contexts stems from the particularity with which they have to be invested in order to qualify as historical. This is not to say that descriptions of historical entities and of the contexts they inhabit lack correspondence truth. Figurative descriptions - like literalist predications 
- can refer to real as well as to possible events, structures, and processes. It is only that their mode of reference is indirect rather than direct. The point is that the attributes of time- and space-specific entities are so numerous that such entities can be posited as distinct objects of knowledge only by figurative description. Such description constitutes what Ricoeur calls a "con-figuration" (a grasping together in consciousness of the kind commonly met with in metaphorical expression) of a field of historical phenomena as a complex structure-in-process, which can then be explicated by being "re-figurated" in the different modes of analysis prevailing in the different kinds of science. ${ }^{7}$

The important point about this theory of the figurative nature of all description in historical reflection is that it provides us with a clue to the nature of the different modes of construing both the nature of fields of historical phenomena and the different ways in which the relations between entities and their contexts can be conceptualized. First, fields of historical phenomena are constituted, the elements in them differentiated and distributed, the family relations among the elements rendered identifiable, and the forces conducing to integration and disintegration of the field prefigured by such discursive techniques as condensation, displacement, symbolization, and secondary elaboration. These discursive techniques correspond to the linguistic techniques of characterizing relations among and within entities in the different modes of figuration traditionally identified as metaphor, metonymy, synecdoche, and irony. The identification of the relation between techniques of discursivity and those of figurative speech provides a basis for regarding the different kinds of analytical method brought to bear upon phenomenal fields constituted as possible objects of reflection by description as functions of the modes of figuration in which the initial description of phenomena have been cast.

In an earlier work on the dominant modes of nineteenth-century historical representation, ${ }^{8}$ I suggested that contextualist explanations gained their specific explanation-effects in the extent to which they recapitulated, on the level of explicit argument, a structure of relationships already deposited at the level of initial description of the phenomena-to-be-explained by the figurative mode of irony: the trope that derives its effect of appositiveness to the description of things by playing upon the relation of opposition. Reconsidering this theory in the light of our present concerns, I would revise and amend it in the following way:

I. Contextualist strategies of explanation (in historiography) feature descriptions of phenomenal fields in which some event, agent, institution, 
or process is apprehended as being in some way opposed to its immediate milieu. It is apprehended (or has been represented) as having been so different from other generally similar entities inhabiting the milieu as to be incomprehensible as a species of the class to which these entities belong (the great man or woman, the catastrophic event, the new and unforeseen movement, the monstrous action, and so on).

2. The entity in question must be thus worked up into a possible object for a specifically contextualist treatment by being initially described as apparently alien to its milieu and hence incomprehensible by reference to anything conceived to be typical of its milieu.

3. Analysis proceeds by a simultaneous redescription both of the milieu and of the entity to be explained by being related to the milieu. This redescription - which may be extended over the long trajectory of a narrative or a "thick description" of microphenomena-effects the kind of tacit and explicit transcodification which we have been taught to perceive in the operation of all discourses. What is originally described in one metalanguage is progressively redescribed in another, so as to effect an exchange of qualities and textures between the entity to be explained and the milieu. The redescription transforms a milieu ("the social institutions of France in the eighteenth century”) into an identifiable context (eighteenth-century French society) by translating nominative designators of collectivities into adjectival designators of essences ("Frenchness", "eighteenth century-ishness"). The same is done with entities inhabiting the context: Louis XIV, the Estates General, the working classes of Paris, the peasantry, and so on. Each is individualized by being at once differentiated from other entities generally similar to it and at the same time made into an expression of the essence of the context shared by all. The operation in question conforms punctually to that which produces the "general form of commodity value" ("Allgemeine Wertform") analyzed by Marx as the secret ("Geheimnis") of the fetish nature of the commodity form of value ("Der Fetischcharackter der Ware") in part I, chapter I of Capital. The secret of every contextualist analysis of a historical entity's relationship to its context is always that of a deep relation.

4. The relation between a historical entity and its context may be construed in a number of ways. Whence the possibility of a number of different but equally plausible interpretations of the relation between any given historical entity and its context. Because both the description of the context and that of the entities inhabiting it are figurative, the relations between them can be construed in the different modalities of figuration 
itself: metaphorical (a relation of analogy or similitude), metonymic (a relation of contiguity or causation), synecdochic (a relation of identification and expressivity), and ironic (a relation of opposition).

Any of these modalities of relationship can be imputed to any given entity's relation to its context - with equal plausibility - for the reason that the constitution of particular entities, of contexts, of the differences and the relations between them is a function of the language used in their initial description as potential objects of analysis.

I realize that this analysis of contextualism in historical description is highly abstract. In fact, it has turned out to be extremely formalist, which means that, in all probability, it will not conform to any given contextualist analysis of any specific historical entity in any historical work against which we might choose to test it. This suggests that the utility of the theoretical model (that of the relation between initial description in a figurative linguistic mode and contextualist analysis) used in this analysis is itself heuristic, rather than analytical, in nature. It would be interesting to have a contextualist analysis of heuristic procedures.

Finally, I am aware that I have not followed the convention of providing what is called a concrete example of a specifically contextualist analysis of a historical phenomenon. While I do not have the time to do that on this occasion (I have done it in other works and at length), I do offer, by way of an analogy to the problem that concerns us, an analysis of a debate over the relation between formalism and contextualism in a field outside the social sciences. The field of studies is literary criticism; the issue is that of the advent of what has come to be called New Historicism.

The occasion for the writing of this analysis was the publication of a set of some twenty-five essays on New Historicism by historians, social theorists, literary critics, and literary historians, traditionalist and modernist, Marxist and liberal-conservative, formalist and contextualist. ${ }^{9}$ Some New Historicists present their project as little more than an attempt to restore a historical dimension to American literary studies. On the face of it, they wish only to supplement prevailing formalist practices by extending attention to the historical contexts in which literary texts originate. Thus, according to Louis Montrose, in "Professing the Renaissance: The Poetics and Politics of Culture," New Historicism represents an effort merely to refigure "the socio-cultural field within which canonical . . . literary and dramatic works were originally produced" and to situate such works "not only in relationship to other genres and modes of discourse but also in relationship to contemporaneous social institutions and non-discursive 
practices." 10 There is very little here to which other critics, whether traditional literary scholars, cultural materialists, feminists, or social historians, could reasonably take exception. In the process of elaborating the theory, methods, techniques, and aims of this project, however, the New Historicists have, inadvertently or by design, run afoul of some reigning orthodoxies in both literary and historical studies.

Thus, for example, Louis Montrose, after setting forth the New Historicist program in relatively conventional terms, goes on to say, "In effect, this project reorients the axis of intertextuality, substituting for the diachronic text of an autonomous literary history the synchronic text of a cultural system" ( I7). Here Montrose has shifted the interests and grounds of New Historicism considerably. First, it is now "a cultural system," rather than "contemporaneous social institutions and non-discursive practices," to which literary works are to be related. Second, it is now the synchronic rather than the diachronic aspects of the relationship between literature and the cultural system that becomes the preferred focus of the New Historicists' attention. Third, in his characterization of the New Historicist project as a reorientation of "the axis of intertextuality" Montrose implicitly effects a shift from the notion that literature consists of a body of works to the notion that it consists of a set of texts, with all that the term texts implies in contemporary poststructuralist discussions of language, discourse, and culture. And fourth, the idea of text has now been explicitly constituted as a tertium comparationis by which to characterize the differences and to mediate between an older, formalist notion of an autonomous literary history and a newer, historicist notion of literature as a function of the cultural system. It is the text of a cultural system that is to be substituted for the text of an autonomous literary history. Consequently, what was originally represented as an interest in studying the relation between literary works and their sociocultural contexts is suddenly revealed as a radical reconceptualization of literary works, their sociocultural contexts, the relations between them and, therefore, of history itself - all are now to be considered as kinds of text.

A formulation such as this offends against a number of orthodoxies in both literary and historical studies. First, by suggesting that literary texts can be illuminated by the study of their relations to their historical contexts, the New Historicists offend against the formalist tenets of an older but still powerful New Criticism. New Historicists appear to be returning to the older philological approach to the study of literary texts and in the process committing what New Critics called the genetic fallacy. Second, by suggest- 
ing that it is possible to distinguish between text and context, they offend against the newer, poststructuralist versions of formalism. According to poststructuralist theory, there is nothing outside texts, and consequently the efforts of the New Historicists to distinguish between text and context lead to the commission of the "referential fallacy." Third, the ways in which they construe the nature of the historical context give offense to historians in general. For the New Historicists, the historical context is the cultural system. Social institutions and practices, including politics, are construed as functions of this system, rather than the reverse. Thus, New Historicism appears to be based on what might be called the culturalist fallacy, which marks it as a brand of historical idealism. And, fourth, the way the New Historicists construe the relations between literary texts and the cultural system gives offense to historians and traditional literary scholars alike. This relationship is conceived to be intertextual in nature. It is a relationship between two kinds of text: literary on the one side, cultural on the other. Whence the charge that New Historicism is reductionist in a double sense: it reduces the social to the status of a function of the cultural, and then it further reduces the cultural to the status of a text. All of which adds up to the commission of what might be called the textualist fallacy.

As thus envisaged, New Historicism is anything but a synthesis of formalist and historical approaches to the study of literature. On the contrary, it appears rather more as an attempt to combine what some historians regard as formalist fallacies (culturalism and textualism) in the study of history with what some formalist literary theorists regard as historicist fallacies (geneticism and referentiality) in the study of literature. Thus, in "Literary Criticism and the Politics of New Historicism," Elizabeth FoxGenovese, speaking as representative of a properly historical approach to the study of cultural phenomena, argues that the New Historicists are not geneticist or referential enough. ${ }^{11}$ Their culturalogical (literary theory) approach and textualist (poststructuralist) biases blind them to the social structural and political nature of history.

So, too, it is less the formalism of New Historicist approaches to the study of literary texts and their contexts than the peculiar kind of formalism (Geertzian, de Manian, Derridean, Foucaultian) that offends the various "cultural materialists" represented in this volume: Newton, Thomas, Klancher, Pecora. ${ }^{12}$ For these critics, the New Historicists are simply not materialist enough in their formalism. Thus, it would seem, the New Historicists are both too historical and not historical enough; they are too formalist and not formalist enough, depending upon which variety of historical theory or of literary theory is taken as the basis for criticizing them. 
To be sure, there are many good reasons for criticizing a textualist approach to the study of culture, society, or a given period of history, but the contention that textualism is inherently a- or antihistorical is not one of them. For whether history is considered simply as the past, the documentary record of this past, or the body of reliable information about the past established by professional historians, there is no such thing as a distinctively historical method by which to study this history. Indeed, the history of historical studies displays ample evidence of the necessity of importing conceptual models, analytical methods, and representational strategies from other disciplines for the analysis of structures and processes considered to be generally historical in nature. In principle, therefore, there is nothing inherently a- or antihistorical in importing models, methods, and strategies borrowed from Geertzian cultural anthropology, Foucaultian discourse theory, Derridean or de Manian deconstructionism, Saussurean semiotics, Lacanian psychoanalytical theory, or Jakobsonian poetics into historical studies. The version of history that you will get by employing such models, methods, and strategies will certainly look different from that composed on the basis of other principles, such as those of Marxist dialectics or the methods of what used to be called the new social history. But it will be a historical history nonetheless if it takes as its object of study any aspect of the past, distinguishes between that object and its various contexts, periodizes the processes of change governing the relationships between them, posits specific causal forces as governing these processes, and represents the part of history thus marked out for study as a complex structure of relationships at once integrated at any given moment and developing and changing across any sequence of such moments.

Admittedly, the use of a culturalogical as against a sociological model for orienting an approach to the study of history carries with it implications of a decidedly ideological order. These implications are specified by Vincent Pecora, Brook Thomas, Elizabeth Fox-Genovese, Jon Klancher, and Frank Lentricchia, with greater or lesser relevance to the actual critical practices of the New Historicists themselves. But both the identification of these implications and the grounds for condemning them as ahistorical are themselves functions of the ideological positions of these critics. And indeed, the specific criticisms directed against the New Historicists by these critics turn for the most part on political and ethical issues. But it has to be said that a preference for a sociological over a culturalogical approach to the study of history cannot be justified by an appeal to the "facts" of history, since it is precisely the nature of these facts and the determination of what they are facts of that are at issue in the conflict between the two approaches. 
So, obviously, it is less the culturalogical approach to the study of history than the specific culturalogy employed by the New Historicists that offends their critics. Whether it is Geertzian culturalogy, with its technique of thick description, alleged blindness to political realities, and conservative ethnocentrism (Pecora); or Foucaultian culturalogy, with its theory of epistemes, reduction of social and cultural processes to "discursive practices," political pessimism, and ethical egotism, ${ }^{13}$ it is the kind of culturalogy used by the New Historicists to study history which gives offense. And here it is the shared textualism of both Geertzian and Foucaultian culturalogy, whatever the other differences between them, which is the sticking point.

Is there anything inherently ahistorical in the use of text as a model for construing, first, the cultural system conceived as the primary unit of historical study and, second, the elements or aspects of the unit thus construed? Every approach to the study of history presupposes some model for construing its object of study, for the simple reason that since history comprises everything that ever happened in the past, it requires some tertium comparationis by which to distinguish between what is historical and what is not and, beyond that, between what is significant and what is relatively insignificant, within this past. This is the function of the model of the social structure appealed to by Fox-Genovese in her critique of the literary theoretical bias of the New Historicists. And this is also the function of the model of the base-superstructure relationship appealed to more or less openly by cultural materialist critics of New Historicism, such as Thomas and Pecora. For the New Historicists, apparently, it is language in general, specifically discursive language, and particularly textualized discursive language that serves as the tertium comparationis without which it cannot do its work or play its game of historical study. So, the question at issue is whether the concept of text can legitimately be used as a viable tertium comparationis by which to identify a specifically historical phenomenon and whether, if it can be so used, it can yield any significant knowledge about the relative historical significance and insignificance of the events, structures, and processes of history.

First, it should be said that every approach to the study of the past presupposes or entails some version of a textualist theory of historical reality of some kind. This is because, primarily, the historical past is, as Fredric Jameson has argued, accessible to study "only by way of prior (re)textualization," whether this be in the form of the documentary record or in the form of accounts of what happened in the past written up by historians themselves on the basis of their research into the record. ${ }^{14}$ Second, histor- 
ical accounts of the past are themselves based upon the presumed adequacy of a written representation or textualization of the events of the past to the reality of those events themselves. Historical events, whatever else they may be, are events that really happened or are believed really to have happened, but which are no longer directly accessible to perception. As such, in order to be constituted as objects of reflection, they must be described-and described in some kind of natural or technical language. The analysis or explanation, whether nomological or narrativistic, which is subsequently provided of the events is always an analysis or explanation of the events as previously described. The description is a product of processes of linguistic condensation, displacement, symbolization, and secondary revision of the kind that inform the production of texts. On this basis alone, one is justified in speaking of history as a text.

The statement "History is a text" is, certainly, metaphorical, but it is no more metaphorical than Marx's statement that "all previous history is the history of class struggle" or the statement by Fox-Genovese that "history, at least good history, in contrast to antiquarianism, is inescapably structural" (2I6). More importantly, the statement "History is a text" is in no way inconsistent with these other statements about the nature of history. On the contrary, it is or at least can be so considered for methodological purposes, if anything, a qualification of these other statements. As thus envisaged, the textualism of the New Historicists, like the textualisms of structuralists and poststructuralists, of Geertz and Foucault, has the advantage of making explicit and therefore subject to criticism the textualist element in any approach to the study of history. And beyond that, it permits us to see that the conflict between the New Historicists and their critics, especially those of them who come from literary studies or cultural studies in general, is a conflict between different theories of textuality.

It is worth recalling that, for the New Historicists, the principal problem for which their brand of historicism was to be a solution was less formalism than the brand of literary history that formalism produced. The older formalist treatment of literary works presupposed both the autonomy of literature with respect to its historical contexts and the incomparability of individual works with one another except insofar as they manifest the same or similar stylistic features. Consequently, the history of literature could be conceived only as a sequence of unique stylistic moments, each of which could be grasped as a paradigmatic structure, but the relations among which, because of the uniqueness of each, had to remain in principle indeterminable. New Historicism, if I understand Montrose correctly, wishes to 
continue to honor this conception of literary history as a sequence of unique moments each of which can be grasped as a discrete structure of relationships paradigmatically organized, but it also wishes to extend the principle of paradigmatic structuration to include nonliterary texts, on the one hand, and the social institutions and practices that comprise historical contexts, on the other.

The result of all this is a view of history as a sequence of integral cultural systems of which both literature and social institutions and practices are to be regarded as manifestations or expressions and the relations among which are to be regarded as mutually determining and determined. Whence Montrose's suggestion that

we might . . entertain the propositions that the interdependent processes of subjectification and structuration are both ineluctably social and historical; that social systems are produced and reproduced in the interactive social practices of individuals and groups; that collective structures may enable as well as constrain individual agency; that the possibilities and patterns for action are always socially and historically situated, always limited and limiting, and that there is no necessary relationship between the intentions of actors and the outcomes of their actions. (2I)

It seems to me that there is nothing here - or very little - that should give offense to Fox-Genovese or the cohort of structural social historians for which she speaks. There is plenty of room for what Fox-Genovese represents as the properly historical view, that literary texts are a "function, or articulation of context," rather than the reverse, namely, that the context is a function and articulation of literary texts - a view she attributes to the New Historicists. To be sure, it is the nature of this function, or articulation, that is at issue. Is the literary text to be accorded any special status as a function, or articulation, of its context? Does the literary text function as an especially privileged historical datum, not only yielding insight into the nature of its context but also providing a model for the study of that context as well? Montrose thinks it does; Fox-Genovese thinks it doesn't.

But the crucial differences between them turn upon the question of the nature of that context of which the literary text is to be considered a function, or articulation. Montrose explicitly rejects the view that literature is "an autonomous aesthetic order that transcends the shifting pressures and particularities of material needs and interests." And while he also rejects the notion that it is either "a collection of inert discursive records of 'real' 
events" or merely "a superstructural reflexion of an economic base," I presume, on the basis of her own remarks, that these are views that FoxGenovese could share without too much difficulty. If literary texts are functions, or articulations, of their historical contexts, it does not follow that they are nothing but records or reflections of such contexts. In fact, Montrose argues only for the "relative autonomy" of literary works, their status as evidence of the human capacity to respond, and not merely react, to the social and cultural conditions of the time and place of their production.

Montrose's propositions are perfectly compatible with Fox-Genovese's contention that "history, at least good history, . . . is inescapably structural." And I take this to be true as well of both the principles and practices of New Historicism as represented in the work of Catherine Gallagher and Stephen Greenblatt. New Historicism in general argues only for what Montrose calls the relative autonomy of literature, which can hardly be objectionable even to Marxist historians and social theorists, since it is the relative autonomy of human consciousness and action and of the cultural superstructure, which includes literature, which constitutes a main problematic of their historical studies and authorizes the employment of a dialectical method for the analysis of all specifically historical phenomena. If the agents and agencies of historical reality were not relatively autonomous with respect to the dominant structures prevailing at a given time and place, such structures would undergo no changes of a specifically historical, as against a generally natural, kind at all.

All of which suggests that, if New Historicism retains residues of the formalism that it seeks to supplement or revise, this is true of Marxist historicism as well. Marxism and New Historicism alike are committed to some notion of a paradigmatic relationship between cultural forms, on the one side, and social relations of production, on the other, in discrete periods of history. And for critics on the Left, including cultural materialists, or various oppositionalist critics, including feminists and ethnocritics, to pillory New Historicism for the formalist and therefore antihistorical nature of its theory, methods, or practices amounts to no more than a denial of those aspects of their own theories, methods, and practices which they share with the New Historicists themselves.

But there is another aspect of the New Historicism over which there exists a possibility of genuinely principled disagreement with both traditional bourgeois historians and their Marxist counterparts. This has to do with the manner in which the New Historicists, as represented in this instance by Montrose, conceptualize the syntagmatic dimension of the his- 
tory of literature and by extension the history of both culture and society as well.

Recall that Montrose speaks of "substituting for the diachronic text of an autonomous literary history the synchronic text of a cultural system" (my emphases). Recall, too, that it is this substitution that is to provide the desired historical supplement to the formalist manner of construing the history of literature as a diachronic sequence of unique moments of literarity. The formulation appears strange because conventionally, diachronic is taken to be synonymous with a specifically historical, and synchronic with a generally ahistorical treatment of phenomena. So, how could one possibly redress the balance of a predominantly formalist approach to the study of literary history by substituting for it or supplementing it with a specifically synchronic treatment?

Here it might be helpful to recall Roman Jakobson's famous characterization of the similarities and differences between the poetic and the metalinguistic functions of language. According to Jakobson, "The poetic function projects the principle of equivalence from the axis of selection [i.e., the paradigmatic axis] onto the axis of combination [i.e., the syntagmatic axis]."15 The principle of equivalence thus comes to serve as the device constitutive of the patterns and periodicities of a distinctively poetic sequentiality. The metalinguistic function of language, by contrast, refers to and specifies the "code" in which an utterance is cast. It, too, "makes a sequential use of equivalent units when combining synonymic expressions into an equational sentence: A=A ('Mare is the female of the horse')." But, Jakobson argues, "Poetry and metalanguage ... are in diametrical opposition to each other: in metalanguage the sequence is used to build an equation, whereas in poetry the equation is used to build a sequence." Something like this formulation of the relationship between the poetic and the metalinguistic functions of language might lie behind and inform Montrose's notion of the differences between "the diachronic text of an autonomous literary history" and "the synchronic text of a cultural system." As thus envisaged, what appears at first sight to be a conflict between diachronic and synchronic conceptualizations of historical processes could be seen, upon further reflection, to involve contrasting notions of the nature of historical sequentiality. In the former, formalist instance, the sequence of literary periods, authors, works, corpora, genres, and so on is used to build a series of equations ( $\mathrm{A}=\mathrm{A}$ ["Shakespeare is a classic"; "the Elizabethan Renaissance was an apex of English literature"; "Hamlet is a tragedy"; "Wordsworth was the quintessential British Romantic lyricist," etc.]). The ex- 
planatory effect of the series thus built is a function of the progressive classification of historical entities (Shakespeare, the Elizabethan Renaissance, Wordsworth, Hamlet) as instantiations or exemplifications of the categories constituting the code of English literary history (classic, Renaissance, tragedy, Romantic, lyric, etc.). Although each instance or exemplification might be treated as a unique moment in the sequence, it is its status as a "function, or articulation," of the fundamental structure (or code) of English literary history that reveals its meaning.

In the latter, New Historicist instance, by contrast, an equation (e.g., "Literature is a relatively autonomous medium of cultural production and exchange, whose forms and functions vary with changes in the cultural system at large") is used to build a sequence of discrete moments, the pattern of which would be retrodictively discernible but not prospectively predictable from within any given moment of the sequence itself. This would imply not that no fundamental structure or code is discernible in the production of the sequence, but only that the code cannot be appealed to in order to account for the unique features of specific moments in the series that comprises the sequence. As thus construed, a historical sequence would have to be envisaged as a complex interaction between two kinds of syntagmatic process: one corresponding to the metalinguistic dimension of Jakobson's linguistic model, the other corresponding to the poetic dimension thereof.

It seems evident that the principal criticisms leveled against the New Historicists are advanced on the presumption that historical sequences are to be comprehended as functions of forces more codelike than poetic in nature. Moreover, the general gist of these criticisms is that the New Historicists share this presumption but have simply misidentified the nature of the code or codes that actually determine the structures and processes of historical sequences, seeking to substitute a cultural, literary, discursive, or poetic code for others more primary - political, social, class, ethnic, gender, and so on.

But, in my understanding of the matter at least, the New Historicists have advanced the notion of a cultural poetics and, by extension, a historical poetics as a means of identifying those aspects of historical sequences that conduce to the breaking, revision, or weakening of the dominant codes social, political, cultural, psychological, and so on-prevailing at specific times and places in history. Whence their interest in what appears to be the emergent, episodic, anecdotal, contingent, exotic, abjected, or simply uncanny aspects of the historical record. These aspects of history can be 
deemed poetic, in the sense of "creative" (rather than that of "fanciful" or "imaginary"), in that they appear to escape, transcend, contravene, undermine, or contest the rules, laws, and principles of the modes of social organization, structures of political superordination and subordination, and cultural codes predominating at the time of their appearance. In this respect, they can be said to resemble poetic speech, which, even though it may contravene the rules of both grammar and logic, not only has meaning, but also always implicitly challenges the canonical rules of linguistic expression prevailing at the time of its utterance.

It is not that such poetic aspects of history are its sole content. Nor is it that history displays no evidence of being informed by processes more logical than poetical in kind. It is just that, as Vico argued in the New Science, the logic of history is as much poetical as it is grammatical in kind.

Practitioners of established fields of studies in the human and social sciences, such as sociology, economics, politics, linguistics, or literary studies, go to history for a variety of reasons and in a variety of ways. When they do so, they are usually looking for information about some aspect of the specific object of interest that their discipline has been established to study: social structures, economic practices, political institutions, language use, literary works, and so on. Often, however, students of an established discipline may turn to history less for information about their own specialized objects of interest than for the kind of knowledge a specifically historical approach to the study of those objects is supposed to be able to provide. In this case, they are compelled to make specific claims about the nature of history, whether considered simply as the past, the documentary record of the past, or what historians have established as reliable information about the past, and to make explicit what they understand to be the specifically historical approach they are using for the study of their own special objects of interest. And it is here that they run the risk of offending both professional historians, practitioners of the one discipline in the human sciences that takes history as its special object of interest, and other practitioners of their own field of studies who either have their own versions of what history consists of or view their special objects of interest as intractable by the methods used in other disciplines, history included.

So it is With the NeW historicists. On the evidence presented in Veeser's anthology, they appear to have turned to history less for information about that literature of which they are students than for the kind of knowledge that a specifically historical approach to its study might 
yield. What they have discovered, however, is that there is no such thing as a specifically historical approach to the study of history but that there is a variety of such approaches, at least as many as there are positions on the current ideological spectrum; that, in fact, to embrace a historical approach to the study of anything entails or implies a distinctive philosophy of history; and that, finally, one's philosophy of history is a function as much of the way one construes one's own special object of scholarly interest as it is of one's knowledge of history itself. 


\section{The Modernist Event}

History does not break down into stories but into images.

- Walter Benjamin

The coming extinction of art is prefigured in the increasing impossibility of representing historical events.

- Theodor Adorno

It is a commonplace of contemporary criticism that modernist literature and, by extension, modernist art in general dissolves the trinity of event, character, and plot which still provided the staple both of the nineteenthcentury realist novel and of that historiography from which nineteenthcentury literature derived its model of realism. But the tendency of modernist literature to dissolve the event has especially important implications for understanding the ways in which contemporary Western culture construes the relationship between literature and history. Modern historical research and writing could get by without the notions of character and plot, as the invention of a subjectless and plotless historiography in the twentieth century has amply demonstrated. ${ }^{1}$ But the dissolution of the event as a basic unit of temporal occurrence and building block of history undermines the very concept of factuality and threatens therewith the distinction between realistic and merely imaginary discourse. The dissolution of the event undermines a founding presupposition of Western realism: the opposition between fact and fiction. Modernism resolves the problems posed by tradi- 
tional realism, namely, how to represent reality realistically, by simply abandoning the ground on which realism is construed in terms of an opposition between fact and fiction. The denial of the reality of the event undermines the very notion of fact informing traditional realism. Therewith, the taboo against mixing fact with fiction except in manifestly imaginative discourse is abolished. And, as current critical opinion suggests, the very notion of fiction is set aside in the conceptualization of literature as a mode of writing which abandons both the referential and poetic functions of language use.

It is this aspect of modernism that informs the creation of the new genres of postmodernist parahistorical representation, in both written and visual form, called variously docudrama, faction, infotainment, the fiction of fact, historical metafiction, and the like. ${ }^{2}$ These genres are represented by books such as Capote's In Cold Blood, Mailer's Executioner's Song, Doctorow's Ragtime, Thomas's White Hotel, De Lillo's Libra, and Reed's Flight to Canada; the television versions of Holocaust and Roots; films such as The Night Porter (Cavani), The Damned (Visconti), Hitler: A Film from Germany (Syberberg), The Return of Martin Guerre (Tavernier), and, more recently, Oliver Stone's JFK and Spielberg's Schindler's List. All deal with historical phenomena, and all of them appear to fictionalize, to a greater or lesser degree, the historical events and characters that serve as their referents in history.

These works, however, differ crucially from those of their generic prototype, the nineteenth-century historical novel. That genre was born of the inscription within and interference between an imaginary tale of romance and a set of real historical events. The interference had the effect of endowing the imaginary events with the concreteness of reality while at the same time endowing the historical events with the magical aura peculiar to the romance. ${ }^{3}$ However, the relationship between the historical novel and its projected readership was mediated by a distinctive contract: its intended effects depended upon the presumed capacity of the reader to distinguish between real and imaginary events, between fact and fiction, and therefore between life and literature. Without this capacity, the affect in which the familiar (the reader's own reveries) was rendered exotic while the exotic (the historical past or the lives of the great) was rendered familiar could not have been produced.

What happens in the postmodernist docudrama or historical metafiction is not so much the reversal of this relationship (such that real events are given the marks of imaginary ones while imaginary events are endowed with reality) as the placing in abeyance of the distinction between the real 
and the imaginary. Everything is presented as if it were of the same ontological order, both real and imaginary - realistically imaginary or imaginarily real, with the result that the referential function of the images of events is etiolated. Thus, the contract that originally mediated the relationship between the nineteenth-century (bourgeois?) reader and the author of the historical novel has been dissolved. And what you get, as Gertrude Himmelfarb tells us, is "history as you like it," representations of history in which anything goes - to the detriment of both truth and moral responsibility, in her view. It is exactly the sort of thing of which Oliver Stone has been so often accused since the appearance of JFK ( I99I).

Stone was criticized by journalists, historians, politicians, and political pundits for his treatment of the events surrounding the assassination of President John F. Kennedy. In part, this was a result of the "content" of his film. He was accused, among other things, of fostering paranoia by suggesting that President Kennedy's assassination was a result of a conspiracy involving highly placed persons in the United States government. But also - and for some critics even more seriously-Stone's film seemed to blur the distinction between fact and fiction by treating a historical event as if there were no limits on what could legitimately be said about it, ${ }^{4}$ and thereby bringing under question the very principle of objectivity on the basis of which one might discriminate between truth, on the one side, and myth, ideology, illusion, and lie, on the other.

Thus, in a review of JFK that appeared in the Times Literary Supplement entitled "Movie Madness?" Richard Grenier wrote:

And so Oliver Stone romps through the assassination of John Kennedy, inventing evidence that supports his thesis [of conspiracy], suppressing all evidence that conflicts with it, directing his film in a pummelling style, a left to the jaw, a right to the solar plexus, flashing forward, flashing backward, crosscutting relentlessly, shooting "in tight" (in close), blurring, obfuscating, bludgeoning the viewer until Stone wins, he hopes, by a TKO. ${ }^{5}$

Note that Grenier objects to the ways in which Stone slants evidence concerning the assassination, but he is especially offended by the form of Stone's presentation, his "pummelling" and "bludgeoning" style, which apparently distorts even those events whose occurrence can be established on the basis of historical evidence. This style is treated as if it were a violation of the spectator's powers of perception.

So, too, another film critic, David Armstrong, was as much irked by 
the form as he was by the content of Stone's movie. He excoriated what he called Stone's "appropriation of TV car commercial quick-cutting" and reported that, for him, "watching JFK was like watching three hours of MTV without the music." But Armstrong disliked "the film as a film" for other reasons as well, reasons more moral than artistic. "I am troubled, ... by Stone's mix'n'match of recreated scenes and archival footage," because "young viewers to whom [Stone] dedicates the film could take his farreaching conjectures as literal truth." Armstrong suggests, then, that Stone's editing techniques might destroy the capacity of young viewers to distinguish between a real and a merely imaginary event. ${ }^{6}$ All of the events depicted in the film - whether attested by historical evidence, based on conjecture, or simply made up in order to help the plot along or to lend credence to Stone's paranoid fantasies - are presented as if they were equally historical, which is to say, equally real, or as if they had really happened. And this in spite of the fact that Stone is on record as professing not to know the difference between history and something that people make up, in other words, as viewing all events as equally imaginary, at least insofar as they are represented events. ${ }^{7}$

Issues such as these arise within the context of the experience, memory, or awareness of events that not only could not possibly have occurred before the twentieth century but whose nature, scope, and implications no prior age could even have imagined. Some of these events - such as the two world wars, a growth in world population hitherto unimaginable, poverty and hunger on a scale never before experienced, pollution of the ecosphere by nuclear explosions and the indiscriminate disposal of contaminants, programs of genocide undertaken by societies utilizing scientific technology and rationalized procedures of governance and warfare (of which the German genocide of six million European Jews is paradigmatic) - function in the consciousness of certain social groups exactly as infantile traumas are conceived to function in the psyche of neurotic individuals. This means that they cannot be simply forgotten and put out of mind or, conversely, adequately remembered, which is to say, clearly and unambiguously identified as to their meaning and contextualized in the group memory in such a way as to reduce the shadow they cast over the group's capacities to go into its present and envision a future free of their debilitating effects. ${ }^{8}$

The suggestion that, for the groups most immediately affected by or fixated upon these events, their meanings remain ambiguous and their consignment to the past difficult to effectuate should not be taken to imply in any way that such events never happened. On the contrary, not only are 
their occurrences amply attested, but also, their continuing effects on current societies and generations that had no direct experience of them are readily documentable. But among those effects must be listed the difficulty felt by present generations of arriving at some agreement as to their meaning - by which I mean what the facts established about such events can possibly tell us about the nature of our own current social and cultural endowment and what attitude we ought to take with respect to them as we make plans for our own future. In other words, what is at issue here is not the facts of the matter regarding such events but the different possible meanings that such facts can be construed as bearing.

The distinction between facts and meanings is usually taken to be a basis of historical relativism. This is because, in conventional historical inquiry, the facts established about a specific event are taken to be the meaning of that event. Facts are supposed to provide the basis for arbitrating among the variety of different meanings that different groups can assign to an event for different ideological or political reasons. But the facts are a function of the meaning assigned to events, not some primitive data that determine what meanings an event can have. It is the anomalous nature of modernist events - their resistance to inherited categories and conventions for assigning meanings to events - that undermine not only the status of facts in relation to events but also the status of the event in general.

But to consider the issue of historical objectivity in terms of an opposition of real to imaginary events, on which the opposition of fact to fiction is in turn based, obscures an important development in Western culture which distinguishes modernism in the arts from all previous forms of realism. Indeed, it seems as difficult to conceive of a treatment of historical reality that would not use fictional techniques in the representation of events as it is to conceive of a serious fiction that did not in some way or at some level make claims about the nature and meaning of history. ${ }^{9}$ And this for a number of quite obvious reasons. First, the twentieth century is marked by the occurrence of certain "holocaustal" events (two world wars, the Great Depression, nuclear weapons and communications technology, the population explosion, the mutilation of the zoosphere, famine, genocide as a policy consciously undertaken by "modernized" regimes, etc.) that bear little similarity to what earlier historians conventionally took as their objects of study and do not, therefore, lend themselves to understanding by the commonsensical techniques utilized in conventional historical inquiry nor even to representation by the techniques of writing typically favored by historians from Herodotus to Arthur Schlesinger. Nor does any 
of several varieties of quantitative analysis, of the kind practiced in the social sciences, capture the novelty of such events. ${ }^{10}$ Moreover, these kinds of event do not lend themselves to explanation in terms of the categories underwritten by traditional humanistic historiography, which features the activity of human agents conceived to be in some way fully conscious and morally responsible for their actions and capable of discriminating clearly between the causes of historical events and their effects over the long as well as the short run in relatively commonsensical ways - in other words, agents who are presumed to understand history in much the same way as professional historians do.

But beyond that, the historical event, by which one used to mean something like "the assassination of the thirty-fifth president of the United States," has been dissolved as an object of a respectably scientific knowledge. Such events can serve as the contents of bodies of information; but as possible objects of a knowledge of history that might lay claim to the status of scientific lore, they are of interest only as elements of a statistical series. Indeed, such singular events as the assassination of a head of state are worthy of study only as a hypothetical presupposition necessary to the constitution of a documentary record whose inconsistencies, contradictions, gaps, and distortions of the event presumed to be their common referent itself moves to the fore as the principal object of investigation. As for such singular events of the past, the only thing that can be said about them is that they occurred at particular times and places. ${ }^{11}$

An event such as the assassination of President John F. Kennedy will inevitably continue to generate the interest of history buffs and even of professional historians as long as it can be made to seem relevant to current concerns, political, ideological, or group- or individual-psychological, as the case may be. However, any attempt to provide an objective account of the event, either by breaking it up into a mass of its details or by setting it within its context, must conjure with two circumstances: one is that the number of details identifiable in any singular event is potentially infinite; and the other is that the context of any singular event is infinitely extensive or at least is not objectively determinable. ${ }^{12}$ Moreover, the historical event, traditionally conceived as an event that was not only observable but also observed, is by definition an event that is no longer observable, and hence it cannot serve as an object of a knowledge as certain as that about present events that can still be observed. This is why it is perfectly respectable to fall back upon the time-honored tradition of representing such singular events as the assassination of the thirty-fifth president of the United States as a 
story and to try to explain it by narrativizing (fabulating) it - as Oliver Stone did in JFK. ${ }^{13}$

But this is where the distinction between the fact as against the event of modernism must be addressed. The notion of the historical event has undergone radical transformation as a result of the occurrence in our century of events of a scope, scale, and depth unimaginable by earlier historians and the dismantling of the concept of the event as an object of a specifically scientific kind of knowledge. So too, however, for the notion of the story; it has suffered tremendous fraying and at least potential dissolution as a result of that revolution in representational practices known as cultural modernism ${ }^{14}$ and the technologies of representation made possible by the electronic revolution.

On this last point, we can consider profitably the power of the modern media to represent events in such a way as to render them not only impervious to every effort to explain them but also resistant to any attempt to represent them in a story form. The modern electronic media can manipulate recorded images so as literally to explode events before the eyes of viewers. The uses made in courtroom presentations of television images of Los Angeles police beating a black man (Rodney King) had the effect of making this seemingly unambiguously documented event virtually unintelligible as an event. The very precision and detail of the imagistic representation of the event are what threw it open to a wide variety of interpretations of "what was really going on" in the scene depicted. The contingency of the videographic recording of the event (the videographer happened to be within sight of the scene with camcorder available, loaded, functioning, etc.) precluded the fiction that the events recorded followed a specific scenario, script, or plot line. It is no accident, as it used to be said, that accidents have traditionally served as the very archetype of what historians formerly thought of as events, but the accidents in question were always of a certain kind, namely, the sort that yielded to the imperatives of storytelling and followed the rules of narrativization.

But not only are modern postindustrial accidents more incomprehensible than anything earlier generations could possibly have imagined (think of Chernobyl), but the photo and video documentation of such accidents is so full that it is difficult to work them up as elements of a single objective story. Moreover, in many instances, the documentation of such events is so manipulable as to discourage the effort to derive explanations of the occurrences of which the documentation is supposed to be a recorded image. "It is no accident," then, that discussions of the modernist event tend in the 
direction of an aesthetics of the sublime-and-the-disgusting rather than that of the beautiful-and-the-ugly.

An example of what I have in mind is provided by an article in the periodical $I-800$. Here Michael Turits analyzed the hermeneutic gymnastics inspired by media coverage of two amply documented techno-air disasters: the collision of three Italian MB 339A (Frecce tricolori) jet planes in an air show over Ramstein, Germany, in August I988, killing 50 and injuring 360; and the explosion in 1986 of the NASA Challenger space shuttle, just after lift-off in full view of a live audience and millions of television viewers. In his analysis of the media's presentations of these events, Turits likens the impact of their endless re-presentations on TV to the ambiguating effects of those televised replays of crucial events in sporting contests. Turits observes that, "when the [Challenger] blew up and the Frecce tricolori collided, ... the optical geometries yielded by endless replays far outran the capacities of the network techno-refs to make a call.” What had been promised as a clarification of what happened actually produced widespread cognitive disorientation, not to say a despair at ever being able to identify the elements of the events in order to render possible an objective analysis of their causes and consequences. Thus, Turits notes:

Like an out-of-control computer virus somehow lodged in the network's video editing desks, the Ramstein collision and the Challenger explosion could do nothing but frantically play themselves over and over... The frameby-frame re-runs that followed [the Challenger explosion] for months served the same purpose as the media's obsession with the deep-sea recovery of the shuttle and astronaut remains - to reconstruct the too brief event as a visually intelligible accident.

The networks played the tapes of the Challenger explosion over and over. In response to the question of why they had done so, the news commentator Tom Brokaw said: "What else could we do? People wanted answers." ${ }^{5}$ But, as Turits remarks, the tapes certainly provided no answers. All that the "morphing" technology used to re-present the event provided was a sense of its evanescence. It appeared impossible to tell any single authoritative story about what really happened - which meant that one could tell any number of possible stories about it.

And this is why the issues raised in the controversy over JFK could be profitably set within a more recent phase of the debate over the relation of historical fact to fiction peculiar to the discussion of the relation between 
modernism and postmodernism. For literary (and, for that matter, filmic) modernism (whatever else it may be) marks the end of storytelling - understood in Walter Benjamin's sense of "the tale" by which the lore, wisdom, and commonplaces of a culture are transmitted from one generation to another in the form of the followable story. After modernism, when it comes to the task of storytelling, whether in historical or in literary writing, the traditional techniques of narration become unusable - except in parody. ${ }^{16}$ Modernist literary practice effectively explodes the notion of those characters who had formerly served as the subjects of stories or at least as representatives of possible perspectives on the events of the story; and it resists the temptation to emplot events and the actions of the characters so as to produce the meaning-effect derived by demonstrating how one's end may be contained in one's beginning. Modernism thereby effects what Fredric Jameson calls the derealization of the event itself. And it does this by consistently voiding the event of its traditional narrativistic function of indexing the irruption of fate, destiny, grace, fortune, providence, and even of history itself into a life (or at least into some lives) "in order to pull the sting of novelty" and give the life thus affected at worst a semblance of pattern and at best an actual, transocial, and transhistorical significance. ${ }^{17}$

Jameson shows how Sartre, in a typically modernist work like Naw$s e a,{ }^{18}$ thematizes the experience of time as a series of instants that either fail to take on the form of a story or fall apart into sherds and fragments of existence. The thematization takes the form of a representation of the ineradicable differences - indeed, the opposition - between ordinary life and a putatively adventurous one. Thus, in a scene analyzed by Jameson, the protagonist Roquentin reflects to himself:

I have never had adventures. Things have happened to me, events, incidents, anything you like. But no adventures.... I had imagined that at certain times my life could take on a rare and precious quality. There was no need for extraordinary circumstances: all I asked for was a little precision. . . . From time to time, for example, when they play music in the cafés, I look back and tell myself: in the old days, in London, Meknes, Tokyo, I have known great moments, I have had adventures. Now I am deprived of this. I have suddenly learned, without any apparent reason, that I have been lying to myself for ten years. And naturally, everything they tell about in books can happen in real life, but not in the same way. It is to this way of happening that I clung so tightly. $(53-55)$ 
Roquentin's problem is that, to him, in order for an event to have the meaning of an adventure, it would have to resemble the kinds of event met with in adventure stories. Events would have to be narratable. Here is how Sartre represents Roquentin's desire for story-events:

This is what I thought: for the most banal event to become an adventure, you must (and this is enough) begin to recount it. This is what fools people: a man is always a teller of tales, he lives somehow surrounded by his stories and the stories of others, he sees everything that happens to him through them; and he tries to live his own life as if he were telling a story.

But you have to choose: live or tell.

Roquentin's melancholy stems from his realization that:

Nothing bappens while you live. The scenery changes, people come and go out, that's all. There are no beginnings. Days are tacked on to days without rhyme or reason, an interminable, monotonous addition. ... That's living. But everything changes when you tell about life; it's a change no one notices: the proof is that people talk about true stories. As if there could possibly be true stories; things happen one way and we tell about them in the opposite sense. You seem to start at the beginning: "It was a fine autumn evening in I922. I was a notary's clerk in Marommes." And in reality you have started at the end. It was there, invisible and present, it is the one which gives to words the pomp and value of a beginning.... I wanted the moments of my life to follow and offer themselves like those of a life remembered [as in Proust!]. You might as well try to catch time by the tail. (56-58 passim; my emphases)

And this realization leads him to conclude:

This feeling of adventure definitely does not come from events: I have proved it. It's rather the way in which the moments are linked together. I think this is what happens: you suddenly feel time is passing, that each instant leads to another, this one to another one, and so on; that each instant is annihilated, and that it isn't worth while to hold it back, etc., etc. And then you attribute this property to events which appear to you in the instants: what belongs to the form you carry over to the content. You talk a lot about this amazing flow of time but you hardly see it. ... (79; my emphasis)

If I remember correctly, they call that the irreversibility of time. The feel- 
ing of adventure would simply be that of the irreversibility of time. But why don't we always have it? Is it that time is not always irreversible? There are moments when you have the impression that you can do what you want, go forward or backward, that it has no importance; and then other times when you might say that the links have been tightened and, in that case, it's not a question of missing your turn because you could never start again. (80)

These passages from Sartre today seem dated, melodramatic, even hackneyed - as the recent past always does - but they usefully point up the bases of a distinctively modernist apprehension that the meaning, form, or coherence of events, whether real or imaginary ones, is a function of their narrativization. Jameson concludes that the modernist derealization of the event amounts to a rejection of the historicity of all events and that this is what throws the modernist sensibility open to the attractions of myth (the myths of Oedipus, Ulysses, Finnegan, and so on) or the extravagances of melodrama (typically institutionalized in the genre of the detective, spy, crime, or extraterrestrial alien story). In the former case, the meaning of otherwise unimaginable events is seen to reside in their resemblance to timeless archetypal stories - like the death of the young hero-leader, JFK. In the latter case, meaning is rendered spectral, seeming to consist solely in the spatial dispersion of the phenomena that had originally seemed to have converged only in order to indicate the occurrence of an event.

Sartre's treatment of the event is a representation (Vorstellung) of a thought about it, rather than a presentation (Darstellung) of the event itself. A typically modernist presentation of the event is found in a passage from Virginia Woolf's last novel, Between the Acts. ${ }^{19}$ The title itself indicates a typical concern of high modernism, namely, an interest in what, if anything, goes on in the intervals between those rare instants in our lives in which something eventful seems to be happening. But the story thematizes the insubstantiality not only of the intervals between events but also of those events whose seeming occurrence renders possible the apprehension of what comes between them as an interval.

In Between the Acts, the life of the Oliver family seems to be as orderly as the pageant that is to be performed by the villagers on the family estate on that single "day in June in I939" which frames the nonaction of the story. The pageant is depicted, however, as differing from the real world by its possession of a discernible plot; its intervals mark the acts which themselves represent identifiable periods of English history from the Middle Ages to the present. In the intervals between the acts of the pageant, the members of 
the Oliver family and their guests disperse and recombine in moments of what always turn out to be failed epiphanies, so that in reality the events that might have served to mark out a plot in their lives never quite occur. What happens "between the acts" is nothing at all, indeed the difference between the acts and the intervals between them is progressively smudged and finally erased. The principal difference we are left with is that between the pageant, with all its acts marked by events, and the real life of the spectators, in which no events whatsoever occur. An eventful instant of time would have been one that would have collected and condensed the vagrant events that are experienced more as intervals than as occurrences and endowed them with pattern and cohesion, if only for a moment. But there are no such events in this story. All of the events that take place before, during, between, and after the acts of the pageant itself are shown to have been as insubstantial as what takes place between the individual frames of a movie film and as fictitious as those historical events depicted in the pageant.

The passage I referred to as exemplifying the typically modernist approach to the representation of an event appears in the second scene of the story (there are no chapter designations). The central figure of the novel, Isabella (Mrs. Giles) Oliver, has just entered the library of the family house, located "in a remote village in the very heart of England," on the morning of the pageant. Her father-in-law, Bart Oliver, a retired civil servant, is already there, reading the newspaper. As she enters, she recalls a phrase uttered by a woman visitor to the library some years earlier.

"The library's always the nicest room in the house," she quoted, and ran her eyes along the books. "The mirror of the soul," books were. . . . The Fairie Queene and Kinglake's Crimea; Keats and The Kreutzer Sonata. There they were, reflecting. What? What remedy was there for her at her age - the age of the century, thirty-nine - in books? Book-shy she was, like the rest of her generation; and gun-shy, too. Yet as a person with a raging tooth runs her eye in a chemist shop over green bottles with gilt scrolls on them lest one of them may contain a cure, she considered: Keats and Shelley; Yeats and Donne. Or perhaps not a poem; a life. The life of Garibaldi. The life of Lord Palmerston. Or perhaps not a person's life; a county's. The Antiquities of Durbam; The Proceedings of the Archaeological Society of Nottingham. Or not a life at all, but science-Eddington, Darwin, Jeans.

None of them stopped her toothache. For her generation the newspaper was a book; and, as her father-in-law dropped the Times, she took it and read: "A horse with a green tail . .." which was fantastic. Next, "The guard at 
Whitehall ..." which was romantic and then, building word upon word, she read: "The troopers told her the horse had a green tail; but she found it was just an ordinary horse. And they dragged her up to the barrack room where she was thrown upon a bed. Then one of the troopers removed part of her clothing, and she screamed and hit him about the face ..."

That was real; so real that on the mahogany door panels she saw the Arch in Whitehall; through the Arch the barrack room; in the barrack room the bed, and on the bed the girl was screaming and hitting him about the face, when the door (for in fact it was a door) opened and in came Mrs. Swithin carrying a hammer.

She advanced, sidling, as if the floor were fluid under her shabby garden shoes, and, advancing, pursed her lips and smiled, sidelong, at her brother. Not a word passed between them as she went to the cupboard in the corner and replaced the hammer, which she had taken without asking leave; together - she unclosed her fist - with a handful of nails. ( I9-20)

Notice that quite a few (and for the most part mundane) events are registered here: Isabella peruses the bookshelves for a possible remedy for the ills that afflict her generation - significantly marked by a date: I939. She considers poetry, biography, history, science and turns away from them all, to the newspaper where she reads an account of an event, a rape, an event so surreal that she sees it "on the ... panels" of the library door. But the image of the event, which happened in the past, metamorphoses, without a break in grammar or syntax, into that of Mrs. Swithin, Bart's sister, entering the library in the fictive present: and "on the bed the girl was screaming and hitting him about the face, when the door (for in fact it was a door) opened and in came Mrs. Swithin carrying a hammer.”

The image of the girl being raped leaks into that of the quite ordinary event of Mrs. Swithin entering the library and contaminates it, endowing it with a sinister, phantasmagoric aspect: Mrs. Swithin "advanced, sidling, as if the floor were fluid under her shabby garden shoes, and, advancing, pursed her lips and smiled, sidelong, at her brother. Not a word passed between them as she went to the cupboard in the corner and replaced the hammer, which she had taken without asking leave; together - she unclosed her fist - with a handful of nails" (my emphases). The two events, the rape of the girl and the entrance of Mrs. Swithin into the library, are endowed with an equal measure of significance or, rather, of ambiguity of meaning. There is no way of distinguishing between their respective phenomenal aspects or their different significances. Both events flow out of their outlines. And 
flow out of the narrative as well. The effect of the representation is to endow all events with spectral qualities. Mrs. Swithin's replacement of the hammer leads to an exchange between herself and her brother which Isabella recognizes - uncannily - as having taken place every summer for the last seven years.

Every summer, for seven summers now, Isa had heard the same words; about the hammer and the nails; the pageant and the weather. Every year they said, would it be wet or fine; and every years it was - one or the other. The same chime [of the clock] followed the same chime, only this year beneath the chime she heard: "The girl screamed and hit him about the face with a hammer." (22)

The outside of events, their phenomenal aspects, and their insides, their possible meanings or significances, have been collapsed and fused. The meaning of events remains indistinguishable from their occurrence, but their occurrence is unstable, fluid, phantasmagoric - as phantasmagoric as the slow motion, reverse angle, zoom, and rerun of the video representations of the Challenger explosion. This is not to say that such events are not representable, only that techniques of representation somewhat different from those developed at the height of artistic realism may be called for.

Contemporary discussions of the ethics and aesthetics of representing the Holocaust of the European Jews - what I take to be the paradigmatic modernist event in Western European history-provide insights into the modernist view of the relationship between history and fiction. With respect to the question of how most responsibly to represent the Holocaust, the most extreme position is not that of the so-called revisionists, who deny that this event ever happened; ${ }^{20}$ but, rather, that of those who hold that this event is of such a kind as to escape the grasp of any language even to describe it and of any medium - verbal, visual, oral, or gestural - to represent it, much less of any merely historical account adequately to explain it. This position is represented in George Steiner's oft quoted remark, "The world of Auschwitz lies outside speech as it lies outside reason."21 Or that of the philosopher Emile Fackenheim: "The Holocaust . . . resists explanation - the historical kind that seeks causes, and the theological kind that seeks meaning and purpose. . . The Holocaust, it would appear, is a qualitatively unique event, different in kind even from other instances of genocide. One cannot comprehend [the Holocaust] but only confront and object."22 
The historian Christopher R. Browning addresses questions and assertions such as these in a remarkably subtle reflection on the difficulties he had to face in his efforts to reconstruct, represent, and explain a massacre of some I,500 Jews - women, children, elders, and young men - by German Army Reserve Battalion Io I on I 3 July 1942 in the woods outside the Polish village of Jozefów. Browning has spent years pondering the documents that attest to the facts of this event and interviewed I 25 members of the battalion who, neither regular soldiers nor members of the SS, took on the role of professional killers in the course of their service as anonymous executors of the genocidal policy conceived and implemented by their Nazi leaders. Browning's aim was to write the history of one day in the life of the "little men" who were the perpetrators of specific crimes against specific people at a specific time and place in a past that is rapidly receding from living memory and passing into history. And in his report on his research, Browning asks:

Can the history of such men ever be written? Not just the social, organizational, and institutional history of the units they belonged to. And not just the ideological and decision-making history of the policies they carried out. Can one recapture the experiential history of these killers - the choices they faced, the emotions they felt, the coping mechanisms they employed, the changes they underwent? ${ }^{23}$

He concludes that such an "experiential history" of this event, all too typical of all too many events of the Holocaust, is virtually impossible to conceive. The Holocaust, he reminds us, "was not an abstraction. It was a real event in which more than five million Jews were murdered, most in a manner so violent and on a scale so vast that historians and others trying to write about these events have experienced nothing in their personal lives that remotely compares." And he goes on to assert that "historians of the Holocaust, in short, know nothing - in an experiential sense - about their subject." This kind of "experiential shortcoming," Browning points out, "is quite different from their not having experienced, for example, the Constitutional Convention in Philadelphia or Caesar's conquest of Gaul. Indeed, a recurring theme of witnesses [to the Holocaust] is how 'unbelievable' [that event] was to them even as they lived through it." ${ }^{24}$

The shortcoming in question pertains to the nature of the events under scrutiny; these events seem to resist the traditional historian's effort at the kind of empathy which would permit one to see them, as it were, 
from the inside, in this case, from the perpetrators' perspective. And the difficulty, Browning argues, is not methodological. It is a question not of establishing the facts of the matter but of representing the events established as facts in such a way as to make those events believable to readers who have no more experience of such events than the historian himself.

Browning, in short, draws back from suggesting what appears to me to be the obvious conclusion one might derive from this problem. Which is that the problem is indeed not one of method but, rather, one of representation and that this problem, that of representing the events of the Holocaust, requires the full exploitation of modernist as well as premodernist artistic techniques for its resolution. He draws back from this possibility because, like Saul Friedlander and other experts in the study of representations of the Holocaust, whether in writing, film, photography, monuments, or anything else, he fears the effects of any aestheticization of this event. And especially by making it into the subject matter of a narrative, a story that, by its possible "humanization" of the perpetrators, might enfable the eventrender it fit therefore for investment by fantasies of intactness, wholeness, and health which the very occurrence of the event denies.

According to Eric Santner, the danger of yielding to the impulse to tell the story of the Holocaust - and, by extension, any other traumatic event - opens the investigator of it to the danger of "narrative fetishism," which is, on his view, a "strategy of undoing, in fantasy, the need for mourning by simulating a condition of intactness, typically by situating the site and origin of loss elsewhere." ${ }^{25}$ In short, the threat posed by the representation of such events as the Holocaust, the Nazi Final Solution, the assassination of a charismatic leader such as Kennedy or Martin Luther King or Gandhi, an event, such as the destruction of the Challenger, which had been symbolically orchestrated to represent the aspirations of a whole community, this threat is nothing other than that of turning them into the subject matter of a narrative. Telling a story, however truthful, about such traumatic events might very well provide a kind of intellectual mastery of the anxiety that memory of their occurrence may incite in an individual or a community. But precisely insofar as the story is identifiable as a story, it can provide no lasting psychic mastery of such events.

And this is why it seems to me that the kinds of antinarrative nonstories produced by literary modernism offer the only prospect for adequate representations of the kind of "unnatural" events - including the Holocaust - that mark our era and distinguish it absolutely from all of the history that has come before it. In other words, what Jameson calls the psycho- 
pathologies of modernist writings and film, which he lists as "their artificial closures, the blockage of narrative, [their] deformation and formal compensations, the dissociation or splitting of narrative functions, including the repression of certain of them, and so forth,"26 - it is these very psychopathological techniques, which explode the conventions of the traditional tale (the passing of which was lamented and at the same time justified by Benjamin in his famous essay "The Storyteller"), that offer the possibility of representing such traumatic events as those produced by the monstrous growth and expansion of technological modernity (of which Nazism and the Holocaust are manifestations) in a manner less fetishizing than any traditional representation of them would necessarily be.

What I am suggesting is that the stylistic innovations of modernism, born as they were of an effort to come to terms with the anticipated loss of the peculiar sense of history which modernism is ritually criticized for not possessing, may provide better instruments for representing modernist events (and premodernist events in which we have a typically modernist interest) than the storytelling techniques traditionally utilized by historians for the representation of the events of the past that are supposed to be crucial to the development of their communities' identity. Modernist techniques of representation provide the possibility of defetishizing both events and the fantasy accounts of them which deny the threat they pose in the very process of pretending to represent them realistically and clear the way for that process of mourning which alone can relieve the burden of history and make a more if not totally realistic perception of current problems possible.

It is fortunate, therefore, that we have in the work of one of the greatest of modernist writers a theorization of this problem of representing events in the narrative. In four lectures entitled Narration, ${ }^{27}$ delivered at the University of Chicago in 1936, Gertrude Stein reflected on the unreality of the event in contrast to "things which have really existed." An event, she suggested, was only an "outside without an inside," whereas a thing that has existed has its outside inside itself. When "the outside is outside," she said, "it is not begun and when it is outside it is not ended and when it is neither begun nor ended it is not either a thing which has existed it is simply an event." She went on to contrast both journalistic and historical treatments of events with a specifically modernist artistic treatment of them, on the basis of the failure of the former kind to put "the outside inside."

In real life that is if you like in the newspapers which are not real life but real life with the reality left out, the reality being the inside and the newspapers 
being the outside and never is the outside inside and never is the inside outside except in the rare and peculiar cases when the outside breaks through to be inside because the outside is so part of some inside that even a description of the outside cannot completely relieve the outside of the inside.

And so in the newspapers you like to know the answer in crime stories in reading crime and in written crime stories knowing the answer spoils it. After all in the written thing the answer is a let down from the interest and that is so every time that is what spoils most crime stories unless another mystery crops up during the crime and that mystery remains.

And then there is another very peculiar thing in the newspaper thing it is the crime in the story it is the detective that is the thing.

Now do you begin to see the difference between the inside and the outside.

In the newspaper thing it is the crime it is the criminal that is interesting, in the story it is the story about the crime that is interesting. (59)

As for historical representation, she has this to say:

Anyone can see that there is more confusion that is to say perhaps not more confusion but that it is a more difficult thing to write history to make it anything than to make anything that is anything be anything because in history you have everything, you have the newspapers and the conversations and letter writing and the mystery stories and audience and in every direction an audience that fits anything in every way in which an audience can fit itself to be anything, and there is of course as I have been saying so much to trouble any one about any one of any of these things. (54)

It was, Stein argued - or rather poetized - because of the specifically modern awareness of the exteriority of events that their narrative treatment was so difficult.

We talked a great deal all this time how hard it is to tell anything anything that has been anything that is, and that makes a narrative and that makes history and that makes literature and is history literary.

Well how far have we come.

Can history be literature when it has such a burden a burden of everything, a burden of so many days which are days one after the other and each has its happening and still as in the newspaper what can make it matter it is is not happening to-day, the best thing that can happen about that happening is that it can happen again. And that makes the comfort of history to a historian 
that history repeats itself, that is really the only comfort that a historian can have from anything happening and really and truly it does not happen again not as it used to happen again because now we know really know so much that has happened that really we do not know that what has happened does not happen again and so that for poor comfort has been taken away from the historian.

What I mean is this, history has gotten to be so that anybody can if they go on know that everything that happened is what happened and as it all did happen it is a very serious thing that so much was happening. Very well then. What would be the addition to anything if everything is happening, look out of any window, any window nowadays is on a high building if it happens right and see what is happening. Well enough said, it is not necessary to go on with recognition, but soon you do know anybody can know, that it is all real enough. It is all real enough, not only real enough but and that is where it is such a difficult thing not real enough for writing, real enough for seeing, almost real enough for remembering but remembering in itself is not really an important enough thing to really need recalling, insofar as it is not seeing, but remembering is seeing and so anything is an important enough thing for seeing but it is not an important enough thing for writing, it is an important enough thing for talking but not an important enough thing for telling.

That is really the trouble with what history is, it is important enough for seeing but not important enough for writing, it is important enough for talking but not important enough for telling. And that is what makes everybody so troubled about it all about what history is, because after all it ought to be important enough for telling for writing and not only important enough for talking and seeing, it really ought to be, it really ought to be, but can it be. Cannot it really be. (59)

Now the same thing is true when the newspaper tells about any real thing, the real thing having happened it is completed and being completed can not be remembered because the thing in its essence being completed can not be remembered because the thing in its essence being completed there is no emotion in remembering it, it is a fact like any other and having been done it is for the purposes of memory a thing having no vitality. While anything which is a relief and in a made up situation as it gets more and more exciting when the exciting rises to being really exciting then it is a relief then it is a thing that has emotion when that thing is a remembered thing.

Now you must see how true this is about the crime story and the actual crime. The actual crime is a crime that is a fact and it having been done that in 
itself is a completion and so for purposes of memory with very rare exceptions where a personality connected with it is overpowering there is no memory to bother any one. Completion is completion, a thing done is a thing done so it has in it no quality of ending or beginning. Therefore in real life it is the crime and as the newspaper has to feel about it as if it were in the act of seeing or doing it, they cannot really take on detecting they can only take on the crime, they cannot take on anything that takes on beginning and ending and in the detecting end of detective stories there is nothing but going on beginning and ending. Anybody does naturally feel that that a detective is just that that a detective is just that that it is a continuity of beginning and ending and reality nothing but that. (42)

I will resist the impulse to comment on this passage since it is composed in such a way as to collapse the distinction between its form and its semantic content on which the possibility of commentary pretending to clarify what the passage "means" is based. But as I was first revising this essay, the newspapers were filled with accounts of another "trial of the century," in this case, preliminary hearings in the case of a famous African American athlete and movie personality, O. J. Simpson, suspected of brutally murdering his (white) wife (mother of his two children) and her male companion (a male model and aspiring actor, white and Jewish). These court proceedings were themselves preceded by a bizarre incident in which Simpson, apparently contemplating escape from the country, led police on a slow-moving "chase" on the freeways of Los Angeles to the accompaniment of television cameras, nationwide radio and TV coverage, and the same kind of commentary as that which attended the explosion of the Challenger or the very athletic events in which Simpson had made his fortune. Few events of such notoriety have been so amply documented as this chase, which featured live spectators who had rushed to the route of the flight to cheer Simpson, thereby being transformed into actors in the scene by the television camera's eye.

What is the inside and what the outside of this event? What the beginning and what the end? Although the trial of Simpson was intended to determine the specific role played by him in the commission of the crime of double murder, it is evident that this trial was another event rather than a continuation of the event that occasioned it. Interestingly, the prosecuting attorneys announced that they would not seek the death penalty for Simpson if he were convicted of the crime, indicating that, given the American public's affection for this hero, any effort to seek the death penalty would 
prejudice the possibility of a jury's convicting him. The crime-event was already being detached from the trial-event, almost as if to suggest that they belonged to different universes of occurrence. In fact, the trial had the purpose of providing a scenario compatible with a commonplace of the discourse of justice, namely, that everyone is equal under the law but that the law of the rich and famous is one thing and that of the poor and obscure quite another. 


\section{AuERBACH'S Literary History Figural Causation and Modernist Historicism}

In the preface to The Political Unconscious, Fredric Jameson remarked that "of literary history today we may observe that its task is at one with that proposed by Louis Althusser for historiography in general: not to elaborate some achieved and lifelike simulacrum of its supposed object, but rather to 'produce' the latter's 'concept." "I Jameson then went on to cite Auerbach's Mimesis as an example of the kind of work he had in mind. "This is indeed what the greatest modern or modernizing literary histories - such as Erich Auerbach's Mimesis - have sought to do, in their critical practice, if not in their theory." In this essay, I intend to follow out the line of thought adumbrated by Jameson and to inquire into the concept of literary history elaborated in Auerbach's work, and especially in Mimesis. I shall argue that Auerbach advances a distinctively modernist version of that historicism of which he was both historian and theoretician and that Mimesis itself consists of an application of this modernist historicism to the history of Western literature. ${ }^{2}$ Finally, I will suggest that the notion of figural causation might provide a key to an understanding of what is distinctively historicist and modernist in Auerbach's concept of literary history, if not of history in general.

If Mimesis is - as Jameson averred - an example of an attempt to produce literary history's concept, the concept in question is a peculiarly aesthetic one. In Mimesis, the specific content of the history of Western literary realism is shown to consist in the figure of "figurality" itself and its "idea" to inhere within the notion of the progressive fulfillment (Erfüllung) of that 
figure. In a word, Mimesis presents Western literary history as a story of the fulfillment of the figure of figurality. ${ }^{3}$ This is only to say that Western literature's concept consists in the recognition that every representation (Vorstellung) is also a presentation (Darstellung) and, as such, inspires Western writers to the development of a practice of stylistic innovation ever better adapted to the depiction of a reality as various in its forms as it is multiple in its meanings. The history of Western literature displays an ever fuller consciousness of Western literature's unique project, which is nothing other than the fulfillment of its unique promise to represent reality realistically. And because this reality is construed as consisting of a human nature that is historically inflected, the history of its representation can never come to a definitive closure or end, any more than its ultimate origin can be identified. ${ }^{4}$ Thus, although the history of Western literature displays the plot structure of a redemption, this redemption takes the form less of a fulfillment of a promise than of an ever renewed promise of fulfillment.

The notion of fulfillment is crucial for understanding the peculiar nature of Auerbach's conception of historical redemption. It provides him with a modern equivalent of classical telos and a secular equivalent of Christian apocalypse. It allows him to endow history with the meaning of a progressus toward a goal that is never ultimately realizable nor even fully specifiable. It gives him a concept of a peculiarly historical mode of causation, different from ancient teleological notions, on the one side, and modern scientific, mechanistic notions, on the other. This distinctively historical mode of causation I propose to call figural causation. It informs the process in which humanity makes itself through its unique capacity to fulfill the multiple figures in which and by which reality is at once represented as an object for contemplation and presented as a prize, a pretium, an object of desire worthy of the human effort to comprehend and control it.

Evfüllung must here be understood as a kind of anomalous, nondetermining causal force or ateleological end. A fulfillment is not the determined effect of a prior cause, the teleologically governed realization of an inherent potential, or the Hegelian actualization (Verwicklichung) of an informing notion (Begriff). The kind of Er-füllung envisaged by Auerbach is the kind suggested by such synonymous prefixed lexemes as English per-formance, con-summation, com-pliance, ac-complishment, and the like, all of which are suggestive of the kinds of actions of which morally responsible persons are thought to be capable, actions such as fulfilling a promise, cleaving to the terms of an oath, carrying out assumed duties, remaining faithful to a friend, and the like. In this respect, then, to say, for example, that a given 
historical event is a fulfillment of an earlier one is not to say that the prior event caused or determined the later event or that the later event is the actualization or effect of the prior one. It is to say that historical events can be related to one another in the way that a figure is related to its fulfillment in a narrative or a poem. The fulfillment of a figure over the course of a given period of time or narrative diachrony is not predictable on the basis of whatever might be known about the figure itself apart from its fulfilled form. No more could one predict that a promise will necessarily be fulfilled on the basis of whatever might be known about the person who made the promise. For while it is true that a promise could not be fulfilled unless it had first been made, the making of a promise itself is only a necessary, not a sufficient condition for the fulfillment thereof. This is why the making of a promise can be deduced retrospectively from a fulfillment, but a fulfillment cannot be inferred prospectively from the making of a promise.

And so it is with the relationships between the kinds of event we wish to call historical as against, say, natural events. A given historical event can be viewed as the fulfillment of an earlier and apparently utterly unconnected event when the agents responsible for the occurrence of the later event link it "genealogically" to the earlier one. ${ }^{5}$ The linkage between historical events of this kind is neither causal nor genetic. For example, there is no necessity at all governing the relation between, say, Italian Renaissance culture and classical Greek-Latin civilization. The relationships between the earlier and the later phenomena are purely retrospective, consisting of the decisions on the parts of a number of historical agents, from the time of Dante or thereabouts on into the sixteenth century, to choose to regard themselves and their cultural endowment as if they had actually descended from the earlier prototype. ${ }^{6}$ The linkage is established from the point in time experienced as a present to a past, not, as in genetic relationships, from the past to the present. To view an event such as the Italian Renaissance as a fulfillment of the much earlier Greek-Latin culture (and that whole series of other renascences which preceded the Italian Renaissance, from the eighth through the twelfth centuries) is to direct attention to what is new and original in Renaissance culture rather than to what is old and traditional about it. To be sure, the fifteenth-century Italian Renaissance was one in that series of renascences whose occurrence established the possibility of the fifteenthcentury version thereof. In this sense, the fifteenth-century Renaissance repeats those earlier ones, but with important differences: the choices of the specific aspects of Greek-Latin culture that will serve as putative ancestors of the Italian Renaissance revivalists are unique to this later period. These 
choices, taken in their entirety, not only define the nature of the fifteenthcentury Renaissance but retrospectively redefine the nature of the earlier Greek-Latin cultural model, which is now constituted as a figure that achieves a (new) fulfillment in a later affiliation.

We can deduce the occurrence of the earlier event insofar as it is linked by necessity to the later one: there could not have been any revival of GreekLatin culture had there not already been such a culture to revive. So, too, we can use the earlier event to illuminate the later event insofar as the later one fulfills the earlier. But fulfillment must be understood on the analogy of a specifically aesthetic rather than a theological model of figuralism. Thus, for example, the exodus of the ancient Hebrews from Egypt as related in the Old Testament was traditionally treated by medieval biblical exegetes as a figure that was fulfilled in the liberation of humanity from the Old Law promised in the New Testament; but this is an example of a theological and specifically Christian expropriation of Hebrew religion. There are no objective grounds for linking the two events as elements of the same historical sequence; and indeed, modern Jewish exegetes quite explicitly reject this interpretation of the meaning of the earlier event. In fact, the only historical ground for viewing the liberation from the Law stressed by St. Paul especially as having been prefigured in the flight from Egypt consists in the long process of expropriation of the Hebrew Bible by its Christian interpreters since the time of St. Paul himself. Which is to say that figuralism has its own history - as Auerbach pointed out in both Mimesis and the wellknown essay "Figura" a number of times. The Christian interpreters view the relation between the earlier and the later events as genetic and causal, as willed by God and therefore providential. The aesthetic conception of the relation places the principal weight of meaning on the act of retrospective appropriation of an earlier event by the treatment of it as a figure of a later one. It is not a matter of factuality; the facts of the earlier event remain the same even after appropriation. What has changed is the relationship that agents of a later time retrospectively establish with the earlier event as an element in their own past - a past on the basis of which a specific present is defined.

It is in this sense that later events in the history of literature are to be viewed, in Auerbachian terms, as fulfillments of earlier ones. The later events are not caused by the earlier ones, certainly are not determined by them. Nor are the later events predictable on any grounds of teleology as realizations of earlier potentialities. They are related in the way that a rhetorical figure, such as a pun or metaphor, appearing in an early passage of a 
text might be related to another figure, such as a catachresis or irony, appearing in a later passage - in the way that a premise of a joke is fulfilled in its punch line, or the conflicts in an opening scene of a play are fulfilled in its ending. The later figure fulfills the earlier by repeating the elements thereof, but with a difference.

The model is most pertinently utilizable in the study of literary styles and genres. Thus, for example, the relationships obtaining among the Homeric, Virgilian, and Dantean kinds of epic (as well as the relationship between these three and the early modern novel) constitute a sequence of figure fulfillment relationships. And so, too, for the relationships that Auerbach posits among the various incarnations or instantiations of the tradition of realistic representation, from the Gospels and the sermo bumilis, through Dantean figural realism, down to aesthetic historism, Romantic figuralism, historistic realism, and modernism. ${ }^{7}$

What I have been suggesting is that Auerbach's Mimesis not only is a history of a specific kind of literary representation, that is, figuralism, but is also a history conceived as a sequence of figure-fulfillment relationships. In other words, the figure-fulfillment model is used by Auerbach to provide the diachronic plot of the history of Western literature. It provides the principle of mediation between successive periods of literary history or at least between successive periods within a common tradition of literary practice. Indeed, it would appear that, in his view, an actual figure-fulfillmentfigure relationship, a genealogical relationship of successive expropriations, is what constitutes a tradition as such. The figure-fulfillment model is, therefore, a model for comprehending the syntagmatic dimensions of historical happening and for constructing the narrative line for the presentation of that history.

But what about the paradigmatic or synchronic dimension of literary history? If Auerbach uses the figure-fulfillment model as a way of delineating periods in the evolution of literary realism, how does he conceptualize relationships intrinsic to a given period, such questions as those of the integrity and coherence of an age, epoch, or era, that of the text-context relationship, and more specifically, the representative nature of the text? To put it in Jameson's terms once again, here the problem of representation takes precedence over that of presentation. In what sense can a text be said to represent the period or the context in which it was composed?

The text-context relationship is a problem that formalisms typically moot and the various historicisms treat as having been resolved in the theory of reflection. For example, an older Marxist criticism typically posited 
the sociohistorical context in terms of class membership, class structure, class conflict, and so on, and then proceeded to look for reflected images of this context in the literary text. The relative realism or ideological deformation of a given literary representation was then to be measured in terms of the extent to which the context thus posited was adequately - veraciously or undistortedly - reflected in the text. The text itself was considered to have no special illuminative function; its status as evidence of the historical period in which it was produced resided in the extent to which it confirmed evidence found in nonliterary, documentary sources.

For Auerbach, on the other hand, the literary text appears as a synecdoche of its context, which is to say it is a particular kind of a fulfillment of the figure of the context. In his actual hermeneutic practice, Auerbach tends to present the text as a representation not so much of its social, political, and economic milieus as of its author's experience of those milieus; and as such, the text appears or is presented as a fulfillment of a figure of this experience.

In this case, the relationship of the figure (the author's experience of the context) to its fulfillment (the text) is that of the implicit to the explicit. It is exactly the kind of relationship that, according to Auerbach, Balzac posits in Le Père Goriot between Mme. Vauquer and the pension over which she presides as patronne. Thus, Auerbach quotes Balzac, who says of Mme. Vauquer's relationship to her milieu: "Enfin toute sa personne explique la pension, comme la pension implique sa personne."8 This relationship of the implicit to the explicit, is not, Auerbach stresses in his comment on the Balzac passage, logical; the one term of the relationship is not deducible from the other: "The entire description [of Mme. Vauquer and her pension] is directed at the mimetic imagination of the reader ...; the thesis of the stylistic unity of the milieu, which includes the people in it, is not established rationally but is represented [vorgestellt] as a striking and immediately apprehended state of things, purely suggestively, without any proof" (47I; 439).

The representation is structured by what Auerbach calls "einem Hauptmotiv, ... das Motiv der Harmonie zwischen ihrer Person einerseits und dem Raum, ... der Pension, etc., . . . anderseits" (470; 438). This "harmony thesis," as Auerbach calls it, is simply presupposed (vorausgesetzt) by Balzac; it appears in the form of "merely suggestive comparisons, not proofs nor even beginnings of proof $(47 \mathrm{I} ; 439)$. Thus, Auerbach concludes, "What confronts us [in the passage from Balzac] is the unity of a particular milieu, felt as a total concept of a demonic-organic nature and presented entirely by suggestive and sensory means" $(472)$. This does not mean that 
Balzac's realism is superior to other or earlier forms of representation. It is simply different, and different because it is itself a product (ein Erzengnis) of its period (Epoche), which is to say, Auerbach adds, that Balzac's realism "is itself a part and a result of an atmosphere" (473; 44I; my emphases).

"A part and a result of an atmosphere": it might seem that Balzac has mystified the fundamental relationships between author and milieu, author and text, text and context, and the parts and the whole of any context by using the metaphor of atmosphere to describe a period. What could be murkier? But just after he has remarked on the cogency of this notion of atmosphere, he continues, "It is far more difficult to describe with any accuracy the intellectual attitude which dominates Balzac's own particular manner of presentation" (474). This is because, Auerbach says, Balzac's temperament ("emotional, fiery, and uncritical") is itself a fulfillment of a milieu grasped by Balzac himself as an umbra and imago. Balzac "bombastically takes every entanglement as tragic, every urge as a great passion; he is always ready to declare every person in misfortune a hero or a saint; if it is a woman he compares her to an angel or the Madonna; every energetic scoundrel, ... he converts into a demon, etc." (482; 449).

This tendency "to sense hidden demonic forces everywhere and to exaggerate expression to the point of melodrama" is taken to be "in conformity with" (es entsprach) the temperament of the author, on the one side, and "the Romantic way of life," on the other $(582 ; 449)$. That is to say, Balzac's style - which unites a specific generic form or mode (melodrama) with a distinct content ("demonic forces") - is itself a figura that unites his milieu with his work as an imago to a veritas.

Thus, what is most characteristic of Auerbach's concept of literary history is the way he uses the figuralist model to explicate not only the relation between various literary texts but also the relation between literature and its historical contexts. For him, the representative literary text may be at once (I) a fulfillment of a previous text and (2) a potential prefiguration of some later text, but also (3) a figuration of its author's experience of a historical milieu, and therefore (4) a fulfillment of a prefiguration of a piece of historical reality. In other words, it is not a matter of an author having an experience of a historical milieu and then representing it, in a figurative way, in his text. On the contrary, the experience is already a figure and, insofar as it will serve as a content or referent of a further representation, it is a prefiguration that is fulfilled only in a literary text.

Thus, if what Auerbach called Figuralstruktur serves as a model for transforming a series of literary periods into a sequence of figures and their 
fulfillments, thereby providing the paradigm for a mapping of the syntagmatic axis of historical happening, so, too, does it serve as a model for characterizing the relation between a specific text and a period style, on the one hand, and the style of a text and its context, on the other. The linkage between a prefigurative aspect of a given culture (a text, a style, a period) and its fulfilled form is suggested by mere similarity - of their forms, their contents, or the relations obtaining between forms and contents. But the perception and subsequent demonstration of a general similarity, such as between, say, Dante's figural realism and Balzac's atmospheric realism, do not end the analysis. The two terms linked by similarity or resemblance must be subjected to a double articulation: the earlier terms must themselves be shown to be fulfillments of even earlier figures and the later terms shown to be prefigurations of even later styles.

Moreover, the figure that is implicit in one and explicit in the other must be named and the modality of their relationship specified. The later terms in a series of presentations (Darstellungen) have an explanatory function vis-à-vis the earlier ones: the later terms complete, consummate, or otherwise explicate the earlier ones in the way, for example, that Balzac's atmospheric realism can be said to complete, consummate, or explicate Dante's figural realism. By the same token, however, the earlier term explains the later one insofar as it serves as a necessary precondition of the latter. But not a sufficient precondition, because this could be provided only by the particular temperament of a specific author in which a milieu is converted into a figure by the poetic imagination. ${ }^{9}$

On the face of it, Mimesis: Dargestellte Wirklichkeit in der abendländischen Literatur is a historical treatment of the ways in which reality (Wirklichkeit) has been presented (dargestellte) in Western literary discourse. ${ }^{10}$ But the subject of this history, named in the title as mimesis ("imitation"), is not to be understood as the effort to produce a verbal mirror image of some extraverbal reality. Rather, Auerbach writes the history of mimesis as a story of the development of a specific kind of figuration; and he seeks to document - by offering a series of specific examples - the transformations in the dominant modes of mimesis as figuration in Western literary discourse from the time of the Evangelists to the middle of the twentieth century. ${ }^{11}$

There is nothing very mysterious about the idea of mimesis as figuration. Auerbach's idea of figuration is based upon Christian interpretations of ancient Judaism as an anticipation or prolepsis of Christianity. According to the Christian exegetes, those personages, events, and actions reported in the Old Testament are to be understood as having both a literal and a figurative dimension. On the one hand, they are to be apprehended as real 
and not merely as fictions. On the other, they are to be apprehended as indicators of yet-to-come personages, events, and actions that will fulfillthat is, both complete and reveal - the relevance of the earlier ones to the promised revelation of God's will and purpose for His Creation. This notion of a real event that was complete in itself and full in its meaning at the moment of its happening but was at the same time the bearer of a meaning that would be revealed only in a different and equally complete event at a later time supplied Auerbach with a model for conceptualizing the relationships among specifically historical events. The relationships in question are of the kind that, since Nietzsche, have come to be called genealogical.

The Christian schema of the figure and its fulfillment (used by Christian thinkers to interpret the relation between the Old Testament and the New, between Judaism and Christianity, between this world and the beyond, between the present and the future, and [in Dante] even between paganism and Christianity) is grasped by Auerbach as itself a figure that will be fulfilled in the modern idea of history. Indeed, Auerbach holds that history is precisely that mode of existence in which events can be at once fulfillments of earlier events and figures of later ones. Such a schema provided him with a way of characterizing the peculiar combination of novelty and continuity which distinguished historical from natural existence. This combination was a mystery for both Aristotelian teleology and Newtonian physical science, both of which could conceive of causation as going in one direction only, from a cause to its effect and from an earlier to a later moment. The truth contained latently in the idea of God's purpose being revealed in the schema of figure and fulfillment was that the meaning of events happening in present history is contained precisely in what they reveal about certain earlier events to which they may bear no causal or genetic relationship whatsoever. Their relationship is genealogical insofar as the agents responsible for the occurrence of the later event will have chosen the earlier event as an element of the later event's genealogy.

Thus, for example, in The Eighteenth Brumaire of Lonis Buonaparte, Marx does not suggest that the French revolution of (February) I 848 was caused in any mechanistic way by the French Revolution of 1789 . Nor does he represent the two revolutions as related genetically. The later revolution is affiliated genealogically with the earlier one inasmuch as the agents responsible for the later one identify their revolution (however justly or unjustly) as a completion of the earlier one. When Marx says that, in biological evolution, it is man that explains the monkey, rather than the other way around, he is advancing a distinctively historicist way of relating the later to an earlier phenomenon. Similarly, in historical evolution, the revo- 
lution of I 789 may have been an effect of, say, the Protestant Reformation or the Enlightenment and, as such, an ending of a process rather than a prefiguration of events yet to come. ${ }^{12}$ But as a historical event, it remains open to retrospective appropriation by any later group that may choose it as the legitimating prototype of its own project of self-making and hence an element of its genealogy.

In Mimesis, figuralism is presented as an enormously difficult, profound, but above all, characteristic achievement of Western culture, emerging in the Gospels' notion of the seriousness, even tragic nature of the lives of ordinary human beings, extending through Dante, the Renaissance, Rousseau, the atmospheric realism of Balzac, and the descriptivism of Flaubert, down to the modernism of Woolf, Proust, and Joyce in the twentieth century. ${ }^{13}$ Obviously, Auerbach wished to write a historical account of that attitude or worldview known as realism, which arose in the West and infused the dominant stream not only of modern Western literature but also of Western (Baconian) science and (bourgeois) historiography. ${ }^{14} \mathrm{He}$ wished to account for the fact that Western culture sought in particular to resist surrendering to the "blooming buzzing confusion" of mere sense data, on the one side, without falling prey to the transcendentalizing impulses of religion and Platonic philosophy, on the other. ${ }^{15}$ For him, it was figuralism that accounted for Western culture's unique achievement of identifying reality as history.

In what sense can it be said, then, that Auerbach's work, and Mimesis especially, contributed to the production of a concept of literary history specifically modernist (modern or modernizing) in kind?

Superficially, of course, Auerbach's own literary historiography, especially as represented by Mimesis, incarnates the historicist position of which he was both a theoretician and historian. Indeed, in many respects, the doctrine of historicism is the key to the understanding of his history of literary realism. The growth of realism in Western literature is chronicled by Auerbach in Mimesis as coextensive and even synonymous with the growth of that historicist point of view which crystallized in Germany at the beginning of the nineteenth century. ${ }^{16}$ At one point, he even states that literary realism, as represented by Balzac, is nothing other than a product of the specifically historicist impulse to view "the present as history." Viewing social reality under the aspect of history was what Western literature had been working toward since the representation in the Gospels of the "tragic seriousness" of the everyday life of ordinary human beings and the dissolution of a sense of qualitative differences among members of different social classes that this representation implied. Historicism was nothing other than 
the discovery that human life and society found whatever meaning they might possess in history, not in any metaphysical beyond or transcendental religious realm. Literary realism in its classic, nineteenth-century incarnation was the application of this perspective to the representation of present social reality. Thus, Auerbach could write in Mimesis:

When people realize that epochs and societies are not to be judged in terms of a pattern concept of what is desirable absolutely speaking but rather in terms of their own premises; when people reckon among such premises not only natural factors like climate and soil but also the intellectual and historical factors; when, in other words, they come to develop a sense of historical dynamics, of the incomparability of historical phenomena and of their constant inner mobility; when they come to appreciate the vital unity of individual epochs, so that each epoch appears as a whole whose character is reflected in each of its manifestations; when, finally, they accept the conviction that the meaning of events cannot be grasped in abstract and general forms of cognition and that the material needed to understand it must not be sought exclusively in the upper strata of society and in major political events but also in art, economy, material and intellectual culture, in the depths of the workaday world and its men and women, because it is only there that one can grasp what is unique, what is animated by inner forces, and what, in both a more concrete and a more profound sense, is universally valid: then it is to be expected that those insights will also be transferred to the present and that, in consequence, the present too will be seen as incomparable and unique, as animated by inner forces and in a constant state of development; in other words, as a piece of history, whose everyday depths and total inner structure lay claim to our interest both in their origins and in the direction taken by their development. Now, we know that the insights which I have just enumerated and which, taken all together, represent the intellectual trend known as Historism. (443-44)

A realist literary criticism would apply this perspective in the study of literary texts. That is to say, it would find the meaning of a literary text in its relations to a historical context, not to some Platonic archetype of literature or art or beauty nor to any changeless canon of classics which putatively incarnated the essence of literarity. And surely this is what Auerbach sought to do in that series of diachronic contextualizations of specific literary texts which comprises the manifest content of Mimesis.

It must be recalled, however, that Auerbach historicizes historicism itself in the same way that he historicizes realism. He does not treat histor- 
icism as a transcendental perspective on human reality. It is a specifically eighteenth- and nineteenth-century Weltanschaumng, whose meaning and authority were intimately linked to a social system (a society of classes), political apparatus (that of the emerging nation-states), and cultural endowment (that of a revised, classical humanism) which would sustain fatal blows in the first half of the twentieth century. If he regarded historicism as a progressive, even lastingly valuable moment in the history of Western culture, he also recognized that historicism itself had a history. Like realism itself, historicism would undergo transmutations and metamorphoses, as its contexts - social, political, cultural-changed. And indeed, in the famous last chapter of Mimesis, "Der braune Strumpf," in which he tries to divine the relation between literary modernism (Joyce, Woolf, Proust) and realism (Stendhal, Balzac, Flaubert), Auerbach posits a form of modernist historicism so radically different from its nineteenth-century prototype as to appear to consist of a repudiation of history itself. But, as Auerbach makes quite clear in a passage (548) in which he likens his own method of textual analysis to the style of Virginia Woolf, it remains possible to be a modernist and a historicist at the same time. It requires only a different way of construing the field of historical occurrences or, at least, the field of literary-historical events. And it turns out that, when viewed from the perspective provided by Auerbach's analysis of literary modernism, his history of "the representation of reality in Western literature" is an example of this very modernist historicism. In Mimesis, Auerbach produces the concept of a distinctively modernist historicist literary history.

The manifest story told by Auerbach is of the twofold order of changes that have taken place in the relations between the classical hierarchy of literary ${ }^{17}$ (poetic or discursive) styles (high, middle, and low or humble) and genres (tragedy, comedy, epic, romance, novel, history, essay, satire), on the one side, and a social reality in which people are divided into classes and treated as more or less human and consequently considered to be more or less worthy of being represented as the subjects of these styles and genres, on the other. On the manifest level, the story works out very well indeed: in the literary practice of the West, the styles are progressively defetishized, democratized, and mixed, and the human subject is progressively declassed and even - so the famous analysis of a passage from To the Lighthouse suggests - degendered. Thus, the various periods in the history of Western literary realism can be defined in terms of their characteristic mixtures of styles and of the extent to which they succeed in grasping the content of history as a social reality delivered from class division. 
However, running across this periodization and uniting its parts into a larger whole at the level of plot or dianoia is an account of the filling out, exfoliation, or elaboration of a specifically figural conception of the relations among those things that inhabit history. Indeed, if, in many respects, Mimesis is ultimately the story of how Western literature came to grasp historicity as humanity's distinctive mode of being in the world, this mode of being in the world is represented as one in which individuals, events, institutions, and (obviously) discourses are apprehended as bearing a distinctively figural relationship to one another. Unlike other natural things, which are related to one another only by material causality, historical things are related to one another as elements of structures of figuration (Figuralstrukturen). This means that things historical can be apprehended in their historicity only insofar as they can be grasped as elements of wholes that, in both their synchronic and diachronic dimensions, are related as linguistic figures are related to their fulfillments. This particular insight and this particular concept of historicity inform the specifically modernist version of literary realism as represented by Joyce, Woolf, and Proust in Mimesis.

Auerbach is quite explicit in characterizing modernism as a kind of fulfillment of rather than as a reaction to earlier realisms. ${ }^{18}$ Auerbach does not present literary modernism as a flight from history. To be sure, Auerbach's characterization of modernism's principal stylistic and semantic features amounts to a claim that it has transcended nineteenth-century historicism. But it seems to me that Auerbach interprets modernism as a further development of nineteenth-century realism, hence as a fulfillment of nineteenth-century realism's identification of reality with history - and hence as a further elaboration of the notion of history itself. What appears to be a rejection of history is a further elaboration of its nineteenthcentury form, which now appears as a figure beginning to be fulfilled in mid-twentieth century. ${ }^{19}$ It is not history that is being rejected but the nineteenth-century form of it.

As thus envisaged, modernism effects the closure of the gap between history and the premodernist version of literature called fiction. The rigid opposition between history and fiction which authorizes the nineteenthcentury, historicist idea of history, in which the term history names both reality and the very criterion of realism in representational practices, is canceled in modernism's implicit critique of nineteenth-century notions of reality and its rejection of nineteenth-century realism's idea of what realistic representation consisted of. In modernism, literature takes shape as a manner of writing which effectively transcends the older oppositions between 
the literal and the figurative dimensions of language, on the one hand, and between the factual and fictional modes of discourse, on the other. Consequently, modernism is to be seen as setting aside as well the longstanding distinction between history and fiction, not in order to collapse one into the other but in order to image a historical reality purged of the myths of such "grand narratives" as fate, providence, Geist, progress, the dialectic, and even the myth of the final realization of realism itself.

Recall Auerbach's well-known summary of the characteristic features of the modernist style in his exegesis of a passage from Virginia Woolf's To the Lighthouse. Among the "distinguishing stylistic characteristics" of that modernism which the passage has been chosen to exemplify, Auerbach lists:

I. the disappearance of the "writer as narrator of objective facts; almost everything stated appears by way of reflection in the consciousness of the dramatis personae";

2. the dissolution of any "viewpoint ... outside the novel from which the people and events within it are observed, ...”;

3. the predominance of a "tone of doubt and questioning" in the narrator's interpretation of those events seemingly described in an objective manner;

4. the employment of such devices as "erlebte Rede, stream of consciousness, monologue intérieur" for "aesthetic purposes" that "obscure and obliterate the impression of an objective reality completely known to the author...";

5. The use of new techniques for the representation of the experience of time and temporality, for example, use of the "chance occasion" to release "processes of consciousness" which remain unconnected to a "specific subject of thought"; obliteration of the distinction between exterior and interior time; and representation of events not as "successive episodes of [a] story" but as random occurrences. (534-38)

This list of attributes does not, of course, describe the manifest level on which Mimesis unfolds. But Auerbach's suggestion that the technique of representation found in Woolf's work approximates to the method used in Mimesis for the analysis both of the structures of texts and of their relations to their contexts permits us to look for the similarities between Mimesis and the classic texts of literary modernism. 


\section{Freud's Tropology of Dreaming}

In chapter 6 of The Interpretation of Dreams, Freud discusses the ways in which libidinal impulses given an ideational expression in dream-thoughts (Gedanken) - the impulses motivating the dream-become transformed into a dream's manifest contents (Inhalte) - the symbols, scenes, and events that seem to occur in the dream. He identifies four operations in this process of transformation: condensation (Verdichtungsarbeit), displacement (Verschiebungsarbeit), (the means and considerations of) representability (Darstellbarkeit), ${ }^{1}$ and secondary revision (sekundäre Bearbeitung). These operations are not to be understood as tactics or defense mechanisms (Abwehrmechanismen) employed by the psyche to evade confrontation with a painful reality. A dream may display evidences of a desire to evade reality, for example, may show a tendency in the dreamer toward projection, regression, or the like; but in this chapter, Freud is concerned less with the defense mechanisms that the psyche may employ to evade reality than with the operations utilized by all dreamers for fashioning a specific "dream-content" out of the more primary dream-thoughts. In other words, whereas defense mechanisms are specifically evasive processes, the mechanisms of the dreamwork are, as it were, positive transformations in which libidinal impulses (expressed in the dream-thoughts) are made into figurative signifiers (the dream-contents) of those impulses. Thus, in the summary of this chapter, Freud concludes that the form of the dream, the dream as it is experienced, is fashioned by:

a) the displacement of psychical intensities to the point of a transvaluation of all psychical values; 
b) the imposition of considerations of presentability [Darstellbarkeit], by which thoughts are given visual or acoustical form;

c) the creation of greater intensities through condensation; and

d) an imposition of the appearance of logical relations among or distancing of the elements of the dream-contents through secondary revision. ${ }^{2}$

In his discussion of the dream-work, Freud shows a tendency to fuse one operation with another or to view them as working simultaneously on the material of the dream-thoughts. Some recent commentators have suggested the possibility of subsuming certain of the operations discriminated by Freud under others; Norman Holland, for example, has suggested that displacement is a master category, under which condensation and secondary revision can be subsumed. ${ }^{3}$ This is consistent with Freud's notion of the totalizing nature of the dream-work by which the psyche is able to enjoy the contemplation of the dream-thoughts while satisfying the censor, representative of moral consciousness. But Freud insists on the distinctions among the four operations of the dream-work and goes to considerable trouble to characterize each of them in its own terms. And we may ask, therefore, why Freud insists on four distinct operations for the dream-work. Why only four categories when modern commentators, in their efforts to identify the number of defense mechanisms utilized by the psyche, find as many as thirty-nine? ${ }^{4}$

I believe that what Freud has done in his reflections on the relations between the dream-content and its more basic dream-thoughts is to rediscover, or reinvent, the theory of tropes conventionally used by rhetoricians in his culture to characterize figurative language in general and to explicate the relation between literal and figurative meanings in poetic discourse specifically. The correspondence of two of the operations of the dream-work (condensation and displacement) to two of the tropes of figurative language (metaphor and metonymy, respectively) has been noted by Jakobson and fruitfully exploited by literary critics and social theorists already. ${ }^{5}$ But the full delineation of the analogies between the nineteenthcentury theory of the tropes and Freud's theory of the dream-work has not, to my knowledge, been attempted.

It is not, of course, a matter of influences. We do not have to suppose that Freud borrowed the ideas of some contemporary theorist of figurative language and imported them into his considerations of the dream-work. Such ideas were a part of the general culture that Freud would have imbibed especially in his early schooling, a large part of which consisted in 
training in rhetoric, composition, and eloquence, in spite of the bad light in which rhetoric was seen in the estimation of writers, scientists, and philosophers alike. Nor does the analogy between Freud's conception of the dream-work and the conventional theory of tropes detract at all from the theoretical validity or heuristic utility of the former. It matters little whether the operation by which the elements of a dream are charged with "greater intensities" is called metaphorization or condensation. Freud often speaks of the dream-work as being analogous to poetic discourse, and it is not therefore surprising that he found metaphorization present in it, whether he called it that or not. Moreover, his conception of the relation between the dream-thoughts and the dream-contents is precisely analogous to that form of poetic discourse which literary theorists and biblical exegetes call allegorization. ${ }^{6}$

The four operations identified by Freud function in the same way that the tropes do in allegory to mediate between the literal and the figurative levels of meaning of the text. By noting the precise similarities between the conventional theory of the tropes, on the one side, and the operations of the dream-work as postulated by Freud, on the other, we can not only comprehend why he insists on four operations (rather than some other number) but also, in the process, gain a clearer understanding of both the tropes and Freud's conception of the dream-work simultaneously.

It should be stressed that Freud had no way of observing the operations of the dream-work directly. He knows them only as their effects appear in the report of the dream given by the patient or, when it is a case of one of his own dreams, as these effects appear in his memory of the dream. He takes cognizance of this when he stresses that the same operations appear in the composition of the dream-report on waking as operated during the dream itself to effect the transformation of the dream-thoughts into the dream-contents. A number of levels of transformation are thus postulated between the libidinal impulses occasioning the dream and the final interpretation given of it by the analyst: impulse, dream-thoughts, censorship, repression, construction of the dream-contents, memory of the dream, the dreamer's spoken or written account of the dream, the analyst's analysis of the dream. The favored object of the interpretation is of course the dream-report (or the analyst's transcription of the report). On the basis of the contents of the report, the analyst then proceeds to reconstruct the dream-thoughts.

The deduction proceeds on the basis of the analyst's capacity to identify evidences of the operations of condensation, displacement, representa- 
tion, and secondary revision. Having identified these evidences, the analyst proceeds to determine the specific impulses in the services of which they were employed. The nature of these impulses, in turn, is determined by appeal to the theory of the structure of the psyche which precedes, both logically and temporally in the evolution of Freud's own thought, the theory of the dream-work itself. One could, therefore, reject the theory of the dream-work without rejecting the theory of the structure of the psyche that precedes it, or the reverse. The Freudian theory of the psyche does not concern us here. We are concerned only with the theory of the dream-work and wish to determine the extent to which it corresponds to the theory of tropes and helps us better to understand this theory. For if Freud's theory of the dream-work is even minimally plausible, then we have a way of grounding the theory of tropes in a general theory of consciousness in which the relations between literal and figurative meaning in a host of fields of speculation, from anthropology to literary criticism and philosophy, can be explicated.

A trope is literally a "turn" or deviation from literal speech or the conventional meaning and order of words. The number of possible turns has never been determined definitively, but they include all of the figures of speech which the play of the categories of similarity and difference, spatial or temporal relationship, qualitative variation among members of a single species or genus, and contrastive inversion makes possible, from ablatio ("taking away") to zengma ("yoking").

Within the general category of figures of speech, however, it has been conventional since the Renaissance to discriminate among four principal modes of figuration and to classify figures of speech in terms of four fundamental categories: metaphor, metonymy, synecdoche, and irony. These categories or class names of the figures of speech are derived from the consideration of the mode of relationship presumed to sanction the conjunction or disjunction of entities or their qualities signified in the specific figure of speech employed. Thus, metaphor (literally, "transfer") is sanctioned by the presumption of some resemblance between any two or more objects conventionally classified as belonging to different species. Metonymy (literally, "name change") presupposes the spatial or temporal contiguity of the objects conflated in a reductive metaphor. Synecdoche (literally, "grasping together") presupposes the sharing of essential qualities behind or beneath manifest attributes of two or more entities. And irony (literally, "illusion") presupposes a fundamental contrast between things or qualities conventionally presumed to be affined or similar. 
Following the usage of post-Renaissance rhetoricians, therefore, I shall use the term trope to refer to the mode of relationship presupposed in the use of any given turn of speech and the term figure to refer to any specific turn in an utterance or discourse. In other words, the tropes will be the class names of generic categories of figures of speech. Thus, a catachresis (such as "blind mouths") is a figure of speech classified in the genus irony, because it gains its effect by playing upon the sense of contrast between eyes (to which the adjective blind might be conventionally applied) and mouths (which are not normally thought of as being blind). The force of the figure derives from the contrast between the expectation of what noun might follow the adjective blind (eyes) and the noun (mouths) actually used by Milton (in Lycidas) in this phrase. ${ }^{7}$ The revisionary aspect of this figure, to use Freud's term, derives from the retrospective reflection compelled by the conjunction of the noun mouths with the adjective blind. The total effect is to widen our appreciation of the force of both the adjective and the noun as signs and, at the same time, to bring under question implicitly the rule of usage which had formerly constrained us to use blind primarily with eyes, and mouths primarily with adjectives such as loud, silent, open, closed, and so on. In fact, blind in this context has the effect of suggesting both "unseeing" and "open" and either "vocal" or "mute," depending upon the secondary associations we bring to the words blind and mouths together.

I will pursue the discussion of the other tropes shortly. For the moment, I will concentrate on the analogies between the trope of irony and Freud's category of secondary revision in his discussion of the dream-work, since it is in this case that the similarities between rhetorical and Freudian concepts are most easily perceivable.

The principal example of secondary revision given by Freud is the dreamer's recognition during the dream that "this is only a dream" (my emphasis). ${ }^{8}$ Such a recognition occurs, he tells us, when the censor has been taken unawares and has let through, into the dream's manifest content, some "unacceptable material" ( $527 ; 400)$. In his discussion of other manifestations of secondary revision, Freud speaks about both what happens in the dream and what happens in the analysand's account of the dream, that is, the dream-report. Thus, for example, he notes the presence in what must obviously be the dream-report of interpolations introduced by the phrase as if ("it was as if I was descending an endless staircase") and additions to or subtractions from the original account of the dream. Secondary revision, Freud concludes, seeks to remold the dream material into "something like a day-dream" (530; 40I-2). 
This interpretation, addition, subtraction, or remolding presupposes a certain psychic distance from the dream experience and, moreover, a heightened psychic consciousness, an interplay of the sleeping and the waking worlds, where the critical faculties of the dreamer are brought into play, and the dream features are refashioned in the service of such waking values as logical consistency, propriety, consistency, coherency, and the rest (528$37 ; 400 \mathrm{ff}$.). Secondary revision is ironical in mode because it mediates between those manifest features of the dream which are identical with the dream-thoughts and the imperatives of the censor. It is ironical insofar as it takes a critical stance vis-à-vis the dream-contents. And it is ironical insofar as it seeks to substitute another, more "suitable" content for the offending one or else seeks to deny the significance of the dream in the process of dreaming ("this is only a dream").

As Laplanche and Pontalis point out, "secondary revision may be said to resemble rationalization." What is meant in ordinary parlance by rationalization may itself be termed ironical, insofar as the rationalizer is seeking to mediate between alternative accounts of the same set of phenomena, recognizes at least two possible accounts, and wishes both to defend the preferred version and negate or neutralize the distasteful one. As in daydreaming, so, too, in secondary revision, the psyche is simultaneously dreaming and directing the contours of the dream in response to wishfulfilling fantasies. There is present, then, in secondary revision as described by Freud, the same duality of referent characteristically met with in ironic discourse: to some manifest object, on the one side, and to a secondary, indirectly indicated object, on the other side.

That this ironical element is crucial to Freud's conception of the process that he calls secondary revision is further suggested by the kinds of example he cites to illustrate the process: the "joke" inscriptions on the Fliegende Blätter, intended to make a scramble of letters look like a Latin motto while really having a meaning only in German; and Havelock Ellis's earlier characterization of the process: "Sleeping consciousness we may even imagine as saying to itself in effect, 'Here comes our master, waking consciousness, who attaches such mighty importance to reason and logic and so forth. Quick! gather things up, put them in order - any order will do-before he enters to take possession" (539). The phrase that serves as an emblem of the whole process ("It is only a dream") is itself an example of the ironic figure of thought known as syncrisis (Latin, dissimulatio), or saying one thing and meaning another.

The correspondence of the mechanism of secondary revision to the 
trope of irony is easily seen, for the play of contrasts between manifest and latent meanings is most easily discerned in the operations of both processes: contrasts between the true and the false, the desirable and the undesirable, appearance and reality, the logical and the illogical. If Freud is right in his general analysis of the nature and function of dreams, then all dreams are ironical-saying one thing but meaning another, in the way that poetic allegories are ironical. And condensation, displacement, and representation may be said to function in the service of this generally ironic purpose. But there is a double irony in the process of secondary revision; for as Freud notes, this is a process that operates on materials already distorted through the working of the other mechanisms of dream formation. Freud's insistence that secondary revision not only works on preformed materials but also "operates simultaneously in a conductive and selective sense upon the mass of material present in the dream-thoughts" does not detract from the ironical nature of the process. On the contrary, this fact merely points to the similarity between the operations of the sleeping and the waking consciousness, in the latter of which irony is a primary, rather than secondary, function of discourse.

There can be no doubt, however, that Freud consigns to secondary revision and, a fortiori, to irony a second order of importance in comparison to the other mechanisms of condensation, displacement, and representation. This is suggested by his location of the operations of secondary revision on the threshold between waking and sleeping consciousness and his insistence on its predominance in that form of near-waking consciousness called daydreaming. Accordingly, we would be justified in concluding that from a Freudian perspective, this trope has to be accorded a privileged place in that form of conscious fiction making which includes art, speculative philosophy, poetry, all types of narrative, and even science-where systematization in response to some version of a reality principle is the conscious aim.

This is not to say, of course, that condensation, displacement, and representation do not have their place in waking thought. It is impossible to imagine it without them. Along with perception, they provide, as it were, the raw material out of which the waking consciousness makes its images of reality, which are then refined by secondary revisions more or less conscious and aim oriented. In the dream-work, however, the other operations are more important. The further we fall into dream-sleep, the less we revise; the less we revise, the more we allow the free play of primary figuration. Or, in Freud's terminology, the less "wakeful" we are in dreaming, the 
more easily we condense, displace, and represent in order to compose the structure of the dream-content.

Condensation is a process by which both the elements of the dream and the dream as a whole are charged or supercharged (overdetermined) with fictive force. Theorists of psychoanalysis now generally hold that the operations of this mechanism cannot be dissociated from those of the mechanism of displacement, since condensation occurs when a single idea comes to "represent several associated chains at whose point of intersection it is located." In other words, a condensation occurs along a diachronic axis at the point where a number of chains of displacements meet. In The Interpretation of Dreams, however, Freud stresses the compressing or compacting function of this mechanism: "Dreams are brief, meagre and laconic in comparison with the range and wealth of the dream-thoughts" (3 I3; 235). The dream-thoughts are packed or layered, creating an effect of depth along a vertical axis. Thus, Freud contrasts any written account of a dream which "may perhaps fill half a page" and the interpreter's analysis of it, setting out the dream-thoughts underlying it and possibly occupying "six, eight, or a dozen times as much space.” But condensation is not to be confused with mere reduction of the "size" of the dream or, for that matter, with omissions in the dream-report $(3 \mathrm{I} 5 ; 234)$. On the contrary, the examples Freud gives to elucidate the process of condensation (puns, neologisms, and slips of the tongue) and his insistence that "the work of condensation in dreams is seen at its clearest when it handles words and names" (330; 248) suggest that the concept of condensation represents Freud's reworking or rediscovery of the trope of metaphor.

In condensation, as in metaphor, it is the functioning of some third term, usually a shared attribute, which serves as the unspoken justification for the linking of two entities or events by the copula of equivalency. Just as the term beauty functions as the unspoken third term justifying the identification of the beloved with the rose in the metaphorical figure "My love is a rose" so, too, Freud, in his analysis of "The Dream of the Botanical Monograph," writes that the botanical monograph appearing in the dream "turned out to be an 'intermediate common entity' between the two experiences of the previous day: it was taken over unaltered from the indifferent impression and was linked with the psychically significant event by copious associative connections" (316;238). Moreover, he continues:

Not only the compound idea, "botanical monograph," however, but each of its components, "botanical" and "monograph" separately, led by numerous 
connecting paths deeper and deeper into the tangle of dream-thoughts. "Botanical" was related to the figure of Professor Gartner [Gardener], to the blooming looks of his wife, to my patient Flora and to the lady [Frau L.] of whom I had told the story of the forgotten flowers. Gartner led in turn to the laboratory and to my conversation with Königstein. My two patients [Flora and Frau L.] had been mentioned in the course of this conversation. A train of thought joined the lady with the flowers to my wife's favourite flowers and thence to the title of the monograph which I had seen for a moment during the day. In addition to these, "botanical" recalled an episode at my secondary school and an examination while I was at the University. A fresh topic touched upon in my conversation with Dr. Königstein - my favourite hobbies - was joined, through the intermediate link of what I jokingly called my favourite flower, the artichoke, with the train of thought proceeding from the forgotten flowers. Behind "artichokes" lay, on the one hand, my thoughts about Italy and, on the other hand, a scene from my childhood which was the opening of what have since become my intimate relations with books. Thus "botanical" was a regular nodal point in the dream. Numerous trains of thought converged upon it, which, as I can guarantee, had appropriately entered into the context of the conversation with Dr. Königstein. Here we find ourselves in a factory of thoughts where, as in the "weaver's masterpiece" -

\section{Ein Tritt tausend Fäden regt,}

Die Schifflein herüber hinüber schiessen,

Die Föden ungesehen fliessen,

Ein Schlag tausend Verbindungen schlagt.

\section{[A thousand threads one treadle throws}

Where fly the shuttles hither and thither

Unseen the threads are knit together

And an infinite combination grows.

-Bayard Taylor's translation of Goethe's Faust, pt. I, scene 4]

So, too, "monograph" in the dream touches upon two subjects: the onesidedness of my studies and the costliness of my favourite hobbies. The first investigation leads us to conclude that the elements "botanical" and "monograph" found their way into the content of the dream because they possessed copious contacts with the majority of the dream-thoughts, because that is to say, they constituted 'nodal points' upon which a great number of the dream- 
thoughts converged, and because they had several meanings in connection with the interpretation of the dream. The explanation of this fundamental fact can also be put in another way: each of the elements of the dream's content turns out to have been "overdetermined" - to have been represented in the dream-thoughts many times over. (316-I 8; 238-39; my emphases)

We may add: overdetermined in the way that any metaphor must be; for to assert the identity of two entities or events manifestly different, as one does in metaphor, is not only a negative evasion of the literal but also a positive joining of that which God or nature has put asunder. Such joining is inevitably overdetermined, as the effort to leap any gap must be. And if this is the case with a single metaphor, how much more so must it be the case with chains of metaphors which, in allegory as in dreams, represent not only condensations of individual elements but a condensation of all of these condensations.

Not only are the elements of a dream determined by the dream-thoughts many times over, but the individual dream-thoughts are represented in the dream by several elements. Associative paths lead from one element of the dream to several dream-thoughts, and from one dream-thought to several elements of the dream. Thus a dream is not constructed by each individual dream-thought, or group of dream-thoughts, finding (in abbreviated form) separate representation in the content of the dream - in the kind of way in which an electorate chooses parliamentary representatives; a dream is constructed, rather, by the whole mass of dream-thoughts being submitted to a sort of manipulative process in which those elements which have the most numerous and strongest supports acquire the right of entry into the dreamcontent - in a manner analogous to election by scrutin de liste [vote by list]. In the case of every dream which I have submitted to an analysis of this kind I have invariably found these same fundamental principles confirmed: the elements of the dream are constructed out of the whole mass of dream-thoughts and each one of those elements is shown to have been determined many times over in relation to the dream-thoughts. ( 3 I $8 ; 239-40)$

The crucial concept in this passage, for my purposes, is neither overdetermination nor determined but rather representation (Vertretung), for within this context it has a meaning quite different from that which it has in Freud's discussion of representability (Darstellbarkeit) conceived primarily as pictorialization or more generally visualization of thoughts, words, and 
ideas. He says that "the individual dream-thoughts are represented in the dream by several elements" which can be viewed as a kind of metaphorical conflation - in the way that Dante represents the Divine Presence in his Commedia. So, too, each individual element of the dream leads to "several dream-thoughts." This characterization of the twofold relationship between an individual element of the dream-contents and a host of dreamthoughts, on the one side, and between an individual dream-thought and several elements, on the other, conjures up a complex web of relationships that are all conflated in the manifestly archetypal function of the two images "botanical" and "monograph." They are metaphors of subsets of metaphors ("blooming looks," the names Flora and Gartner, "artichokes," "studies," "hobbies," and so forth) which have literal referents, certainly, but are themselves charged with secondary or figurative meanings as well. Condensation, in short, is Freud's term for those complex metaphors which gather other, simpler metaphorical images together into a chain of associations of the sort met with in allegory. His system gains in persuasive power by his invention of his own terminological system for designating the relationships between primary and secondary levels of dreams. But his characterization of those relationships is strictly analogous to that which conventional rhetoric designates as sanctioning the trope of metaphor and the construction of figures of thought by resemblance.

To be sure, Freud speaks only of "connecting paths," "trains of thought," "intermediate links," and so on, which relate one image to another in "the tangle of dream-thoughts." The elements "botanical" and "monograph" are said to have "found their way into the content of the dream" because they possessed "copious contacts with the majority of the dream-thoughts." This adds little to our understanding of the nature of these contacts - as little as the appositive clauses that follow it: "because, that is to say, they constituted 'nodal points' upon which a great number of dream-thoughts converged, and because they had several meanings in connection with the interpretation of the dream" (my emphases). It must be granted, however, that in Freud's characterization of the process, what he calls "trains of thought" are formed by chains of figures of speech which are both metaphorical and metonymical in nature.

Thus, for example, some of the connections are provided by the apprehension of generic similarities apprehended across species differences, that is, in the mode of metaphor. "Professor Gartner," "the blooming looks" of his wife, Freud's patient "Flora," "his wife's favourite flowers," and the "title of the monograph" are generically related by virtue of their shared 
florality. But florality is a species attribute only of the name of Freud's patient and those flowers actually favored by Freud's wife. Gartner, however, is related to flowers only as a gardener is related to flowers, that is, by contiguity rather than resemblance. Similarly, the "title of the monograph" is related to flowers only insofar as botany includes, among other things, the study of flowering plants, thus by a metonymy that characterizes a whole scientific discipline by only one of its objects of study.

We can say, then, that Freud, in his analysis of the dream, offers a chain of metaphors (connections made on the basis of resemblance) and metonymies (connections made on the basis of contiguity) which he interprets in the mode of metaphor alone. He assumes that all of the connections are formed by apprehensions of a resemblance to the "botanical monograph" which "turned out to be the 'intermediate common entity' between the two experiences of the previous day" (3I6). In his view, all of the metaphors in the dream were associated by their resemblance to that common entity. As we have seen, however, his examples include both metaphors and metonymies.

Before proceeding to an analysis of Freud's conception of displacement, it will be well to point out an ambiguity in the terminology of conventional rhetorical theory. As I noted earlier, the terms metaphor, metonymy, synecdoche, and irony function in this theory both as names of specific figures of speech and as names of classes of figures of speech. Thus, for example, "roseate dawn" is a metaphor and "fifty sails" (for "fifty ships") is a metonymy; but a paranomasia or pun (flower =flour) is metaphorical because its effect is based on the resemblance between two words; whereas an antonomasia, in which a proper name is substituted for a quality associated with the person bearing it (Jovian head=godlike head) is metonymical, because it is based on the contiguity of the name and a quality.

The ambiguity of these terms is heightened by the fact that in common usage the word metaphor is employed to designate figures of speech in general, and the adjective metaphorical is used to characterize any figurative usage. Thus, metonymy, synecdoche, and irony are all commonly called metaphorical, and so they are inasmuch as they consist of the transfer (Latin, translatio) of the name or word for one thing to some other thing. What should be borne in mind, however, in distinguishing between a given figure of speech and the class of figures to which it may be assigned is the modality presumed to characterize the relationship existing between the entities designated by the names or words being exchanged. If the transfer is effected on the presumption of the resemblance between the things being 
compared, the resultant figure of speech will be classified as a metaphor; if on the basis of their spatial or temporal contiguity, as metonymy; if on the basis of shared essential qualities, as synecdoche; and if on the basis of a suggested contrast in the face of apparent similarity, as irony.

These considerations permit us to distinguish between specific kinds of figuration present in a dream-content and the general process by which a set of figurations condenses the dream-content out of the dream-thoughtor conversely, gather up the dream-thoughts under the aegis of a specific element of the dream-content. This general process functions in the mode of metaphor, "metafiguratively", as it were, gathering specific figurations together under the sign of resemblance and fusing them into the structure of the manifest form of the dream-content.

Condensation, like metaphor, functions synchronically - operating on the vertical axis of the dream structure, correlating the surface and deep levels of the dream. Displacement, by contrast, functions diachronically, operating on the horizontal axis of the dream narrative, in order to effect variations in the intensities of condensation at different places within the total structure. Freud states as much: "The dream [content] is . . differently centered from the dream-thoughts - its content has different elements as its central point." Thus, "in the dream of the botanical monograph, ... the central point of the dream-content was obviously the element 'botanical'; whereas the dream-thoughts were concerned with the complications arising between colleagues from their professional obligations, and further with the charge that I was in the habit of sacrificing too much for the sake of my hobbies" (340). This decentering of principal elements of the dream-thoughts in the dream-contents, a process that seems to act contrary to the process of condensation effecting overdetermination (i.e., as a kind of underdetermination), Freud calls displacement. Freud gives comparatively little space in The Interpretation of Dreams to the mechanism of displacement, but in his summary of chapter 6, he attributes to this mechanism the power to effect "a transvaluation [Umwertung] of all psychical values" $(545 ; 4 \mathrm{I} 3)$.

Certainly, Freud seems to conceive displacement within the context of what Laplanche and Pontalis call "the hypothesis of a cathectic energy 'capable of increase, diminution, displacement and discharges,' " that is, as a kind of electrical field across which energy charges flow, collect, and fuse. ${ }^{10}$ As thus envisioned, the dream elements form a system of connections along which a charge can run, from idea to idea, from affect to idea, or from affect to affect, coming to rest on any element different from that which occupies 
a central place in the dream-thoughts. Thus, displacement, like symbolization and secondary revision, effects a difference between the dreamthoughts and the dream-content. But the final effect of the process is less important than the means by which the effect is achieved: displacement effects a shift of psychic intensities across a chain of elements by substitutions on the basis of contiguity.

To speak of displacement is to speak of deferral and substitution not on the basis of resemblance or similarity of the entities exchanged but, rather, on the basis of contiguity. "The consequence of the displacement," Freud writes, "is that the dream-content no longer resembles the core of the dream-thoughts [reflected in the effects of condensation] and that the dream gives no more than a distortion of the dream-wish which exists in the unconscious." Note that here Freud has introduced another term, designating a metaoneiric level of psychic activity, that is, the dream-wish. This wish, he continues, must "escape the censorship imposed by resistance," and one way it does so is by displacement of the "elements of the dream-thoughts" (344; 259; my emphasis).

Now, as Freud conceives the process of displacement, elements may be moved along a horizontal axis forward or backward in the dream-narrative (operations corresponding to the figures of metalepsis [transumptio] and prolepsis [anticipatio]) or along a vertical axis such that they are overstressed or understressed (operations corresponding to the figures of hyperbole [exaggeratio] and litotes [diminutio]). These two kinds of movement or substitution, the rhetoricians tell us, play upon the distinction between the inside and outside of a plane of conceptual content such that denominations can occur in the mode of metonymy. The term metonymy literally means only "name change" but specifically indicates the substitution of the name of an entity by the name of another entity contiguous with it in time or space.

The most common forms of metonymy are those which substitute the name of a cause for the name of an effect (as when we substitute lightning for flash of light, suggesting that the lightning caused the flash) or the reverse; or the substitution of a proper name (Jove) for a quality (power) which the nominal referent possesses, or the reverse. The notion of substitutions of names drawn from outside the plane of conceptual content, used by Lausberg to distinguish between metaphor and synecdoche, refers to the presumption of a distinction between causes and effects or parts and wholes, on the basis of which the borrowing of terms for substitution can be effected. ${ }^{11}$ Thus, for example, the use of the name of Shakespeare for his 
works (as in "I love to read Shakespeare") presupposes a relationship between the author (cause) and his works (effect) on the basis of which the substitution of the one for the other can be made. (Cf. bottle for wine, i.e., container for thing contained; arms for battle, i.e., instruments for an activity; or crown for monarchy, i.e., part for the whole). What metonymy does is provide a basis for the kind of distinction that Freud wishes to make between the ideational content of dreams and the affectual weights with which their several elements may be charged in the dream-report itself. It is in the relationship between ideation and affect that displacement does its principal work in the dream-construction.

That such is the case is shown by Freud's centering of his own discussion of examples of displacement in the subsection of chapter 6 entitled "Affects in Dreams." In dreams, Freud says, "the ideational content is not accompanied by the affective consequences that we should regard as inevitable in waking thought. . . . In a dream I may be in a horrible, dangerous and disgusting situation without feeling any fear or repulsion; while another time, or the contrary, I may be terrified at something harmless and delighted at something childish.” Analysis of situations such as these suggests that "the ideational material has undergone displacement and substitutions, whereas the affects have remained unaltered" (497-98; 375-76).

Unlike condensation, which strengthens psychic intensities by aggregation and cross-sorting, displacement reorders ideas in such a way as to disengage them from the affective charge they would normally have in waking consciousness. Like metonymy, in short, displacement smoothes out the surface of ideational experience, dissolves the distinction between forms and contents or signs and references, and effects substitutions across the ideational chain syntagmatically.

Thus, for example, in the dream of the three lions, in which the dreamer felt no fear in their presence, Freud first separates the images of the lions from the idea "lion" in the manner of a distinction between a container and contained; next, likens the distinction to that between a lion figure and Snug, the joiner, who hides in such a figure in A Midsummer Night's Dream; then identifies the true ideational content of the trio of lions with the dreamer's father's superior (who was a "social lion" but had been kind to her [the dreamer] nonetheless); and ends, finally, with a moral: "the same is true of all dream-lions of which the dreamer is not afraid" (499-500; $377-78$ ). The substitution of one ideational content (that of the image in the dream) for another ideational content (that of the true referent) is effected by displacement in the mode of metonymy. In the dream cited, 
Freud seizes upon a metaphor (father's superior $=$ a social lion) and a chain of resemblances between real and metaphorical lions to disclose the ideational content of the presiding image. But the relationship between the two ideational contents (apparent and real), on the one side, and the dominant affect (lack of fear), on the other, is interpreted metonymically: specifically, the substitution of an image of lions for that of a leonine person within the context of an affect (fear) associated by contiguity only with the latter. The affect, in other words, is borrowed from a domain extrinsic to that in which the manifest ideational content would normally be found; or conversely, the ideational content is imported from an affective domain in which the manifest ideational content would normally be located.

The above can serve as an example of Freud's use of the mode of metonymy to explicate substitutions along a horizontal axis in the manner suggested by the following diagram:

\begin{tabular}{|c|c|c|}
\hline $\begin{array}{c}\text { Ideational Content } I=\text { lions } \\
\text { (Manifest) }\end{array}$ & $\leftrightarrow$ & Ideational Content $2=$ "a social lion" \\
\hline$\downarrow$ & & $\downarrow$ \\
\hline Affect $_{I}=$ fear & & Affect $2=$ lack of fear \\
\hline
\end{tabular}

Affect 2 (lack of fear) remains constant, while Ideational Content $I$ is substituted for Ideational Content 2. Content I is substituted for Content 2 by virtue of their similarity (i.e., metaphorically); but Affect 2 can be linked to Ideational Content I by virtue of its contiguity with the common term of both contents, that is, "leoninity." In a word, Affect 2 is linked to Ideational Content 2, as a specific person might be linked to a specific affect, that is, by the presence of the two in the same place. The axis of the substitution is horizontal because the base of the dream, its affect, remains constant throughout the process of substitution.

As an example of substitution along a vertical axis, we may take those examples of dreams that Freud analyzes in terms of substitution by antithesis. ${ }^{12}$ Antithesis itself is a figure of rhetoric (contention, contraposition, opposition), but Freud uses the term to characterize a process in which an affect is transformed into its opposite (fear into courage, love into hatred, sadness into cheerfulness, etc.). In other words, whereas in the dream of the three lions, Freud has concentrated on the substitution of one ideational content for another, in the dream displaying evidence of antithetical trans- 
formations, he is concerned with the substitution of affective states. In these dreams, to be sure, the ideational contents are masked by displacementfor example, in the dream of the enemy warships, the Herr P. who appears as the governor of the castle along with Freud at the beginning of the dream and later dies as a result of Freud's questions to him is revealed in the analysis to be a surrogate or double of Freud himself (500-50I; 378-79). But the death of the governor is notable to Freud the analyst of the dream inasmuch as it made no impression on Freud the actor in the dream. Since the analysis revealed that the death of the governor was a symbolic apprehension (prolepsis) of Freud's own "premature death," it should have been attended by feelings of terror or fright. But it was not, and Freud speculates "it must have been" from the death scene that "the fright was detached and brought into connection with the sight of some warships," which subsequently are shown in the dream to represent no threat to the castle and its inhabitants (Freud's family) at all $(502 ; 379-80)$. Since Freud believes the image of the warships to have derived from his observation of a flotilla during a visit to Venice, the memory of which was "filled with the most cheerful recollections," Freud concludes that the affect that should have been present in the death scene had been displaced onto the scene of the warships' appearance in the dream. Thus, he writes: "Here, then, in the process of changing the dream-thoughts into the manifest dream-content, I have transformed cheerfulness into fear, and I need only hint that this transformation was itself giving expression to a portion of the latent dream-content." And he concludes: "This example proves, however, that the dream-work is at liberty to detach an affect from its connections in the dream-thoughts and introduce it at any other point it chooses in the manifest dream” (502;379-80).

Leaving aside the adequacy of the details of the analysis of the dream, what are the specific moves Freud makes in the analysis itself? What, in a word, does he presuppose about the dream that permits him to postulate the displacement of one affect by another? The answer to these questions has to do with the metonymical conflations operating on the vertical axis of the dream structure, between ideational contents on the upper level and affects on the lower. Thus, "wherever there is an affect in the dream, it is also to be found in the dream-thoughts, but the reverse is not true." That is, the conjoining of an affect with an ideational content always proceeds from the dream-thoughts to the dream-content, or the conjunctive impulse may be blocked, so that the dream-contents appear affectively indifferent - but it is impossible "to enter into the dream-thoughts without being deeply 
moved" (505; 38I). Having said this, however, Freud does not so much analyze as simply describe a process of affective displacement. Tropological analysis shows that the process operates in the mode of metonymy. Thus, in the dream, the image of the warships is shown to be linked to real warships that Freud observed in Venice. But whereas the original experience had been attended by feelings of happiness, the image in the dream had been charged with feelings of fear. This fear, in turn, was related by similarity to thoughts Freud had entertained about "the maritime war between America and Spain and to anxieties to which it had given rise about the fate of my relatives in America” (5OI-2; 379).

In suggesting that the fear felt in the dream at the sight of the warships was the result of a displacement of affect from the death of the governor, Freud implicitly links death and fear by contiguity rather than causality. If they were considered to be linked causally, then wherever the one appeared, the other would be present too. That Freud conceives death and fear to be linked by contiguity rather than causality can be inferred from the fact that he construes the affect fear as being detachable from the event death and projectable onto another event, the appearance of warships in the dream. The true ideational content of the warship image, the British ships observed at Venice, had actually been associated with another affect, namely, happiness. That happiness is associated with warships at all is a consequence of a metonymic substitution of an element in a situation (British warships) with the situation itself (the visit to Venice), that is, a substitution of part for whole. The ideational content warships is metaphorically related to the thought maritime war of Freud's waking consciousness; and the anxiety associated, in this instance causally, with maritime war became detached from its causal nexus and cathected onto another ideational content, the ships in the dream, thus reinforcing the fear already detached from the scene of the governor's death. As for the happiness displaced by the attachment of the affect fear to the ships that had originally in waking life been associated with it, this must now be supposed to have migrated into the region of the death scene, offsetting the affect fear, which was potentially occupying that site, and creating the indifference which Freud claims he felt in its presence. ${ }^{13}$

We may now specify the nature of the movement of these displacements. First, it should be noted that the affects are conceived to move horizontally on the level of the dream-thoughts, before surfacing, as it were, as affective colorations of images in the dream-contents. But the images become affectively charged by a movement that is articulated along a verti- 
cal axis connecting the dream-contents to the dream-thoughts beneath them, and to the dream-wish or fear on yet a lower level. The horizontal movements follow a chain of contiguity (rather than resemblances). The connection between a given ideational content and its affective coloration as it appears in the dream-scenario is anything but causal, being purely adventitious in nature - any image might have been seized upon by the vagrant affect. The causal connection between the image and the affect is a consequence of some compromise between the imperatives of the censor and the dream-wish. There is no essential connection between ideational content and affect at all. They are related in the dream-scenario by contiguity only $(525 ; 398)$.

The longest section of chapter 6 of The Interpretation of Dreams is devoted to presentability (Darstellbarkeit), the means by which dreams present logical relations among the elements of the dream-thoughts and translate notions, ideas, concepts, and words into pictorial images, symbols, and so forth. Working in the service of condensation and displacement, presentation is conceived nonetheless by Freud as a mechanism or process of the dream-work in its own right. The relation between a presentation and what it presents is direct, but the purpose of presentation is to mask both the elements of the dream-thoughts and the relations between them. Condensation and displacement determine what might be called the gross structure of the dream, the syntax, as it were. The means and considerations (Rücksichten) of representability, by contrast, provide what might be called the lexical and grammatical components: images, on the one side, and categories of image, on the other.

The connectives if (conditional), because (causal), just as (simile), although (counterfactual), either... or (antithetical), and "all other conjunctions without which we cannot understand sentences or speeches," by representing diverse elements simultaneously, by representing some parts more extensively than others, by giving them exactly equal weight, or by representing them as the same thing, and by superimposing two visual images upon each other or otherwise combining them by "reversal, or turning a thing into its opposite," or by reversing chronological order so that, for example, an effect precedes its cause, and even producing a "dream within a dream" to express the wish that "the thing described as a dream had never happened" (347-53;260-68) - these means of representation are to be distinguished from the more nearly conscious operations of secondary revision by which the dream-contents are further endowed with an explicit logical coherence or distanced ironically. 
Such are the syntactical, or combinatorial, techniques employed in the dream-work, corresponding to the department of rhetoric called arrangement (dispositio, taxis). It will be noted that, for Freud, these techniques are always employed in the interests of unification or homogeneity of manifest contents. Thus, Freud remarks that "one and only one of these logical relations is very highly favored by the mechanism of dream-formation, namely, the relation of similarity, consonance, or approximation - the relation of 'just as'" $(354 ; 266-67)$. So, too, the dream-work takes place within a mood of positivity, even though it must use masking operations to achieve its aims. "'No' seems not to exist so far as dreams are concerned. They show a particular preference for combining contraries into a unity or for representing them as one and the same thing" $(353 ; 265)$.

Now, it might be thought that here Freud has once more rediscovered the metaphorical elements of the dream, the trope that is likened to condensation, especially inasmuch as he stresses the preference of the representation for "similarity, consonance, the possession of common attributes." But, in fact, Freud explicitly states that "the representation of the relation of similarity is assisted by the tendency of the dream-work toward condensation $(355 ; 267)$. As was shown in our discussion of condensation above, the dream-work utilizes the similarity of images arising in the dream to effect condensations, and their dissimilarity to effect displacements. But what makes two things similar is not their shared manifest attributes but rather some "concealed common element" $(357 ; 268-69)$ which oftentimes - as in the case of the construction of monsters in dreams - "could never have been objects of actual perceptions" $(359 ; 270)$. The "concealed common element" that justifies identification and composition of different aspects of the dream-thoughts is less an external attribute (such as the warships in the dream of the castle) than a single essential quality, such that any object possessing that quality can stand for any other object possessing it. This relationship corresponds to the linguistic trope of synecdoche (and figure of thought by development: hypotyposis or intellectio, literally, "understanding one thing with another").

Lausberg defines synecdoche as a "displacement of the denomination of the thing indicated onto the plain of conceptual content, i.e., from the greater to the smaller or the reverse or from the genus to species or the reverse" (e.g., "New York" for "the baseball team located there," "arms" for "sword and gun both," or "heart" for the quality of "generosity" attributed both to the person and the organ designated by that term (as in "he is all heart") ${ }^{14}$ The distinctions between synecdoche and metaphor, on the one 
hand, and between synecdoche and metonymy, on the other, are important not only for the understanding of the tropes themselves but also for understanding the distinction in Freud between condensation and representation, on the one side, and between representation and displacement, on the other. Here the differentia consist of identification by shared external attributes (metaphor and condensation), by contiguity (metonymy and displacement), and by shared essential qualities (synecdoche and representation). So much is obvious from the care that Freud gives to the means of representation used in the dream-work to produce the effects of identification and compositional integrity. And it becomes even more obvious when, in section D of chapter 6 , he turns to the classification of the symbols actually appearing in dreams in the service of the considerations informing the dream-work.

In his introduction to section D, Freud contrasts displacements consisting in the "replacing of some one particular idea by another in some way closely associated with it ... used to facilitate condensation insofar as, by their means, instead of two elements, a single common element intermediate between them found its way into the dream" (374; 282 ; my emphasis) and displacement in which "a single element has its verbal form replaced by another," that is, "the abstract expression in the dream-thought" is "exchanged for a pictorial and concrete one" $(375 ; 283)$. The relationship indicated here is that between an abstract and a concrete term $(376 ; 284$; my emphasis), a relationship that Freud likens to that implicit in hieroglyphic writing. Here the image and the thought are conceived to share an essential quality.

For example, in the dream of the lady at the opera, the tower in the dream is interpreted as standing for both the high social position of the man she desired and the place of his ultimate confinement, an insane asylum, commonly referred to as a "Fool's Tower" (Narrenturm) $(378 ; 285)$. So, too, in another dream analyzed by Freud, a lady's hat is analyzed as a symbol of both the male genitals and the lady's husband by virtue of the shape of the hat, on the one side, and its beauty, on the other (395-97; 299-300). In neither case is the adequacy of the symbol to that which it represents dependent upon the contiguity of the objects providing the terms of the equation. Towers and aristocrats and insane asylums are not related in part-whole relationships, nor do they normally appear together simultaneously. Nor can towers be said to resemble aristocrats or insane asylums. What they shared in the dreamer's unconscious was the essential quality of height, physical, social, and cultural, respectively (Narrenturm being the associa- 
tion supplied by Freud in this instance as a kind of folk memory element permitting understanding of the connection). And similarly for the hat with the uneven, drooping flaps in the second dream. The hat, the lady's husband, and his genitals were associated in the lady's unconscious by their shared essential quality of beauty, not because they were all normally contiguous with one another or because they all resembled one another in external attributes (although in this case, the uneven length of the hat's flaps is interpreted as resembling the unevenness of the husband's genitals). Similarly with neckties, which in Freud's view not only resemble the penis, but even more importantly, "can be chosen according to taste-a liberty which, in the case of the object symbolized, is forbidden by nature" (39I; 295).

The sharing of essential qualities by objects, their names, and their conceptual contents, Freud argues, derives from patterns of experience that are personal, on the one hand, and more generally public or cultural, on the other. And it is these patterns that make it possible for him to conceive of a science of dream interpretation that can disclose the essential quality types to be found in all dreams. In the personal domain, the somatic structure and individual life history of the dreamer (and especially the psychosexual development) are crucial. "The more one is concerned with the solution of dreams, the more one is driven to recognize that the majority of the dreams of adults deal with sexual material and give expression to erotic wishes" $(43 \mathrm{I} ; 326-27)$. It is the predominantly sexual and somatic basis of dreams that makes a science of symbolism or representation possible $(386 ; 29 \mathrm{I}-$ 92). Just as there are a topics of the body and a syntax of psychosexual development, there are a topics and syntax of a given individual's dream patterns.

But on the public or cultural side, another shared base for symbolization can be found: symbolism, Freud says, "is not peculiar to dreams, but is characteristic of unconscious ideation, in particular among the people, and it is to be found in folklore, and popular myths, legends, linguistic idioms, proverbial wisdom and current jokes, to a more complete extent than in dreams" (386; 29I-92). And the history of the race displays the same kind of continuity as that found in the history of the individual: "Things that are symbolically connected today were probably united in prehistoric times by conceptual and linguistic identity" $(387 ; 292)$. It is this twofold order of experience that necessitates a twofold technique of interpretation: based, on the one hand, "on the dreamer's associations" and, on the other, "on the interpreter's knowledge of symbols" $(388 ; 293)$. It remains to the interpreter's discretion whether an element of the dream-content is to be taken 
literally or figuratively $(376 ; 283-84)$, but in the latter case, a symbolic interpretation proceeds on the basis of "established linguistic usage" (378; 285 ) - as in the Narrenturm example cited above.

Dreaming, Freud says, differs from waking thought in both degree and kind. "The dream-work is not simply more careless, more irrational, more forgetful and more incomplete than waking thought; it is completely different from it qualitatively and for that reason not immediately comparable with it. It does not think, calculate or judge in any way at all; it restricts itself to giving things a new form" $(545 ; 4 \mathrm{I} 3)$.

Freud's omission from late editions of this work of two essays by Otto Rank which he had appended to chapter 6 in early editions, "Dreams and Creative Writing" and "Dreams and Myths," indicates perhaps Freud's apprehension of the extent to which he had imported traditional concepts of rhetoric and poetics into his analysis of the dream-work. The similarities between dreaming and poetizing had been remarked by him many times, with the suggestion that dreams and poems were informed by similar aims, mechanisms, and considerations. But although Freud tended in his writings on art and literature to view them as sublimations of the same materials present in the dream-thoughts and as governed by the same wish-fulfilling fantasies, he nonetheless continued to distinguish rigorously between the general aims of dreams and those of artistic products. Whereas the latter were concerned to communicate information, the former were concerned to mask it; and whereas art sought the appropriate form for the representation of ideational contents, the dream sought a form that masked much more than it revealed.

And it was the form of the dream that mattered most to him. This is why he considered the dream-work as the linchpin of his system. In a note added to The Interpretation of Dreams in 1925, Freud spoke of the confusion into which many analysts had fallen by "seeking the essence of dreams in their latent content." This confusion betokened a failure to distinguish between the form and the content of the dream. "At bottom," he said, "dreams are nothing other than a particular form of thinking, made possible by the conditions of the state of sleep. It is the dream-work which creates that form, and it alone is the essence of dreaming - the explanation of its peculiar nature" (544, n. 2; 4I 3, n. 2; my emphasis). In other words, the form of the dream is itself a content, in exactly the same way that we conceive it to be in our assessment of the value of a work of art.

Needless to say, I am as little concerned to assess the validity of Freud's notions about the relation between dream-work and art-work as I 
am to assess the clinical utility of his theory of the former. What I have sought to do is to demonstrate that, in his efforts to identify the mechanisms by which the dream-work gives new form to the ideational contents and their attendant affective charges arising on the level of the dreamthoughts, Freud has reinvented, rediscovered, or simply recalled the traditional theory of tropes as found in nineteenth-century rhetoric and poetics. And not only has he recalled it, but he has recalled as well the relations among the tropes which that theory has presupposed. To say this, I hasten once more to stress, is neither to detract from the originality of Freud's achievement nor to suggest an influence on or borrowing by him from another field of inquiry. On the contrary, the fine distinctions that Freud draws and the attention to detail which he displays in his reflections on the dream-work permit us to view his chapter 6 of The Interpretation of Dreams as a contribution to the general field of theory of figuration. As long as that field had been limited to the analysis of high art, little progress could be made beyond the kind of tropological analyses which medieval and Renaissance rhetoricians used in order to discern the relation between literal and figurative dimensions of discourse. And this because those engaged in the analysis of a specific work inevitably had an interest in defending or undermining a particular interpretation of the semantic content of a given (especially classic) work. This was hardly the case with such personal or private productions as dreams, especially of persons openly described frequently as neurotics. Here the relation between form and content, between syntax and semantics, and the nature of their mediation could be removed from the question of the authority of the analysandum as a cultural paradigm or monument. So, too, the whole question of the quality of the creative psyche raised by Romanticist aesthetics in terms of the difference between genius and ordinary consciousness could be mooted and the mechanisms of transformational tactics studied as a topic suigeneris.

Freud's use of literary examples to illustrate aspects of the dream-work indicates the affinity that existed in his own mind between dreaming and poetic creation. This presumed affinity itself would have provided the models necessary to suggest the tropological nature of the dream-work. His contemplation of writings composed by authors who consciously used theory of tropes to guide their own composition (e.g., Chaucer, Dante, Shakespeare, Rabelais, Rousseau, Goethe, Schiller, and Heine, not to mention lesser lights such as Daudet, Dumas, and Rider Haggard) would have been enough to inspire his translation of the traditional principles of prose composition to the analysis of the principles of the dream-work. 
I stress, too, that this analysis of the tropological nature of Freud's conception of the dynamics of the dream-work says nothing at all about the validity or invalidity of other concepts used to explain the purpose, aim, and function of dreaming. Theories such as those of infantile sexuality, Oedipus complex, latency, return of the repressed, and so on have to do with the semantics of consciousness rather than with the grammar, syntax, and rhetoric of dreaming. It would be interesting, however, to undertake a tropological analysis of such diachronic compositions as Totem and Taboo or Moses and Monotheism, works that, precisely because they are metapsychological, must display the operations of the tropes for the mediation between data and plot structures which give them their specific narrative forms and mythic contents.

Such an analysis must wait, however, for we are less interested in explicating Freud's methodus interpretandi than in suggesting the ways in which his version of tropology illuminates the conventional theory of figuration. Freud provides us not only with a terminology for characterizing the major terms of non- or extralogical thinking but also with a veritable psychology of figurative discourse. The classical and Renaissance rhetoricians had derived a taxonomy of figures of speech and a theory of the classes of such figures analytically - from the study of the structures of discourse but on the basis of an unquestioned distinction between literal and figurative meaning in speech. Freud's tropological theory brings under question this distinction, at least in the domain of dreaming. To be sure, in his conception of the dream, the true, real, or literal meaning of the dream is given in the dream-thoughts; the dream-contents are a distortion of this meaning. This distortion, by contrast, is literally the literal level of the dream, that which is actually reported. And before its meaning can be disclosed, that is, before its relationship to the unconscious of the dreamer can be established, it must be decoded tropologically, that is, stylistically. It is for this reason that dream analysis in psychotherapy could profit from a study of the theory of tropes.

But whatever contribution the theory of tropes might make to psychotherapy, the gain to the theory of tropes to be had by study of Freud's theory of the dream-work is even greater. For Freud's work points to the grounding of the phenomena of style in the structures of unconscious ideation and to the solution of the problem of the logic of practical discourse. 


\section{Narrative, Description, AND Tropology in Proust}

Contemporary thought about the nature of interpretation, especially in the human and social sciences, tends to stress the ways in which it differs from simple description, on the one hand, and from explanation, on the other. This is not to suggest that interpretation, description, and explanation are in any way mutually exclusive operations; indeed, we could well characterize description and explanation as different kinds of interpretation or, conversely, regard interpretation itself as a kind of explanation which features description over formal argument or demonstration as its modus operandi. But if we do wish to stress the differences between interpretation, on the one side, and both description and explanation, on the other, we would have to insist on the propaedeutic and heuristic aspects, the preclassificatory and preexplanatory functions of interpretation. We might wish to say that interpretation is what we do when we are uncertain how properly to describe some object or situation in which we have an interest and when we are unsure about which of several available analytical methods should be used to explain it. As thus envisaged, interpretation is a product of thought in the preliminary stage of grasping an object by consciousness, thought in the effort of deciding not only how to describe and explain such an object but whether it can be adequately described or explained at all.

Because interpretation typically entertains different ways of describing and explaining some object or situation deemed worthy of the effort to comprehend it, its own modality of discursive articulation is characteristically more tropical than logical in nature. In this feature it will differ from 
any technical description, carried out in conformity with the procedures of a given taxonomic system, and from any explanation provided by a specific analytical method. In interpretative discourse, thought moves by "turns," which are unpredictable prior to their actualization in speech or writing and the relations among which need not bear any relationship of strict deducibility of any one from any other. Because interpretation is systemically doubtful as to the nature of its object of interest, the terminology best suited to the description thereof, and the most appropriate way to explain it, it can proceed only by departing from whatever passes for literal (or technical) language and stereotypical conceptualizations of possible objects of perception and by giving itself over to techniques of figuration by which to fix its referent in consciousness and thereby constitute it as a possible object of cognition. It is this process of prefiguring a referent, so as to constitute it as a possible object of cognition, which distinguishes interpretation from both description and explanation alike. And this is why rhetoric, considered less as a theory of persuasive speech than as the theory of the tropological bases of speech, discourse, and textuality, provides one promising way of comprehending what goes on in interpretative discourse in general.

Because interpretation is a predominantly tropical manner of discourse, it resembles narration, which, in fact, is a discursive tactic often utilized in interpretative discourse. Typically, the successive events that comprise the story line of a narrative are only retrospectively comprehendible after the plot structure of which they are functions has become perceivable; but even then, they are hardly deducible one from another in the manner of the component terms of a syllogism. Similarly, the sequence of turns taken in interpretative discourse resembles more the path traversed in the search for a plot structure adequate to the configuration of a diachronic series of events into a paradigmatic structure of relationships than it does the progressive accommodation of a set of perceptions to the exigencies of a nomological-deductive demonstration.

The similarities between interpretation and narration argue for the essentially figurative nature of the discourses in which they are typically represented in speech or writing. Which is not to say that interpretation, any more than narration, has no literalist dimension to its characteristic mode of articulation. On the contrary, like narration, interpretation does its work or achieves its peculiar effect of providing a kind of understanding of the objects of which it speaks precisely by virtue of its problematization of the relation between literalist and figurative speech. Although an inter- 
pretation typically wishes to speak the literal truth about its objects of interest, it is generated by a fundamental sense of the inadequacy of any convention of literalness to the representation of those objects. And this is why all genuinely interpretative discourse must always appear as both a play of possible figurations of its objects of interest and an allegorization of the act of interpreting itself. Just as all narratives are also, at some level, more or less explicitly articulated metanarratives (discourses as much about narration as about their ostensible, extradiscursive referents), so, too, all genuine interpretations are metainterpretations (discourses as much about interpretation as about their ostensible primary objects of interest). And whereas in both descriptive and explanatory discourses, the metalevels of their articulation can be identified by a combination of grammatical and logical analysis, in interpretative discourse the discernment of the metalevel requires analysis by methods more distinctly rhetorical in nature.

Considerations such as these argue for a reconceptualization of the traditional notion of the relation between the form and the content of interpretative discourse. If we conceive of interpretation as a prefiguration of a given object of interest, then the sequence of turns from one modality of figuration to another must be considered less as an aspect of the form of the discourse than as one of its contents. This does not mean that it is impossible to distinguish between the form and the content of interpretative discourse, that its referential or conceptual content is indeterminable, or that the form of an interpretation is its content. For indeed, it is not only meaningful but also useful to discriminate between the linguistic and generic features of any given interpretative discourse, on the one side, and its referential and explicitly conceptual elements, on the other. But we must also count among the contents of the specifically interpretative discourse the structure of the modalities of figuration utilized in the process of transforming the referent from an object of perception into a possible object of cognition. It is the structure of the modalities of figuration that provides the basis for the equivalent of emplotment in narrative. It is the modalities of figuration which effect the correlation of the linguistic, generic, referential, and conceptual levels of the discourse on its paradigmatic axis; and it is the sequence of these modalities of figuration which presides over the transfers from the paradigmatic to the syntagmatic axes of its articulation. At any rate, this is one way of conceptualizing what a rhetorical approach to the analysis of interpretative discourse might consist of.

I have chosen as an example of interpretative discourse a passage taken from the volume entitled Sodome et Gomorrhe of Proust's $A$ la recherche 
du temps perdu. The passage consists of what appears to be a purely descriptive pause in the main action of the first chapter of the work, which tells of Marcel's attendance at a party of the Princesse de Guermantes. This interlude comes just after Marcel has finally succeeded, with much difficulty, in getting himself introduced to the Prince de Guermantes and has immediately thereafter witnessed (what appears to be) the prince's violent expulsion of his friend Swann from the gathering. It consists of a paragraph that relates Marcel's contemplation of Hubert Robert's fountain in the garden of the Guermantes' palace.

The paragraph represents a scene of interpretation because it describes the effort of the protagonist to grasp by consciousness an object, a work of art, whose beauty is taken for granted but the nature of whose fascination is presumed to be unfathomable. That is to say, the passage belongs to the genre of the ekphrasis (descriptio). I have marked with italics the places at which the narrative turns from one characterization of the fountain to succeeding ones.

Dans une clairière réservée par des beaux arbres dont plusieurs étaient aussi anciens que lui, planté à l'écart, on le voyait de loin, svelte, immobile, durci, ne laissant agiter par la brise que la retombée plus légère de son panache pâle et frémissant. Le XVIIIe siècle avait épuré l'élégance de ses lignes, mais, fixant le style du jet, semblait en avoir arrêté la vie; à cette distance on avait l'impression de l'art plutôt que la sensation de l'eau. Le nuage humide lui-même qui s'amoncelait perpétuellement à son faite gardait le caractère de l'époque comme ceux qui dans le ciel s'assemblent autour des palais de Versailles. Mais de près on se rendait compte que tout en respectant, comme les pierres d'un palais antique, le dessin préalablement tracé, c'était des eaux toujours nouvelles qui, s'élancant et voulant obéir aux ordres anciens de l'architecte, ne les accomplissaient exactement qu'en paraissant les violer, leurs mille bonds épars pouvant seuls donner à distance l'impression d'un unique élan. Celui-ci était en réalité aussi souvent interrompu que l'éparpillement de la chute, alors que, de loin, il m’avait paru infléchissable, dense, d'une continuité sans lacune. D'un peu près, on voyait que cette continuité, en apparence toute linéaire, était assurée à tous les points de l'ascension du jet, partout où il aurait dû se briser, par l'entrée en ligne, par la reprise latérale d'un jet parallèle qui montait plus haut que le premier et était lui-même, à une plus grande hauteur, mais déjà fatigante pour lui, relevé par un troisième. De près, des gouttes sans force retombaient de la colonne d'eau en croisant au passage leurs soeurs montantes, et parfois, déchirées, saisies dans un remous de l'air troublé par ce 
jaillissement sans trêve, flottaient avant d'être chavirées dans le bassin. Elles contrariaent de leurs hésitations, de leur trajet en sens inverse, et estompaient de leur molle vapeur la rectitude et la tension de cette tige, portant au-dessus de soi un nuage oblong fait de mille gouttelettes, mais en apparence peint en brun doré et immuable, qui montait, infrangible, immobile, élancé et rapide, s'ajouter aux nuage du ciel. Malheureusement un coup de vent suffisait à l'envoyer obliquement sur la terre; parfois même un simple jet désobéissant divergeait et, si elle ne s'était pas tenue à une distance respecteuse, aurait mouillé jusqu'aux moelles la foule imprudente et contemplative. ${ }^{1}$

The scene appears at first glance to be a pure description of an object that, because it is a work of art, can only be interpreted, rather than explained. The interpretation itself, however, consists of four successive characterizations of the object, given at different points in Marcel's movement toward the fountain. It is this movement of the speaking subject through space and time, in what appears to be an activity directed at the effort of recognizing and identifying the object, which permits us, following the lead of Gérard Genette, to view this scene as a genuine narrative. Indeed, rather than being a descriptive pause, this scene can be regarded as a small narrative within the larger narrative that recounts the events of Marcel's reentry into that society from which he had been absent for some ten years. And if we accept this characterization of the scene in question, we can then proceed to inquire into its structure as a kind of interpretation by narration, on the one side, and its metanarrational function (as a narrative sequence that has narration itself as an element of its subject matter), on the other.

In his commentary on the scene of Marcel's interpretation of Robert's fountain, Genette simply reproduces the text and marks the terms that indicate its duration and the activity of the protagonist as a "travail de la perception" and "du discernement." It is an example, he says, of a typically Proustian description-as-narrative: "toute une précoce éducation de l'art de voir, de dépasser les faux semblants, de discerner les vraies identités." If, however, we attend to the modalities of figuration in which the successive characterizations of the fountain are cast, we can note two features of this narrative interpretation of the "jet d'eau." One is the tropological structure of the passage which endows it with a signified quite distinct from the thematic content observed by Genette ("l'activité perceptive du personnage contemplant, de ses impressions, découvertes progressives, changements de distance et de perspective, erreurs et corrections, enthousiasmes et déceptions, etc.” $).^{2}$ In fact, the four successive characterizations of the foun- 
tain are cast, respectively, in the modes of metaphor, metonymy, synecdoche, and irony. This tells us something about the narrative logic of the passage and provides us with a way of characterizing the relation between narration and description in Proustian interpretation, if not in interpretation in general.

The other feature of the passage has to do with its structural resemblance to the three discernible scenes of interpretation which precede it in the larger narrative account that it seems to interrupt. These three units consist of (I) the opening chapter of Sodome et Gomorrhe, which recounts the narrator's observation, from a hidden vantage point, of a scene of homosexual seduction, his reflection on the nature of the "descendants of the inhabitants of Sodom," and his classification of the genera and species thereof. For the moment I will note only that the taxonomy provided features successive descriptions or characterizations of four species of the genus male homosexual. (2) This preface is then followed by the chapter in which is related Marcel's efforts to "recognize and identify" the various personages he encounters on the way to his presentation to the prince. Here, too, there are four extended descriptions, this time in the manner of a taxonomy of types of hangers-on of noble society: Marcel's successive descriptions of Professor E - , M. de Vaugoubert, Mme. d'Arpajon, and M. de Bréaute, who actually presents Marcel to the prince. And finally, (3) we have the brief scene with the prince himself, in which Marcel is represented as achieving an illuminating insight into the differences between genuine nobility of character and its hypocritical imitation. This scene, too, is structured as a succession of four distinct perceptions as recognitions.

Each of these three scenes of interpretation features a distinct interpretandum, which we may distinguish as male homosexuality, certain marginalized social types, and nobility, respectively. The specific interpretations provided consist of narrative accounts of the narrator's efforts to recognize and identify the nature and kinds of the objects contemplated. Each of these narrations, in turn, takes the form of four successive descriptions of the object in question, and each description is cast in a distinctive figurative mode. Each narration consists of an account of the narrator's passage among the dominant modalities of figuration, a passage that consists typically, though not exclusively, of a movement from a metaphorical apprehension of the interpretandum, through a metonymic dispersion of its attributes and a synecdochic comprehension of its possible nature, to an ironic distancing of the process of interpretation itself.

It is this pattern, common to all three of the scenes of interpretation 
preceding that in which the fountain of Hubert Robert is described, which serves as the principal signified of the fountain scene itself. And it is the identification of this signified which permits us to comprehend both the placement of the description of the fountain in the larger narrative of which it is a part and its metanarrational function. Its placement in the fourth position of successive scenes of interpretation allows us, on the basis of our understanding of the fourfold structure of the preceding scenes, to regard it as an ironic commentary on the process of interpretation itself; and the fact that it explicitly takes interpretation as its referent permits us to regard it as Proust's own instruction on how to read or interpret the scenes preceding and following it. It is this feature of the scene that permits us to consider it as a condensed model of Proustian interpretation in general, for narrative interpretation specifically, and for the interpretation of the larger narrative of which it is a unit in particular.

I must now, however briefly and inadequately, interpret the scene in which the fountain of Hubert Robert is interpreted by Marcel. I note that this scene is framed by two figures of "deviation," one social, the other natural. The passage ends with an act of désobéissance by one of the jets of the fountain, which results in the drenching of Mme. d'Arpajon, to the general (somewhat vicious) merriment of the assembled company. It begins just after Marcel's conversation with the prince, when he observes this newly revealed paragon of "consideration" sweeping Swann, "avec la puissance d'une pompe aspirante, ... au fond du jardin" (656), in order to show him the door. ${ }^{3}$ It is this event that leads Marcel to remark on the depths of his absorption in the company, from which he seeks to recover "quelque faculté d'attention à la pensée d'aller voir le célèbre jet d'eau d'Hubert Robert.” The four descriptions of this celebrated work of art then follow.

The first description is introduced by a report of the appearance of the fountain seen from afar: "On le voyait de loin, svelte, immobile, durci, ne laissant agiter par la brise que la retombée plus légère de son panache pâle et frémissant." It is an impression captured by or condensed into the image of the "pale and quivering plume." The description itself consists of a specification of the image, as giving "l'impression de l'art," and features the figures of speech of synecdoche ("le XVIIIe siècle"), pun ("style"), two metaphors ("nuage" and "faite"), and a simile ("comme ceux qui"), all of which are advanced in the interest of suggesting the contrast between the impression of the image and the mere sensation that one might have had of it as "eau."

Marcel (or Proust), having figuratively characterized the fountain in the mode of metaphor, might very well have let the matter rest there, but 
instead he presses on to a second description, cast in an altogether different mode of figuration, that of metonymy. From a closer view ("Mais de près"), it was possible, apparently, to realize that ("on se rendait compte que"), while seeming to respect ("tout en respectant"), like the stones of an ancient palace, the design traced out for it beforehand ("comme les pierres d'un palais antique, le dessin préalablement tracé"), the spray of the jet was able to produce the "impression d'un unique élan" only by sending forth ever new streams of water that "springing upwards and wishing to obey the ancient orders of the architect, carried them out to the letter" ("les accomplissaient exactement") only by seeming ("qu'en paraissant") to infringe them ("les violer"). The "single flow" of which one had originally had an impression is now revealed to be "in reality as often interrupted as the scattering of the fall, whereas from a distance it had appeared to me unyielding, solid, unbroken in its continuity."

This is a remarkable passage for my purposes in many ways. First, the passage features two contrasts: one between an original impression from a distance and the kinds of perception made from closer which yield insights into the reality of the object in question, and another between an artist's designs and the realization of them in the work of art itself. But, second, it posits a complex relationship between the traditional rules of artistic composition ("ordres anciens de l'architecte") and the transgression of those rules which appears to be necessary for the creation of any work of art. Indeed, not only do these two sentences tell us much about Proust's notion of the difference between appearance and reality in any object seeming to be whole, solid, unbroken in its continuity, and so on, but they tell us even more about his notion of the role of figuration in the production of literalness itself.

I wish to call the mode of figuration of this passage metonymic for two reasons. First, it reduces the aesthetic appearance of the jet to the material thing it is; it thereby substitutes the material cause of the appearance for its visual effect. This reduction is suggested figuratively in the simile that likens the fluid elements of the water play to the rigid "stones of an ancient palace." Second, the passage explicitly reduces the appearance of orderliness of the spray to the reality of the necessity of appearing to violate the principles governing its composition. These reductions provide insights into both the nature of artistic creativity and the ways in which the products thereof are to be interpreted.

But Marcel (or Proust) does not leave us with these reductions. He presses on to yet another description of the fountain, "D'un peu près," a 
description I wish to call synecdochic because it consists of nothing less than a characterization of the actual structure, what might be called the structural secret, of the "jet d'eau." This passage is cast in the most literalist language of all of the four descriptions provided; there is very little in it that might be called metaphorical in the common meaning of the term. Specifically, the passage consists of an explanation of how the effect of a "continuité sans lacune, ... en apparence toute linéaire" was produced by the architect's setting of the styles of the jets. It is possible actually to draw a diagram of the paths of the jets and of the relationships among them on the basis of this characterization of its structure, in a manner that one could not possibly do with any of the other descriptions.

At the same time, the sense of this passage, perhaps because it is so literalist, so barren of figures of speech, is the most difficult to grasp in a single quick reading. It seems difficult to form an impression of it because it is less about the impressions of the narrator than it is about the actual structure of the "jet d'eau" itself. Here Marcel asserts that "one saw" ("on voyait") how the "uninterrupted continuity of the jet" was assured ("était assurée") by the structure of its design, which he then proceeds to sketch out. The passage is not reductive, in the way the previous passage is, but rather essentializing: what we have is a representation of the relationships among the elements of the spray such that it is impossible to distinguish between its form and its content. In the manner of a synecdoche, the spray is "grasped together" as a whole indistinguishable from the parts that comprise it. Moreover, this description of the structure of the spray replicates the structure of the paragraph itself: the continuity of the paragraph - like the continuity of the jet that it describes - is assured by the "entering into line," by the "lateral incorporation" of a succession of descriptions, each in a different mode, which "mount [s] higher than the first and [is] itself, at an altitude greater but already a strain upon its endurance, relieved by a third." Thus, the third description of the fountain is a synecdoche not only of the "jet d'eau" but also of the paragraph, which describes the fountain in a fourfold manner.

It might seem that, after so totalizing a description of the object, the interpretation would have been completed. But not so. We still have not had a description from "close at hand" ("De près"). This, the fourth description of the fountain, is cast in yet another mode, which I wish to characterize as ironic - not only because, in the extravagance of its figurative technique, it draws attention to the arbitrariness of the figurative modes of the three descriptions that precede it; but also, and above all, 
because it is internally ironic, consisting as it does of a virtual personification of the "jet d'eau" in its first two sentences followed by an abrupt reversal of this process, which returns the fountain to the status of a banal stream of water, in the third and final sentence.

In this last description, no speaking subject is overtly posited. There is no "on voyait", "On avait l'impression de," "on se rendait compte que," or "il m'avait paru" of the kind met with in the other descriptions. The passage begins "De près, des gouttes sans force." Scott Moncrieff translates this phrase: "Seen close at hand, drops without strength" (43), and this is certainly a plausible rendering of its sense. But the French does not say " $V u$ de près" or "De près, on voyait." And indeed, why should it, since this has nothing of the aspect of a report of a perception or of an impression about it? It is, in fact, a hypotypotic or pragmatographic representation, shot through with metaphorical figures of speech but cast in a tone so different from the first description as to belie the adequacy of its dominant mode of figuration to its referent.

The referent of this passage is neither the spray as a whole, the bursts of water emanating from the jets, nor the structure of their relationships but the myriads of "gouttes" and "gouttelettes" which, now personified ("Elles contrariaient") and gendered ("leurs soeurs"), are depicted as actants in a spectacle as chaotic and senseless as the stream of life of which it is an image. The casualties of the process, those "gouttes sans force," who "fall back and float for a while" and "tease with their hesitations" before "being drowned in the basin," are given the positive function of blurring "la rectitude et la tension" of the jet's central stem - positive because the verb used is estompaient, which suggests the artist's toning down or softening of a line. The connotation of this figure is carried over to the characterization of the "oblong cloud" that crowns the stem (tige, with its connotation both of arboreality and of phallic erection). This cloud, although in reality "composed of a thousand tiny drops," presents the appearance of having been painted ("en apparence peint") - painted, moreover, in an "unchanging golden brown" ("en brun doré et immuable"). But the image of this cloud, which apparently rises, "unbreakable, constant, urgent, swift, to mingle with the clouds of the sky", is abruptly dispossessed of its attributes of immutability, constancy, infrangibility, and urgency by the reminder that "unfortunately, a gust of wind was enough to scatter it [l'envoyer] obliquely on the ground"; and a report that "at times indeed a single disobedient jet swerved [divergeait] and, had they not kept a respectful distance, would have drenched to their skins the incautious crowd of gazers." 
It seems to me that this fourth description, which is by turns lyricalelegiac and playful in tone, is at once ironical in its structure and radically revisionary with respect to all three of the preceding descriptions of the fountain. Its revisionary relationship to the first description, cast in the mode of metaphor, is especially striking. While it replicates the metaphorical mode of the first description, it substitutes images of mobility, change, and evanescence for those of immobility, stiffness, and continuity given in the original impression. So, too, the personification of the elements of the "jet d'eau" in the fourth description stands in direct contrast to the assimilation of the qualities of the fountain to those of nobility suggested by the figures of speech used in the first description: "panache," "art," and "Versailles." While the fourth description metaleptically retrieves the metaphorical mode of the first description, it both radically alters the semantic domain from which its figures of speech are drawn and abruptly, almost violently, undercuts the very impulse to metaphorize by its reminder that the fountain is, after all, only a fountain ("Unfortunately, a gust of wind was enough to scatter it obliquely on the ground").

As for the relationship of the fourth description to the second and third descriptions, it can be said that it revises in a significant way the figurative contents of both of the latter. First, the rising, falling, crossing movement assigned to the "gouttes" and "gouttelettes" picks up the images of infringement and scattering of the second description and confirms the metonymic mode in which it is cast even as it effectively denies it by way of its personification of the elements of the spray. Second, this personification of the drops of the spray stands in direct opposition to, not to say negation of, the essentializing schematism of the third or synecdochic description, in which the structure of the "jet d'eau" is set forth.

It is not that the fourth description is to be apprehended as the most precise, correct, comprehensive, or appropriate, in comparison with which the others that make up the set are to be adjudged in some way inferior. The fourth description is given from the point of observation closest to the object being described, but it is no more precise than those launched from the other points further away. Nor is the fourth description to be accorded the status of the kind of revelation or anagnorisis which is supposed to attend the completion of a well-made plot in the conventional narrative. The fountain has not been better comprehended in the fourth description than it was in any of the three preceding descriptions. It is not that we now comprehend the nature of the fountain in the way that we seem to comprehend the successive events of a story as we near its end and are given the crucial bit of information that allows us suddenly to grasp the point of it all. 
It is true that, by the time we have registered the fourth description, in the full consciousness of its overtly ironical mode of figuration, we are permitted to discern something like the kind of plot that permits a retrospective correlation of the events of this story as a story of a particular kind - a specifically ironic story. But what we have been permitted to comprehend is less the nature of the "jet d'eau" than that of the nature of figuration itself. It was by the provision of this exercise in figuration that Proust has set before us a model for comprehending the other passages of description-by-narration in which the passage in question is embedded and which it only seems to interrupt.

I say seems to interrupt, because actually the passage in which the fountain is described in four successive modalities of figuration bears the same relationship to the three preceding and more extended scenes of interpretation that the fourth description of the passage bears to its three preceding parts. Recall that the fountain scene is the fourth of a set of successive narrative segments in which Marcel interprets, by the same process of fourfold figuration, the subjects of male homosexuality, types of social hanger-on, and nobility (in the person of the Prince de Guermantes). I will not try the reader's capacities of toleration for pedantry (which have no doubt been strained to the maximum already) by attempting to demonstrate that these three preceding scenes of interpretation have substantially the same structure as that of the fountain scene. But a cursory rereading of the brief scene in which Marcel is finally introduced to the prince, the scene immediately preceding the interpretation of the fountain, will suggest the ways in which the latter scene is related to those preceding it in the larger narrative. ${ }^{4}$

First, there is no causal or logical connection between the scene in which the prince's nobility is interpreted and that in which the fountain is interpreted. The relationship between them is tropical only. After having exchanged a few words with the prince, Marcel simply "moved away" ("je m'éloignai"). He then catches a glimpse of the prince expelling Swann, "with the force of a suction pump," from the party. And he reports how his absorption in the company ("Tellement distrait dans le monde ...") had all but occluded his powers of perception (“... que je n'appris que le surlendemain, par les journaux, qu'un orchestre tchèque avait joué toute la soirée et que, de minute en minute, s'étaient succédé les feux de Bengale"). It is in response to this absorption "dans le monde" that he decides to seek to recover "some power of attention with the idea of going to look at the celebrated fountain of Hubert Robert." A causal connection is implied between the decision to seek to recover some power of attention by going to 
contemplate Robert's masterpiece and the contemplation of it which follows, but not between the scene of the meeting with the prince and that of the interpretation of the fountain.

Nor is there any logical connection between the two latter scenes: there are no conceivable grounds on which the scene describing the fountain can be deduced from the scene describing the meeting with the prince as a logical consequence. The relation between the scene of the encounter with the prince and that in which the fountain is described is only tropical, which is to say that it is unpredictable, unnecessary, undeducible, arbitrary, and so on, but at the same time functionally effective and retrodictable as a narrative unit once its tropical relationship to what comes before (and what comes after) it is discerned.

It will be noticed that the prince scene is, like the fountain scene, clearly marked by a succession of four distinct recognitions: "je trouvai [l'accueil] du Prince compassé, solennel, hautain"; "je compris tout de suite que [le Prince était] vraiment simple"; "je trouvai dans sa réserve un sentiment ... de la considération"; and "comprenant qu'il ne l'avait posée [sa question] que par de bonne grâce." What is interpreted in this scene is the significance of the words and bearing of the prince for the comprehension of the nature of noble consideration in comparison with the merely feigned camaraderie of those members of the aristocracy who speak to their social inferiors from the first as "man to man." The interpretation consists of successive characterizations of the prince's manner of greeting, the style of his address, the tone of his words, and an example of his speech.

Like the fountain viewed from a distance, at first sight the prince appears "stiff [compassé], solemn, haughty," quite in contrast to the "greeting of the Duc de Guermantes," the prince's cousin, which was, "when he chose, friendly, instinct with good fellowship, cordial and familiar." The prince "barely smiled at me, addressed me gravely as 'Sir," ' in the manner in which Marcel had, he says, "often heard the Duke make fun of."

But then, "from the first words" spoken by the prince to Marcel, the latter realizes that "the fundamentally disdainful man was the Duke, ... and that, of the two cousins, the one who was really simple was the Prince." Marcel then reports that "I found in his reserve a stronger feeling, I do not say of equality, . . but at least of the consideration which one may show for an inferior, such as may be found in all strongly hierarchical societies."

And, finally, Marcel relates the question asked of him by the prince ("Do you intend to follow the career of Monsieur, your father?") and his realization that, since "he had asked it only out of politeness," it required no 
answer and that it remained to him only to move away "to allow him to greet the fresh arrivals."

The sequence of modes of figuration of this set of apprehensions and comprehensions follows the same pattern as that of the fountain scene. First, there are the two metaphorical apprehensions of the prince's manner as seemingly "stiff, solemn, haughty" and that of his cousin the duke's as seemingly "friendly, instinct with good fellowship, cordial and familiar." These apprehensions are immediately reduced, however, in the manner of a metonymy, to the status of masks of two kinds of character (exactly as the "impression de l'art" is reduced to the status of a "sensation de l'eau" in the second description of the fountain), the one "vraiment simple" and the other "foncièrement dédaigneux." In the third characterization of the prince's manner, its aspects are, as it were, grasped together in the synecdoche of "un sentiment plus grand, . . . de la considération qu'on peut accorder à un inférieur, comme il arrive dans tous les milieux fortement hiérarchisés" and the identification of the "hauteur traditionelle" of the representatives of such milieus with a "simplicité réelle" utterly lacking in their more modern brethren "dans l'affectation de la camaraderie badine."

But this comprehension of the prince's consideration is forthwith sublimated into an apprehension of the mere politeness of his question to Marcel: " "Est-ce que vous comptez suivre la carrière de Monsieur votre père?' me dit-il d'un air distant, mais d'intérêt." Moreover, the comprehension of the prince's true nature is immediately belied by the prince's comportment, reported in the paragraph immediately following. Instead of "waiting where he was" to receive the greeting of "fresh arrivals," the prince goes to intercept Swann and rudely carries him off, "with the force of a suction pump, ... in order ... to show him the door." This act of social rupture exactly parallels the swerve of that "single disobedient jet" which drenches Mme. d'Arpajon reported at the end of the fountain scene. The action of the prince has the effect not so much of canceling out as of putting under question the set of apprehensions and comprehensions related in the scene of greeting, in the same way that the unpleasant (désagréable) swerve of the disobedient jet of water distances and problematizes the fourfold description of the fountain in the scene in which it is reported. To be sure, later on in the chapter it will be revealed that the prince had intercepted Swann in order to tell him of his (the prince's) conversion to the party of the Dreyfusards. But this revelation confirms less the prince's authenticity of character than the contingency of the events that had led to his conversion. ${ }^{5}$

If it be granted that the two scenes analyzed do possess the common 
structural features that I have ascribed to them, we can then proceed to specify the nature of their relationship considered as narrational units. I suggest that the scene describing the work of art bears the same figurative relationship to that describing the prince's nobility of character that the fourth description of the fountain (in the ironic mode) bears to the third description of it (in the synecdochic mode). In a word, the paragraph describing the fountain provides an ironic commentary on the purported identification of the true nature of the prince's character in the paragraph containing it. Being about perception-as-interpretation and, more precisely, about the interpretation of an object (a work of art) which is in principle uninterpretable, the fountain scene can be read as calling into question the interpretation of the nature of the prince provided in the scene immediately preceding it. The predominantly ironic structure of the fountain scene reinforces the ironic distantiation of the interpretation of the prince's simple and considerate character already given in the recognition of that nature as being only seemingly "de bonne grace" by the perception of the prince's rude comportment vis-à-vis Swann. The irony informing the fountain scene is thus doubled, being directed, as it is, not only at Marcel's efforts to interpret the fountain but also at the effort to interpret anything having the fascination of a work of art - which would include not only the nobility figuratively represented in the third scene of interpretation but also the representations of social hangers-on and of male homosexuality represented respectively in the second and first scenes of interpretation as well.

That the fountain scene is intended to serve the function of ironically distantiating the description of the prince's seemingly noble nature given in the preceding scene is suggested by the figurative content of the first description of the fountain - as seen "from afar." Recall that the first description of the fountain utilizes three images to specify its nature as a work of art: "panache," "Le XVIIIe siècle," and "Versailles," all three of which are associated metonymically with the nobility of the ancien régime. The successive refigurations of the fountain given in the three descriptions that follow this first characterization have the effect of at once filling out and specifying the content of this attributed impression of nobility and of bringing it under question as an adequate characterization of the work of art itself. Especially the fourth description of the fountain, which purports to reveal the chaos and insubstantiality of the "jet d'eau" when viewed from "de près", has the effect of both affirming and modifying the nobility attributed to the object in the first description.

Coming as it does as the fourth of four successive scenes of interpreta- 
tion, Marcel's effort to interpret the work of art casts its shadow back across the scene immediately preceding it in the narrative, that in which the nobility of the prince is described. And its relationship to that scene, I suggest, is structurally homologous with the relationship of the fourth description of the fountain (in the mode of irony) to the third description of it (in the mode of synecdoche). Once this relationship is recognized, it becomes possible to see the fountain scene as a fulfillment of the figure of noble character given in the prince scene. The figure of the prince, a synecdoche of nobility, is fulfilled in the figure of the work of art, which is to say that it is sublated in the irony with which both nobility and art are treated in the fountain scene.

I would now like to suggest that, on this reading of the text, we are in a position to comprehend the relation of both the fountain scene and the scene with the prince to the other two scenes of interpretation which precede them in the narrative: that is, the scenes that interpret male homosexuality and the types of social hanger-on, respectively. If the fountain scene provides the reader with a model for interpreting all objects that, like the work of art, are presumed to be by nature uninterpretable, and if the signified or implicit reference of the scene is indeed the fourfold refiguration of the object which I have attributed to it, then we are authorized, it seems to me, in looking at the first and second scenes of interpretation - those of male homosexuality and of social hangers-on - in terms of what must be taken as their predominant modes of figuration. And we are permitted, I would further argue, to inquire into the ways in which these earlier scenes may be related to each other and to the sequence of scenes of which they are units in a similar structure of figure and fulfillment. ${ }^{6}$

In this reading, the four subjects of interpretation - male homosexuality, social hangers-on, nobility, and a work of art - can be seen to constitute a series in which the first term (male homosexuality) serves as a figure that is progressively filled out and (provisionally) fulfilled in the fourth (art). Fulfillment is not, of course, to be construed in the manner of medieval biblical exegetes, for whom, for example, the Moses of the Hebrew Bible was a figure finally fulfilled in the Jesus of the New Testament, but, rather, more in the way Dante used the notion as a structural principle of his Commedia, in which a life lived here on earth is treated as a figure of an immanent meaning that is finally made manifest only in a future (beyond time and space, after death). In the case of Dante, the fulfillment of the life figured here on earth consisted of the revelation of the fourfold order of significance of the actions that comprise (the story of) that life: literal, 
figurative, moral, and mystical. Of course, for Dante, the fulfillment of a figure constituted a genuine revelation of its true meaning, so that the fulfillment of a figure results in a repetition of it, but now with its content revealed and its manifest meaning revealed to be only a container or sensory vehicle of its latent meaning - in short, only a figure.

For Proust, the absence of any ground for the revelation of the kind of ultimate meaning that Dante took for granted reduces all meaning to nothing but figuration. This is why it is legitimate to read Proust's narrative as an allegory of figuration itself, with the modalities of figuration as he construed them serving as the basic units of his strategies for emplotting the drama of consciousness which is its manifest subject matter.

The plausibility of this reading can be supported by a number of remarks inserted into his text in the passages I have been considering: "Until then, because I had not understood, I had not seen." "It is the explanation that opens our eyes; the dispelling of an error gives us an additional sense" (12;613). "And here the word fertilise must be understood in a moral sense, since in the physical sense the union of male with male must be sterile" $(22 ; 627)$. "But sometimes the future is latent within us without our knowledge, and our words which we suppose to be false forecast an imminent reality" (3 I ; 639). And, finally, with respect to M. de Charlus:

Now the abstraction had become materialized, the creature at last discerned had lost its power of remaining invisible, and the transformation of $\mathrm{M}$. de Charlus into a new person was so complete that not only the contrasts of his face, of his voice, but, in retrospect, the very ups and downs of his relations with myself, everything that hitherto had seemed to my mind incoherent, became intelligible, brought itself into evidence, just as a sentence which presents no meaning so long as it remains broken up in letters and scattered at random upon a table, expresses, if these letters be rearranged in proper order [dans l'ordre qu'il faut], a thought which one can never afterwards forget. (I2-I3;6I4)

If it could be shown that the four successive scenes of interpretation which open this part of Proust's novel describe the same tropological sequence - from metaphor through metonymy and synecdoche to irony as that described in the culminating fourth (the fountain) scene, this would provide important insights into the nature of interpretation in general and of interpretation by narration specifically. Specifically, it would yield some 
understanding of the paralogic of narrative, on the one hand, and of the extralogical dimensions of interpretative discourse, on the other.

What I want to suggest is that interpretative discourse is governed by the same principles of "configuration" (I borrow the term from Paul Ricoeur) as those used in narration to endow the events that comprise the story being told with the structural coherency of a plot. ${ }^{7}$ In other words, interpretative discourse tells a story - a story in which the interpreter is both the protagonist and the narrator and whose characteristic themes are the processes of search and discovery, loss and retrieval of meaning, recognition and misrecognition, identification and misidentification, naming and misnaming, explanation and obfuscation, illumination and mystification, and so on. The coherence of this story is the coherence of the plot structure or congeries of plot structures by which the story elements are fashioned into an identifiable story type (epic, romance, comedy, tragedy, satire, farce, etc.), what Frye has called an archetypal story. ${ }^{8}$ But, if this is a possible way of construing what goes on in interpretative discourse, it is not a matter of the interpreter simply imposing the pattern of a given plot type on the elements of the story being told, any more than, in a novel, it would be a matter of mechanically fitting the events that comprise the story into the form of a comedy or tragedy. The plot or congeries of plots has to appear to emerge gradually and, as it were, naturally from the events reported on the story level of the discourse, in the way that the tragic nature of a play like Hamlet becomes comprehensible over the course of the play's unfolding as what appears to be merely a series of contingent events.

What, then, are the transformational principles by which a story can be progressively endowed with the structural coherence of a given plot type or, since I am arguing for the formal similarities between narration and interpretation, by which an interpretation can be endowed with a coherence quite other than the kinds of coherence it may possess at the level of the sentence (grammatical coherence) and at the level of demonstration or explicit argument (logical coherence)? Obviously, my answer to this question is figurative coherence, the coherence of the activity of (linguistic) figuration itself.

This having been said, however, we are still left with the task of specifying how figurative coherence is produced in discourse. And in my view, the process of progressive figuration, refiguration, and what (following de Man) we may call disfiguration, held up to us in Proust's descriptive pause in his narrative, is the very model of such a process. ${ }^{9}$ That is to say, in the sequence of tropological modes which leads from an original meta- 
phorical characterization of an interpretandum, through a metonymic reduction and a synecdochic identification, to an ironic apprehension of the figurality of the whole sequence, we have something like the plot of all possible emplotments - the meaning of which is nothing but the process of linguistic figuration itself. This is not the only content of a narrative, to be sure, but it is the one without which any story cannot be told or any plot constructed.

That the four descriptions of the fountain are cast in different modes of figuration and that they have a distinct (and, indeed, even conventional) order of succession permits us to view this passage as Proust's model of what interpretation considered as figuration might consist of. The successive descriptions bear no logical relationship to one another, at least, no relationship that could be mapped out according to the logic of identity and noncontradiction. There is no argument about the nature of the fountain and hardly anything that might be considered a predication about it. The predications contained in the passage are for the most part about what "one" saw, the impressions "one" had, or what "one" realized. Only the fourth description contains direct predications about the spray: "drops ... fell . . a and . . f floated," "they teased . . . and blurred," "a single jet . . . swerved," and so on. Insofar as the passage has a referent, it is less the "jet d'eau" (which is both never really quite described and overdescribed) than the process of translating attentive seeing into language, with language itself, rather than perception, providing the categories of whatever interpretative matter the passage itself may contain.

The metanarrational and metainterpretative functions of the passage can now be specified. Considered as a narrational unit, the paragraph containing the fourfold description of the fountain is related to the three scenes of interpretation that precede it by the four figurative modes that comprise the substance of its own form. It is figuratively related to the scene of the prince's greeting by contiguity, formal similitude, structural homology, and parodistic repetition, which is to say, metonymically, metaphorically, synecdochally, and ironically. Considered as a model of interpretation itself, the fountain scene provides a paradigm of how to read the three more extensive scenes of interpretation that precede it: those in which male homosexuality, society, and nobility are interpreted. If we return to these preceding scenes and reread them in the light of this paradigm, we can apprehend the ways in which these scenes are to be taken as interpretations.

Each of the four subjects successively marked out for contemplation in the opening pages of Sodome et Gommorhe - male homosexuality, the 
social types, an exemplar of high nobility, and a work of art - appears as an enigma resistant to both adequate description and definitive explanation. Each is interpreted, however, and interpreted in the same way, which is to say, submitted to successive characterizations in the four modes of metaphor, metonymy, synecdoche, and irony. This sequence of modes of figuration can be said to constitute something like an equivalent for interpretation to what is commonly called plot in narrative representation.

An emplotment (what Ricoeur calls a mise en intrigue) ${ }^{10}$ of a set of events or, as in the case under examination, of observations, recognitions, identifications, characterizations, and so on, does not constitute an explanation of the sort typically provided by "technical thinking, of an algorithmic nature 'founded on objective modal necessity." "ll Emplotment, rather, provides (or wishes to appear to provide) what hermeneutic theory calls an understanding of a referent, and it does so by what Ricoeur calls configuration, a term that might legitimately be used to translate the Greek synecdoche ("to grasp together," "com-prehend"; Latin, subintellectio). This understanding, in turn, is comprised of a twofold order of signification: a manifest one, in which the object of interest (a referent) is submitted to a succession of descriptions, and a latent one, of which the activity and effects of figuration itself are the referents. And if this can be said of the relationship between any two or more successive passages of an interpretative discourse, it can be said of interpretative discourse as a whole.

How is the scene of the contemplation of the fountain related to the scene of the contemplation of nobility of character, which immediately precedes it, and how are these two scenes related to the scenes of contemplation of social types and of male homosexuality which precede them in the narrative sequence? If, in response to these questions, we say, Figuratively, we shall mean not only that they replicate the kinds and sequences of the modes of figuration employed in their respective emplotments but also that each scene is a fulfillment of the figures of the scenes that precede it. As thus envisaged, the fountain scene gathers up, fulfills, and realizes the figure of the scene of nobility, just as this latter does with respect to that of society, and this scene that of male homosexuality. Each of the subjects of the sequence-male homosexuality, the social types, nobility, and art - is an interpretation of the subjects that precede it in the manner of a fulfillment of the figures contained therein.

It could be fairly asked whether there is any extratextual evidence for this argument. In response it could be pointed out that, if the fountain described in the scene is purely fictive, the artist who is credited with its 
creation, Hubert Robert, was a real human being, a painter and architect whose career spanned the period of the French Revolution. Moreover, Robert was an artist fascinated with the subject of ruins, those caused by natural disruptions, such as floods, earthquakes, fires, and desuetude, and by political acts, such as rebellions, revolutions, jacqueries, sacking, looting, and so on. He not only painted real ruins but also imagined ones, such as his well-known canvases of the Grand Gallery of the Louvre in ruins. So obsessed was Robert with ruins that he earned the nickname of "Robert des ruines," by which he is still known today. Is it too much to suggest that, in choosing to posit as the object of Marcel's effort to recover "some power of attention," the "celebrated fountain of Hubert Robert," Proust was suggesting, by this act of nomination alone, his interest in the relation between art and ruination, the achieved form of a thing and its immanent deliquescence, its impression of solidity and beauty and its real nature as a chaos as senseless as the "jet d'eau" of Hubert Robert when viewed "close at hand"? 


\section{Form, REFERENCE, AND IDEOLOGY in Musical Discourse}

The issues raised in Music and Text: Critical Inquiries, edited by Steven Paul Scher, ${ }^{1}$ touch upon almost all of the aspects of contemporary discussions of language, discourse, and textuality: referentiality and theme, voice and expression, cognitive and ideological codes, audience reception and affect, poetics or style, figurative and literalist meaning, narration and description, and so on. Moreover, these issues are considered within the context of the continuing debate between formalists and historicists over the relevance of knowledge of sociocultural contexts to the understanding of the forms and contents of artistic, and specifically musical, artifacts.

Marshall Brown provides a cultural historical context for our consideration of these issues insofar as they relate to contemporary musicological research. First, he notes a specifically formal problem confronting the attempt to answer the question posed by Newcomb: namely, how might music mean? ${ }^{2}$ Brown points out that, in the musical work, structure is explicit and meaning difficult to discern, whereas in the literary work, meaning is easily discernible but structure is elusive. This insight alerts us to the danger of what we might call the structuralist fallacy: namely, the belief that when we have identified a structure in an artistic work, we have also found its meaning.

Next, Brown reminds us of a historical circumstance that should be borne in mind in any effort to explicate a relationship of similarity and difference between musical and literary expression: our own cultural moment is one in which literature has been "striving toward the condition of 
music," while music has been "striving toward the condition of language." There has been, Brown argues, a tendency in both music and literature "to substitute embodiment for designation in order to restore expressivity where formal control has been lost" $(85)$. There has been a drive toward an "atonal literature" corresponding to Schoenberg's attempt to "emancipate dissonance" in music. Consequently, Brown concludes, the "polarizations" that informed earlier discussions of music and literature and of the possible relations between them have broken down. This implies that the critical terminology used in the analysis of both music and literature cannot be taken for granted and must be used with full understanding of its problematical nature.

While the breakdown of the familiar polarizations with which an earlier critical discourse operated has been disturbing, it does provide an incentive to a fresh consideration of the musical aspect of verbal expression, on the one hand, and the extent to which a semantic content, similar to that figured forth in literary expression, might be said to inhere in musical form, on the other. Efforts in these directions are undertaken in the essays in Music and Text. Therefore, in my commentary, I concentrate on our authors' treatments of such topics as metaphor and figuration in music; plot, time, voice, mode, and theme in musical narration; and the relationship between the musical text and its historical context, which encompasses the problem of ideology, in musical expression. I then offer some general thoughts on the viability of looking at music in terms of literary theory and at literature in terms of musical theory.

\section{Text, Ideology, and Context: Formalism and Historicism}

The essays brought together in Scher's volume permit us to see the ways in which the longstanding conflict between formalist and historicist approaches to the study of cultural artifacts has changed in recent years. Charles Hamm remarks on the general reaction in musicology to the older formalist and positivist methods, and Ellen Rosand speaks of a turn toward a "new historicism" in musicological studies today. The effects of this turn can be seen in the generally contextualist orientation of the essays by John Neubauer, Ruth Solie, Lawrence Kramer, Peter Rabinowitz, Hamm, and Rosand. ${ }^{3}$ All urge the desirability, as much ethical and political as it is theoretical, of studying the relation of music to the social context(s) in which it is composed, performed, transmitted, and received. They point to 
the desirability of a hermeneutic operation, intended to reveal the ways in which the social context bears upon, determines, influences, or otherwise informs the production, form, content, and reception of the musical artifact and, conversely, the ways in which the artifact may affect its context(s). Even the essays by Claudia Stanger, Thomas Grey, and Anthony Newcomb, which remain rather more formalist in method, indicate the need to correlate what is happening within the musical artifact to its generally cul-

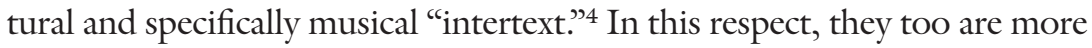
hermeneutic than formalist in their basic approach.

Hermeneutics, however, is no more critically neutral than any other method of analysis. It, too, presumes a number of different ways of construing the relation between cultural artifacts and their contexts. When it comes to the hermeneutic consideration of artworks, two principal orientations predominate: aestheticizing, which presumes that the work of art transcends the social conditions of its production and consequently yields insights into the nature of human creativity in general; and politicizing, which presupposes that works of art at least reflect or may even be determined by the interests, political, cultural, economic, and so on, of specific social groups and classes at specific moments of historical conjuncture.

These two fundamental orientations of hermeneutic criticism extend to the consideration of the nature of both history and the kind of knowledge that we can have of it. As in aesthetic hermeneutics, so, too, in historical hermeneutics: the effort to historicize the relation between works of art and their sociocultural context(s) can take the form of an essentially aestheticizing or a more openly politicizing analysis. In the former case, the relation between works of art and their contexts will be construed as a matter of certain similarities and differences of form; in the latter, the relation will be conceived as a matter of an identity of semantic contents.

Consider, for example, Stanger's approach to the problem of explicating the relation between the musical and the verbal elements in John Harbison's "Flower-Fed Buffaloes." She concentrates on the implicit strategies of structuration - the "codes" that authorize the complex condensations and displacements effected on the paradigmatic and syntagmatic axes of both music and language, not on any superficial similarities of form or reference. According to Stanger, it was the implicit and latent content of the speech by Learned Hand, its structure of oppositions and contrasts and its ideology, which served as the inspiration of Harbison's piece. Instead of setting Hand's speech to music, Harbison apparently chose a number of poetic texts - by Vachel Lindsay, Hart Crane, Michael Fried, and Gary 
Snyder - which he took to represent the deep structural content of Hand's address as the matter to be represented in his song cycle.

Accordingly, the musical settings of these poems replicate and comment on the structure of relationships among the poems; this is what Stanger's mentor, Louis Hjelmslev, would have called the substance of expression of Harbison's work. The musical settings also reinforce the substance of the content (the ideology) of the poetic texts, by their supplementary revision of the form of the content of these poems' thematizations. While generally sharing in the dire vision of America which these poems present, Harbison's settings of them also represent a revision of the traditional musical ideology, the ideology that promoted the view that a musical setting of a verbal text could consist of a simple and direct translation of the meaning of the latter. The ideology of New Music, then, what might be called its politics, is shown to be nothing other than a discovery of the "multiplanar" dimensions of both music and the relations between the tonal and verbal elements in mixed forms such as song or program music in general.

In his essay on Haydn's Creation oratorio, Lawrence Kramer mentions a general skepticism about music as a "bearer of meaning" ( I 39). If such skepticism still exists, these essays, taken together, should help dispel it. All of them address the question posed by Anthony Newcomb: how might music mean? Can music mean or produce meaning-effects similar to those produced in lyric or narrative poetry? In fabulistic or novelistic prose? In didactic and conceptual(izing) discourse? Can music mean in the way that a picture, sculpture, or architectural monument means? Can music assert, predicate, describe, imitate, refer - in the way that speech permits?

Literary discourse (as against everyday practical speech) problematizes the relation between what Roman Jakobson calls the referential, the poetic, and the metalingual (or codifying) functions of language. The contributors to Music and Text have therefore inevitably focused on the extent to which musical utterance manifests the capacity to operate these functions, the ways in which it can be conceived to do so, and the similarities and differences between the meaning-effects produced in musical expression and in literary discourse. Understandably, then, most of the essays take, as their principal test cases for the consideration of our topic, texts that contain both music and words: song, opera, oratorios, program pieces, radiographs (Hamm), and the like. Only Newcomb and Grey chose to test the thesis that "pure" music, instrumental music unsupplemented with words, can narrate, can tell a story, complete with events, characters, plot 
trajectories, and an identifiable thematic content. Arguably, this is the best course to pursue, because any analysis of the relation between music and words in a piece that contains a verbal text or gloss, in the form of a title, epigraph, or program notes, will tend to ignore the problematic relationship between the literal and figurative levels of the verbal matter. The tendency will be to treat the verbal text as a fairly easily discernible literal statement that the musical matter translates in one way or another.

This tendency informs Ruth Solie's study of the ideology of gender in Schumann's Framenliebe songs, Kramer's analysis of prefiguration in Haydn's Creation, David Lewin's discussion of power relations in Mozart's Figaro, and Rosand's characterization of the representation of madness in operas by Monteverdi and Handel. In these essays, the verbal content of the pieces analyzed can be taken for granted as the immediate referent of music insofar as it can be said to refer at all. By concentrating on musical pieces that contain no verbal matter, Newcomb and Grey are forced to confront the problem of identifying an equivalent of a verbal content in musical expression in musical (or musicological) terms alone.

\section{Grey and Newcomb on Narration in Instrumental Music}

Thomas Grey uses a survey of ninetenth-century musical theorists' notions of the idea-contents (heroism, pastoralism, bacchic fury) of Beethoven's symphonies to pose the question of the metaphorical meanings that might reside in the "sound surfaces" of instrumental works such as Beethoven's Seventh Symphony. Concentrating on the metaphoric content and narrative function of the introduction, he discovers that the music produces a particular kind of figurative structure, the "tonal prolepsis," which can be said to narrativize the musical structure of the whole piece on a level quite different from that on which a distinctive cognitive content or Grundidee might be identified by a literalist reading of the musical code of the work. For example, Grey does not accept the "tonal progression $\mathrm{C}-\mathrm{F}-$ $\mathrm{E}$, in which $\mathrm{E}$ functioned as the flatted supertonic of the dominant" in the Vivace, as a sign of the idea of bacchic fury. He views it, rather, as a prolepsis of the "full-scale transposition of the rounded opening group of the movement to $C$ " in the finale. The suggestion is that the musical figure of prolepsis endows the work with a kind of cognitive content quite distinct from the thematic material identified by nineteenth-century commentators.

We might call this kind of cognitive content narrational knowledge, 
that is, the kind of tacit knowledge necessary for the telling and following of stories. This is a kind of extramusical or transmusical knowledge because it is implicit in narrational discourse in general: in jokes and fables, epics, novels, pictorial sequences, and even in architecture (or, at least, in the decorative surfaces of architectural monuments). Such knowledge is required in any effort to follow a story as much as it is required for the production of a discourse that is intended to be followed rather than to be grasped synoptically as a synchronic structure of relationships. Such knowledge, like knowledge of one's mother tongue, need not be attended by or incarnated in any given corpus of information. It presupposes some kind of awareness of such categories as characters, actions, events, conflict, development over time, crisis, climax, denouement, and so on, and of the possible kinds of relations among these without which storytelling and story hearing would be inconceivable. We may call such knowledge, following Louis O. Mink, narrational - a kind of preknowledge of how to narrativize which precedes any explicit knowledge of any given story that might be told about any thing whatsoever.

Considered as a figure of sound, prolepsis can be said to mediate between the form of expression of Beethoven's introduction and its substance of expression. This substance is nothing other than what is meant by the English translation of the term prolepsis: that is, anticipation. By the use of this figure, the composer signals that something will happen later on which will fulfill or actualize what is now indicated as only a possibility or potentiality. Grey calls the effect of this figure prefiguration. The music in which this figure is sounded does not-because, without the aid of speech, it cannot - posit a substance of content of the sort identified as bacchic fury. In a word, the music expresses a figure of narrativity itself: a substance of narrative without either concrete story elements or a plot.

As thus envisaged, music utilizing the figure of prolepsis can be said to project a possible story. This suggests that endings of musical pieces which resolve figures of conflict posited during the course of their articulation might involve the use of the figure of antanaclasis (bending back) or metalepsis (transumption). The important point is that Beethoven's Seventh Symphony can be said to have a cognitive content of a specifically conceptual kind but that it indicates, refers, or represents this content only by way of musical, rather than verbal, figures. Moreover, music can be said to figure its content not, as in speech, indirectly but rather directly. On this view, music can be said to indicate literally the figurative nature of its conceptual context, which content is figuration itself. 
But figuration need not be only diachronic in its articulation. A given figure of speech, such as synecdoche or metaphor, may operate on the paradigmatic axis of meaning production. In this case, the force of meaning is not produced by projecting "the principle of equivalency onto the axis of combination" (Jakobson's definition of the "poetic" function) $)^{6}$ but is produced, rather, by the thickening, deepening, or condensing of connotative significance at specific points on the syntagmatic chain. Figures like prolepsis, metalepsis, metonymy, repetition, and so on produce the narrative effect, but only a part of it: because there can be no narrative effect (or diegesis) without utilizing discursive or descriptive (mimetic) procedures.

Grey tells us something important about musical diegesis - and especially about how beginnings and endings can be joined by figurations that operate across the diachronic axis of musical articulation to produce the narrative effect without really telling a story at all. The next question must be, can musical utterance represent the kinds of character and event which we would imagine to inhabit the genres of prose narrative, from the simple fable all the way up to the polylogical novel?

Tony Newcomb suggests that, in musical discourse, themes function like characters in novels. If this is so, then it is necessary to show how musical themes can be endowed with a kind of depth and complexity that we associate with characters in novels. In his analysis of narrative strategies in Mahler's Ninth Symphony, Newcomb attempts to show how depth of character is produced by the intersection of three elements: "formal paradigm," "thematic recurrence," and "plot archetype." Plot archetypes provide a content more conceptual than verbal at the level of what I have called, following Hjelmslev, the substance of the content.

But this conceptual content turns out to be, in the Mahler case, the sinusoidal plot type of the Romanticist Bildungsroman as interpreted by $\mathrm{M}$. $\mathrm{H}$. Abrams in his book Natural Supernaturalism. The conceptual paradigm of Mahler's Ninth, often interpreted as an expression of death anxieties, is laid out in the contrast between "diatonic purity" and a "subverting, corrupting chromatism." The "effect is one of placid stability undermined" in a succession of collapses, to each of which (what we must necessarily construe as) a heroic protagonist responds with a noble, life-affirming exertion. The meaning of the piece, then, "arises through an interaction of musical conceptual plots and paradigms” ( I3I).

One meaning of Mahler's Ninth, therefore, is the story that Newcomb is able to extract from the interaction between what we might call the substance of the (musical) expression and the substance of a (cognitive) 
content. The former consists of a series of figures similar to Grey's prolepsis, for example, what Newcomb calls slippage, crux, repetition; while the latter consists of the plot type of the Romantic Bildungsroman.

But what are the grounds for positing this plot type as a content of the piece? They appear to be two: first, the general diffusion of the Romance plot type in the culture of Mahler's time - Newcomb tells us that "Mahler's Ninth works with the same conceptual paradigm" as that formulated in Schiller's "forward to Elysium"; and, second, Freud's theory of the psyche as a mechanism that according to Newcomb, effects "the transformation of experience by memory." The latter theme serves as the content of the narrative middle sections of the various movements and of the symphony as a whole. The symphony's "many returns, ... prepared by mimetic collapses and laborious rebuildings that precede them" are "attempts to work the primary experience through to a proper end." Thus, "the incorporation of the past as past within the present through the play of repetition is an essential element in Mahler's last movement” ( I35).

Now, if this reading of the symphony is credible, then it gives us some insight into the relation between Romanticism and that modernism which is usually interpreted as a reaction against (among other things) Romanticism. We can see how, in the case of the modernist Mahler at least, a Romanticist worldview - in the guise of Schiller's injunction to "look, not backward to Arcadia, but forward to Elysium" - is the sublimated content of modernist atonal form. Diatonic harmonics equals spiritual purity, while chromatism equals corruption. The symphony as a whole affirms the desirability of a Romanticist purity over against the debilitating urgencies of modernist corruption. But, in Newcomb's account, what Paul Alpers calls the mode of the piece remains distinctively modernist in its refusal finally, in its ending, to affirm or even to assert the possibility of human triumph over temporality. "The question as to whether the symphony presents the triumph of temporality or the suspension of temporality is left in a state of ambiguous uncertainty" (I36). The difference between this uncertainty and the chest-thumping certainty of Romanticist heroism is the difference between modernism and Romanticism in general.

Thus, the story that we must construct on the basis of our understanding of the musical form and the culturally provided plot content is a story of the working through of the ambiguities and ambivalences of a Romantic worldview chastened by the experiences of a modern world deprived of its enabling illusions. This story is not so much implicit in the symphony (it cannot be deduced analytically from the music as such) as 
latent within it. The story is, in a word, the unconscious of the text, a latent content of the text's unconscious. In psychoanalytical terms, it corresponds to the dream-contents as against the dream-thoughts expressed on the musical surface. Such latent matter can be got at only through the postulation of some universal structure of consciousness or master narrative considered to be even more basic, more primary than the dream-images themselves: for example, the Freudian Oedipal drama or "family romance."

Newcomb does not go quite this far. Instead, he posits a specific version of this psychic theater, the Romance version, which differs from the Freudian version by virtue of its sublimation of the son's conflict with the father, or the social system that the father represents, into a melodramatic conflict of the "pure" youth coming to grips with a metaphysical enemy: time, death, mortality. This sublimation of the conflict between life and death, grasped in symbols of a conflict between purity and corruption, is the mark of ideological discourse in general. Another mark of ideologization is the tendency to leave the apprehension of the social dimensions of individual unhappiness unspecified - in short, to leave the conflict and its resolution in a condition of cognitive ambiguity and, moreover, to celebrate this ambiguity as a kind of higher knowledge or wisdom. Thus, we are compelled to ask whether the "ambiguous uncertainty" that Newcomb posits as the content of the ending of Mahler's symphony is a function of Mahler's ideology (is it really the "meaning" of the piece?) or of Newcomb's (does he share the Romanticist illusion that the meaning of life is the conflict between purity and corruption, that the problem is time rather than our social condition, and that the height of wisdom is to leave the question of the conflict between "the triumph of temporality and the suspension of temporality" in a "state of ambiguous uncertainty"?). Or is the meaning of the piece a product of an ideology of music which sees music's value in the circumstance that it can, in Newcomb's phrase, "embody" the "question" of the relation between "triumph . . . or suspension . . concretely without having to imply an answer" ( 136 ; my emphasis)?

\section{Ideology and Narrativity}

The question of ideology is central to contemporary discussions of narrative inasmuch as narrativization is viewed as the principal discursive instrument of ideologization - considered as the production of selfrepressing or self-disciplining social subjects. In this view, ideology is less a 
specific thought-content or worldview than a process in which individuals are compelled to introject certain master narratives of imaginary social and life histories or archetypal plot structures, on the one side, and are taught to think narrativistically, on the other, that is, to imagine themselves as actors or characters in certain ideal story types or fables, and to grasp the meaning of social relations in narrational, rather than analytical, terms. Ideologies are apprehended as generic class or group fantasies addressed to the imaginary dimensions of consciousness where infantile dreams of individual wholeness, presence, and autonomy operate as compensatory reactions to the actual, severed, and alienating conditions of social existence. The effect of ideology is to reconcile the individual to the feelings of alienation (produced by real social abjection) by providing compensatory illusions of personal ennoblement through heroic endurance of pains actually caused by social, rather than by ontological, conditions of existence. The ideologyeffect deflects the awareness of the social causes of alienation onto the cosmos, where abstractions such as purity and corruption, good and evil, do battle for the individual soul.

\section{How Ideology Works: Kramer and Solie}

The ways in which ideology does its work or plays its game can be seen in Kramer's study of Haydn's Creation and Solie's analysis of Schumann's Frauenliebe songs.

Let us begin with Kramer's treatment of music as "a bearer of meaning” in his analysis of Haydn's Creation. Unlike Newcomb and Grey, who deal with instrumental pieces, Kramer does not have to extract the equivalent of a verbal meaning from the music because the Creation already has a verbal text. But the text is uncertain. There are at least two and possibly three verbal texts. On the one hand, there is the manifest biblical account of the effects of the generative word(s) of the two testaments; ${ }^{7}$ on the other, there is the text of Laplace's nebular hypothesis postulated by Kramer as an element of the work's possible conceptual content. Kramer wishes to determine the extent to which the musical setting can be said to refer or to represent the cognitive contents of these texts. He wishes, as he puts it, to correlate the musical with the verbal content of the work by showing how the score "condenses" and "reinterprets" the "discursive field" by musical means. It is not a text-context relationship that is involved, Kramer tells us, but, rather, a "dialogical" one ( I4I). 
The key to the understanding of this correlation is a theory of musical metaphor, construed apparently on the basis of Peirce's theory of signs and Austin's theory of performative utterances ("speech-acts"). Taking the introduction of "the Representation of Chaos" as a preparation for the appearance of Logos, Kramer identifies an "unharmonized C" as an "Ursound," which both signifies the primal Chaos and serves as a "nucleus" of "everything to follow." In Grey's terms, this unharmonized C is a figure of prolepsis; Kramer says that it "prefigures" the "harmonic significance" of the $\mathrm{C}$ minor that finally appears in measure 4 ( I44).

In his analysis of the "melodic representation of [the] divine word ... that closes the music of Chaos," Kramer hears in "this figure . . . a musical representation of the spirit of God descending to hover over the waters." Here Kramer can be said to be moving from the expression plane to the content plane of the musical discourse. The movement enacts or performs a figure of descent, of divine catabasis.

Kramer grants that "agreement about the form [of this representation of Chaos] seems impossible to reach, but, he avers, "certain formal intentions ... are unmistakable": "recapitulation and movement towards an extended dominant." Moreover, he insists, these intentions "contradict each other." The dominant, he says, "commands immediate expectation," but Haydn "drives the intelligibility of the dominant into the structural background ... [ the] classical recapitulation ... is abrogated." The "paradoxes" are what yield the figurated "fullness" of the utterance of the divine word. And the effect: to make the "light hearable." The "ear of reason" is elevated over and made privy to a knowledge to which the "eye of reason" must remain blind ( I 56-57).

Music, Kramer concludes, "becomes representational not in direct relation to social or physical reality, but in relation to tropes." The (or a) "musical likeness" of Chaos or of "the spirit of God descending" or of the "divine word" represents these objects not mimetically but, rather, metaphorically. Thus, Kramer says that "the musical likeness is the equivalent of a metaphor," and "music becomes representational not in direct relation to social or physical reality but in relation to tropes. "In a word, the references in Haydn's Creation are to figures of thought, such as, for example, paradoxicality. Indeed, it is only by referring us to a figure of thought such as paradoxicality by way of the contradiction between the musical figures of recapitulation and movement that Haydn can posit the (catachretic) figure of a "seeing ear" - the ear that "hears" the "divine light," and, in hearing it, grasps "the divine truth inscribed in the order of nature." Thus, Haydn's 
narrative of Creation, in contrast to that given in the words of both Genesis and John's Gospel, effects a synthesis of religious and scientific visions of truth - "touch[ing] our human senses as a primary image for Enlightenment itself” (I6I).

Now, the ideology of knowledge revealed in Kramer's analysis is one that seeks to convince that any contradiction that might appear between religious faith and scientific reason is only apparent, that in reality the two visions are resolvable in an apprehension of a higher truth than that which can be given by perception or by a thought unaided by revelation. The organ posited as the instrument of this insight is not that of any of the senses used alone or in combination but, rather, that of an organ (the ear) which has taken over the function of another (the eye). The "hearing eye," like Addison's "shining voices" of the heavenly "orbs", figures forth catachretically (like Milton's "blind mouths") - a truth unknowable to reason's demands for a merely logical coherence.

But is this ideology Haydn's or Kramer's?

More Kramer's than Haydn's, I would say; but there seems to be a truth in it which points, metaphorically or figuratively, to a specifically musicological ideology: namely, the belief that the meaning borne by musical utterance has to do with rhythms, meters, and modes of bodily existence. Arguably, it is these that give to speech what Jakobson calls its "sound shape" in both poetic and prosaic, and therefore narrative, utterance. ${ }^{8}$ For whatever else narrative discourse may be, it differs from dissertative discourse in virtue of its efforts to capture in language the conflicts, dissonances, and contradictions of human existence and social being. Its resolutions or closes are always forced, arbitrary, partial in some way. By moving to a plane of pure relationships, beyond the messy ambiguities of incarnated existence, music can give expression to, represent, and mimetically reproduce the kinds of conflict and contradiction that are structurally resolvable. But resolvable only in a figurative way: as catachresis, irony, oxymoron, and so on, are resolvable by being transumed in a vision, metaphysical or mystical, of a coincidentia oppositorum.

The question of knowledge and power as the basis of ideologization is addressed in Ruth Solie's essay on the gendered self in Schumann's Framenliebe songs. She analyzes the ideology of gender informing Chamisso's poem cycle and Schumann's setting of it. She argues that both the verbal texts and their musical settings reflect the patriarchalist-misogynist social code of early-nineteenth-century Europe. They do so, moreover, not so much by speaking to or about women as by impersonating women. Here 
are two males presuming to masquerade as women and speak with women's voices. The ideological content of the song cycle, then, is not so much its misrepresentation of women (indeed, the songs convey what the patriarchalist social system demanded of women in the way of subjection and abjection all too accurately) as the trick that is played on women by providing them with (falsely feminized) male voices.

Solie thus identifies the (expression of the) content of the song cycle as an idealized or imaginary story of the woman whose being is comprised solely of her function as a "reflecting mirror" of her heroic husband. It is thus he and not she who emerges as the real protagonist of the cycle and as the ideal author of whatever pseudosubjectivity the woman can ever lay claim to. Solie interprets the cycle, then, as an apparatus for the alienation of women from themselves and others and their transformation into little more than dummies of their ventriloquist male rulers.

How this apparatus operates can be seen most clearly in her analysis of song 3 of the cycle, a passage of which she characterizes as "the most strikingly alienated stanza in the song." This song ("Ich kann's nicht fassen"), she says, "is about misperception," about the heroine's "having been 'tricked' (berückt) and unable to understand her own experience." The word tricked, she points out, "is first set with an appropriate diminished seventh chord, and its implications more fully played out in the song's ending, which proceeds from deceptive (and altered) plagal cadential patterns [that are] further marked by a devious Picardy-esque shift to the major mode." Thus, Schumann subverts the heroine's "melodramatic wish for death by a major-mode setting, and her hopes for unendlicher Lust with a sudden turn to minor. ... Whereas the poetic text moves, albeit limply, toward affirmation ..., the composer, cycling yet again, returns her not once but twice to her original state of tricked bewilderment" (23I).

The grounds for this interpretation apparently lie in the semantic contrast between a negative expression (a wish for death) and the putative positivity of a major mode setting and, conversely, between a positive expression (of hope for endless joy) and the presumed negativity of a minor mode setting. A negative is canceled out or subverted by a positive, and a positive is canceled out or subverted by a negative. What she has done is to identify the expressive dimension of the content of Schumann's song.

According to Solie's account, Schumann's music emphasizes and, as it were, doubles the affective or conative force of the poems' implicit verbal content. Schumann excises certain elements of the poems and substitutes other, more extreme versions of their misogynistic meanings. And, finally, 
he fills in gaps in Chamisso's narrative in order to figure forth an imaginary Framenleben, the sole meaning of which is the idealized Herrenleben that is the music's deep content.

All this is convincing, but it should be said that, in Solie's account of the matter, the question of the substance of the content of both the poem cycle and its musical setting remains unspecified. For if, as she argues, this is a song cycle in which males impersonate women and speak in an (imaginary) woman's voice, then it is the latent content of these men's voices, and not in what they explicitly say or what is implicitly present in what they say, which constitutes the ultimate ideological dimension of the text. The explicit semantic content of the text is not ideological inasmuch as it is the literal meaning and as such is directly apprehendible by its auditor-readers. It is difficult to believe that any woman could not see through this dimension of the songs. How could any woman have been "tricked" by this representation of her life? So, there must be something more going on here than a trick.

In order to get at this something more, we must ask: what is the conflict for which Schumann's song cycle might be considered an imaginary resolution? Solie suggests that gender relationships were undergoing radical - and to males radically threatening - transformations in the early nineteenth century. The patriarchalist response to these transformations, she argues, was to set up and disseminate the myth of "the eternal feminine" ("das ewige Weibheit"). Solie says that this myth was not available to earlier cultural formations, but in fact the myth is as old as myth itself. Therefore, it is not the myth itself, which appears wherever the patriarchy prevails, but its specific inflection in Chamisso-Schumann's use of it that provides its historically specific ideological content.

Considered as an impersonation by males of an imaginary female voice, the song cycle might be viewed as an index of the ambivalence felt about male identity - and especially about the identity of the male artist during this particular historical period. The period witnessed a deep transformation of the patterns of male homosocial bonding in which both the ideal of manliness and that of the possible relationships that males might have with other males, including homoerotic ones, were undergoing radical redefinition. Moreover, the domain of work, including artistic work, was being restructured; specifically, while middle-class women were being relegated to the domestic sphere as the sole place of their legitimate activity, the domain of artistic work was being "feminized," which is to say, marginalized by being made the sphere of a sensibility more feminine than mas- 
culine in nature. Considered as the domain of feeling rather than of rationality, artistic activity came to be thought of as being inhabited by social types whose gender ambiguity marked them as suspect in every regard.

I have no quarrel with Solie's analysis of the musical content of Schumann's songs, although I would like to have it documented that major always denotes positive and minor negative or at least was presumed to have been apprehendible as such at the time Schumann composed this piece. (This may be common knowledge among musicologists.) The crucial point for me turns upon the words being glossed by Schumann's music at the point in the text focused on by Solie, Traum (dream) and berïckt (tricked). In fact, the passage is not, as Solie claims, about misperception but about miscomprehension and disbelief ("Ich kann's nicht fassen, nicht glauben") and their cause ("es hat ein Traum mich berückt"). It is a dream that has tricked her. Can the word berïckt be read as a "subversion" of the insight contained in the phrase "a dream has tricked me" or "I have been taken in by a dream"? Or can it be plausibly interpreted as a reinforcement of the insight contained in the expression? For, according to Solie's account, the heroine has indeed been taken in.

But is this not an affirmation, on the figurative level, of the truth contained in the expression of tricked bewilderment on the literal level of the heroine's verbal utterance? Is not Schumann suggesting, against the "moves . . . towards affirmation" of Chamisso's text, that the heroine has indeed been tricked by a dream and that her perception of her own bewilderment is a true perception of her condition? Is not Schumann's subversion of the heroine's melodramatic wish for death and her hopes for endless joy more realistic than Chamisso's representations of these feelings as evidence of her true passion?

Of course, we cannot decide the matter definitively. If Schumann's music is a subversion of Chamisso's verbal text, what is being subverted: the literal or the figurative, the denoted or the connoted content of the verbal assertion? When the heroine asserts that "es hat ein Traum mich berückt," she is speaking figuratively: she asserts that she has been tricked by a dream. Traum here has to be read as "illusion," and it is set in a diminished seventh chord. Why a diminished seventh? What does a setting in diminished seventh $d o$ ? Does this setting subvert the force of the assertion and its possible truth or does it reinforce the sense of the illusory nature of the dream that is causing the heroine's incapacity to comprehend and believe her feelings, perceptions, and so on? Does it mean that she really has been tricked or that she has not? 
Solie's discussion of the "figure of woman" in the Franenliebe cycle reveals the relation between the expression plane and the content plane of a musical discourse that has been added to the verbal discourse of Chamisso's poem cycle. This musical supplement is a product of a specifically musical figuration of an already figured verbal content. In the process of supplementation, the techniques of condensation, displacement, and symbolization are used to revise the verbal text in conformity to impulses both conscious and unconscious. The ideology of the piece consists of the relationships obtaining between these two kinds of impulse. This permits the distinction between what is implicit in the text and what is or remains only latent within it. The former content can be derived by logical analysis from explicitly stated assertions about the nature of reality - "a woman's love and life." The latter can only be derived by analysis of the figuratively connoted content of what is only denoted on the literal and manifest levels of the text (musical and verbal).

The distinction between the implicit content of a text and what is latent within it poses clear problems for the interpreter desiring to grasp the relationship of the text to its context and thus its ideological function. The implicit is what is logically entailed, both as necessary presuppositions and as possible conclusions, by what is explicitly said on the literal level of the text's articulation. One can take what has been said explicitly and derive from it a long chain of possible beliefs, convictions, assertions, and so on, to which the speaker can be said to be implicitly committed by logical necessity.

Thus, when Chamisso's text has the imaginary woman speaker present herself as living only insofar as she can bathe in the reflected glory of her husband, "the Lord of All," the implication is that husbands are "Lords of All" and that women properly live only insofar as they can bathe in the reflected glory of their husbands. Similarly, when Schumann sets the phrase in which the heroine expresses her hope for "endless joy" in a diminished seventh chord, the literal implication is that Schumann intends to diminish the basis of such hope.

If, however, one reads both the verbal expression "endless joy" and the musical expression "diminished seventh" as figures, which they undeniably are, then the question becomes: what literal meaning had to be repressed, avoided, or swerved away from, such that it could only be expressed indirectly or figuratively? Actually, "endless joy" is an example of the figure of hyperbole and "diminished seventh" is, or at least functions here as, an instance of the figure of litotes or understatement. Could we gain a more complete understanding of the work under study, and more- 
over of its ideologizing function, by augmenting our logical analysis of what it explicitly says with a rhetorical analysis of what it figuratively expresses and therefore latently contains?

Such an operation is or seems to be the purpose of Ellen Rosand's study of the representation of madness by musical means in her analysis of operas by Monteverdi and Handel. She begins by pointing out that, in dramatic conventions in the West, madness is often represented by a character's lapse from speech into song. The musical setting of the speech of a character represented in the libretto as mad often serves to intensify the madness-effect by "subordinating its own logic to the illogic of the text," thereby "reinforcing and complementing" the sense of the words. But, according to Rosand, music can figure madness in its own right and does so by the violence it enacts upon whatever stylistic regularities it has originally laid down as the manifest sign of its own normality (242).

This is a nice insight, telling us something important about musical expression in general. If one test of sanity is the capacity to use grammatically correct speech and logically coherent discourse, then any lapse into singing in the midst of speaking and discoursing must be viewed as a kind of temporary insanity. ${ }^{9}$ Or, to put it another way, if a test of sanity is to be able to operate the difference between the literal and the metaphoric uses of speech, then any lapse into singing in the midst of speaking indicates a lapse into pure figuration. (A seventeenth-century definition of madness was the attempt to live a metaphor - in the manner of Don Quixote.) According to this view, one could argue that musical expression or the conjoining of music and words inevitably erases any possibility of distinguishing between the literal and the figurative levels of utterance. This does not mean that an analysis of what is being expressed in musical utterance is impossible; but it does mean that techniques of figurative, rather than of logical or grammatical, analysis are what are called for.

Rosand shows us the ways in which music can represent madness, not by referring us to a specific conceptual content of the idea of madness prevailing at a given time and place (such as melancholia or hydrophobia or paranoia) but, rather, by the way in which music can do violence to and undercut its own feigned normality. It is the sheer conventionality of a given style of expression, whether in words or in music, which is exposed when madness is allowed to irrupt into the scene of expression or representation. Or is it the madness of conventionality itself, the violence that it enacts upon the self and subject of speech, that is being figuratively suggested in music charged with the task of representing madness? Rosand 
suggests as much when she concludes: "The portrayal of madness is an exercise in operatic consciousness raising. For just as each individual mad scene sheds light on the stylistic conventions of its own period, so all such portrayals, in exploiting the tension between text and music, raising it to a level of primacy, call attention to the precariousness of 'normal' reciprocity, of the balance of operatic discourse in general" (287). But, we might add, so too, for music in general and, beyond that, all poetic speech or stylized utterance. So even for Schumann's song cycle, which, in its attempt to impersonate the woman's voice, also "calls attention to the precariousness of 'normal' reciprocity" and the impossibility of representing either a life or a love except by figurative means.

\section{Voice, Mode, and Latency in Poetic and Musical Expression: Alpers}

In the case of a musical setting of a poem or piece of prose, we are inclined to concentrate on the extent to which the music translates or glosses the verbal text or, as stressed by Solie and Rosand, the ways in which the music revises and edits the text, reinforcing, supplementing, or subverting its manifest meaning. The danger, I have tried to suggest, is that the manifest meaning may be stressed at the expense of the latent meaning. Among the kinds of latent meaning that might be supposed to inhabit the repressed sectors of a literary text is that which is manifested in the mode in which it is cast.

The relevance of the concept of mode to any interest we might have in a historical or ideological analysis of works of art is indicated by Alpers' characterization of mode in literature. He defines mode as "the literary manifestation, in a given work, not of its attitudes in a loose sense, but of its assumptions about buman nature and our situation" and, more specifically, assumptions about human "strength [or weakness] relative to [a] world." $"$ The presumption of strength or weakness is manifested, as Northrop Frye tells us, in two kinds of relationship represented in literary texts: first, the protagonist's relationship to his or her environment, both physical and social; and, second, the artist's presumed relationship to his or her intended audience. ${ }^{11}$

The only difficulty with translating these precepts into operational terms is that the specifically poetic text (with the possible exception of epic genres) typically takes for granted the problematic nature of both relation- 
ships as the condition necessitating its composition. It is the problematic nature of these relationships that constitutes a latent content of the poetic utterance, however confident it appears to be in the expression of "strength relative to world" on its manifest level of expression. Thus, for example, Alpers shows us how Herbert's "Vertue" plays off a "fairly direct equation of rhetorical and spiritual firmness" against the "suggestion" that "not only the poet's physical being but also his poetry is subject to mortality. The firm conclusions of [the poem's] rhetoric are made out to share the mutability of natural things." Moreover, the trope of the third stanza, in which "the death of natural beauty" is figured as "a sequence of musical cadences", suggests to Alpers a "manifestation of a sense of vulnerability central to the poem's [own] rhetoric" (67).

"How does the poem negotiate the tension between spiritual vulnerability and firmness?” Alpers asks. Is Herbert's (or the poem's) voice one that, as Helen Vendler has it, "never gives" (68)? Or is it one that yields to an apprehension of its own mortality in what Alpers calls "the rhetorical force" of the last line ("Then chiefly lives")? Or does it both yield and not yield? Does it both affirm and deny, at one and the same time, its own mortality? If so, the poem states a logical contradiction and expresses a feeling of ambivalence about the doctrine of the immortality of the soul. Or does it, rather, simply posit the aporetic nature of an incarnated spirit, consciousness, or conscience in the elaboration of the rhetorical figure of paradox? If so, the contradiction expressed on one level (the expression of the content) is deprived of its force at another level (that of the substance of the content) in much the same way that what appear to be contradictory character traits of a person become, when apprehended as paradoxical, both interesting and attractive as evidence of that person's depth.

Alpers raises the question of how one might set Herbert's "Vertue" to music. Obviously, it could be set in any number of ways - and with perfect freedom, on the part of the composer, to set it in whatever way he or she might choose. Would there be any obligation on the part of the composer to remain true to the poem's form or its content or to both of these? It is difficult to say. Should, for example, the composer credit his or her readings of the text, in the way Harbison apparently took responsibility for discerning the real content not only of Learned Hand's speech but also of the poems by Lindsay, Crane, Fried, and Snyder? Should the composer consult critics' interpretations of those literary works they have chosen to set to music? What would be gained in the way of understanding the task either of translation or of revisionary setting? 
Actually, Alpers' readings of the poems he has chosen to deal with show that something could be gained from such a collaboration. What he has done is to suggest that the meaning of the poetic text is not a matter of form alone or of content alone but is, rather, a function of the modalities in which the relations between forms and contents are figured. ${ }^{12}$ Thus, he alerts us to the difference between the ways in which a discourse produces meaning by way of codification, on the one hand, and by way of poeticization, on the other. The difference is that which Alpers specifies as obtaining between genre and mode. We can ourselves characterize genre as a codifying protocol, mode as a poeticizing one.

Roman Jakobson pointed out that the metalingual and the poetic functions of verbal utterances both work to project the "principle of equivalence [by which referents are endowed with 'meaning'] from the paradigmatic onto the syntagmatic axis" of articulation. But, he insisted, these two functions are opposed in the kind of equivalences they feature: whereas the metalingual or codifying function makes unities out of equivalences ("A=A": Horse is a species of the class Equns caballus), the poetic function makes equivalences out of unities $(\mathrm{A}=\mathrm{Not} \mathrm{A}$ : "My music shows ye have your closes"; "America, like a hounded shark"; "Women have served ... as looking glasses," and so on). The principle of equivalence utilized in "Horse is a species of the class Equns caballus" is that of direct predication; the code is implicit but derivable by grammatical analysis of and logical deduction from the explicitly stated elements of the utterance. ${ }^{13}$ The principle of equivalence utilized in "My music shows ye have your closes" is not metalingual; it does not tell us what the elements of the object-language of the phrase (My, ye, your, shows, have, music, and closes) mean. There is a code implicit in the phrase, but it is a local and arguably idiolectal code of figurative condensation and tropical displacement. This code is not derivable by a grammatical analysis of and logical deduction from the explicitly stated elements of the utterance. The meaning of the phrase, consequently, is latent, which is to say psychophysiological, rather than implicit. The structure of the phrase can be analyzed rhetorically, but such analysis will not provide a basis for a literal translation or paraphrase of its full semantic content. Recall Marshall Brown's reminder: the structure of a text is not to be confused with its meaning; a structure is a means of meaning production.

The semantic content of a text consists as much of the specific figurations and tropes by which the principle of equivalence is projected from the paradigmatic onto the syntagmatic axis of articulation as it does of what the phrase seems to be literally asserting. These specific figurations and the 
tropes that effect their specific successivity mean precisely by their evasion of every literalist, lexical, and grammatical expectation.

Thus, the referent of music in Herbert's phrase "My music shows ye have your closes" is utterly undeterminable. Even if it is read as a metaphor for the poem or the poetry of the poet, the idea that music could show anything, even in the sense of "manifesting," "displaying," or "demonstrating," is absurd - a catachresis; but the notion that this music could show that the "Sweet spring" apostrophized in line I of the stanza has its "closes" (like the "box where sweets compacted lie" to which the spring is likened by apposition in line 2) is even more absurd. For even if closes is read as "cadences" (a sixteenth-century usage), thereby saving the logic of music as a figure for poetry, it makes no sense to say that either music or poetry "shows" that "spring" has its "cadences." But the logic of the phrase consists of the figures of alliteration ( $M y$ music, ye . . your) and internal rhyme (shows ... closes) and the poetic necessity of having an end rhyme for roses, which ends line I of the stanza. Too much meaning or not enough? Or meaning of a kind different from both grammatical sense and extratextual referentiality?

So, what might be the composer's obligations to the poetic text that he or she might decide to set to music? According to Alpers' view of the nature of the poetic text, the composer should be especially attentive to the mode in which the work is cast, the feeling of strength or weakness relative to the world that pervades the text. In other words, it is not so much a matter of finding musical equivalents of what the text literally says or what it suggests by the use of specific figures of speech and tropes. It is a matter of suggesting by musical means the mode of relationship to the world that is the poem's own latent content.

\section{Formalism and Ideology: Cone and Lewin}

A consistently formalist approach to the study of musical artworks is represented in this collection by the essays by Edward Cone and David Lewin. ${ }^{14}$ In Cone's consideration of the nature of voice in song and of the persona of the singer in Schumann's lieder, there is no reference to the social context in which specific notions of both voice and persona function as elements of a specific ideology of poetic creativity. There are many references to the cultural and specifically musical context of Schumann's songs, but the relationships presumed to exist between the sung text and the 
cultural context are those of a perfect identity of formal contents. Indeed, Cone appears to have embraced the ideology of poetic creativity predominant in Schumann himself if not in Romantic aesthetics in general. This embrace results in deep insights into the internal dynamics of the songs referred to by Cone in his explication of the relations obtaining between words and music in specific lieder. It yields forceful instruction for the performance of these songs. It leads to the identification of a specific kind of irony in a composer traditionally thought to be lacking in irony altogether. In short, it permits us to view and to hear Schumann's songs from within their culturally provided interior.

But the interpretation of vocal persona as the persona of the composer (rather than that of the poet-singer) remains historically unmediated by any reference to the ideology of poetic creativity prevailing during Schumann's time. As a result, at the level of the theoretical payoff of Cone's essay, he ends up reasserting and affirming the very Romanticist ideology of poetic creativity that he wished to analyze.

That Cone is more an advocate than an analyst of this Romanticist ideology is indicated by the extent to which he adverts to a hypostatized notion of a poetic-musical consciousness seemingly perfect in self-knowledge and control of its own thought-contents and processes. While Cone refers to the conscious and subconscious elements of the hypothesized composer's persona, he nowhere suggests that this kind of persona might have an unconscious, which is to say, might be the unconscious bearer of values, fantasies, and illusions as well as of genuine insights - especially regarding the nature of personae themselves - of a given time, place, and sociocultural condition. The ignoring of the possibility of an unconscious dimension of the composer's persona no doubt reflects a suspicion of a currently dominant notion of selfhood, Freudian or generally psychoanalytical, which is itself ideological in nature. But without a theory of consciousness which features some version of an unconscious and generally ideological motivation in the composition of selves and personae, the notion of a specifically poetic creativity remains subject to the Promethean illusions of its Romanticist formulation.

David Lewin's perspicuous reading of a phrase in Mozart's Figaro is similarly formalist in method and similarly seeks to avoid consideration of the possibility that the work or its composer(s) operated under any kind of unconscious motivation. His essay, however, is much more pragmatically oriented than Cone's, being more concerned with the derivation of possible 
stage directions from a rigorously formalist analysis of the score than with the persona of either the author of the libretto or the composer. What emerges from Lewin's analysis, however, is something like an ideology of the stage director and, indeed, of the musical analyst which resembles the Promethean and timeless "composer's persona" projected by Cone.

In Lewin's essay, there is no suggestion that the social roles of the director or the analyst might be historically specific, that what it meant to be a stage director or a musical analyst was different in Mozart's time, place, and sociocultural condition from what it means in our own historical moment. Indeed, both stage direction and analysis are viewed as Promethean activities: the latter leaves no element of the text and score undisclosed, the former supposes a level of self-conscious knowledge of and control over the singer-actor similar to that posited by Cone for the composer's persona.

Nonetheless (and perhaps this is a result of the pragmatic purpose informing Lewin's analytic exercise), ideology - and moreover, ideology understood as a practice reinforcing of structures of domination and subordination - insinuates itself into Lewin's handling of his materials. It appears in his characterization of the themes of the opera and especially of the passage he analyzes. Note that Lewin recommends "the idea of command" as the "point of departure for continuing and elaborating our [his] analysis-cum-direction" of the opening of the first-act trio of Figaro, "Cosa sento!" According to his interpretation of the passage, it is an allegory of outrage and confusion passing over into the count's taking command of self and situation and then "issu[ing] a command" ( I65).

Lewin makes a persuasive case for the idea that the count's utterance "Cosa sento!" refers to the music of measures $\mathrm{I}-3$ (a "loud agitated tutti that elaborates a dominant seventh harmony, demanding resolution") and portrays the "confused outrage" of the count expressed in his words only in measures $2-3$. This provides the basis for the generalization that, first, the count takes his cues primarily from the music, rather than from the words preceding, and that, second, "Mozart . . . consistently displaces the actual words forwards in time" in relationship to the musical motives that always precede them. Whence, then, the interpretation of the count's persona: "Mozart's Count does not give impetus to the music by his verbal utterances, as an effective authority figure should. . . Rather, he consistently takes his verbal cues from whatever music he has just heard." And the consequent direction to the actor playing the role of the count: "The actor should take the loud agitated music of measure $\mathrm{I}-3$, and not Basilio's earlier 
disparaging gossip [about the count] as a cue for the reaction 'Cosa sento!' Thus, Lewin concludes, "throughout the first half of the trio, ... the Count continues to take his cues, both thematic and tonal, from preceding music," while "Basilio and Susanna struggle to take control of those cues. They contend in initiating themes and harmonic moves to which the Count responds; each thereby tries to win the authority of the Count to use against the other" ( I66-67).

What we have here, then, according to Lewin, is a dramatic musical representation of the loss and recovery of control, authority, and the power of command by the count; a power struggle between subaltern figures, the music master Basilio and the count's inamorata, Susanna, to expropriate that authority for use against each other; and the triumph - at least in Basilio's solo following upon the passage in question - of a "fawning hypocrite" (Basilio) over both the lecherous aristocrat (the count) and the lying and dissimulating woman (Susanna) (I7I-72).

The whole passage, and especially Basilio's solo, as analyzed by Lewin, fairly cries out for an ideological analysis of the extent to which it participates in or resists complicity with the dominant structure of social relationships, class and gender roles especially, of the historical moment in which they were composed. In the "infinite tennis game" between Basilio and the Count, Lewin perceives a figure of "a struggle for power and control between the two males" in which the woman, Susanna, "has no place whatsoever." In Lewin's interpretation, Basilio's victory in this game derives from the "hypocritical fawning" that in both Da Ponte's text and Mozart's musical setting is, in contrast to Beaumarchais's original version, elevated from the status of a "flat character trait" into a supreme instantiation of "manipulative mastery" through parody. Basilio's music not only "apes his master's model right up to the final cadence, as if he were about to confirm the Count's tonic closure," but it also trumps (could we say, deconstructs?) the model by substituting "C-minor-to-F" for the count's "final harmonies, F-to-Bb" (I72-73).

Moreover, this manipulative mastery is extended to encompass Susanna as well, and by a similarly parodistic gesture, in this case, to the love aria ("Non so più") previously sung by Cherubino to Susanna. This gesture functions, according to Lewin, as a weapon in the duel between Basilio and Susanna "for the Count's authority"; it serves to "outwit and foil Susanna" by making sure that "she knows [Basilio's] suspicion" that she has been dallying with Cherubino and "suspects his certain knowledge." Lewin 
"imagines" (his term) that "while Basilio's solo is manipulating the Count," he (Basilio) is "casually perusing" a score of Cherubino's song (which may have been dropped in flight from the approaching count) and "darting one sly leer at Susanna." Thus, while "manipulating the Count in all sorts of ways", Basilio can also keep "a tight grip on Susanna" ( 175 ).

Now, Lewin's manifest admiration of the genius of Mozart and the talent of Da Ponte takes the form of a celebration of the power - indeed the manipulative power - of the former over the latter and of both over Beaumarchais, the original author of the story. Beyond this: it leads to the suggestion that Mozart and Da Ponte must have admired the manipulative power of the "fawning hypocrite" manipulator of men, and suborner of women represented by the character Basilio in Beaumarchais's story. Beyond that: it leads Lewin to celebrate the manipulative power of music over words in general. And, finally, beyond that: in his (admittedly imaginary) characterization of Basilio as a manipulator whose principal instrument is, on the one side, his music and, on the other, his talents as a "musical analyst" (he is imagined as "casually perusing" the score of Cherubino's song while his "solo is manipulating the Count"), Lewin appears to be indulging himself in a fantasy of the power of analysis over performance. ${ }^{15}$

Such celebrations of manipulative power are easily recognizable as compensatory responses to the apprehension of those who make them to their own relative social powerlessness. This is not to demean Lewin's interpretation of the passage in question. On the contrary, his analysis of this passage amply demonstrates the especial fascination that manipulative power held for Mozart, his generation, and the social groups of his historical epoch. Moreover, in their ascription of this power to such a petitbourgeois figure as Basilio, who is, after all, only a music master, Mozart, Da Ponte, and Beaumarchais alike can be seen as participating in a fantasy of "the democratization of power" that overrides any consideration of birth or social status (though not of gender). This is a fantasy quite other than that of "the power of democracy." Lewin shows the extent to which this fantasy of the democratization of power, a fantasy that would be theorized in different ways by thinkers as diverse as Rousseau, Diderot, Hegel, Stendhal, Marx, and Nietzsche, pervaded the consciousness of Mozart himself. But Lewin leaves this fantasy "unanalyzed." He simply or, rather, complexly shows how the fantasy works in Mozart's music to endow it with a content or meaning that can serve as a basis for the stage director's manipulative control of the actor-singers subject to his command. 
Contextualization and Reception: Hamm, Neubauer, and Rabinowitz

The question of the relation of the musical work to its historical context has been raised in a variety of ways in Music and Text, but most explicitly and most radically by Charles Hamm, John Neubauer, and Peter Rabinowitz. Unlike those who relate the musical work to the context of its original time of production and in terms of its ideological content, these three critics take their point of departure from the postmodernist notion of the openness of the work of art and the function of the performer or audience in the production of the work's possible meaning.

Thus, in his consideration of the reception in Black South Africa of Lionel Richie's "All Night Long (All Night)," Hamm first stresses the difficulty of imputing any specific meaning to the work itself; it is, in his view, a generic pop hit. This means that the song is a mélange of codes and pseudocodes that do not - in Hamm's reading - add up to any determinable meaning. Specific meanings are produced, Hamm says, "only at the moment of reception" and are "shaped by the cultural capital of the listener" $(25-26)$.

Hamm stresses the multiplicity of contexts - national, regional, ethnic, class, political, and so on - that could have determined how Richie's piece might have been received. Moreover, he suggests that these contexts are so different from that in which the song was originally written and produced that any reference either to the tradition of rock-'n'-roll, on the one hand, or to anything identifiable as a clear reference in the lyrics, on the other, would be irrelevant to an interpretation of its true or dominant meaning. Indeed, Hamm notes that the nonmeanings or "ambiguities deliberately built into Richie's song" were perhaps the source of its popularity. Individuals and groups in a wide variety of social contexts could read into the song a host of meanings that could endow it with a power it would otherwise lack (37).

Hamm's broader purpose appears to be to challenge the conventional notion of the "canonic" musical work as an "ideal object" possessing "an immutable and unshifting 'real' meaning that is to be unfolded by the scholar." He concludes his essay by asking whether classical music might not be as generic in its content as Richie's pop hit and as open, therefore, to as many interpretations as there are contexts in which it might be heard (37).

The implications of Hamm's position could be unsettling to critics, I should think. For notice that the critic's role would consist not of determin- 
ing the real or true meaning of a given musical work but, rather - insofar as one were interested in meaning at all - in identifying the contexts in which it may have been heard and surveying the various meanings imputed to it by listeners in those contexts. What is the status of this suggestion? Is it descriptive of the difference between a musicologist's interest and that of the ethnomusicologist or historian of music? Or is it prescriptive of what musicologists ought to be doing when they study any piece of music, old or new, native or exotic, traditional or experimental? If the latter were the case, in what would the musicologist's expertise consist? If there is nothing specifically musical about the meaning of a given piece of music, this could imply either that musicologists should not concern themselves with meaning or that they should concentrate on ethnohistorical studies of musical works. In the former case, one could justify the most austere formalism; in the latter, the most fulsome historicism.

Similar issues and choices are raised by the essays of John Neubauer and Peter Rabinowitz. Both address the issue of whether not only modernist and postmodernist but also classical works of art can be said to contain "intrinsic meaning." Neither suggests that there is no meaning in musical compositions, but both appear to believe that whatever meaning may have been built into a work by the composer either is irretrievable or, if retrievable, enjoys no special status in the determination of a work's potential meaning. Neubauer bases his conclusions on a conception of the ineluctable openness of the artistic work, while Rabinowitz founds his on the power of the listener legitimately to attribute meanings to works of art which their composers could not even have imagined.

Thus, Neubauer begins his essay with a consideration of the constraints that institutions (both formal and informal) bring to bear upon composers, performers, and listeners alike. He then proceeds to reflect on the crucial role of the performer of the musical piece, the relation between performing and listening, and the similarities between performing and reading. He concludes by questioning the possibility of distinguishing, on ontological grounds, among "closed," "open," and "in progress" works. Thus, he points out, even performance authenticists such as Koopman and Harnoncourt, who pretend to perform earlier works "as they really were," run up against the limitations of systems of musical notation that will "encode only a fraction of what composers have in their mind." He goes on to remark on the irony of Harnoncourt's preference of eighteenth-century classical over nineteenth-century Romantic music; it turns out that the former granted an interpretative freedom to performers that the latter de- 
nied. Thus, while "advocates of authentic performance practices seek to recreate a lost pristine tradition," they "actually . . . offer exhilarating new interpretations that manifest a contemporary preoccupation with performance. Authentic performance practices destabilize the text by privileging the performer and blurring the line that separates him from the author" ( I I-I3).

This circumstance allows us to recognize how important is the performer's (and by extension, the listener's) share in the realization of any given work's potential meaning. Not that the performer or listener is perfectly free. (Who is?) The institutional constraints on listening and performing are quite as effective as they are on composition. The challenge, Neubauer concludes, is to work out an analytical model that will focus on the relationships among composition, performance, reception, and institutional structures all at once.

This is a tall order, and it appears to be the project on which Peter Rabinowitz has embarked. Like Neubauer and Hamm, Rabinowitz begins by questioning the notion of the musical (or artistic) "thing in itself" and quickly moves on to consider the ways in which conventions "shape and control the experiences of the listener." He envisages a "model of listening" based on a "model of reading" which would feature the identification of levels of comprehension (technical and attributive), on the one hand, and certain "rules of listening" ( rules of notice, signification, configuration, and coherence), on the other. This combination of levels and rules would, according to Rabinowitz's account, permit conceptualization of the active aspect of listening and determination of the ways in which the listener attributes meaning to the work even when it is so open as to defy interpretation. He speaks of "attributive screens," which function like a grammar and syntax of listening and correspond to the codes (linguistic and cultural) that must be operated in the acts of reading, writing, and speaking alike (40 ff.).

A similar notion of speech and writing led in poststructuralism, and especially in the work of Derrida and de Man, to the doctrine of the "undecidability" of the literary work of art. Rabinowitz does not go this far. He remains within the structuralist ambit, envisaging the possibility of communication between cultures and across different epochs within the same cultural tradition in virtue of the possibility of the critic's translating between different attributive screens. But this is to place the critic's activities in a position denied to composers, performers, and other listeners. Rabinowitz appears to suggest that critics, unlike other listeners, would not so 
much attribute meaning to other people's attributive screens as actually know what these attributive screens consist in.

However, as the history of poststructuralism demonstrates, when one begins to theorize the idea of the open work, it is difficult to resist extending it to include the theorist's own ideas. And so, too, with the notion of the audience's share in the production of meaning. If the work of art is conceived less as an object possessing a determinable form and identifiable content than as a kind of Rorschach blot onto which the audience can freely project whatever its attributive screen suggests, why should not the critic's work be conceived in exactly the same way? Yet, surely Charles Hamm would not wish us to believe that the meaning of his essay is solely or even primarily a function of the various contexts in which it is received and read. Nor would Neubauer wish us to consider his essay as an open work.

But how should we mediate the differences between our intention to communicate clearly and effectively and our audiences' power and right to interpret what our discourse means as well as what it explicitly asserts? Hamm, Rabinowitz, and Neubauer force us to consider this question anew and with respect to our responses as critics and theorists to musical discourse in particular.

Where does that leave us?

It is, of course, difficult to find a single thread running through such diverse and diversely conceived essays and impossible to derive a single moral from consideration of them. Nonetheless, it seems possible to say the following: What all these theorists appear to envision is a kind of historicalformalist approach to musical criticism. On the evidence of the essays in Music and Text, we can see the extent to which this new approach is indebted to recent work in structural linguistics, semiotics, textology, narratology, literary hermeneutics (including reception theory, speech-act theory, New Historicism, poststructuralism, and deconstruction), cultural materialism, and feminist theory. We can see how much practitioners of the new approach have learned from recent literary theory about the ways in which the artistic text can be related to its historical context. We also see how literary theorists might learn from musicological theorists about the formal aspects of literary texts, the ways in which they might, as Carolyn Abbate has expressed it, fail to mean and escape explanation. But in addition, we can see the difficulties confronting efforts to construe musical works on the analogy to literary texts and how attempts to relate both of these to their historical context(s) require a full theorization of what is meant by history itself. 
Beyond that, it should be remembered that the very effort to import literary theory into musicology implies fundamental differences between literature and music. It is unlikely that any set of critical or theoretical principles devised to deal primarily with verbal discourse can effectively address the principal problems of musical criticism and theory. What literary theory and criticism can contribute to musicology and music criticism is insight into the nature of discourse in general. It would follow that musicology could profit from this exchange only insofar as music could be considered as a form or mode of discourse. And in that case, exchange would run both ways, for if music were a form or mode of discourse, then literary theory would have as much to learn from musicology as music criticism has to learn from literary studies. 


\section{NoTES}

\section{Chapter I Literary Theory and Historical Writing}

I. Jacques Barzun, "The Critic, the Public, the Past," Salmagundi 68-69 (Fall I985-Winter I986): 206.

2. Paul Veyne writes: "There is no method of history because history makes no demands; so long as one relates true things, it is satisfied. It seeks only truth, in which it is not science, which seeks exactness. It imposes no norms; no rule of the game subtends it, nothing is unacceptable to it. That is the most original characteristic of the historical genre." Writing History: Essay on Epistemology, trans. Mina Moore-Rinvolucri (Middletown, Conn.: Wesleyan University Press, I984), I2.

3. Benedetto Croce, Primi saggi, 3d ed. (Bari: La Terza, I95 I), 38. I have surveyed the debate over the status of narrative in historiography in "The Question of Narrative in Contemporary Historical Theory," History and Theory 23, no. I ( I984) : I-33. Most of my own work in historiographical theory addresses this question: Metahistory: The Historical Imagination in Nineteenth-Century Europe (Baltimore: Johns Hopkins University Press, I973); The Tropics of Discourse: Essays in Cultural Criticism (Baltimore: Johns Hopkins University Press, 1978); and The Content of the Form: Narrative Discourse and Historical Representation (Baltimore: Johns Hopkins University Press, 1987). These works constitute the background of this essay, so I will not cite them repeatedly.

4. Cf. Christopher Norris, "Narrative Theory or Theory-as-Narrative: The Politics of 'Post-Modern' Reason," in The Contest of Faculties: Philosophy and Theory after Deconstruction (London: Methuen, I985), chap. I.

5. I tried to deal with this issue in "The Problem of Style in Realistic Representation: Marx and Flaubert," in The Concept of Style, ed. Berel Lang (Philadelphia: University of Pennsylvania Press, I979), 213-29. But see now Stephen Bann's 
brilliant work The Clothing of Clio: A Study of the Representation of History in Nineteenth-Century Britain and France (Cambridge: Cambridge University Press, 1984); and Linda Orr's superb review of it in History and Theory 24, no. 3 (1985): 307-25.

6. The best summary of the importance of the work of these philosophers for theory of the historical text is F. R. Ankersmit, "The Dilemma of Contemporary Anglo-Saxon Philosophy of History," History and Theory, Beiheft 25 (1986). Ankersmit, Narrative Logic: A Semantic Analysis of the Historian's Language (The Hague: Nijhoff, I983), places the discussion of historical narrative on a ground quite new and different from all previous discussions.

7. Prior to the early nineteenth century, historiography was regarded as a branch of oratorical discourse and a proper subject of the theory of rhetoric. It was, however, disengaged from rhetoric in the course of the nineteenth century as a result of the movement to render historical studies more scientific. The twofold attack on rhetoric, from Romantic poetics, on the one side, and positivist philosophy, on the other, led to the general disparagement of rhetoric throughout Western high culture. Literature supplanted oratorical discourse as the practice of writing, and philology supplanted rhetoric as the general science of language. The theoretical problem of historical writing then became the specification of history's relation to literature, but since literature was commonly thought to be a mysterious product of poetic creativity, no solution of the problem was possible. As for history's relation to philology, it was generally acknowledged that philology was simply the historical method applied to the study of linguistic phenomena. But since the historical method was in turn regarded as simply the philological method applied to the study of the historical (documentary) record, the problem of method remained locked within a tautological circle from which there was no exit. See my essay, "Rhetoric and History", in Hayden White and Frank E. Manuel, Theories of History: Clark Memorial Library Papers (Los Angeles: William Andrews Clark Memorial Library, I978); and Lionel Gossman, "History and Literature: Reproduction or Signification," in The Writing of History: Literary Form and Historical Understanding, ed. Robert $\mathrm{H}$. Canary and Henry Kozicki (Madison, Wis.: University of Wisconsin Press, I978). For an exposé of philology as pseudoscience, see Hans Aarsleff, From Locke to Saussure: Essays on the Study of Language and Intellectual History (Minneapolis: University of Minnesota Press, I982), 278-92. For a typical example of the way historiography was dealt with in eighteenth-century rhetoric, see the shrewd observations of the unfairly maligned Hugh Blair, Lectures in Rhetoric and Belles-Lettres ( 1783 ; reprint, Carbondale: University of Southern Illinois Press, 1965), 2: 246-89.

8. Ankersmit, "Dilemma," 44-74.

9. E. H. Gombrich, Art and Illusion: A Study in the Psychology of Pictorial Representation (London, I960), passim. Cf. my essay, "The Culture of Criticism," in 
Liberations: New Essays on the Humanities in Revolution, ed. Ihab Hassan (Middletown, Conn.: Wesleyan University Press, I97 I), chap. 4.

I0. I discuss Ricoeur's theories in "The Metaphysics of Narrativity: Time and Symbol in Ricoeur's Philosophy of History," in my book The Content of the Form. This is a revision and expansion of a review of Ricoeur's Time and Narrative, originally published as "The Rule of Narrativity: Symbolic Discourse and the Experiences of Time in Ricoeur's Thought," in A la recherche du sens/In Search of Meaning, ed. Theodore-F. Geraets (Ottawa: University of Ottawa Press, I985), 287-99.

I I. Ankersmit, "Dilemma."

I2. Ibid., my emphasis.

I3. Roland Barthes, The Fashion System, trans. Matthew Ward and Richard Howard (New York: Hill and Wang, I983), 230-32.

I4. Paul Ricoeur, Time and Narrative, trans. Kathleen McLaughlin and David Pellauer (Chicago: University of Chicago Press, I984), 2: 208-25.

I 5. I follow Valesio's lead in trying to establish the usage of rhetorics as indicating the theoretical study of discourse, by analogy with poetics as indicating the theoretical study of poetry. See Paolo Valesio, Novantiqua: Rhetorics as a Contemporary Theory (Bloomington: University of Indiana Press, I980), chap. I.

I6. But our tropology is useful for the analysis not only of nonformalized discourses but of formalized ones as well. Formalized discourses are simply those in which lexicons, grammars, and syntaxes have been openly and systematically, rather than covertly and unsystematically, tropologized. This is why formalized discourses do not require the same kind of analysis as nonformalized ones.

I7. David Hackett Fischer, Historians' Fallacies: Toward a Logic of Historical Thought (New York: Harper \& Row, I970), catalogued all the various kinds of fallacy which could be found in historians' discourses, from the most technical to the most speculative. Fischer's aim was to make historians more aware of the technical aspects of argumentation. What he demonstrated was the virtual impossibility of writing a historical discourse without committing a host of logical fallacies. Did that mean that historians' works containing a large number of logical fallacies should be thrown out? Obviously not; what was needed was a rhetorical analysis of such work. The logic of historical discourse is rhetoric.

I 8. Tropology is the unfinished business of modern, and especially semiotic, linguistics. For some theorists, it is a secondary, for others a primary problem of discourse analysis. For Jakobson, Benveniste, Burke, Lausberg, Bloom, de Man, Derrida, the $M u$ group of the University of Liège, Perelman, Todorov, Barthes, and others, it was a primary problem. I began with Vico, went on to Nietzsche ("Geschichte der griechischen Beredsamkeit," in Nietzsche's Werke, Bd. XVIII, Dritte Abteilung. Bd. II. Philologica, herausgegeben von Otto Crusius [Leipzig, I9I2], 20I-67), thence to Kenneth Burke (especially The Grammar of Motives [Berkeley: University of California Press, I969], app. D, "Four 
Master Tropes," 503-19), and from there to the authors mentioned in the preceding sentence. Traditional rhetorical theory deriving from the classical period tends to view tropology as the theory of figures of speech and thought, whereas the authors I cite view it as the basis for a theory of discourse. Crucial to anyone interested in the psychological basis of tropology is Freud's essay on primary process thought in "The Dreamwork," chap. 6 of The Interpretation of Dreams, trans. and ed. James Strachey ( I900; reprint, New York: Avon Books, I965). Here Freud reinvents the tropes in the form of the four mechanisms he identifies as operative in the transformation of the dream-thoughts into the contents of the dream: condensation, displacement, symbolization, and secondary revision.

I9. This is argued at length in my Metahistory and Tropics of Discourse. Many critics do not like this argument. Cf. Ricoeur, Time and Narrative, I: I6I-68; and Sande Cohen, Historical Culture: On the Recoding of an Academic Discipline (Berkeley: University of California Press, I986), 8I.

20. Arnaldo Momigliano, "La retorica della storia e la storia della retorica," Sui fondamenti della storia antica (Turin: Einaudi, 1984), 466. This is a critique of my work, basically hostile but fair. I forbear analyzing the rhetoric of Momigliano's own discourse, but if I were to do so, I might begin with the title of this essay.

2I. Ibid.

22. Gene H. Bell-Villada, Criticism and the State (Political and Otherwise) of the Americas, Criticism in the University: Triquarterly Series on Criticism and Culture, no. I (Evanston, Ill.: Northwestern University Press, I 985), I43.

23. See n. 3 above.

24. On the functions of the speech situation, see Roman Jakobson, "Closing Statement: Linguistics and Poetics," in Style in Language, ed. Thomas A. Sebeok (Cambridge: MIT Press, I978), 350-58.

25. Roland Barthes, "Le discours de l'histoire" and "L'effet du réel", in Le bruissement de la langue (Paris: Editions du Seuil, I984), I 53-74.

26. This debate has been fully surveyed by Ricoeur, Time and Narrative, vol. I, chap. 4 .

27. See Barthes, "Le discours de l'histoire"; Julia Kristeva, "The Novel as Polylogue," in Desire in Language: A Semiotic Approach to Literature and Art, trans. Thomas Gora, Alice Jardine, and Leon S. Roudiez (New York: Columbia University Press, I980), chap. 7; Jean-François Lyotard, The Postmodern Condition: A Report on Knowledge, trans. Geoff Bennington and Brian Massumi (Minneapolis: University of Minnesota Press, I984); Jacques Derrida, "The Law of Genre," Critical Inquiry 7, no. I ( I980): 55-82; Cohen, Historical Culture, intro., chap. I, conclusion. The whole question of narrative in historical writing is discussed in Pietro Rossi, ed., La teoria della storiografia oggi (Milan: Il saggiatori, I983), with contributions by Danto, Mommsen, Furet, Koselleck, 
Dray, Winch, et alia. See also the provocative study by Jean Pierre Faye, Théorie du récit: Introduction aux “langages totalitaires" (Paris: Hermann, I972).

28. Laurence Stone, "The Revival of Narrative: Reflections on the Old New History," Past and Present 5 (Nov. I979): 3-24; James Henretta, "Social History as Lived and Written," American Historical Review 84 ( I979): I293-I322; Bernard Bailyn, "The Challenge of Modern Historiography," American Historical Review 87 ( I982): I-24; Emmanuel Leroy Ladurie, The Territory of the Historian, trans. Ben and Sian Reynolds (Chicago: University of Chicago Press, I979), I I I ff.; and Dominick LaCapra, History and Criticism (Ithaca: Cornell University Press, I985), chap. I. It should be said that LaCapra's book is more of a defense of rhetorical historiography than of narrative historiography per se.

29. See Fredric Jameson, foreword to Lyotard, Postmodern Condition, xi. Jameson, The Political Unconscious: Narrative as a Socially Symbolic Act (Ithaca: Cornell University Press, I98I), is an extended, sustained, and powerful defense of this view.

30. See Christopher Norris, "Philosophy as a Kind of Narrative: Rorty on Postmodern Liberal Culture," in Contest of Faculties.

3I. "I take temporality to be that structure of existence that reaches language in narrativity and narrativity to be the language structure that has temporality as its ultimate referent. Their relationship is therefore reciprocal.” Paul Ricoeur, "Narrative Time," Critical Inquiry 7, no. I (I980): I69.

32. I regret not being able to develop this notion at greater length on this occasion. If I had the space, I would argue something like the following: it is generally agreed that historical narrative produces knowledge-as-understanding by what W. H. Walsh, as early as I95 I, called "colligation." See his Philosophy of History: An Introduction (New York, I960), 59-66. The late Louis O. Mink picked up this notion and developed it in his conception of the configurational mode of thinking, which he identifies with historical understanding (in contrast to the theoretical and "categoreal" modes). See esp. Mink, "History and Fiction as Modes of Comprehension," New Literary History I, no. 3 ( I970): 54I-58. Ricoeur uses the notion of configuration as the centerpiece of his argument about narrative as emplotment in both historiography and fictional writing. See Ricoeur, Time and Narrative, vol. I, chap. 2; and vol. 2 of this work, subtitled The Configuration of Time in Fictional Narrative. As analyzed by these theorists, the operations of colligation and configuration (and Ricoeur's "emplotment") appear to be exactly what is involved in synecdoche, that is, the tropological act of "grasping together." Of course, the relation of synecdoche to symbolization is manifest: you can only grasp together what has already been thrown together. On the figure of synecdoche, see Heinrich Lausberg, Handbuch der literarischen Rhetorik (Munich: M. Heubner, I960), sects. 572-77.

33. The classic formulation is by Erich Auerbach, Mimesis: The Representation of Reality in Western Literature, trans. Willard R. Trask (Princeton: Princeton Uni- 
versity Press, I968), chaps. I7-I8. All of Georg Lukacs' work on realism in nineteenth-century literature carries the same theme, but for a brief handling in connection with narrative, see his "Describe or Narrate?" in Writer and Critic and Other Essays, trans. Arthur D. Kahn (New York: Merlin, I97I), I I0-48. Fredric Jameson develops further the Lukacsian indictment in The Political Unconscious, wherein modernism is interpreted as a phase in the development of realism in which history is repressed. On the topic of realism in modern criticism, cf. René Wellek, "The Concept of Realism in Literary Scholarship," in Concepts of Criticism (New Haven, Conn.: Yale University Press, I967), 222-55.

34. This is the explicit theme in Fredric Jameson, Fables of Aggression: Wyndham Lewis, the Modernist as Fascist (Berkeley: University of California Press, I979).

35. There is a massive literature on the subject, but the whole development both of historicism and the debate over it are surveyed authoritatively by Georg Iggers, The German Conception of History: The National Tradition of Historical Thought from Herder to the Present (Middletown, Conn.: Wesleyan University Press, I968).

36. Roland Barthes, "Jeunes Chercheurs," Communications I9 (I972): I-5.

37. Barthes, "Le discours de l'histoire," I66.

\section{Chapter 2 Historical Emplotment and the Problem of Truth in Historical Representation}

I. Historical discourses consist also, obviously, of explanations cast in the form of arguments more or less formalizable. I do not address the issue of the relation between explanations cast in the mode of formal arguments and what I would call the explanation-effects produced by the narrativization of events. It is the felicitous combination of arguments with narrative representations which accounts for the appeal of a specifically historical representation of reality. But the precise nature of the relation between arguments and narrativizations in histories is unclear.

2. I have in mind here the farcical version of the events of $1848-5 \mathrm{I}$ in France composed by Marx in open competition with the tragic and comic versions of those same events set forth by Hugo and Proudhon, respectively.

3. Unless, that is, we are prepared to entertain the idea that any given body of facts is infinitely variously interpretable and that one aim of historical discourse is to multiply the number of interpretations we have of any given set of events rather than to work toward the production of a "best" interpretation. Cf. work by Paul Veyne, C. Behan McCullagh, Peter Munz, and F. R. Ankersmit.

4. Saul Friedlander, Reflets du Nazisme (Paris: Editions de Seuil, I982), 76 ff.

5. Art Spiegelman, Maus: A Survivor's Tale (New York: Pantheon Books, I986).

6. Andreas Hillgruber, Zweierlei Untergang: Die Zerschlagung des Deutschen Reiches und das Ende des europäischen Judentums (Berlin: Siedler, I986), 64. 
7. Thus, Hillgruber writes: "Das sind Dimensionen, die ins Anthropologische, ins Sozialpsychologische und ins Individualpsychologisiche gehen und die Frage einer möglichen Wiederholung unter anderem ideologischen Vorzeichen in tatsächlich oder vermeintlich wiederum extremen Situationen und Konstellationen aufwerfen. Das geht über jenes Wachhalten der Erinnerung an der Millionen der Opfer hinaus, das dem Historiker aufgegeben ist. Denn hier wird ein zentrales Problem der Gegenwart und der Zukunft berührt und die Aufgabe des Historkers transzendiert. Hier geht es um eine fundamentale Herausforderung an jedermann" (ibid., 98-99).

8. Most of the relevant documents can be found in "Historikerstreit": Die Dokumentation der Kontropersen um die Enzigartigkeit der nationalsozialistischen Judenvernichtung (Munich: Piper, I989). See also "Special Issue on the Historikerstreit," New German Critique, no. 44 (Spring/Summer I988).

9. The plot type is a crucial element in the constitution of what Bakhtin calls the "chronotope", a socially structured domain of the natural world that defines the horizon of possible events, actions, agents, agencies, social roles, and so forth of all imaginative fictions - and all real ones, too. A dominant plot type determines the classes of things perceivable, the modes of their relationships, the periodicities of their development, and the possible meanings they can reveal. Every generic plot type presupposes a chronotope, and every chronotope presumes a limited number of the kinds of story that can be told about events happening within its horizon.

Io. George Steiner, quoted in Berel Lang, Act and Idea in the Nazi Genocide (Chicago: University of Chicago Press, I990), I5I. Page numbers of all further citations to this work appear in parentheses in the text.

I I. Alice and A. R. Eckhardt, "Studying the Holocaust's Impact Today: Some Dilemmas of Language and Method," in Echoes from the Holocaust: Philosophical Reflections on a Dark Time, ed. Alan Rosenberg and Gerald E. Myers (Philadelphia: Temple University Press, I989), 439.

I2. Cf. Edith Milton, "The Dangers of Memory”, New York Times Book Review, 28 Jan. I990, 27, for some perspicuous comments on the efforts of younger writers who, lacking any direct experience of the Holocaust, nonetheless attempt to make it personal. This is a review of David Rosenberg, ed., Testimony: Contemporary Writers Make the Holocaust Personal (New York: Times Book, I990). Milton remarks on the "obvious paradox at the heart of any anthology that offers to recollect genocide in tranquility." She goes on to praise only those essays which, "far from pretending to come to grips with the Holocaust, ... . emphasize their authors' necessary aloofness. Indeed, . . . since subjectivity and obliqueness are the only approaches possible," the best essays in the collection are those which "make a virtue of being subjective and oblique." Milton, "Dangers of Memory," 27.

I3. As in, for example, such performative actions as those of promising or swearing 
an oath. In actions such as these in which the agent seems to act upon itself, the use of the middle voice permits avoidance of the notion that the subject is split in two, that is, into an agent who administers the oath and a patient who takes it. Thus, Attic Greek expresses the action of composing an oath in the active voice (logou poiein) and that of swearing an oath not in the passive but in the middle voice (logou poiesthai). Barthes gives the example of thuein, "to offer a sacrifice for another" (active) versus thuesthai, "to offer a sacrifice for oneself" (middle). Roland Barthes, "To Write: An Intransitive Verb?" in The Rustle of Language, trans. Richard Howard (Berkeley: University of California Press, I989), I 8.

I4. Ibid., I9.

15. Jacques Derrida, "Differance," in Speech and Phenomena and Other Essays on Husserl's Theory of Signs, trans. David B. Allison (Evanston, Ill.: Northwestern University Press, 1973), I30.

I6. Cf. Saul Friedlander's introduction to Gerald Fleming, Hitler and the Final Solution (Berkeley: University of California Press, I984): "On the limited level of the analysis of Nazi policies, an answer to the debate between the various groups appears to be possible. On the level of global interpretation, however, the real difficulties remain. The historian who is not encumbered with ideological or conceptual blinkers easily recognizes that it is Nazi anti-Semitism and the antiJewish policy of the Third Reich that gives Nazism its sui generis character. By virtue of this fact, inquiries into the nature of Nazism take on a new dimension that renders it unclassifiable. ... If [however] one admits that the Jewish problem was at the center, was the very essence of the system, many [studies of the Final Solution] lose their coherence, and historiography is confronted with an enigma that defies normal interpretative categories. . . . We know in detail what occurred, we know the sequence of the events and their probable interaction, but the profound dynamics of the phenomena escapes us" (my emphases).

I7. Erich Auerbach, Mimesis: The Representation of Reality in Western Literature, trans. Willard R. Trask (Princeton: Princeton University Press, I968), 49I.

I8. Ibid., 534-39.

19. This is the view held by Fredric Jameson and most explicitly argued in Fables of Aggression: Wyndham Lewis, the Modernist as Fascist (Berkeley: University of California Press, I979). It is a commonplace of leftist interpretations of modernism.

20. Primo Levi, The Periodic Table, trans. Raymond Rosenthal (New York: Schocken Books, I984), 332-33.

\section{Chapter 3 Formalist and Contextualist Strategies in Historical Explanation}

This chapter was first presented at a symposium, "Formalism and Context in the Social Sciences," held at the University of Chicago, Division of the Social Sciences, on 4-5 May 1989. 
I. This is how the issues were posed for participants in the symposium.

2. Paul Veyne, Writing History: Essays on Epistemology, trans. Mina Moore-Rinvolucri (Middletown, Conn.: Wesleyan University Press, 1984), 28-29.

3. As Foucault remarks: "Obviously, History [in the sense of the apprehension of things in the modalities of their being as both analogous and successive] is not to be understood as the compilation of factual succession or sequences as they may have occurred; it is the fundamental mode of being of empiricities, upon the basis of which they are affirmed, posited, arranged and distributed in the space of knowledge for the use of such disciplines as may arise. . . It is no doubt because of this that History becomes so divided, in accordance with an ambiguity that is probably impossible to control, into an empirical science of events and that radical mode of being that prescribes their destiny to all empirical beings, to those particular beings that we are." Michel Foucault, The Order of Things: An Archeology of the Human Sciences (New York: Pantheon Books, I970), 2 I9.

4. The difference between historism and historicism is conventionally thought to consist of the contrast between a genuinely historical apprehension of social reality of the kind associated with Ranke, raised to the status of a worldview, and what Popper especially called its scientistic (by which he meant pseudoscientific) counterpart, represented by Hegel and Marx especially. Whereas the former consists of an interest in historical events in their particularity and as elements of complex time- and place-specific sociocultural formations, the latter presumes to generalize the laws governing such events, predict necessary courses of future historical development, and legislate social and political programs on the basis thereof.

According to Popper, historicism is marked by its (duplicitous) feigning of the form and content of scientific knowledge, while what has come to be called historism eschews all effort to explain, retains the narrativistic form of traditional historical representation, and explains the sets of events which constitute its referents by storytelling rather than analysis in the nomologicaldeductive manner. Needless to say, for Popper, the social sciences, insofar as they can never be predictive in the manner of the physical sciences, can legitimately incorporate historist modes of representation and comprehension into their practices, but never historicist ones.

This contrast between historism and historicism and the debate over it within both historiography and the social sciences constitute a ground for discerning the ideological issues underlying the theoretical discussion of the relation between formalism and contextualism. Unfortunately, this discussion is as profitless as the debate over the relation between science and ideology, which, in my view, constitutes a conceptual pairing outside which neither could define the kind of objectivity represented by each. The notion that, in the human and social sciences, the self-conscious assumption of an ideological position constitutes a kind of objectivity superior to that of bourgeois science is 
already present in Marx's critique of Proudhon, is taken up by Lukacs and Goldmann later on, and has received a particularly striking reformulation lately by Fredric Jameson (in The Political Unconscious especially).

5. Erich Auerbach, Mimesis: The Representation of Reality in Western Literature ( I946; Eng. trans. Willard Trask, I968).

6. I will resist dilating on Lévi-Strauss's reflections, at the beginning of The Elementary Structures of Kinship, on the discussion among earlier anthropologists and moralists of whether the taboo on incest belongs to nature or to culture. It is instructive to recall, however, how he proposed to resolve the discussion by showing it to be a nonproblem. He says something to the effect that the incest taboo belongs neither to nature nor to culture but, rather, marks a point in the history of humanity in which the distinction between the two becomes imaginable and the contrast conceived to exist between them begins to function as a basis for a distinctively social life.

Analogously, it might well be that discussions of the social sciences in terms of whether they belong to contextualism or formalism might well be resolved or at least displaced to another theoretical site by following LéviStrauss's lead. Thus, we might ask: Is it possible that the social sciences belong neither to contextualism nor to formalism but, rather, mark the point at which the differences between the historical sciences and the natural sciences become imaginable and the contrasts conceived to exist between them become the basis for a distinctively ideological science?

7. See Paul Ricoeur, Time and Narrative, trans. Kathleen McLaughlin and David Pellauer (Chicago: University of Chicago Press, I984), I: 66 ff. Ricoeur follows the terminology of the late Louis O. Mink in his use of configuration to describe what W. H. Walsh called the colligational aspect of historical explanation by narrative description. He adopts my notion of emplotment to characterize what is involved in the act of narrative configuration. I should note, however, that, although he is sympathetic to my analysis of narrativist figuration for the comprehension of the explanatory effect of historical narratives, he is less than sympathetic to the theory of tropology on which I base it.

8. Hayden White, Metahistory: The Historical Imagination in Nineteenth-Century Europe (Baltimore: Johns Hopkins University Press, I973).

9. H. Aram Veeser, ed., The New Historicism: Political Commitment and the Postmodern Critic (New York: Routledge, 1989); citations in the text are to page numbers of this work.

Io. Louis A. Montrose, "Professing the Renaissance: The Poetics and Politics of Culture", in ibid., I 5-36.

I I. Elizabeth Fox-Genovese, "Literary Criticism and the Politics of New Historicism," in ibid., 21 $3-24$.

I2. Judith Lowder Newton, "History as Usual? Feminism and the New Historicism,'” in Veeser, in ibid., I 52-67; Brook Thomas, "The New Historicism and 
Other Old Fashioned Ideas," in ibid., I 82-203; Jon Klancher, "English Romanticism and Cultural Production," in ibid., 77-88; and Vincent Pecora, "The Limits of Local Knowledge," in ibid., 243-76.

I3. Frank Lentricchia, "Foucault's Legacy: A New Historicism?", in ibid., 23 I-42.

I4. Fredric Jameson, The Political Unconscious: Narrative as a Socially Symbolic Act (Ithaca: Cornell University Press, I98I), 82.

I 5. Roman Jakobson, "Closing Statement: Linguistics and Poetics," in Style in Language, ed. Thomas A. Sebeok (Cambridge: MIT Press, I960), 357-58. Cf. Linda R. Waugh, "The Poetic Function and the Nature of Language," in Roman Jakobson: Verbal Art, Verbal Sign, ed. Krystyna Pomorska and Stephen Rudy (Minneapolis: University of Minnesota Press, I985), I43-46.

\section{Chapter 4 The Modernist Event}

This chapter is a version of the Patricia Doyle Wise Memorial Lecture commissioned by the American Film Institute and delivered at its annual meeting in Los Angeles on 8 April I992. I want to thank the institute for having invited me. I am especially grateful to Professor Vivian Sobchack, UCLA, for her introduction to the lecture, her great conversation over the ten years we were colleagues, and her counsel for the subsequent development of this essay.

I. Fredric Jameson, "Metacommentary [ I97I]," in The Ideologies of Theory: Essays, 197I-86 (Minneapolis: University of Minnesota Press, I988), chap. I.

2. Linda Hutcheon, A Poetics of Postmodernism: History, Theory, Fiction (New York: Routledge, I988), 76, where she notes that in postmodern novels, the focus is on the "process of event becoming fact." Reflecting on Hutcheon's remark, I could not help but relate it to Linda Williams's description of what she calls "the new documentary" films, which, like Shoah or Roger and Me, are less about facts than they are about the filmmaker's search for the facts. She points out also that these films “are, as Stone's film isn't, documentaries" (my emphasis). This suggests that Stone's film ought not be assessed by the criteria we would use to evaluate documentaries. I would suggest that JFK is neither factual nor fictional but rather figurative and should be assessed as a figure first and foremost. Cf. Linda Williams, "Mirrors without Memories: Truth, History, and the New Documentary," Film Quarterly 46, no. 3 (Spring I993): I 3.

3. Cf. Fredric Jameson, "Magical Narratives", in The Political Unconscious: Narrative as a Socially Symbolic Act (Ithaca: Cornell University Press, I98I ), chap. 2.

4. Cf. Gertrude Himmelfarb, "History as You Like It," Times Literary Supplement, I6 Oct. I992, I2-I 5.

5. Richard Grenier, "Movie Madness," ibid., 24 Jan. I992, I6-I7. Grenier goes on to report: "Never in the history of Hollywood has a motion picture been slammed so vehemently by America's political class. Politicians and political writers of every political hue have condemned JFK as irresponsible and even 
crazed: hard left, right, centre.” And then he remarks on the difference between the response of politicians and political writers and that of "film critics, who identify with the country's 'artistic' class." "On the whole," he says, these critics "have rather liked the movie, which sets them conspicuously apart from other American commentators, columnists, journalists, who, with truly extraordinary unanimity, have been absolutely appalled by the film.” And from this contrast of responses, he concludes that "perhaps one should not buy a used car from a film critic" (ibid., I6).

6. David Armstrong and Todd Gitlin, "Killing the Messenger”, Image, I6 Feb. I992, I4. These are separate essays, published under a single title and with the questioning subtitle: "Why Did the Press React So Furiously over Stone's Movie?” See also the remarks of Michael Rogin, “Make My Day!': Spectacle as Amnesia in Imperial Politics," Representations 29 (Winter I990): 99-I23. Armstrong's concern for the sensibilities of the young is telling; when critics start expressing concern for the corruption of youth, it is always a good sign that a work of art has hit a collective nerve.

7. Stone presumably knows the difference between the events of the Vietnam War and various representations of it. He does not seem to be arguing that the events of the war did not happen, only that in representations there is little difference between factual and fictional accounts of those events. His views of history are another matter. In an interview, Stone is quoted as follows: "What is history? Some people say it's a bunch of gossip made up by soldiers who passed it around a campfire. They say such and such happened. They create, they make it bigger, they make it better. I knew guys in combat who made up shit. I'm sure the cowboys did the same. The nature of human beings is that they exaggerate. So, what is history? Who the fuck knows?" Esquire, Nov. I991, 93.

8. The inclusion of the Holocaust in this list may be questioned by scholars of that event who insist on its uniqueness, if not in all of history, then at least in the history of genocides. In my view, all historical events are by definition unique, one of a kind, but still comparable with other events of the same species. The other events in my list are similarly unique of their species. My point is that the events in this list are all uniquely twentieth-century events - events that, unlike, say, the Russian Revolution of I9I7, could have happened earlier or later than they actually did. Why? Because the material and ideological conditions necessary for the occurrence of the Russian Revolution existed much earlier than I9I7.

9. Cf. Sidney Monas, "Introduction: Contemporary Historiography: Some Kicks in the Old Coffin," in Developments in Modern Historiography, ed. H. Kozicki (New York: St. Martin's Press, I992), I-I6.

Io. See Zygmunt Bauman, Modernity and the Holocaust (Ithaca: Cornell University Press, I989), I 22.

I . Cf. Krzysztof Pomian, "Evento," in Enciclopedia Einaudi (Turin: Giulio Einaudi editore, I978), 8: 972-93; and Edgar Morin, ed., Teorie dell'evento (Milan: Bompiani, I972) (Italian trans. of Le retour de l'événement). 
I2. I have discussed the problem of context in "Geschichte erklären. Formalistische und kontextualistische Strategien,' Neme Rundschan N. I05, Heft I ( 1994): 4I56 , now chap. 3 of this book.

I3. And here we may note that posters for Stone's film, not remarked as having any particular significance by any of the reviews I have read, present the title as "JFK: The Story That Won't Go Away." Taken literally, then, the title indicates that the subject of the film is not an event but a story - a story, moreover, that insists itself into the consciousness of a whole generation as a response to a trauma and that can therefore be neither closed and forgotten nor precisely remembered as merely an event of the past.

I4. Thus, Jameson defines literary modernism as a product of a double crisis, on the one hand, a "social crisis of narratable experiences", and, on the other, a "semiotic crisis of narrative paradigms." Fredric Jameson, Sartre: The Origins of a Style (New York: Columbia University Press, I984), 2 I I. I want to make clear that by the term modernism I am not referring to that program of dominating nature through reason, science, and technology supposedly inaugurated by the Enlightenment; I refer, rather, to the literary and artistic movements launched in the late nineteenth and early twentieth centuries against this very program of modernization and its social and cultural effects, the movement represented by writers such as Pound, Eliot, Stein, Joyce, Proust, Woolf, and so on.

I 5. Michael Turits, "Moment of Impact: Three Air-Crashes," I-800 (Fall I989): 34, 35 (my emphasis).

I6. Craig Owen has argued that postmodernism is characterized by a revival of allegorical representation, though of a kind quite different from that repudiated by Romantic aesthetics in the name of the symbol in the nineteenth century. See Owen, "The Allegorical Impulse: Toward a New Theory of Postmodernism," in Beyond Recognition: Representation, Power, and Culture (Berkeley: University of California Press, I992), 52 ff.

I7. Jameson, "The Nature of Events," in Sartre, chap. 2.

I8. Jean-Paul Sartre, Nausea, trans. Lloyd Alexander (Norfolk: New Directions, n.d.); page numbers of all further citations appear in parentheses in the text.

I9. Virginia Woolf, Between the Acts (San Diego: Harcourt, Brace, I970); page numbers of all further citations appear in parentheses in the text.

20. I want to stress the difference between the modernist problematization of the event and the effort on the part of a group of parahistorians known as Revisionists to deny that the event known as the Holocaust ever happened. It should be noted that the revisionists have a very traditional notion of both historical events and evidence. What they wish to establish on the basis of a very literalist interpretation of the evidence is that the occurrence of the Holocaust cannot be proven. They are rather like fundamentalist Christians interpreting the evidence for evolutionism.

21. George Steiner, quoted in Berel Lang, Act and Idea in the Nazi Genocide (Chicago: University of Chicago Press, I990), I5I. 
22. The literal import of Steiner's remark is echoed in the answer to the question, "How is the unspeakable to be spoken about?" proposed by Alice and A. R. Eckhardt: "Certainly, we ought to speak about it, but how can we ever do so?" (my emphasis). See also George Kren's assertion that "the meaning of the Holocaust can never be grasped from the historical record"; and Elie Wiesel's "We shall never understand how Auschwitz was possible." All quotations are taken from Alan Rosenberg and Gerald E. Meyers, eds., Echoes from the Holocaust: Philosophical Reflections on a Dark Time (Philadelphia: Temple University Press, 1989).

23. Christopher R. Browning, "German Memory, Judicial Interrogation, Historical Reconstruction," in Probing the Limits of Representation: Nazism and the Final Solution, ed. Saul Friedlander (Cambridge: Harvard University Press, I992), 27.

24. Ibid., 25. Cf. Martin Jay, "Experience without a Subject: Walter Benjamin and the Novel," New Formations no. 20 (Summer I993): I45-55.

25. Eric Santner, "History beyond the Pleasure Principle”, in Friedlander, Probing the Limits, I46.

26. Jameson, Sartre, 2 Io.

27. Gertrude Stein, Narration: Four Lectures, with an Introduction by Thornton Wilder (Chicago: University of Chicago Press, I993), 59; page numbers of all further citations appear in parentheses in the text.

\section{Chapters Auerbach's Literary History}

I. Fredric Jameson, The Political Unconscious: Narrative as a Socially Symbolic Act (Ithaca: Cornell University Press, I98I).

2. I use the by now more conventional translation, "historicism," for what Auerbach called Historismus, translated "historism" in the English version of Mimesis. By Historismus Auerbach, following Meinecke, intended the worldview that identified reality with history, rather than with a theological or metaphysical, noumenal reality. Prior to the end of the eighteenth century, Meinecke argued, the meaning of history had always been referred to some extratemporal or transcendental ground. After Herder and Goethe, and in Ranke especially, history itself becomes foundational and the meaning of human events established by purely "intrahistorical" reference. Auerbach locates the earliest statements of this worldview in the work of G. B. Vico, which, as Auerbach puts it, proceeds on the basis of the identity of human nature and human history. Cf. Auerbach, "Vico and Aesthetic Historism," in Scenes from the Drama of European Literature: Six Essays (New York: Meridian Books, I959), I98.

3. Here we might note Auerbach's insistence, in "Figura," in Six Essays, on the distinction between figural and allegorical interpretation (ibid., 54). He notes that, in Christian hermeneutics, the Greek myths are interpreted allegorically in 
Christian terms (as in the Christian expropriation of Virgil's Eclogue IV). But Auerbach notes how, in the Commedia, for example, Dante relates pagan to Christian things not allegorically but figurally (63). Thus, Virgil is presented less as an "allegory for reason" than as a "figura" of the "poet-prophet-guide, now fulfilled in another world" (69). "The historical Virgil is 'fulfilled' by the dweller in limbo" (69). Then, in his commentary on Vico, in "Vico and Aesthetic Historicism," also in Six Essays, Auerbach suggests that Vico's philosophy of history is itself figural. The "poetic imagination" of Vico's "first men" (the Age of the Gods) is a "figura," Auerbach argues, of the "poetic imagination" of the "third age" (that of Men) which "fulfills" it (I94).

4. The problem of the origin of Western literary realism is of course dealt with in the positing of the originality of the representation of everyday life in the mode of tragic realism found in the Gospels. Whence the often remarked gap, the leap from the descriptions of Homeric and Old Testament representations of reality in Mimesis, chap. I, "Die Narbe des Odysseus," over the whole of Greek and Hellenistic literature, to the treatments of Petronius, Tacitus, and the Gospel according to Mark, in which the whole of classical protorealism is transcended and Western figural realism is set under way. Erich Auerbach, Mimesis: Dargestellte Wirklichkeit in der abendländischen Literatur, 4th ed. (Bern: Francke Verlag, I967).

5. The term genealogical is intended to summon up the usage by Nietzsche and Foucault.

6. Cf. Bernard Williams's discussion of how we are "related" to Greek culture in his Shame and Necessity (Berkeley: University of California Press, I993).

7. This sequence, too, represents a series of figures and their fulfillments, with each fulfillment itself becoming another figure to be further fulfilled in its turn. This would all be quite justifiably called an example of a kind of Hegelian expressivist conception of historical causation providing the basis for a dialectical analysis of the relations between successive phases of the series, were it not that it is so specifically Viconian in its conceptualization. The relationships are dialectical in the Hegelian sense insofar as Hegel is the theoretician of a notion of historical change more tropical than logical in kind, but it is more Viconian insofar as Vico was not only a more overt theoretician of a poetic logic centered - as de Man would have said-upon rhetoric as trope rather than as persuasion, but also, by Auerbach's lights, at least, the inventor of modern aesthetic historism.

8. Erich Auerbach, Mimesis: The Representation of Reality in Western Literature, trans. Willard R. Trask (Princeton: Princeton University Press, I968), 469; my emphases. Page numbers of further citations appear in parentheses in the text, first to the English edition and then, where applicable, to the German.

9. Recall that Balzac's creative powers are specifically referred not to his intellectual attitude, which is presented as a confused and contradictory set of apo- 
thegms hastily thrown off, but to his temperament - "emotional, fiery, and uncritical" (482).

IO. Notice that the subtitle of Mimesis is Dargestellte Wirklichkeit in der abendländischen Literatur. Although this subtitle is translated into English as The Representation of Reality in Western Literature, in the German the focal term is Wirklichkeit ("reality"), not representation (Vorstellung). Indeed, the notion of representation appears only in the form of a gerundive adjective, dargestellte, which suggests not so much a thing (the or a representation) as an activity, specifically the activity of presentation. Thus, the original subtitle of Mimesis comes to mean something like "presented reality in Western literature," with the connotation that specific representations of reality have been worked up or, more accurately, styled for presentation to someone or something for some purpose, aim, or end. In German, darstellen encompasses the meanings: "to present," "to show," "to produce," and "to exhibit"; as well as: "to sketch," "to delineate," and "to mimic"; and, in theatrical usage, "to perform." So we might say that the phrase dargestellte Wirklichkeit, which gets translated into English as "the representation of reality," might be more accurately - though, to be sure, less elegantly rendered as "the presentation of reality." Translating thus, we could capture both the sense of the constructed nature of any representation of reality and Auerbach's point that there is no such thing as the (in the sense of a single or unitary) representation of reality (in the sense of a changeless substance or noumenon) whose nature is gradually being fully described by successive efforts to represent it realistically. What he himself presents is a sequence of successive efforts by writers working in a generally delineated tradition of presented representations to devise ways of capturing in written utterance the multiplicity and change characteristic of social and more generally human reality - and always failing in that process in the end. The inevitability of this failure is suggested by the epigraph of the book, the line from Andrew Marvel: "Had we but world enough and time" (my emphasis).

I I. Note here that the famous first chapter, "Die Narbe des Odysseus," sconstitutes a veritable prehistory, prologue, or proem to the actual subject of mimesis as figuration. Here it is suggested that figuralist representation was unknown to both the Homeric and the most ancient biblical epics. The programmatic nature of Auerbach's interpretations of these texts is reflected in his stress on the elements of each which permits one to oppose it to the other. For example, Homer is all surface and detail, the Bible all depth and typological; the one is spatial, the other temporal; the one features metonymic, the other metaphorical relations, and so on. Figural realism, the history of which takes up the remaining nineteen chapters, supposedly mediates, dialectically, as it were, between what Jakobson called the "two axes" of discourse, the paradigmatic and syntagmatic. As thus envisaged, Auerbach's figuralism is the tropical movement between the two axes of speech. 
I2. The idea that the revolution of $\mathrm{I} 789$ was not itself a revolution but only an eruption of forces long latent, a delayed effect of causes originating in the Reformation, has been a topos of historical interpretation at least since Tocqueville.

I3. Considered as a figure fulfilled, however, any given text within an identifiable tradition, such as, for example, Dante's Commedia, can itself serve as a prefiguration of a later text, such as, for example, Balzac's Comédie humaine, which can be viewed as the fulfillment of Dante's text. So, too, for texts within a single author's corpus: for example, the Vita nuova is interpreted as a prefiguration of the Commedia, which in its turn is also a fulfillment of the Aeneid of Virgil. But this prefiguration / figure / fulfillment model can be used for the construction of whole traditions of writing, in which a later text is viewed not so much as an effect, offspring, or descendant of an earlier text as a product of an author's choice of an earlier text as a model. Finally, the prefiguration / figure/fulfillment paradigm can be used to characterize the relation between whole epochs, such as that between the Italian Renaissance and classical antiquity.

I4. The famous first chapter of Mimesis, "Odysseus's Scar," depicts two stylistic conventions, those of the Homeric and of the ancient Hebrew epics, which do not prefigure the representational practices of Western realism. They are different antitypes to Western literary realism, which emerges, according to Auerbach, only with the Gospels. Whence the famous gap in the account of Western literary realism, the omission of Greek and Hellenistic literature.

I5. In this, his project, originally published in I946, resembled that of E. H. Gombrich, in Art and Illusion: A Study in the Psychology of Pictorial Representation (London: Phaidon, I960).

I6. Auerbach takes Meinecke's interpretation of the birth of historicism (Historismus) at face value (Mimesis, 444).

I7. It is worth recalling, it seems to me, that the notion of literature itself and the idea of a manner of writing that is specifically literary in nature are specifically modern concepts. Indeed, it is arguable that modernism amounts to an attempt to contrive a mode of language use which, in its transcendence of the dichotomy between factual and fictional discourse, produces a writing that is both imaginary and cognitional. Auerbach appears to have grasped this in his discussions of the strain of realism which emerges in Flaubert and culminates (is fulfilled) in the style of Virginia Woolf.

I8. This continuity is to be seen in Auerbach's description of the relation between the historical context of the twentieth and that of the nineteenth century ( $M i$ mesis, 549). See also the last paragraph of Mimesis, in which Auerbach dilates on the realism of Virginia Woolf's style (556).

I9. The more "the random moment" is exploited, Auerbach writes, "the more the elementary things which our lives have in common come to light. The more numerous, varied, and simple the people are who appear as subjects of such random moments, the more effectively must what they have in common shine 
forth. In this unprejudiced and exploratory type of representation we cannot but see to what an extent-below the surface conflicts - the differences between men's way of life and forms of thought have already lessened. The strata of societies and their different ways of life have become inextricably mingled.... So the complicated process of dissolution which led to fragmentation of the exterior action, to reflection of consciousness, and to stratification of time seems to be tending toward a very simple solution. Perhaps it will be too simple to please those who, despite all its dangers and catastrophes, admire and love our epoch for the sake of its abundance of life and the incomparable historical vantage point which it affords. But they are few in number, and probably will not live to see much more than the first forewarnings of the approaching unification and simplification" (ibid., 552-53).

\section{Chapter 6 Freud's Tropology of Dreaming}

I have been working on this essay for a number of years, since I975 at least. In I985, when teaching at the University of California, San Diego, I gave a copy of a draft of it to Sara Steinberg, who used it as the basis of her article, "The Master Tropes of Dreaming: Rhetoric as a Family Affair," American Journal of Semiotics 4, nos. 3-4 ( I986): 29-50. She did not cite this essay but instead referred to my treatment of the tropes in Metahistory: The Historical Imagination in NineteenthCentury Europe (Baltimore: Johns Hopkins University Press, I973). I wanted to put this on the record lest it be thought that my essay derived from hers. As can be easily seen, my interests are quite technically rhetorical. I wanted to identify the use of figures of speech and tropes in Freud's "rhetoric of dreaming." Ms. Steinberg was concerned to relate them to the structure and dynamics of Freud's "family romance" and use the Greimasian "semiotic square" to map out the relations among the tropes. Ms. Steinberg died on 3I July I986. She was a promising student, a "reentry" woman who faced her death with courage and lucidity.

I. Representation is the term conventionally used to translate Freud's Darstellung, but actually presentation would be a better rendering because it captures the sense of theatrical activity and "dressing up" contained in Darstellung. Recall that in his treatment of Darstellung in the dream, Freud is concerned primarily with symbols and symbolizations. I can be represented (vorgestellte) by things or persons quite different in aspect from myself. But only I can present (darstelle) myself as what I truly wish to appear to be. The German Vorstellung could have been used had Freud intended to speak only of representation.

2. Sigmund Freud, The Interpretation of Dreams, trans. and ed. James Strachey ( 1900; reprint, New York: Avon Books, I965), 545-46; my emphases. German edition: Die Traumdeutung (Frankfurt am Main: Fischer Taschenbuch Verlag, I988), 4I3-I4. The citations are to the English translation, followed, where applicable, by citations to the German. 
3. Norman Holland, "Defence, Displacement and the Ego's Algebra, Part II," International Journal of Psycho-Analysis 54 ( I973): 248-50.

4. Jean Laplanche and J.-B. Pontalis, The Language of Psychoanalysis, trans. Donald Nicholson-Smith (New York: W. W. Norton, I973), I09-I I.

5. Roman Jakobson, "The Metaphoric and Metonymic Poles," in Roman Jakobson and Morris Halle, Fundamentals of Language (The Hague: Mouton, I956), chap. 5; Emile Benveniste, "Remarks on the Function of Language in Freudian Theory," in Problems of General Linguistics, trans. Mary Elizabeth Weeks (Coral Gables, Fla.: University of Miami Press, I97I), 75.

6. See Joel Fineman, "The Structure of Allegorical Desire", in Allegory and Representation, ed. Stephen J. Greenblatt (Baltimore: Johns Hopkins University Press, I98I), 26-60.

7. "Blind mouths! that scarce themselves know how to hold / A sheep-hook, or have learned aught else the least / That to the faithful herdman's art belongs!” John Milton, Lycidas, 11. I I9-2I. The term alludes to bishops who, instead of feeding their sheep, feed off them.

8. "Das ist ja nur ein Traum" (526-27; 399).

9. Laplanche and Pontalis, Language of Psychoanalysis, 4I2.

Io. Ibid., I2I.

I I. Heinrich Lausberg, Elementi di ritorica (Bologna: Il Mulino, I969), I23. trans. Lea Ritter Santini of Elemente der literarischen Rhetorik (Munich: Max Hueber Verlag, I967).

I2. The dream exemplifies displacement on "the principle of antithesis" (500;378).

I3. On "the indifferent," see esp. 504-5; 38I.

I4. See Lausberg, Elementi di vitorica, I I I-I6.

\section{Chapter 7 Narrative, Description, and Tropology in Proust}

I. Marcel Proust, "Sodome et Gomorrhe," in A la recherche du temps perdu, II. Texte établi et présenté par Pierre Clarac et André Ferré (Paris: Librairie Gallimard, Bibliothèque de la Pléiade, I954), 656-57; all quotations in French are from this edition. For an English translation of Sodome et Gomorrhe, see Proust, Cities of the Plain, trans. C. K. Scott Moncrieff (New York: Vintage Books, I970); all quotations in English are from this translation. Where two page numbers appear in parentheses, the first refers to the English translation and the second to the French original.

2. Gérard Genette, Figures III (Paris: Editions du Seuil, I972), I 36.

3. Swann explains later on in the chapter why the prince intercepted him and whisked him off for a private conversation. The prince had wished to inform him of his own conversion to the Dreyfusard cause. Swann professes to be unsurprised by the conversion, viewing it as virtually inevitable, given the prince's "nature si droite" (7I2). Marcel notes that "Swann oubliait que, dans l'après-midi, il m’avait dit au contraire que les opinions en cette affaire Dreyfus 
étaient commandées par l'atavisme." Whereas Swann had attributed SaintLoup's conversion to Dreyfus's cause to "intelligence," he attributes that of the prince to his "droiture du coeur," something like that "simplicity" that Marcel had perceived as the secret of the prince's nobility of character during his conversation with him. But this perception of the prince's nobility of character is brought under question in Marcel's comment on Swann's recognition of the prince's "straightforwardness." "En réalité, nous découvrons toujours après coup que nos adversaires avaient une raison d'être du parti où ils sont et que ne tient pas à ce qu'il peut y avoir de juste dans ce parti, et que ceux qui pensent comme nous, c'est que l'intelligence, si leur nature morale est trop basse pour être invoquée, ou leur droiture, si leur pénétration est faible, les y a contraints” (7I2).

4. "Autant l'accueil du duc de Guermantes était, quand il le voulait, aimable, empreint de camaraderie, cordial et familier, autant je trouvai celui du Prince compassé, solennel, hautain. Il me sourit à peine, m’appela gravement: 'Monsieur.' J'avais souvent entendu le duc se moquer de la morgue de son cousin. Mais aux premiers mots qu'ils me dit et qui, par leur froideur et leur sérieux faisaient le plus entier contraste avec le langage de bon camarade de Basin, je compris tout de suite que l'homme foncièrement dédaigneux était le duc qui vous parlait dès la première visite de 'pair à compagnon,' et que, des deux cousins, celui qui était vraiment simple c'était le Prince. Je trouvai dans sa réserve un sentiment plus grand, je ne dirai pas d'égalité, car ce n'eût pas été concevable pour lui, au moins de la considération qu'on peut accorder à un inférieur, comme il arrive dans tous les milieux fortement hiérarchisés, au Palais par example, dans une Faculté, où un procureur général ou un 'doyen', conscients de leur haute charge, cachent peut-être plus de simplicité réelle et, quand on les connâit davantage, plus de bonté, de cordialité, dans leur hauteur traditionnelle que de plus modernes dans l'affectation de la camaraderie badine. 'Est-ce que vous comptez suivre la carrière de Monsieur votre pére?' me dit-il d'un air distant, mais d'intérêt. Je répondis sommairement à sa question, comprenant qu'il ne l'avait posée que par bonne grâce, et je m'éloignai pour le laisser accueillir les nouveaux arrivants" (655). I have italicized the verbs indicating the four successive recognitions of the prince's nature.

5. See above, n. 4 .

6. I hope that I shall not be understood as using the notion of figure and fulfillment in any theological sense. As I conceive it, a figure is fulfilled when the full tropological range of a metaphorical characterization of a thing, person, process, institution, and so on is worked through in a discourse. See the beginning of chap. 5, above. Thus, for example, in Marx's discussion of the "forms of value" in chapter I of Capital, the last term, "the money form of value," can be said to fulfill, in the sense of inverting and revealing the latent content of, the first term, "the Elementary form." The relation between the first term and the 
last of a given sequence of figurations of a thing should not be viewed as analogous to that governing the relation between a major premise and a conclusion of a syllogism. The only necessity governing the relations among a succession of figurations is tropical, that is to say, is given by the possible modalities of figuration itself, not logical in nature.

7. On configuration, see Paul Ricoeur, Time and Narrative, trans. Kathleen McLaughlin and David Pellauer (Chicago: University of Chicago Press, I984), 2: $64 \mathrm{ff}$.

8. Northrop Frye, Anatomy of Criticism: Four Essays (Princeton: Princeton University Press, I973), I3 I ff.

9. Paul de Man, "Shelley Disfigured," in The Rhetoric of Romanticism (New York: Columbia University Press, I984), 93 ff. But recall the words Proust places in the mouth of Charlus, who, when commenting on Bréautés futile efforts to improve on Robert's fountain by placing lights around it, remarks, "C'est beaucoup plus difficile de défigurer un chef-d’oeuvre que de le créer” (659).

Io. Ricoeur, Time and Narrative, I: I 55-68.

I I. Cf. Paul J. Perron, introduction to A. J. Greimas, On Meaning: Selected Writings in Semiotic Theory (Minneapolis: University of Minnesota Press, I987), xxxix.

\section{Chapter 8 Form, Reference, and Ideology in Musical Discourse}

This chapter originated as a paper presented at a conference at Dartmouth College in 1988 on the relations obtaining between musical works and literary texts. The papers were later published as Music and Text: Critical Inquiries, edited by Steven Paul Scher. I was invited to comment on the proceedings from the perspective of a cultural historian and proponent of interdisciplinary approaches to the human sciences. I accepted this invitation with - as they sayconsiderable trepidation, because I knew virtually nothing about musicology and less about current debate in the field. But I was to be only half of a team, the other commentator being Joseph Kerman, who knows more about music, its history, and the study of it than anyone I have ever met. His oral comments at the end of the conference were, as usual, brilliantly illuminating, but unfortunately he was unable to write them up for inclusion in the published volume. This left me as the sole commentator on the proceedings and as appearing to pretend to competencies in musicology which I do not possess. I want to stress, therefore, that my sole aim in this essay is to comment on the work of others from the standpoint of a worker in the field of discourse theory. I have decided to include this essay in this book as a test case for assessing the critical grasp that discourse theory might provide for cultural critics working at the interface of two or more disciplines.

I. Steven Paul Scher, ed., Music and Text: Critical Inquiries (Cambridge: Cambridge University Press, I992). 
2. Marshall Brown, "Origins of Modernism: Musical Structures and Narrative Forms," in ibid., 75-92.

3. Anthony Newcomb, "Narrative Archetypes and Mahler's Ninth Symphony", in ibid., I 8-36; John Neubauer, "Music and Literature: The Institutional Dimensions," in ibid., 3-20; Ruth A. Solie, "Whose Life? The Gendered Self in Schumann's Frauenliebe Songs", in ibid., 219-40; Lawrence Kramer, "Music and Representation: The Instance of Haydn's Creation," in ibid., I39-62; Peter J. Rabinowitz, "Chord and Discourse: Listening through the Written Word”, in ibid., 38-56; Charles Hamm, "Privileging the Moment of Reception: Music and Radio in South Africa," in ibid., 2 I-37; Ellen Rosand, "Operatic Madness: A Challenge to Convention," in ibid., 24I-87.

4. Claudia Stanger, "The Semiotic Elements of a Multiplanar Discourse: John Harbison's Setting of Michael Fried's 'Depths,'” in ibid., I93-216; Thomas Grey, "Metaphorical Modes in Nineteenth-Century Music Criticism: Image, Narrative, and Idea," in ibid., 93-I I7.

5. John Harbison, "The Flower-Fed Buffaloes," Nonesuch Recording H-7I 366 ( I979).

6. Roman Jakobson, "Closing Statement: Linguistics and Poetics," in Style in Language, ed. Thomas A. Sebeok (Cambridge: MIT Press, I960), 358-59.

7. In Genesis: "And God said: 'Let there be light"”; and in the Gospel according to John: "In the beginning was the Word, ..."

8. Linda R. Waugh, "The Poetic Function and the Nature of Language", in Roman Jakobson: Verbal Art, Verbal Sign, ed. Krystyna Pomorska and Stephen Rudy (Minneapolis: University of Minnesota Press, I985), I44-45.

9. Cf. Paolo Valesio, "The Language of Madness in the Renaissance," Yearbook of Italian Studies I ( I97I), 206-I I.

Io. Paul Alpers, "Lyrical Modes," in Scher, Music and Text, 63; my emphases.

I I. Northrop Frye, Anatomy of Criticism: Four Essays (Princeton: Princeton University Press, I957), 53.

I2. Harold Powers, "Mode," in The New Grove Dictionary of Music, I2: 376-450.

I3. Waugh, "Poetic Function," I 55 ff.

I4. Edward T. Cone, "Poet's Love or Composer's Love”" in Scher, Music and Text, I77-92; David Lewin, “Musical Analysis as Stage Direction,” in ibid., I63-76.

I 5. I am quoting phrases from the original manuscript of Lewin's essay, on which my commentary was based, because I think it confirms my original characterization of his original interpretation of Basilio as a "fantasy." In the manuscript version of his essay, Lewin wrote that he "imagines" Basilio at the start of the scene leafing through the score of Cherubino's "Voi che sapete," which might suggest that Basilio was not only a performer of music but also (like Lewin himself?) an analyst. In the published version of the essay, he writes: "For some time I believed that Basilio . . might be looking at the score [of Cherubino's 'Voi che sapete']" (ibid., I74 n. 5). But after it had been pointed out to him that 
the score in question had been given by Basilio to Susanna earlier in the day, he was forced to drop this interpretation of the action and abandon the notion that Basilio was an analyst. It turns out that Basilio is only a manipulating performer - which alters the stage directions that an analyst like Lewin would assign to him.

The point I wish to make is analytical and not merely performative. If one begins an analysis of a text with classificatory categories set in opposition to each other (analysis versus performance, let us say); and one of the categories has to be ruled out as plausible on the basis of a textual datum that confutes the assignment of that term to a particular action, person, or situation; then one is forced to reduce these to the status of a manifestation of the opposed category. In this case, Basilio was originally characterized as both an analyst and a performer in order to endow him with a level of self-consciousness that would result in a different kind of performance by the actor of Basilio's role. Basilio would be portrayed as not only a fawning hypocrite but as one with unusual analytical skills and, therefore, unusual powers of manipulation. But since it is now thought that Basilio cannot have been an analyst, it is left for him to be played as only a performer - as if successful performance of a role, even that of a hypocrite, did not presuppose analytical as well as performative powers. Could one ever imagine the successful performance of a role, whether in society or in a stage play, that did not include analysis as its basis? 

Abbate, Carolyn, I75

Abrams, Meyer H., I 53

Alpers, Paul, on mode in literature, I64-67

Ankersmit, Frank, on historical discourse as interpretation, $6-7$

Annales: against the event, 43-44; and narrative historiography, 20; Ricoeur on, IO

Armstrong, David, review of JFK, 6869

Auerbach, Erich: on Balzac as atmospheric realist, 92-93; on context-text relation, 9I-92; on figura, I90n. 3; and figural causation, 87, 99; on fulfillment, 87-9I; on historicism, 50-5 I, 96-97, I90n. 3 ; on literary history, 90-9I; on mimesis as figuration, 94; on modernism, 39, 99-100; as modernist historian, 87; on modern realism, 40, 50-5I; on Woolf, 98, I00

Barthes, Roland: on discourse of history, 25; on intransitive writing, 37; on middle voice, 38-39; on modernism, 39; on narrativity as mythic, 202I, 25-26; on theory of the text, 25
Barzun, Jacques, on history as written discourse, $\mathrm{I}-2$

Bell-Villada, Gene, quoted on literary theory in historical discourse, $\mathrm{I} 2-\mathrm{I} 3$

Benjamin, Walter, on end of storytelling, 74, 82

Between the Acts (Woolf), history in, 76-79

Brokaw, Tom, on Challenger explosion, 73

Brown, Marshall, on music and literature, I47-48, I66

Browning, Christopher, on history of Holocaust, 80-8I

Cone, Edward, on vocal persona, I68 contextualism: Auerbach's version of, 9I-92; as explanatory strategy, 43, 5I-52; in historiography, 44, 50, 54; origin of, 50 ; and physical sciences, 43

cultural poetics, and New Historicism, 64-65

de Man, Paul, on disfiguration, I43

Derrida, Jacques: on middle voice, 39; on narrative as genre of the law, 20 
description: in contextualism, 53; and figuration, 59, I27-28; and narration, $126-28$

discourse: and emplotment, 9; form and content of, 4 ; historical, I-2; and language, 2I; and narrative, 22; and relativism, $\mathrm{I} 4$; and representation, 4-5; Ricoeur on, 6; scientific, 2-3; storytelling in, 5 ; and tropology, 8-9, I I, 52

dreamwork, in Freud: mechanisms of, IOI-4; and poetic discourse, $\mathrm{IO}_{3}$

Eckhardt, Alice and A. R., on unspeakability of Holocaust, 33 Ellis, Havelock, quoted by Freud on secondary revision, I06

emplotment: of Final Solution, 30; and historical representation, 28; in historical writing, 9; Ricoeur on, I86n. 7

event: and Annales, 43; disappearance of, in modernism, 66, 7I, 74; historical, 89; Jameson on, 74; postindustrial, 72; Sartre on, 75; Stein on, 82-83; traumatic, 69-72

explanation: contextualist, $43,52-53$; formalist, 43; in historical discourse, 5

Fackenheim, Emile, on Holocaust, 79 fact, historical: and fiction, I0; and historical interpretation, 29; and meanings in history, 70-71; and stories, $29-30$

Fascism, and literary modernism, 23 fiction: and historical fact, I0, I 3 ; and history, 9, 79

figurality: Christian doctrine of, 90, 9495; and fulfillment, 87

figuration: in contextualism, 53-54; and description, 59; and dreamwork in Freud, I02-3; Lang on, 33-36; mimesis as, in Auerbach, 94-95, 99; in music, I52-53; and narrative, I28; principal kinds of, I I ; in Proust, I 32-37, I39-40; referentiality of, $5 \mathrm{I}-52$; theories of, I I; and tropes, $52-54$

Final Solution, emplotment of, 29-30 formalism: as explanatory strategy, 43 ; and historiography, 48-49; and ideology in music, I67-68; and New Historicism, 54

Foucault, Michel, on history, I 85n. 3 Fox-Genovese, Elizabeth, on New Historicism, 56-58, 60

Freud, Sigmund: condensation, I08IO; considerations of presentability, I IO-I 2, I I9-2 I; displacement, I I 2I 7; on figuration in dreamwork, I02, I04, I20-2 I; Holland on displacement in, I02; Jakobson on, I02; mechanisms of dreamwork, IOI-4; and Rank, I23; secondary revision, I05-8; symbolization, I22-23

Friedlander, Saul: on aestheticization of Holocaust, 30-3I; on Final Solution as historiographical problem, 28, I 84 n. I6

Frye, Northrop, on plot types, I I, I 43 fulfillment: Christian doctrine of, 90; and figuration, Auerbach on, 87-9I

geneticism, and structuralism, 47-48 Genette, Gérard, on description as narration in Proust, I 30

genre: and historical themes, 3 I; Maus as historical genre, $3 \mathrm{I}-32$

Gombrich, E. H., on realism in painting, 6

Grenier, Richard, review of $J F K, 68$ Grey, Thomas, on narration in music, I $5 \mathrm{I}-53$ 
Hamm, Charles, I48; on musical reception, $\mathrm{I} 72-73$

hermeneutics, in interpretation of music, I49

Hillgruber, Andreas: criticism of, 3032; on Third Reich, 32-33

Himmelfarb, Gertrude, 68

historicism (bistorismus): Auerbach on, 50, 96-97, I90n. 2; as contextualism, 50; and "historism," I 85n. 4; modernist, 87; in physical sciences, 43

historiography: Ankersmit on, 6; classics of, 6-7; and contextualism, 4446,54 ; and formalism, 46; and language, 4 ; and literary theory, 25 ; poetic nature of, 7, 9; and postmodernism, 67-68; and relativism, I4; storytelling in, 27-28; structuralist, 8-9; as verbal artifact, 4, 2 I

historism. See historicism

history: Auerbach on, 95-96; explanation in, 5; and fiction, 9, 79; literary, 87; and Marxism, 24; and narrative, 22, 30; and the past, 2 ; research in, 78; and rhetoric, $\mathrm{I78n}$. 7 ; as science, I9-23; sequentiality in, 59-60; and social sciences, 23, 44-45; Stein on nature of, 84-85; Stone on, I88n. 7; subject matter of, 4

Hjelmslev, Louis, I 50, I 53

Holland, Norman, on displacement in Freud, I02

Holocaust: Browning on, 80-8I;

Eckhardts on, 33; Fackenheim on, 79; Lang on, 33-36; Maus as history of, 3I-32; Milton on, I83n. I2; as modernist event, 39, 69-70, 79; revisionists on, I89n. 20; Santner on, 8I; Steiner on, 33; uniqueness of, 42, I 88n. 2; unrepresentability of, 33 Huizinga, Jan, quoted, 33 ideology: and formalism in music, I6768; of gender, I 5 I ; and narrative, I $55-56$

interpretation: Ankersmit on, 6-7; in history, 3; and narrative, 30, I26-28

Jakobson, Roman, I 58: on dreamwork in Freud, I02; on linguistic functions, 62, I50, I53; on principle of equivalence, I66

Jameson, Fredric: on Auerbach's Mimesis, 87; on derealization of event, 74 ; on narrative, 20-2I, 82-83; on Sartre and narrative, $74-75$

JFK (film): as history, 68-69; reviewed by David Armstrong, 68-69, 7I-72; reviewed by Richard Grenier, 68

Kennedy, John F., assassination of, 68; accounts of, 7I-72; Oliver Stone's treatment of, 68-69

King, Rodney, 72

Kramer, Lawrence: on Haydn's Creation, $\mathrm{I} 56-58$; on meaning in music, I 50, I $57-58$

Kristeva, Julia, on narrative as ideology, 20

Lang, Berel: on Holocaust and figurative writing, 33-35; on Holocaust as literal event, 36 ; on intransitive writing, 37

language: figurative and literal, 6; and historical discourse, 4-5, 2I; and music, I50-5I; and tropology, I5-I9

Lausberg, Heinrich, on synecdoche, I2O-2 I

Levi, Primo, style of, 42

Lewin, David, on Figaro, I69-7 I

literary theory: and historical writing, I-3, 24-26; and modernism, 24

literature, and history, $2 \mathrm{I}$ 
Lyotard, Jean-François, on narrative and history, $2 \mathrm{I}$

MacIntyre, Alisdair, on narrative and knowledge, 2 I

Mahler, Gustav, Newcomb on, I 53-55

Marx, Karl, Capital, 53; on commodity fetishism, 53, I96n. 6; The Eighteenth Brumaire of Louis Buonaparte, 95-96

Marxism, as science of history, 24, 49

Maus: A Survivor's Tale (Spiegelman), as history, $3 \mathrm{I}-32$

middle voice: Barthes on, 38-39; Derrida on, 39

Milton, Edith, on Holocaust, I83n. I2

Mink, Louis O., I 52, I 8In. 32

mode, Alpers on, I64-66

modernism: Auerbach on, 40-4I, 99Ioo; Barthes on, 39; and event, 6667; and fascism, 23; and history, 23; and literary theory, 24; and narrative, 23, 82; and Nazism, 4I

Momigliano, Arnaldo, on historiographical style, I I-I2

Montrose, Louis, on New Historicism, 54-55, 59-62

music: hermeneutics of, I49; and ideology, I 5 I; and its intertext, I49; meaning in, I50; and narrative, I50$5 \mathrm{I}$; and social context, I48-49; and text, I48

Music and Text (Scher), I47-48

myth, and narrative, $2 \mathrm{I}-22$

\section{Narration (Gertrude Stein), 82-86}

narrative: Barthes on, 20; Derrida on, 20; and emplotment, 29-30; function of, in historical text, 3, 28-29; and ideology, I55-56; and interpretation, 30, I27-28; Jameson on, 82-83; Kristeva on, 20; Mink on, I 52; in music, Grey on, I 5 I-52; and myth, 22; Newcomb on, I 53-54; in Proust, I30; and representation, 22; Santner on, 8I; and scientific discourse, 3, 25-26

Nausea (Sartre), 74-76

Nazism, and Final Solution, 28

Neubauer, John, on institutional restraints on meaning, I $73-74$

Newcomb, Anthony: on Mahler's Ninth, I53; on meaning in music, I 50; on narration in music, I $53-54^{-5}$

New Criticism, on genetic fallacy, 55 ; and New Historicists, 55-56

New Historicism: and cultural poetics, 63-64; and formalism, 54; FoxGenovese on, 57-58, 60-6I; and Marxism, 6I; Montrose on, 54-55, 59-62; and New Criticism, 55-56; Pecora on, 57-58; and textualism, 57

Pecora, Vincent P., on New Historicism, 57-58

philosophy of history, and historiography, 44-45

plot types: and chronotopes, I83n. 9; and genres, 29; in music, I 54-55 postmodernism: genres of, 67; and historical novel, 67; and historiography, 67-68

Proust, Marcel: description in, I28-29, I 3 I-32; ekphrasis in, I29; figure and fulfillment in, I4I; Genette on, I30; modes of figuration in, $132-37$, I 3940; and narrative, I $30, \mathrm{I} 44-45$

Rabinowitz, Peter, on models of listening, $\mathrm{I} 74-75$

Rank, Otto, and Freud, I 23 realism, Auerbach on, 40, 50-5I referentiality, figurative, $5 \mathrm{I}-52$ relativism: and facts, 70 ; and historiography, $\mathrm{I} 4,27-28$ 
representation: and Final Solution, 283I, 8I; Freud on, I94n. I; historical, 4,28

revisionists, and Holocaust, I 89n. 20

Robert, Hubert, in Proust, I46 romance, $67-68$

Rosand, Ellen, I48: on madness in musical discourse, I63-64

Ricoeur, Paul: on configuration, 52, I 43; on emplotment, I45; on historical discourse, 6, Io; on narrative, 20; on structures of temporality, 22

Santner, Eric, on fetishism of narrative, $8 \mathrm{I}$

Sartre, Jean-Paul: on event, 75 ; Nausea, $74-76$

Scher, Steven Paul (Music and Text), I47 Simpson, O. J., 85

sequentiality, in historical explanation, $59,62-63$

social sciences: and history, 23-24, 4I47 ; and philosophy of history, $44-45$

Solie, Ruth: on ideology of gender in music, I 5 I; on Schumann's

Franenliebe, I 58-63

Spiegelman, Art, Maus as historical account, 3I-32

Stanger, Claudia: on Harbison, I4950; use of Hjelmslev's methods, I 50

Stein, Gertrude: on event, 82-83; Narration, 82-86; on nature of history, $84-85$

Steinberg, Sara, on tropes of dreaming, I94

Steiner, George, on problem of Holocaust, 33
Stone, Oliver (JFK), 68-69; on history, I $88 \mathrm{n} .7$

stories: in historiography, 27-28; in music, I 54-55

storytelling: Benjamin on end of, 74 , 82; and emplotment, 9; in historical trauma, $8 \mathrm{I}-82$

Structuralism: and geneticism, 47-48; in historiography, 8,9 ; popularity of, $48-49$

techno-event, Michael Turits on, 73 text: as synecdoche of context, in Auer-

bach, 92; theory of, Barthes on, 25 textualism, and New Historicism, 57 Third Reich, Hillgruber on, 32-33 trauma, and storytelling, 82 tropes, kinds of, I I-I9, 53-54; in Freud's work, IOI, I04-5

tropology: Bell-Villada on, 13 ; and contextualism, 5I-52; and discourse, 8I0; and linguistics, I79n. I8;

Momigliano on, I2; theory of, I II9, 52

Turits, Michael, on modernist technoevents, 73

Veyne, Paul, on history, 45, I77n. 2

Woolf, Virginia: Auerbach on, 40-4I, 97, I00; Between the Acts, 76-79; event in, 77-79

writing: and fiction, I3; historical, I-2

Zweierlei Untergang (Hillgruber), 3233 
The Library of Congress has cataloged the hardcover edition of this book as follows:

White, Hayden V., 1928-

Figural realism : studies in the mimesis effect / Hayden White.

p. $\mathrm{cm}$.

Includes bibliographical references.

ISBN 0-8018-5997-2 (alk. paper)

I. Criticism. 2. History in literature. 3. Mimesis.

4. Literature and history. 5. Historiography. I. Title.

$\mathrm{PN}_{50}$.W48 1999

$80 I^{\prime} .95-\mathrm{DC}_{21}$

98-794I

ISBN 0-8018-6524-7 (pbk.) 